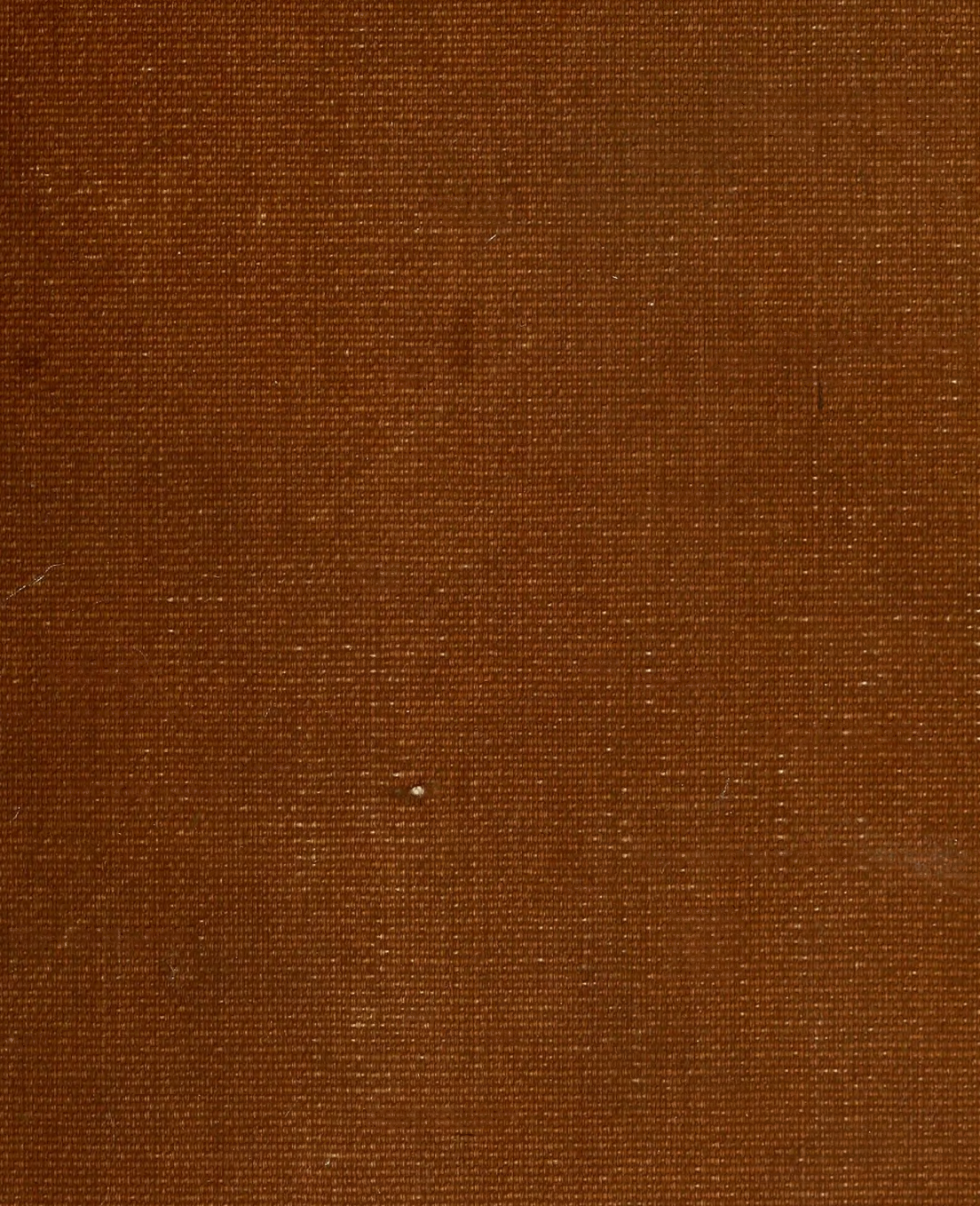




\section{THE UNIVERSITY}

$$
\text { OF ILLINOIS }
$$
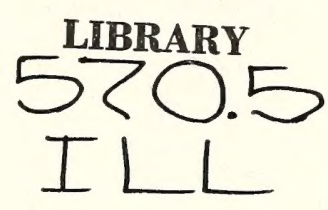

v.15,cop.2 
eturn this book on or before the itest Date stamped below. A arge is made on all overdue oks.

University of Illinois Library

\section{UL 281952}

AUGG 41952

APR 91953

APR 1 1953

DEC 71954

bct. 9.1969 

Digitized by the Internet Archive in 2011 with funding from

University of Illinois Urbana-Champaign

http://www.archive.org/details/genericclassific15ross 



\section{ILLINOIS BIOLOGICAL MONOGRAPHS}

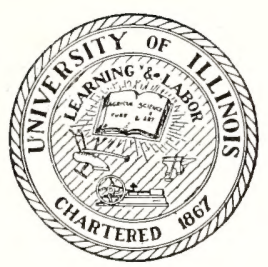

Published by the University of Illinois Under the Auspices of the Graduate School Urbana, ILLINOIS 
EDITORIAL COMMITTEE

John Theodore Buch holz

Fred Wilbur Tanner

Harley Jones Van Cleave 


\title{
A GENERIC CLASSIFICATION OF THE NEARCTIC SAWFLIES (HYMENOPTERA, SYMPHYTA)
}

\author{
WITH SEVENTEEN PLATES
}

BY

Herbert H. Ross

Contribution No. 188 from the Entomological Laboratories of the University of Illinois, in Cooperation with the Illinois State Natural History Survey 



\section{CONTENTS}

Introduction . . . . . . . . . . . . . . . 7

Methods . . . . . . . . . . . . 7

Materials . . . . . . . . . . . . 8

Morphology . . . . . . . . . . . . . . . . 9

Head and Appendages . . . . . . . . . . . . 9

Thorax and Appendages . . . . . . . . . . 22

Abdomen and Appendages $\quad . \quad$. . . . . . . . . 29

Phylogeny . . . . . . . . . . . . . . . . 33

The Superfamilies of Sawflies . . . . . . . . 33

Family Groupings . . . . . . . . . . . . 34

Hypothesis of Genealogy . . . . . . . . 35

Larval Characters . . . . . . . . . . . 45

Biology . . . . . . . . . . . . . . . 46

Summary of Phylogeny . . . . . . . . . . 48

Taxonomy . . . . . . . . . . . . . . . . 50

Superfamily Tenthredinoidea . . . . . . . . . 51

Superfamily Megalodontoidea . . . . . . . . 106

Superfamily Siricoidea _ . . . . . . . . 110

Superfamily Cephoidea . . . . . . . . . . 114

Bibliography . . . . . . . . . . . . 117

Plates . . . . . . . . . . . . . . . . 127

Index . . . . . . . . . . . 162 


\section{ACKNOWLEDGMENT}

This monograph is an elaboration of a thesis submitted in partial fulfillment for the degree of Doctor of Philosophy in Entomology in the Graduate School of the University of Illinois in 1933. The work was done under the direction of Dr. W. P. Hayes, to whom I am indebted for unceasing help throughout the investigation.

I am indebted also to Dr. R. Malaise, of Stockholm, Sweden, to Mr. Takeuchi, of Kyoto, Japan, and to Mr. O. Conde, of Riga, Latvia, for much valuable Eurasian material; and to Mr. R. B. Benson, of the British Museum, for a great deal of assistance and information on the genotypes of many genera.

A great aid in my work has been the frequent discussion of many points regarding morphology, taxonomy, nomenclature, and phylogeny with Dr. H. J. Van Cleave, of the University of Illinois, and with Dr. T. H. Frison, Dr. C. O. Mohr, and Dr. B. D. Burks, of the Illinois State Natural History Survey. 


\section{INTRODUCTION}

Few problems in the Hymenoptera have been so disputed as the general classification of the sawfly groups. Practically no two authors have agreed either on the subject of major groupings or the basic reasons for their divisions. The present study is an attempt to find fundamental morphological evidence which will separate the sawflies into groups and show the paths of evolution followed in their development. While such a study is almost necessarily incomplete without a lifetime of work, nevertheless structures have been found which show definitely some of the relationships and groupings of these insects. It is, I believe, the first time such a study has been based on the comparative morphology of the body and its appendages, rather than on only those characters which may be seen without dissection. It seems worth while to present these findings now in an endeavor to put the classification of the sawflies on a more stable basis.

Another grave difficulty confronting the North American sawfly worker has been the almost total lack of illustrated keys to the genera. Little effort has been made in the past to correlate the generic names used in various parts of the world, so that in many cases a considerable re-shuffling has been imperative. The solution of these problems has been linked very closely with the classification of the higher categories.

In the unravelling of these problems, palæontology has given us no clues, since the earliest known hymenopterous fossils belong to specialized groups which occur at the present day. These include such families as the Cephidae, Orussidae, and Siricidae. Fossils showing the nature of the earliest and most primitive Hymenoptera are still unknown. The utilization of embryological evidence has been impossible because of lack of material except in very few instances; and it is doubtful if a great deal could be learned from this source. This has left open only one avenue of approach, comparative morphology. The problem has therefore resolved itself into piecing together evidence drawn only from the differences and similarities found in the parts of those sawflies existing at the present day.

\section{Methods}

A large number of the drawings were made from pinned specimens. This is especially true of the characters used in generic keys, such as antennae, tarsi, sheaths, etc. The remainder were made from cleared specimens. The specimens were soaked in 25 per cent caustic potash $(\mathrm{KOH})$ for three to twenty-four hours, depending on their darkness, hardness, etc. The male genitalia were preserved in glycerine in small vials; the saws, wings, and legs were mounted in either balsam or euparal on slides; and the larger structures were preserved in 80 per cent ethyl alcohol. 


\section{Materials}

The taxonomic portion of this study is based on an examination of about 50,000 sawflies, including 90 per cent of the types of nearctic species. This material has been accumulated through the courtesy of the officers of the following institutions: Academy of Natural Sciences of Philadelphia; Brigham Young University; California Academy of Sciences; Canadian National Museum; Colorado Agricultural College; Cornell University; Deutsches Entomologische Institut; Entomological Branch, Canadian Department of Agriculture; Field Museum of Chicago; Illinois State Natural History Survey; Iowa State College; Iowa Wesleyan College; Kansas State Agricultural College; MacDonald College; McGill University; Montana State Agricultural College; New York State Museum; Ohio State University; Oregon Agricultural College; Purdue University; South Dakota Agricultural College; Texas Agricultural College; United States National Museum; University of Alberta; University of British Columbia; University of Colorado; University of Idaho; University of Illinois; University of Kansas; University of Michigan; University of Nebraska; University of Oklahoma; University of Wisconsin; Washington Agricultural College. 


\section{MORPHOLOGY}

The first work to be published dealing with the comparative morphology of sawflies was Hartig's "Die Familien der Blattwespen und Holzwespen" in 1837. This contains descriptions and many illustrations of the mouthparts, antennae, and other miscellaneous characters. It is, in fact, a veritable classic of sawfly morphology.

Since that time several workers have greatly increased our knowledge of sawfly morphology. Cameron in various papers (1882, etc.) gave descriptions and illustrations of many parts in other species. Van Dine (1906) described and illustrated the mouthparts of Pamphilizu; MacGillivray (1906) made an exhaustive study of the wings of sawflies; Snodgrass (1911) illustrated the thoracic structure of many forms; Crampton (1919) described and illustrated almost all types of male genitalia found in the group; Boulonge (1924) made a remarkably fine study of the male genitalia, with special reference to the muscles and their attachment; Bird (1926) made a detailed morphological study of Hoplocampa halcyon (Norton); and Taylor (1931) has made a complete histological and internal anatomical study of the head of a few species of Tenthredinidae. Marlatt (1896), Smulyan (1923), Middleton and Rohwer (in several papers) have made some morphological studies, mostly in connection with taxonomic work. Aside from these, references to sawfly morphology are scattered in general texts and papers on insect anatomy and phylogeny.

In the following discussion no attempt is made to offer a complete treatise on sawfly morphology. Only those characters have been discussed which, on close study, appeared to offer differences indicating relationships of groups, or to possess differences which might be used in such a capacity at a later date. The following parts have been studied and illustrated in greatest detail: the head, its endoskeleton and appendages; the external anatomy of the thorax and first two abdominal segments; the wing venation and the male genitalia. In addition to these major parts some other characters, such as tibial spurs, have been of considerable help in corroborating the phylogenetic arrangements presented herein.

\section{Head and Appendages}

\section{Head Capsule}

The head is always hypognathous, having the mouthparts directed downwards in repose. They may be directed forward when in use, but this is caused by a swinging forward of the entire head in a pendulum motion, the hinge being partly at the odontoidea and partly at the dorsal margin. This latter point of articulation is due to the moving of the head and "atlas" together (see p. 23). 
Many sutures and sclerites found in the heads of primitive insects are obsolescent or entirely absent in the heads of sawflies. See Plate I, figs. 1,2. Not only this, but no other parts have been added. The epicranial suture (ep) is present in only a few forms (e.g., Pergidae, Megalodontidae), and in these it is only a crease ending at a point between the lateral ocelli. The clypealiae and mandibulariae are entirely absent. The clypeus (cl) is not divided transversely into a pre- and postclypeus. It is separated from the front (f) by a furrow instead of a well-marked suture, and separated from the genae $(\mathrm{g})$ by a suture or furrow. The lateral arms of the epicranial sutures are lacking, so that the definition of the vertex and front is practically impossible. The anterior aspect of the head, however, is provided with several furrows, ridges, and areas which bear a fixed relation to the ocelli, eyes, base of antennae, and tentorinae. These have been given a terminology by Marlatt, Rohwer, and MacGillivray; and although the names bear no relation to the hypothetical areas of the head, they are of great use in taxonomic description.

The antennal sclerites are usually fused with the surrounding head capsule, but sometimes separated from it by a suture which is more or less visible when the head is cleared in potash. The antennae, fig. 1, articulate with a distinct antacoila, which is peg-shaped and located on the ventral or meso-ventral margin of the antennal socket. The oculata or eye sclerite, fig. 17 (oc), is not visible externally, but consists of an internal, converging, sclerotized shelf upon which the eye rests. The compound eyes (e) themselves are always large, composed of a very large number of facets. Three ocelli (o) are always present, situated between the dorsal portions of the compound eyes.

In the Siricoidea, Plate II, fig. 18, a groove ( $\mathrm{gr}$ ) is present, running ventrad or caudad of the antennal sockets, which receives the basal segments of the antennae in repose.

On the posterior margin of the head of all sawflies the occipital and occipitopostgenal sutures are both absent. A distinct crassa $(\mathrm{cr})$ is frequently present, originating at the postcoila of the mandible (ptc), extending dorsad and sometimes completely encircling the occipital region, fig. 2. It is always represented by a rounded, elevated portion if it is not present as a distinct ridge. The maxillariae $(\mathrm{mx})$ are always present, defined by distinct furrows or sutures, and each is provided with an odontoidea (od), which articulates with the cervicum. The ventral end of the maxillariae bears the paracoila, upon which the maxillae articulate. In those forms possessing a genapont the maxillariae are confined to the margins of the occipital foramen and the paracoilae are not in evidence, fig. 19.

Sawfly heads vary considerably in shape, size, and sturdiness, in the relative positions of eyes and antennae, width of malar space, and many other points. These, however, are more useful in a study of taxonomy 
than in morphology and will not be discussed further here. The most important matter is a consideration of the structure and origin of the types of head, which have a significant bearing on the relationships of the various groups of sawflies.

Head Types.-Four types of head are found, figs. 2, 5, 8, 19, characterized by the manner in which the genae or other parts are formed around the oral cavity or maxacava, and the occipital foramen. These types are termed open, fig. 2, maxapontal, fig. 8, genapontal, fig. 19, and closed, fig. 5 , on a descriptive basis.

Open Head, figs. 1 and 2.-This is the simplest type, from which all the other types are derived. Maxillariae long and slender, not united on the meson, the dorsal half bearing the odontoidea, the ventral margin bearing a small process, the paracoila. Postgenae neither produced mesally, nor over-lapping the maxillariae. This results in the occipital foramen being continuous with the maxacava, or oral cavity. The sides and anterior margin of the clypeus are free and the mandibles are never encircled at the base by the head capsule. This type occurs in the superfamily Tenthredinoidea and the families Xyelidae and Blasticotomidae. In the Tenthredinoid family Cimbicidae the maxillariae are very large, but are not fused together on the meson as they appear to be at first glance.

Maxapontal Head, figs. 7, 8.- Similar to the above type but with the ventral portion of the maxillariae fused on the meson, forming a bridge (maxaponta, mp) between the postgenae. The maxacava is therefore separated from the occipital foramen. This type is found in the family Cephidae.

Most of the Ichneumonoidea, figs. 10, 11, have a head similar in type to the Cephoid head, differing in having the fused maxillariae and the mesal margins of the postgenae produced at an angle into the interior of the head, forming a wide shelf upon which the maxillae and labium are folded in repose. The basin-like area thus formed has been called the "trophacava" by Salman (1929). It seems to me that this term is unnecessary and that MacGillivray's prior term "maxacava" can be applied equally well, irrespective of the type of head, to that region between the postgenae into which the maxillae and labium are folded in repose. The fusion of postgenae or maxillariae on the mesal line serves only to restrict this area without altering its position or function. If the different conditions of the maxacavae are to be named, it would seem better to apply adjectives to the name maxacava as they have been applied to antennae of different shapes.

Closed Head, figs. 4, 5.--This is a most curious head capsule. The ventral portion of the maxillariae $(\mathrm{mx})$ are joined on the meson, forming a broad bridge between the postgenae, and separating the occipital for- 
amen from the maxacava. The postgenae are produced meso-ventrally, the entire clypeus is folded back under the ventral side of the head, and the lateral areas of the clypeus are fused with the triangular, meso-ventral areas of the postgenae. The head, therefore, instead of being open on the ventral side, has only three small openings in its wall of armour through which the mouthparts protrude-two small, lateral holes through which the mandibles protrude, and a larger circular, median one which represents the maxacava and receives the maxillae and labium. The labrum is attached to the ventral margin of the maxacava (which is also the distal margin of the clypeus) and is directed posteriorly, covering the apex of the labium in repose. This type of head is restricted in the sawfly groups to the families Megalodontidae and Pamphiliidae. It must have evolved from the open type, but no intermediate steps have been observed.

Genapontal Head, figs. 18, 19.--The diagnostic character of the heads placed in this category is the presence of a true genaponta (gp). The postgenae have been produced mesad and have united on the meson, divided only by a postgenal suture, and form a bridge across the back of the head. This separates the occipital foramen from the maxacava. The maxillariae $(\mathrm{mx})$ have apparently been squeezed dorsad and lie around the ventral and lateral margins of the occipital foramen. The odontoidea (od), as usual, are borne by them. This type of head is characteristic of the superfamily Siricoidea, including the family Orussidae. In Syntexis, fig. 20, and Xiphydria the genaponta is very narrow, representing an intermediate in its formation.

The heads of the Siricoidea present a very fine example of the migration of parts, culminating in the condition found in the Orussidae. The Orussid head has been considered by most authors as representing a type very distinct from all other sawfly heads, but a critical analysis shows it to be the final product in a rather well marked chain of modifications. These are concerned with the cephalic aspect of the head which develops (1) a distinct groove for the reception of the basal segments of the antennae in repose, fig. 18, gr, and (2) the migration of the clypeus, antennal sockets, and part of the frontal region to the ventral aspect of the head.

In Syntexis and Xiphydria, figs. 20,21, 22, the more primitive genera in the superfamily, the antennae are inserted midway between the supratentorina and the pretentorina, and well up on the cephalic aspect; the antennal groove is very shallow, extending ventro-laterad of the antennal sockets, and not definitely marked at its lower extremity on the ventral margin of the head; and the clypeus is only slightly turned underneath. In the Siricidae, fig. 18, conditions are much different. The antennal sockets have migrated ventrad, and are adjacent to the pretentorina and distant from the supratentorina; the antennal grooves are much deeper 
and well marked for their entire length; and almost half of the clypeus has turned under itself, so that it forms a shelf which almost completely hides the labrum. In Orussus, figs. 23, 24, this migration has gone much farther. The entire clypeus and the portion of the front bearing the antennae have become turned under and now form part of the ventral aspect of the head; the antennal grooves extend along the ventral aspect and some distance up the caudal aspect; but the eyes and ocelli have assumed a more dorsal position than in either the Xiphydriidae or Siricidae.

\section{Tentorium}

The tentorium is readily identified, comprising the entire inner skeleton of the head, fig. 3.. For its study it is an easy matter to pick the larger heads to pieces with a needle or to clear the smaller ones in caustic potash and cut off most of one side of the head with scissors.

The tentorium, fig. 3 , is composed of the following parts: (1) the corpotentorium (cp), which is the more massive area from which the other parts apparently branch, comprising two lateral plates connected dorsally by a bridge; (2) the metatentorium $(\mathrm{mt})$, which is the part of the corpotentorium adjacent to the metatentorial openings, and which is sometimes continued dorsally and ventro-laterally to form shelf-like metatentorial thickenings; (3) the supratentoria (st), represented by two arms issuing from the anterior or antero-dorsal margin of the corpotentorium and joining the head above or near the antennae; and (4) the pretentoria ( $\mathrm{pr}$ ), two arms extending ventrad or latero-ventrad from the antero-ventral margin of the corpotentorium, often appearing continuous with it, and always provided with mesal, shelf-like processes.

The caudo-cephalic width of the corpotentorial bridge seems to vary considerably within closely allied groups, and therefore may be of little phylogenetic significance. The position and direction of the supratentorial arms, on the other hand, seem to offer characters of some application.

Tenthredinoidea.-Tenthredo, fig. 6.-Supratentoria arising at the dorso-anterior margin of corpotentorium and slanting in a dorsal angle to the head capsule. Pretentoria large, appearing confluent with the corpotentorium. Metatentorial thickenings fairly wide, running from the corpotentorium to the dorsal margin of the head. Cimbex, fig. 9.- Similar to above, but with the pretentoria very short and stout, undoubtedly an adaption to the extremely strong mandibles and head of the species.

Megalodontoidea.-Macroxyela, figs. 3, 29.-Very similar to Tenthredinoidea.

SiRICOIDEA.-Xiphydria, fig. 25.- Supratentoria slender, arising from the anterior part of the corpotentorium, considerably ventrad compared 
with their connection in the Tenthredinoidea. Pretentoria more slender than in the Tenthredinoidea, and directed more nearly ventrad. Tremex, figs. 30, 31.- Similar to Xiphydria, differing in having a longer corpotentorium and a much wider bridge across it. Orussus, figs. 26, 27.Markedly different from any other in the sawflies. Supratentoria short, not reaching the head capsule, their apices needle-like, apparently connected to the head only by a band of muscle. Pretentoria large and thick, directed almost exactly ventrad, their mesal processes large and almost joining on the meson. Corpotentorium short, the bridge very narrow; the supratentoria arising at the antero-dorsal margin.

CEPHoIdeA.-Janus, fig. 12.-Similar in many respects to Xiphydria. Supratentoria arising simultaneously with the pretentoria from the anteroventral portion of the corpotentorium; relatively slender. Pretentoria directed almost ventrad, less robust than in the Tenthredinoidea and Megalodontoidea, similar in this respect to Xiphydria. Corpotentorium fairly large and long, the bridge wide, and bearing on its anterior margin a small but distinct corportendon.

Ichneumonoidea.-Braconidae, Aleiodes, figs. 17, 28.-Unlike any of the sawfly tentoria. Supratentoria very long and slender, apparently arising from the pretentoria. Pretentoria long and robust with lateral processes as in the Cephidae; not differentiated from the corpotentorium. Corpotentorium with a narrow bridge from the centre of which arises a prominent corpotendon, furcate at the tip; laterally confluent with the pretentoria.

\section{The Braconid Head}

The type of head found in the primitive Braconidae, figs. 10, 11, seems at first glance to be very different from any of the sawfly heads. A study of the essential differences, however, shows that it may be derived from the Cephid head with only a few changes, although these are of quite a revolutionary nature. The evidence offered by other structures is fairly conclusive that the Braconidae originated from a Cephid-like stem, which would therefore demand that the Braconid head be a specialized product of the Cephid head.

The Braconid head differs from that of its progenitor in three important characteristics: (1) the maxillariae $(\mathrm{mx})$ are apparently lengthened to form a gular-like sclerite; (2) the margins of the postgenae and the fused part of the maxillariae are bent back into the head cavity to form a broad shelf upon which the maxillae rest in repose; and (3) the tentorium has assumed the shape shown in fig. 28 with a long corpotendon, long supratentorial arms, and a small corpotentorium. Judging by the relative size and shape of the Braconid and Cephid heads, the former was formed 
by a movement and readjustment of parts suggested by the following reconstruction. Starting with the Cephid head, fig. 8, the maxillariae continued to fuse dorsally on the meson, increasing the size of the fused portion and decreasing the size of the occipital foramen. Either subsequent to, or concurrent with, this fusion, the margin of the head around the maxacava (including both postgenae and maxillariae) began bending inward. This continued, increasing the width of the shelf around the maxacava and pushing the metatentorial openings dorsad. Such a series of events would culminate in a head similar in external appearance to that of the Braconidae.

The derivation of the tentorium is not so simple, for the Braconid tentorium is indeed different from the Cephid. The corpotentorium, however, has remained in the middle of the occipital foramen, so that it also must have moved dorsad. In doing so its lateral expanse could easily have been reduced, which would tend to reduce the angle made in the Cephid between the pretentorial arms and the corpotentorium. The large corpotendon is easily explained as an enlargement of the very small one found in the Cephid head. The remainder of the differences will have to be considered simply as readjustments to the new type of head which has evolved.

\section{Labrum}

In almost all sawflies the labrum (1) is at least as wide as long, sometimes retracted slightly under the clypeus so that only the anterior margin is visible, figs. 13, 14. The only exception to this is the long, narrow labrum present in the superfamily Siricoidea, figs. 15, 16.

\section{Mandibles}

As would naturally be expected with a group of such varied habits, the sawflies exhibit an array of mandibles which is variable in the extreme. From the standpoint of the entire group they are not of great significance in showing relationships. They will, however, undoubtedly prove interesting when more is known of the feeding habits of the adults. A glance at Plates II and III will reveal the diversity found in the group.

Almost all the mandibles have lost the brustiae, prostheca, acia, and a definite mola, and possess only the dentes, or teeth. It is likely that in forms with three or more teeth, figs. 34-36, both proxadentes (px) and distadentes $(\mathrm{dx})$ are represented. In other forms having only two teeth present, figs. 39-41, it is impossible to say whether both or only one of these sets is present. In all cases except the Xyelidae, therefore, these will be referred to simply as teeth.

The lateral aspect of all sawfly mandibles is provided with abundant slender setae, but to date patches of them which correspond to the 
brustiae found in more primitive groups have been discovered only in the mandibles of some larval Argidae, fig. 34.

The mandibles of the Xyelidae, fig. 35, are unique in that they possess a larger number of parts than any others in the sawflies. The left mandible has both proxadentes and distadentes differentiated, and a large incised area which has been identified as the mola (ma). The right mandible has the mola very greatly developed into a cusp-like projection which fits into the mola on the left mandible. The brustiae and prostheca are lacking.

The family Tenthredinidae presents a great variety of mandibles, all of which can be traced from a simple, two-toothed form, fig. 51. From this bidentate mandible some have evolved which have lost the inner tooth and become sickle-shaped, figs. 48-50, and others which have developed additional teeth, as shown in figs, 42-44. This is discussed more fully in the treatment of the phylogeny of the Tenthredinidae (see page 61).

The mandibles in some other families have undergone considerable modification. Conspicuous among these are the spatulate, toothless mandibles of the Orussidae, fig. 37, the long, sickle-shaped mandibles of the Pamphiliidae, fig. 4, and those of the Xyelidae, described above.

\section{Maxillae}

Except in the family Siricidae, the maxillae of the sawflies, Plate IV, follow essentially a uniform plan. The cardo (cd) is undivided and articulates with the maxillary sclerite. The stipes is sometimes divided longitudinally into the eustipes (eus) and parastipes (ps), in which case the parastipes is always only a narrow, inconspicuous sclerite. The lacinia (lc) is always membranous, sometimes adorned with setae. The galea (gl) is undivided in most forms, but in the Xyelidae, fig. 61, is divided into an ectogalea (ecg) and endogalea (eg). The palpi (p) have from one to six segments. The palpifer is referred to here simply as the first or basal segment of the palpus. The Siricidae, fig. 84, present a case of extreme fusion in which none of the above parts are differentiated except the cardo and palpi.

From the standpoint of phylogeny, the structure of the maxillae offers only incidental help. Two points, however, are of great interest, the similarity of this appendage in the Syntectidae, fig. 70, Xiphydriidae, fig. 69, and Orussidae, fig. 68, and the lack of specialization in the lower Braconids, fig. 67 , over the sawfly type.

Xyelidae. - The two divisions of the galea of the Xyelidae were termed the ectogalea and the endogalea by Crampton (1923). The progressive development of the endogalea, figs. $61,62,65$, from a constricted 
portion of the galea to a long digitate lobe, suggests that these two parts might be homologous to the proxagalea and distagalea found in other insects. The question, however, is entirely open to conjecture; and it seems safest to adopt Crampton's names at present.

Macroxyela, fig. 65.-Cardo short and trapezoidal. Stipes indistinctly divided into eustipes and parastipes, sclerotized on the ventral (ectal) side. Lacinia rounded, clothed with a patch of long setae; apparently continuous with the parastipes. Endogalea a distinct mesal lobe, set with peg-like setae on the mesal margin; ectogalea slightly hooked at the apex, with long setae on the margin. Palpi four-segmented, the last one with a submembranous apex.

Pleroneura, fig. 62.-Lacinia membranous, with an apical row of setae. Galea divided by a furrow into a proximo-lateral ectogalea and a mesodistal endogalea, the latter armed with stout setae.

Xyelecia, fig. 61.-Lacinia longer, clavate. Endogalea digitate, long, with a few, scattered, peg-like setae; ectogalea long and relatively slender, with stout setae at the apex.

Argidae.-Arge, fig. 63.-Cardo relatively long, folded under the rest of the maxilla in repose. Eustipes large, parastipes very narrow. Lacinia borne at the end of the parastipes, small and triangular, with fine setae on its mesal margin. Galea borne on the eustipes, large and submembranous, with tuft of setae on the ental side. Palpi six-segmented, relatively long and robust.

Cimbicidae.-Trichiosoma, fig. 64.-Cardo long, folded underneath the remainder of the maxilla in repose. Eustipes large and rectangular, parastipes very narrow. Lacinia almost as large as the galea, with fine setae along the margins. Galea with the basal portion semi-sclerotized, the apical portion forming a rounded, membranous cap bearing a few setae. Palpi scarcely longer than the parastipes, six-segmented, and moderately robust.

These last two maxillae are representative of the group of families contained in the Tenthredinoidea and the family Pamphiliidae. Differences are found in the relative portions of the various segments of the palpi, and the development of the lacinia and galea, but these do not change the fundamental aspect in relation to the other groups.

Syntectidae.-Syntexis, fig. 70.-Cardo small, somewhat trapezoidal. Stipes much as in other groups, the suture dividing it from the parastipes only barely indicated. Lacinia very large, membranous, with a few weak setae at apex; with a crease marking off a relatively wide area along the mesal margin. Galea broadly hook-shaped, submembranous on the lateroventral side, provided with a brush of stout setae on the meso-dorsal 
side. Palpi five-segmented, apparently with little or no articulation between the third and fourth segments; relatively long and moderately slender.

XIPHYdRIIDAe.-Xiphydria, fig. 69.-Cardo short, almost square. Stipes much as above, apparently not divided longitudinally into eustipes and parastipes. Lacinia a very weak, rounded, membranous lobe, with only one or two weak setae at apex. Galea much larger, submembranous, covered with fine setae. Palpi five-segmented, short and slender. Judging from the close relationship of this genus with Syntexis, the second palpal segment of Xyphydria represents the fused second and third of Syntexis.

Orussidae.-Orussus, fig. 68.-Cardo short, rectangular. Stipes normal, the parastipes very narrow and separated by a distinct suture from the eustipes. Lacinia a large trapezoidal lobe, entirely membranous and without setae, very much resembling that of Syntexis. Galea no larger than the lacinia, membranous on the ventral side, with a thick pad of strong setae on the dorsal side. Palpi about four times the length of stipes, five-segmented, the second segment short, the remainder long, the fifth and the apical portion of the fourth armed with truncate setae.

Siricidae.-Urocerus, fig. 84.-Maxillae extremely reduced; the stipes of the two maxillae fused along the mesal line without a stuture remaining, so that the two maxillae form a single lunate structure (st). Cardines (cd) also fused on the meson, appearing as two tubercles, each with a thread attached to the basal margin. These threads are attached within the head. Lacinia either atrophied or fused with the galea ( $g 1)$. Galea continuous with the stipes, the entire appendage uniformly submembranous. Palpi (max. p.) reduced to a single bulbous segment.

Cephidae.-Cephus, fig. 66.-Cardo short and trapezoidal. Stipes undivided, normal in general shape; slightly creased at apex to suggest the distal portion of the suture separating the eustipes and parastipes. Lacinia very small, submembranous. Galea large, also submembranous, with a proximo-lateral lobe or fold which appears to form a distinct sclerite. Palpi six-segmented, slightly longer than the stipes.

BRACONIDAE.-Aleiodes, fig. 67.--Similar in general plan to Syntexis, Xiphydria, and Cephus. Cardo almost as long as stipes. Stipes undivided, bearing at its distal end the membranous lacinia and the submembranous galea. Galea with a brush of stout setae on its ental side. Palpi six-segmented, four or five times the length of the stipes.

\section{Labium}

The various types of labia, Plate V, found in the sawfly groups present a heterogeneous outlay. Most of the differences are due to the relative development of the alaglossa (alg), which is composed of the 
fused pair of glossae, and the paraglossae (pgl). The submentum (sm) is usually present, of various sizes and shapes. The mentum is apparently absent. The stipulae (sti) are represented by a sclerotized area basad of or around the palpi and basad of the glossae and paraglossae. The palpi have two, three, or four segments. The paraglossae and the alaglossae are distinct except in the Siricidae, fig. 84, and some Tenthredinoidea (e.g., Loboceridae, fig. 76), in which they all have fused completely to form a totaglossa.

Cimbicidae.-Trichiosoma, fig. 71.-Submentum elongated, diamondshaped, separated from the stipulae by a considerable area of membrane. Stipulae bi-emarginate distally forming a median triangle. Palpi foursegmented, the two apical segments provided with sensory areas. Paraglossae large, almost twice the width of the alaglossa, both finely setate on the apical third, the latarima extending to the membranous ligula. Typical of most of the families in the Tenthredinoidea and the family Megalodontidae. In the Blasticotomidae the paraglossae and alaglossa are much reduced but distinct.

LoBoceridae.-Incalia, fig. 76.-Differs markedly from the above in having the paraglossae and alaglossa entirely fused to form a totaglossa. This also occurs in Decameria (Perreyiidae).

Argidae.-Arge, figs. 72, 73.-Submentum and stipulae differing in shape from the above. Stipulae produced mesad to near hypopharynx, somewhat stirrup fashion. Hypopharynx a large sclerotized area with abundant setae. Condition of hypopharynx and stipulae essentially typical of all sawflies with well developed labial parts.

Xyelidae.-Macroxyela, fig. 77.-Submentum shield-shaped, adjacent to the stipulae. Palpi three-segmented, the apical half of the third segment with numerous stout setae. Paraglossae short, with several spinelike setae; alaglossa absent, represented by a membranous area connecting the bases of the paraglossae. In Megaxyela the palpi are four-segmented.

CEPHIDAE-Janus, fig. 81.-Stipulae reduced to a narrow, sclerotized band. Palpi four-segmented. Paraglossae lobe-like, only half the width of the alaglossa; alaglossa similarly lobe-like; both of them stumpy and set with thick, small setae and united at the base. Below them is a trapezoidal sclerite $(\mathrm{x})$ set in the apical membranous portion of the stipulae.

Xiphydritdae.-Xiphydria, fig. 82, 83.-Submentum represented by a triangular sclerotized area between the bases of the maxillae, gradually fusing into the membranous area basad of the stipulae. Stipulae with only a narrow, sclerotized basal area. Palpi large, three-segmented, the apical segment with an ovate sensory area. Paraglossae slender, small, and curved, alaglossa broader and more or less truncate at the apex; both 
paraglossae and alaglossa very small; the latarima extending basad for the exposed length of the alaglossa.

Orussidae.-Orussus, fig. 80.-Stipulae large, encircling the base of the palpi. Palpi three-segmented, the third segment club-shaped and with curved, strong setae. Paraglossae small, separated from the glossa by sutures, but otherwise not free from it; alaglossa large, with a depressed, membranous, median area; all approaching the condition of a totaglossa.

Siricidae.-Urocerus, figs. 84, 85.--Submentum represented by a small sclerotized area between the cardines of the fused maxillae. Stipulae large and shield-shaped, not produced anteriorly into a stirrup-like process. All parts of the glossae united into a totaglossa. Palpi three-segmented, the apical one with a round, membranous, sensory area. Hypopharynx (hy) reduced to a small area of setae, fig. 85.

Syntectidae.-Syntexis, figs. 78, 79.--Submentum ovate, situated in the membrane between the bases of the maxillae. Stipulae large, embracing the bases of the palpi. Palpi three-segmented, the third segment clavate and armed with stout, curved spines similar to those found in the Orussidae. Paraglossae thin and flap-like; alaglossa U-shaped, encircling the paraglossae at their base, these latter being situated within the circle of the alaglossa and covering most of it from view when seen from the posterior aspect. The alaglossa of this species might superficially be termed a "duplaglossa," which has previously been considered as restricted to the higher Hymenoptera. It is very similar to that found in the Braconidae (see Aleiodes, fig. 75), having similar rows of microtrichiae on the anterior face. It differs slightly from the true duplaglossae, however, in that the paraglossae are contained within the hollow semi-circle formed by the alaglossa instead of being situated beside it.

Braconidae.-Aleiodes, figs. 74, 75.-Stipulae large, similar in type to that found in sawflies. Palpi four segmented. Paraglossae small, reduced to flaps along the base of the duplaglossa. Duplaglossa large, somewhat $\mathrm{V}$-shaped, bearing rows of microtrichiae on the anterior surface.

The trend of development in these labia has been one leading from a condition in which the paraglossae were large and the alaglossa subordinate to them, to one reversing this relation, having the alaglossa large and the paraglossae subordinate to it. This has led to the totaglossa of the Siricidae, Loboceridae, and Perreyiidae on the one hand and the duplaglossa of the Apocrita on the other.

\section{Antennae}

The antennae, figs. 86-107, vary greatly both in shape and the number of segments comprising them. They are frequently of use in the diagnosis 
of genera or larger groups, and undoubtedly offer some of the best characters for keying out the families. They apparently afford few clues as to the phylogeny of the various sawfly groups. There is no gradual development towards a predominant type as, for example, the case of the aristate antennae of the cyclorraphous Diptera. They will be discussed, therefore, simply according to shape.

Filiform and setaceous.-This is the common type found in most of the sawflies. The number of segments may vary from six in the Acorduleceridae, fig. 95, to thirty or more in the Pamphiliidae, fig. 88. An interesting deviation from the setaceous type is found in the Argidae, Xyelidae, and Blasticotomidae. The third segment has become greatly lengthened and thickened, and the remaining apical segments are either absent (Argidae, fig. 97), reduced to a small stub (Blasticotomidae, fig. 96) or form a slender, segmented filament (Xyelidae, figs. 86, 87).

Furcate.-The males of some genera of the Argidae have undergone a further modification of the enlarged third segment, which is divided longitudinally for almost its entire length, forming two slender filaments which are usually somewhat curled and harp-shaped, fig. 98.

Fusiform.-Some species of Macrophya, fig. 103, and the females of Orussus, fig. 92, have the preapical segments enlarged, giving it a decided spindle shape.

Serrate.-In those families in which setaceous or filiform antennae are the rule, occasionally genera appear in which the antennae are more or less distinctly serrate. In some Diprionid genera, e.g., Augomonoctenus, fig. 107, and Monoctenus, the female antennae are markedly serrate. In some Tenthredinidae, e.g., Ceratulus, fig. 355, both sexes have serrate antennae.

Pectinate. - The males of Diprionidae, fig. 105, the genus Pterygophorus and the genus Cladius (Tenthredinidae), fig. 104, have antennae which are very conspicuously pectinate. The females associated with these may have the antennae either setaceous, serrate, or pectinate, but in the latter case, fig. 106, never to the same extent as the males.

Flabellate.-The males of Megalodonta have curious antennae, fig. 94. The segments of the flagellum are provided with distinct lamellae which are small and ovate, and may be folded back in repose so that the antenna appears filiform.

Clavate.-The Pergidae and some groups of the genus Tenthredo, figs. 101, 102, of the family Tenthredinidae have antennae with a well-formed, but not conspicuous club.

Capitate.-In the Cimbicidae the club is large and the "handle" (third segment) is very slender, fig. 100 . 


\section{ThORAX AND APPENDAgES}

Since the thorax of sawflies has been studied in comparison with that of the Apocrita and other orders by Snodgrass (1911), only those parts will be mentioned in this discussion which have shown differences of taxonomic or phylogenetic significance within the sawfly groups. These consist chiefly of the cervical sclerites, mesonotum, and mesopostnotum.

\section{Cervical Sclerites}

Crampton's interpretation of these sclerites is adopted here. This postulates, fig. 146, that the large, lateral sclerites (cv) lying anterodorsad of the prosternum represent the enlarged cervical sclerites to which are fused the reduced propleurae $(\mathrm{pl})$. In the Tenthredinoidea the propleurae are usually demarked by a suture, but even in some of these forms it is almost impossible to be sure of these sutures.

In most of the Tenthredinoidea the ventro-mesal portion of the cervical sclerites is $\mathrm{V}$-shaped or $\mathrm{U}$-shaped, not meeting on the meson, figs. 155,156 . In other members of the superfamily, the sclerites practically meet on the meson, and the ventro-mesal margin is truncate, figs. 157,158 , or subtruncate, fig. 154 . This enlargement and strengthening appears to be purely adaptive and a modification very easily acquired. Thus, in the family Tenthredinidae these sclerites have become truncate and approximate on the meson in the subfamilies Tenthredininae, Dolerinae, and Allantinae. The primitive genera of the Tenthredininae and Allantinae have these sclerites unmodified, so that the development of these truncate sclerites has occurred independently in each of the three subfamilies mentioned.

In the Cimbicidae, fig. 159, an interesting modification occurs. The lateral angles of the prosternum unite with the mesal margin of the cervical sclerites to form a precoxal bridge. This, however, is not the primitive condition typical of the sawflies, but simply an aberrant off shoot.

In the Siricoidea, figs. 132, 133, and Cephoidea, fig. 131, the cervical sclerites are very large, with the ventro-mesal margins truncate and more approximate than in any of the Tenthredinoidea. This is the condition typical of the Apocrita.

\section{Propleurae}

The propleurae are either separated from the cervical sclerites by a distinct suture, or undifferentiated, in which case they form the posterior portion of the cervical sclerites. In the Xyelidae, fig. 148, they are extremely small and difficult to differentiate. In the Tenthredinoidea, fig. 146, and some Siricoidea, fig. 147, they are longer, and are almost entirely invaginated into the body, giving an apodeme-like appearance. 
The study of this structure, however, is at present not extensive enough to be used as a basis for any conclusions.

According to Crampton (1926), the propleurae are divided by a distinct suture into the episternum and epimeron, but I have not yet been able to observe this suture. The line of origin of the propleurodeme is difficult to determine exactly, and may be the suture here considered to separate the cervical sclerites and the propleurae. When this and some other uncertain points are finally cleared up, our conception of the homologies of this region may have to be modified.

\section{The "Atlas"}

The cervical sclerites, fig. 129, cv plus bs, (including the fused propleurae) and the probasisternum together from a single unit from the standpoint of function. The head articulates at the anterior end of the cervical sclerites, the prothoracic legs between the basisternum and procoxacondyle. The cervical sclerites and prosternum are firmly united by means of the strong endoskeleton, but are united to the remainder of the body only by membrane. Consequently, the head and front legs have not only their articulation where they join the cervicum and prothorax, but in addition the flexibility allowed by the membranous connection of these parts. For this combination of cervical sclerites and probasisternum the term "atlas" is proposed, since it is analogous to this structure in the vertebrate skeleton.

\section{Prosternum}

The prosternum is primitively represented by two widely separated sclerites, fig. 129, the basisternum (bs) and the spinisternum (ss). The basisternum is between and sometimes partly under the mesal portion of the cervical sclerites, and between the front legs. It is variable in shape, being diamond-shaped, ovate, T-shaped, or I-shaped; internally it bears the large, fused furca.

An unrecorded sclerite, the spinisternum.-The spinisternum (ss), if differentiated as a distinct sclerite, is situated on the meson just anterior to the mesosternum or mesopleurae. It is a small sclerite and usually bears internally a small furcella or plate, fig. 153 (fl). In the Megalodontoidea, some of the families of the Tenthredinoidea (e.g., Argidae, fig. 134) and the Siricidae, fig. 138, it is distinct, but in this last family lacks the furcella. In the Syntectidae, Xiphydriidae, and Cephidae the spinisternum is represented by a very small, indistinct thickening of the membrane only. In the higher Tenthredinoidea, fig. 136, it is apparently fused with the mesosternum and forms the small triangular area between the anterior fork of the mesofurcina. 


\section{Mesosternum}

In many sawflies this area is distinct, separated from the mesepisterna by well-marked sterno-pleural sutures. In others it may be entirely fused with them, or at the most separated by obsolescent sutures. There is a deep suture along the meson which marks the emargination of the fused and lengthened furca, fig. 153, (fc).

Xyelidae and Pamphilitdae, fig. 129.-Sternum (ms) forming a triangular area, divided from the episterna by a distinct or at least a well-marked suture; episterna (eps) produced mesally and fused anterior to the sternum to form a wide presternal bridge (psb).

Cephoidea, fig. 131.- Sternum triangular, longer than in the above, the sterno-pleural sutures converging and meeting near the anterior margin of the segment. Presternal bridge very narrow, not distinctly differentiated from the antecostal ridge of the sclerites.

SiricoideA.- Syntectidae, fig. 130.-Sternum more or less short and triangular, set off from the episterna by distinct sutures terminating anteriorly on the meson in deep pits. Episterna bilobed anteriorly, the three incisions between the lobes membranous. Furcal suture extending to the anterior margin of the segment, apparently representing a narrow tongue of the sternum separating the two episterna. The condition is peculiar, apparently most resembling the Pamphiliid type, fig. 129.

Xiphydrimdae, fig. 132, and Siricidae, figs. 137, 138.-Sternum fused with episterna with no evident suture. In these two families, however, the furca does not quite reach the anterior margin of the segment, indicating the presence of a narrow presternal bridge. Furthermore, there is a triangular area, fig. 138, (ms), separated from the lateral areas by a convexity, by slight differences in texture and by a lack of large punctures. This area may be regarded with certainty as the true sternal region.

Orussidae, fig. 133.-In this family also the sternum is fused with the episterna with no distinct suture between them. There are, however, faint remnants of the sterno-pleural sutures in the form of impressions on the external surface of the sclerites. When traced out these delineate a triangular sternum, the tip of which just reaches the anterior margin of the segment.

Tenthredinoidea and Megalodontidae, fig. 134.- Sternum trapezoidal, episterna well separated anteriorly, not forming a presternal bridge. This condition is present in the Pergidae, Pterygophoridae, Loboceridae, Perreyiidae, and some genera of the Argidae, fig. 134. In other Argidae and the Cimbicidae the sterno-pleural suture is weak or entirely absent, as is the case with all the remaining Tenthredinoidea, figs. 135, 136. In these latter, however, it is a simple matter to demonstrate that they 
are a derivative of the trapezoidal type of sternum, since the path of the sterno-pleural suture is indicated as in fig. 134 by lines of punctures, color differences, depressions in the surface of the sclerite, and a distinct internal line of muscle attachment.

\section{Pronotum}

This sclerite is quite varied in shape. In the Xyelidae, fig. 120, (pn), Cephidae, fig. 121, and Syntectidae, fig. 122, it is somewhat rectangular, and slightly narrowed on the meson; in the Xiphydriidae, figs. 123, 141, Siricidae, fig. 127, and Orussidae, figs. 128, 142, it is of approximately the same dimensions but tilted forward into a vertical position. In the Tenthredinoidea, figs. 124,139 , it is greatly reduced on the meson, forming only a narrow collar at this point.

\section{Mesonotum}

The sawfly mesonotum, fig. 120 (II), is primitively divided into four major parts-praescutum (prs) subdivided on the meson into two lateral halves, scutum (scut), scutellum ( $\mathrm{scl}$ ), and postnotum (ptn), most of which is invaginated underneath the metanotum. The postero-lateral areas of the scutum are usually markedly declivous, forming the parascutellar areas (is). Some groups have an apparent posterior lobe of the scutellum, the post-tergite ( $\mathrm{pt}$ ). All the sclerites are subject to variation, which may be discussed to best advantage according to taxonomic units.

Megalodontoidea, fig. 120.-Praescutum diamond-shaped; scutum large, not divided transversely; scutellum V-shaped anteriorly; the posterior margin of the scutellum produced into a narrow post-tergite $(\mathrm{pt})$; postnotum forming the lateral post-alar bridge, and forming a phragma underneath the metanotum. The phragma, fig. 149, is about two-thirds concealed, the concealed portion consisting of two small lateral lobes and two large median lobes.

Tenthredinoidea, figs. 124, 126.-Similar to the Megalodontoidea. Post-tergite absent in all but the Diprionidae, in which it is only a narrow cord, and the Tenthredinidae, in which it is usually well-developed and triangular, figs. 124, 125. The Acorduleceridae, fig. 126, are unique among the Tenthredinoidea in having the lateral and mesal sutures of the praescutum distinct only for the anterior two-thirds of their length, so that the praescutum is not separated from the scutum which therefore appears much longer than normally; and in having the scutellum transversely sinuate on its anterior margin. Throughout the Tenthredinoidea the postnotum is similar to that of the Megalodontoidea.

Cephoidea, fig. 121.-Similar to the Megalodontoidea, except as follows: post-tergite very small, scarcely present; postnotum, fig. 152 , very 
long, much narrower, with the two small, lateral lobes considerably reduced; parascutellar areas not distinctly set off from the scutum.

Siricoidea. - The Syntectidae, fig. 122, are similar to the Cephidae, fig. 121, (condition of the postnotum unknown). The remainder of the Siricoid families differ considerably from this primitive type.

Xiphydriidae, fig. 123.- Scutum divided by a transverse suture near its middle into anterior and posterior halves. Praescutal sutures extending meso-caudad to this trans-scutal suture, so that the praescutum is much longer than normally. Parascutellar areas relatively distinct. Scutellum differentiated anteriorly and laterally by broad, trench-like sutures. Postnotum as in the Megalodontoidea, fig. 149.

Orussidae, fig. 128.- Scutum divided transversely. Praescutal sutures extending almost longitudinally from the pronotum to the trans-scutal suture; the median praescutal suture absent, so that the praescutum is an undivided, rectangular sclerite. Scutellum distinctly set off by sutures; the scutum apparently solidly united to the postnotum so that the scutellum appears to be surrounded by the scutum. Postnotum longer than in the Xiphydriidae, fig. 150.

Siricidae, fig. 127.- Scutum divided by diagonal, wide, trench-like sutures into an anterior sclerite and two postero-lateral sclerites $(y)$. Praescutal sutures present only as faint traces, the praescutum therefore appearing fused with the anterior sclerite of the scutum. Postnotum considerably lengthened, fig. 151.

\section{Metanotum}

In the Megalodontoidea, fig. 120 (III), Tenthredinoidea, and the family Syntectidae of the Siricoidea, fig. 122, the metanotum is separated from the mesonotum by a deep furrow marking the invagination of the postnotum. In these the scutum and scutellum may be fairly readily identified, figs. 120, 122. In addition to these areas, a pair of hard, opaque, rough areas are present on the scutum, known taxonomically as the cenchri $(\mathrm{cn})$. The praescutum is either absent or undifferentiated. The two chief differences from this condition may be briefly summarized as follows: (1) in the Cephidae, fig. 121, Xiphydriidae, fig. 123, Siricidae and Orussidae, fig. 128, the metanotum is closely appressed to the posterior margin of the mesonotum, and part of the metascutum is hidden from view; in the last three families named, the cenchri appear as small pads protruding from the suture formed by this consolidation; (2) in the Cephidae the cenchri are entirely wanting. The scutellum also is more or less undifferentiated in the families mentioned above.

\section{Mesopleurae}

A hypothetical sawfly mesopleuron would be as follows: prepectus 
present as a distinct sclerite, fig. 129, (pp) ; pleural suture present, dividing the pleuron into the mesoepisternum and mesoepimeron; epimeron divided by a short epimeral suture into the anepimeron (aem) and katepimeron (cem). Unlike the epimeron, the episternum is never divided. The deviations from this type are primarily due to the atrophy of one or more of the sutures.

TenthredinoideA, fig. 139.-Prepectus either present or absent, sometimes the two conditions being found in closely related genera. In some cases the prepectal suture is modified into a furrow and the prepectus is present as a shoulder-like ridge. Pleural suture present. Epimeron divided; anepimeron markedly convex, katepimeron usually flat, the epimeral suture dividing them sometimes obsolete but the two parts distinct due to their great difference in convexity.

Megalodontoidea,--Similar to above, differing in having the epimeron undivided.

Siricoidea and Cephoidea, figs. 140-143.-In these two super-families the epimeron is undivided as in the Megalodontoidea. The pleural suture is either lost or indistinct in most of these families, frequently discernible only at one end.

\section{Metapleurae}

Similar in general features to the mesopleurae, differing, however, in lacking a prepectus and having the sutures disappear in this segment before they do in the mesopleurae. An interesting modification occurs in the Pergidae and Philomastiginae. The metaepimeron is not only undivided but solidly fused with the lateral margin of the first abdominal tergite. Intermediates between this and the free condition are found in the Perreyiinae and to some extent in other members of the Tenthredinoidea.

\section{Legs}

The three pairs of legs are built essentially along the same plan, consisting of the following parts, fig. 110-coxa (cx), two-segmented trochanter (tr), femur (fm), tibia (tb), five-segmented tarsus (ta), and tarsal claws (tc). The only known exception to this is the front leg of the female of Orussus, fig. 108, which has the apical portion of the tibia constricted to form an additional tibial segment and has only four segments to the tarsus, the first segment hidden in the distal end of the tibia so that the tarsus appears three-segmented.

The tibial spurs present several characters worthy of note. Preapical spurs, fig. 110, (psp), numbering from one to four, are present on the middle and hind legs of the Pergidae, Acorduleceridae, the genus Arge in the family Argidae, and the families Xyelidae, Megalodontidae, 
and Cephidae. The front tibia of the genus Acantholyda (Pamphiliidae) also has a pre-apical spur. Occasionally one is found on the middle or hind tibiae of the Loboceridae, and may likely appear haphazardly in other groups.

All the tibiae are provided with one or two apical spurs, fig. 110, (asp). On the middle and hind tibiae they are quite uniform, but on the front tibiae offer some valuable differences as follows. In the Pergidae, Acorduleceridae, Argidae, Pterygophoridae, Cimbicidae, Diprionidae, Perreyiidae, and Loboceridae two are present, both of the same shape, although one may be slightly smaller than the other, fig. 113, (asp). Usually they are pointed but in some genera may be truncate or even slightly swollen at the apex. In the Tenthredinidae, Blasticotomidae, Xyelidae, Megalodontidae, and Orussidae, two apical spurs are present, but one is broadened and branched or incised at its tip, fig. 114. In the Orussidae the unbranched spur is very small, fig. 115. In the remainder of the sawflies, the Cephidae, Syntectidae, Xiphydriidae, and Siricidae, the unbranched spur has been lost entirely, and the modified spur has developed into several different forms. That of Xiphydria, fig. 117, is long and slender, similar to that of Orussus. In the Siricidae, fig. 116, the spur has widened, and the inner side is sub-membranous. In Syntexis, fig. 118, the inner margin has become transversely incised to form a pectinate fringe running almost the entire length of the spur, and the outer tooth of the apical incision is small and slender. In the Cephidae, fig. 119, this outer tooth is very large, the inner one being small.

In some genera of the Siricidae, the middle and hind tibiae have only one apical spur.

\section{Wings}

The multitude of differences found in the venation of sawfly wings has been the basis for several methods of classifying the groups themselves. When, however, the wings are studied after the other parts of the insect, two facts are apparent: (1) the characters of the venation give assistance in tracing evolution in only a few cases, and (2) parallel evolution has occurred in many instances.

The systems of nomenclature for the Hymenopterous wing are many. These have been discussed in a previous paper (Ross, 1936a) and the system there propounded is used here. The simple evolution of the $\mathrm{Hy}$ menopterous venation from the Panorpoid types is the basis for the terminology, which is given in figs. 170 and 211 .

The most primitive characters in the sawfly wings are: (1) a free subcosta in the Xyelidae and Pamphiliidae, fig. 172 ; (2) the unfused condition of media and radial sector, which are therefore separated by the first radio-medial cross-vein, in Pleroneura, fig. 172; (3) the presence 
of the base of all the anal veins in some Siricidae, fig. 173; and (4) the presence of the base of cubitus in the hind wings of some Xyelidae, much as in fig. 170 .

The most marked differences between the superfamilies include: (1) the unique tendency in the Tenthredinoidea for continued basal fusion of media along radial sector, this fusion frequently going back down the stem of radius, fig. $185 ;(2)$ the partial loss of the first radial cross-vein in some Cephidae and its total atrophy in the Orussidae; and (3) the more or less straight course of the veins in the Siricoidea and Cephoidea.

Parallel development has taken place most frequently in the anal veins. There seems to be a tendency in all sawflies for $2 \mathrm{~A} \& 3 \mathrm{~A}$ to fuse with the first anal vein. It has occurred in the Argidae, Diprionidae, and Cimbicidae and is very well illustrated in the Tenthredinidae, figs. 197-210 (see p. 61).

There seems to be little uniformity in the atrophy of veins or crossveins. In many cases the atrophy of a portion of the venation may be simply individual variation, and in other cases it may typify species or genera. The only family in which the venation shows consecutive steps in variation is the Tenthredinidae, under which heading it is discussed fully.

\section{Abdomen and Appendages}

As with the thorax, the general features of the sawfly abdomen have been studied by Snodgrass (1931). Only those parts will be discussed here, therefore, which have some bearing on the question of relationships.

\section{First Abdominal Tergum, or Propodeum}

The first segment is represented only by the tergum, the sternum being either membranous or atrophied. This first tergum is an integral part of the metathorax, since it is fused quite solidly with it in all sawflies. If the body is broken, the break occurs between the mesothorax and metathorax, not between the thorax and abdomen. The first tergite, fig. 120, (1), is typically divided or incised on the meson, to produce two lateral plates. These are referred to in taxonomic literature as the "basal plates" or "propodeum." In some genera or families (e.g., Orussidae, Cimbicidae, and some Tenthredinidae), they have become reunited, fig. 128.

In most sawflies the dorsal contour line of the metathorax and the first two abdominal terga, when viewed laterally, is almost continuous, without marked constrictions between the segments, figs. 139, 140, 142. There are only two distinct exceptions to this: (1) the Xiphydridae, fig. 141, have a distinct constriction between the metanotum and first tergite; and 
(2) the Cephidae, fig. 143, have a very well marked constriction between the first and second tergites. In the Apocrita, fig. 144, the first tergite is entirely fused with the metanotum, and the second and following segments articulate with the first by a ball-and-socket joint. While no such joint as this exists in the Cephidae, the articulation of the rest of the abdomen does occur at this point, and there is a suggestion of a joint at the postero-lateral angle of the first tergite.

\section{Male Genitalia}

The terminology advocated by Crampton (1919) has been used for the parts of the male genital capsule, for the reason that it is the only one taking into account the prior use of names for some other part of an insect. For instance, the terms "cardo," "stipes," and "manubria," used by some authors for parts of the genitalia, are in current usage for sclerites of mouthparts or other appendages, and these Crampton has changed or discarded. His argument is quite sound that this is the only way to arrive eventually at a uniform and nonconfusing terminology of homologous parts of different insects.

The male genitalia, as would be expected, present a multitude of differences, especially in the Tenthredinoidea. As far as can be ascertained at present, a great deal of this variation is of use only in grouping related genera. Only a few of the differences show relationships between larger groups, and these are the differences discussed here.

The genitalia present two different orientations. In one group the adult genital capsule remains in the same orientation as in the pupa. In the other the capsule revolves through a $180^{\circ}$ angle around its linear axis. This was first pointed out by Crampton (1919), and was later shown by Boulonge (1924) to occur just prior to eclosion. Crampton proposed the terms "Orthandria" for those sawflies with normal genitalia and "Strophandria" for those in which the genitalia turned. The latter includes only the Tenthredinoidea, while the former includes the Megalodontoidea, Siricoidea, and Cephoidea.

The genital capsule, fig. 160, is composed of the following sclerites: (1) gonocardo, or basal ring (ca); (2) a pair of gonostipites, (go), comprising the lateral foundation; (3) harpes (h), or appendages of the gonostipites; (4) sagittae (sa) and volsellae (ol); two pairs of sclerotized plates, primitively ventral, but dorsal in the Strophandria or Tenthredinoidea; (5) a pair of penis valves (py), enclosing the true penis; and other structures of a sporadic nature, including the gonamaculae $(\mathrm{gm})$ or apical muscular disc of the harpes of the Megalodontoidea and others, the parapenes (gg) of some Tenthredinoidea, and the median sclerotized style of the Siricidae and Cephidae. 
Tenthredinoidea.-Arge, fig. 160, Trichiosoma, fig. 163, and Acordulecera, fig. 164.--Genitalia are turned so that the volsellae and sagittae are on the dorsal surface. Gonocardo usually present, sometimes partially atrophied. Gonostipites present, varying in form; in the Cimbicidae and Tenthredinidae incised on the ventral surface to form a pair of median lobes or processes, the parapenes. Harpes always present, articulating with the gonostipites; never with gonomaculae. Volsellae and sagittae always approximately the same shape; sagittae with a mesal hook-like process and an apical point or process. Penis valves of many different shapes. They are characters which are extremely valuable in specific diagnosis of many genera.

Megalodontoidea.-Macroxyela, fig. 167.--Capsule not turned, the sagittae and volsellae on the ventral surface. Gonocardo present as a broad band. Gonostipes large, resembling in shape that found in Arge, fig. 160. Harpes articulating with the gonostipes, with an apical gonomacula $(\mathrm{gm})$. Volsellae and sagittae similar to those of Tenthredinoidea, but much reduced. The genitalia of the Megalodontidae are similar in all essentials to those of the Xyelidae with the exception of the gonocardo, which is very narrow, and the volsellae and sagittae which are even further reduced.

SiRICOIDEA.-The genitalia of the families of this group differ greatly, so they are described separately.

Xiphydriidae (Xiphydria, figs. 161, 162).-Very similar to Macroxyela, differing only slightly in the relative size of the parts. Volsellae and sagittae essentially like those of Macroxyela, fig. 167, small, and concealed on the mesal face in repose. Harpes with gonomaculae.

Siricidae (Urocerus, fig. 166).-Dorsal expanse of gonostipites larger, ventral expanse smaller than in Xiphydria. Harpes stout, with gonomaculae. Volsellae represented by a flat, sclerotized plate. Sagittae more erect in position, the apical portion rounded and bearing tooth-like projections. Penis valves stouter. Ventral surface with a long, slender, sclerotized style extending from the base up the meson of the gonostipes to the base of the sagittae.

Orussidae (Orussus, fig. 169).-Very unlike the capsule of any other sawfly. Gonocardo large, wide on the dorsum. Gonostipes with a large dorsal expanse, fused on the center with the volsellae, the two separated by a suture. Sagittae greatly elongated, with a long basal portion and an apical, clasper-like portion which extends slightly beyond the harpes. Harpes separated from the gonostipes by a wide area of membrane, triangular, and more or less inconspicuous due to the larger apex of the sagitta; gonomaculae not present. 
Cephoidea.- The genitalia of the only family in the superfamily show some interesting deviations from other sawfly capsules. Janus, fig. 165.Gonocardo enlarged laterally to form a very thin sheath covering the basal portion of the gonostipes. Gonostipes and harpes separated either by an indistinct suture or not at all, with no articulation between the two sclerites. Volsellae and sagittae with their apices knob-like and provided with minute peg-like elevations.

ICHNeumonoidea.-Braconidae (Aleiodes, fig. 168).-Considerably different in aspect to any of the sawfly genitalia except those of the Cephidae, fig. 164. Gonocardo ring-like, as in the sawflies. Gonostipes and harpes completely fused with no trace of a dividing suture. Sagittae similar in shape and position to those of Janus and Urocerus. Volsellae large, the apical portion triangular. Both volsellae and sagittae provided with small knobs or teeth at apex. The genitalia of several other Ichneumonoids have been examined and found to be of the same type as Aleiodes, the sagittae and volsellae occupying approximately the same position, and the harpes always completely fused with the gonostipites.

A restudy of the male genitalia has substantiated practically all the conclusions pointed out by Crampton. They show that the Megalodontoidea and Xiphydriidae are closely related, and that the former are similar in many respects to the Tenthredinoidea. One point is especially noteworthy. The almost complete fusion of the harpes with the gonostipes in the Cephidae is a distinct step towards the condition found in the Ichneumonoidea, which rebuts as much as anything else the assertion of Rohwer and Cushman that the Orussidae are the true intermediates between the Symphyta and the Apocrita. It is quite evident from the male genitalia that the Cephidae are the true intermediates between these two suborders. 


\section{PHYLOGENY}

In a review of the morphology, three sets of characters stand out as offering a basis for primary groupings of the sawflies. These are:

(1) Head capsule, with its four types:-open, fig. 2 ; maxapontal, fig. 8 ; genapontal, fig. 19 ; and closed, fig. 5.

(2) Mesosternum, with its three types:-trapezoidal, fig. 134, and its derivatives through atrophy; triangular, without a wide presternal bridge, fig. 131; and triangular, with a wide presternal bridge in front of it, fig. 129.

(3) Male genitalia, with two types:-normal, with the sagittae and volsellae ventral in position; and turned so that the sagittae and volsellae are dorsal.

\section{The Superfamilies of Sawflies}

Trial and error grouping on the basis of the above characters shows that any one set does not give satisfactory division. For instance, if we group together all those with the open type of head, we find forms with the trapezoidal sternum and inverted genitalia included among those with the widest presternal bridge and normal genitalia. There are so few discrepancies of this nature, however, that continued experimental groupings bring out the existence of four major divisions of the sawflies, which are considered superfamilies, as follows:

Tenthredinoidea.-This group is unique in having the male genitalia inverted, the pronotum narrow and reduced to a thin strap on the meson, and in combining an open type head with a trapezoidal mesosternum, whether determined by sutures or internal muscle attachments. These two latter characters are not confined to this superfamily but are found together in no other.

Siricoidea.-Set off from all other sawflies by the genapontal head, fig. 19, and spatulate labrum, fig. 15. As nearly as can be determined the sternum is triangular, with definite evidence of a narrow presternal bridge in some forms. This is undoubtedly the most hetergeneous group of the sawflies.

Cephoidea.-This small superfamily is characterized by the maxapontal head, fig. 8, and a large number of other characters not possessed by other sawflies. These include such significant items as: (1) possession of a corpotendon on the tentorium, fig. 12, as well as the apical origin of the supratentorial arms; (2) lack of well differentiated claspers in the male genitalia, fig. 165 ; and (3) lack of cenchri, fig. 121.

Megalodontoidea. - Three families, Xyelidae, Pamphiliidae, and Megalodontidae, have been placed together in this superfamily. They combine 
an odd assortment of extremely diverse characters. The Xyelidae have an open type head, fig. 2, and a wide presternal bridge, fig. 129. The Pamphiliidae have the extreme closed head, fig. 5, but in almost all other respects are similar to the Xyelidae, including the wide presternal bridge. The Megalodontidae also have the closed head and in most characters are similar to the Pamphiliidae but lack all trace of a presternal bridge, in fact have a trapezoidal mesosternum as have the Tenthredinoidea.

\section{Family Groupings}

\section{Tenthredinoidea}

The members of this superfamily have extremely diverse antennae and wings. The antennae include such extreme types as bifurcate, fig. 98, pectinate, fig. 105, serrate, fig. 106, clavate, fig. 101, capitate, fig. 100, and various proportions of simple types, figs. 93, 97. The wings vary in the position of almost any vein or cross-vein, and the shape of almost any cell.

Grouping characters of a more fundamental nature include the presence or absence of (1) preapical spurs on the tibiae, (2) sterno-pleural sutures, and (3) parapenes on the male genitalia, fig. 163. Intergrading forms occur between the extremes of the latter two.

By using characters distinctive to a single group it is possible to break up the nearctic representatives into five families, as follows:

Argidae.-Antennae three-segmented, the third segment long, either simple, fig. 97, or furcate, fig. 98.

Acorduleceridae.-Praescutal sutures atrophied posteriorly, and anterior margin of mesoscutellum sinuate, fig. 126. Antennae six-segmented, small, fig. 95.

Tenthredinidae.-Inner spur of front tibiae cleft at apex, fig. 114. Antennae have eight to ten segments, ranging from filiform to clavate; sometimes with one or two pectinations, fig. 104. Sterno-pleural sutures and preapical spurs absent.

Diprionidae.-Antennae serrate, fig. 107, or pectinate, fig. 105, having at least twelve segments. Sterno-pleural sutures and preapical spurs absent.

Cimbicidae.-Lateral margins of abdomen sharply angled. Antennae capitate, fig. 100. Sterno-pleural sutures and preapical spurs absent.

The Australian and South American faunae contain a large number of forms which are divided by Rohwer and Benson into three or four families, the Pergidae, Loboceridae, Perreyiidae, and Pterygophoridae. These are apparently close relatives of the Argidae and Acorduleceridae, having either preapical spines on the tibiae, sterno-pleural sutures, or the simple 
type of male genitalia without parapenes. A detailed study of this fauna, especially from the neotropical regions, is necessary before the segregation of these groups can be stabilized.

\section{Megalodontoidea}

The head capsules at once divide the nearctic members of this superfamily into two groups, those with an open head, fig. 2, and those with the closed head, fig. 5. Within these two groups there are a few striking differences, so they are considered two families, viz.:

Xyelidae.-Head capsule open, fig. 2. Antennae with third segment greatly lengthened or enlarged, figs. 86, 87. Labium with alaglossa absent, fig. 77.

Pamphiliidae.-Head capsule closed, fig. 5. Antennae filiform, fig. 88. Labium with alaglossa present, as in fig. 71.

\section{Siricoidea}

Of the four superfamilies, the Siricoidea is divisible into the best marked families. The diverse types of mesonotum, mesosternum, mouthparts, etc., indicate the existence of four families, as follows:

Syntectidae.-Mesosternum triangular, fig. 130, with the mesopleurae produced to form two long, rounded processes in front of it. Mesonotum without a transverse suture, but normally divided, fig. 122; head without a groove for the reception of the antennae in repose, fig. 21.

Xiphydriidae.-Mesosternum with sterno-pleural sutures almost atrophied; mesonotum divided by a transverse suture, otherwise normally divided, fig. 123; head with a shallow groove for reception of antennae, fig. 22.

Siricidae.-Mesosternum set off from pleurae as a depressed area, fig. 138 , with a narrow presternal bridge, fig. 137 ; mesonotum with praescutal sutures faint, and with two lateral grooves setting off parascutal lobes, fig. $127(\mathrm{y})$; head with narrow, reniform eyes and a well marked antennal groove, fig. 18.

Orussidae.-A very striking group set off by the head, in which the portion bearing the antennal sockets, pretentorinae, clypeus, and labrum has shifted on to the ventral aspect, figs. 23 and 24 , with a curiously modified tentorium, figs. 26 and 27.

\section{Hypothesis of Genealogy}

The evolutionary tendency of the sawfly groups (and Hymenoptera) has been chiefly in the direction of fusion or simplification of parts. The 
wing venation and the thoracic sclerites, for instance, have been greatly reduced in number of parts in comparison with the Neuropterous types, from one of which they undoubtedly arose (Ross, 1936a). This, however, is not a uniform rule for modifications within the order. Evolution may be expressed equally well by the addition of parts as well as their subtraction. A good example of this is seen in the case of the mandibles in the family Tenthredinidae (Plate III). The four-toothed mandible of Tenthredo, fig. 42, and the one-toothed mandible of Eriocampa, fig. 48, both have developed from the bidentate type represented by Lycaota and Strongylogaster, figs. 46,51 , the former by the addition, the latter by the reduction, of parts. The same is shown by the antennae, the simple, ninesegmented antenna of the Tenthredinidae, fig. 103, having arisen from the same stock as the multi-segmented pectinate antenna of the Diprionidae, fig. 105. The condition of the antenna of the Tenthredinidae has resulted from a reduction in the number of segments and the lengthening of each segment; that of the Diprionidae from the addition of lateral outgrowths to a more or less primitive multi-segmented antenna.

The entire sawfly group is relatively closely knit from a structural basis, when one considers the resemblance of primitive forms of each superfamily. A conclusion based on the extremes in structure between distantly related forms would be very different, but such a conclusion is one-sided and erroneous. In fact, so small is the jump between any two related families that it seems very advisable to consider the group as a single suborder, the Symphyta.

The Symphyta are divisible into two major series, the Strophandria (Tenthredinoidea) and Orthandria (Megalodontoidea, Siricoidea, and Cephoidea). The Strophandria are characterized as follows: male genitalia turned $180^{\circ}$ on the median axis before eclosion; and second radial cross-vein (if present) joins $R_{s}$ distad of the second radio-medial cross-vein. In the Orthandria the male genitalia are not turned and the front wings have second radial cross-vein joined to $R_{s}$ proximad of the second radio-medial cross-vein. The Strophandria comprise a compact group, and the Orthandria contain a series of superfamilies which are closely linked by their respective primitive families, the Xyelidae, Syntectidae, and Cephidae.

The Strophandria have undergone considerable modification of antennae, tibial spurs, wing venation, and mouthparts, and have lost certain sutures in some families, for instance the sterno-pleural and prepectal sutures. In spite of these numerous differences, it seems impossible to divide the group into two or three major groups. It seems probable, on the other hand, that the group might best be expressed as a single, large, pectinate branch, Chart 1. Therefore, the Strophandria are considered as comprising a single superfamily, the Tenthredinoidea. 
The Orthandria present a different condition, Chart 1. They are composed of three distinct groups which may be easily set apart on the basis of head capsule and mesosternum. The Xyelidae and Pamphiliidae are at once segregated from the other Orthandria on the basis of the large presternal bridge, fig. 129 (psb), formed by the fusion of the mesoepisterna anterior to the mesosternum. The two families themselves are remarkably different in respect to the head and mouthparts, but are just as remarkably similar in thoracic structure, legs, and the basic plan

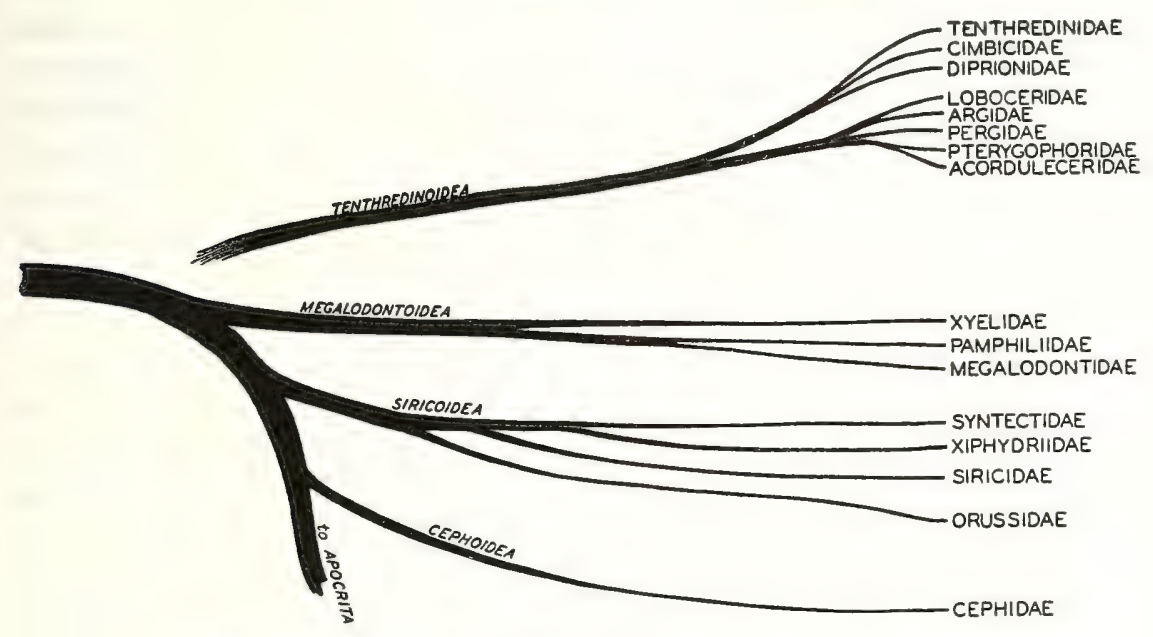

Chart 1.-Genealogical Arrangement of Sawfly Families

of the wings. They are therefore considered collectively as the superfamily Megalodontoidea.

The remaining families of the Orthandria are divided into two superfamilies on the basis of the head capsule: (1) the Cephoidea (including Cephidae only) have the occipital foramen separated from the maxacava by a maxapont, fig. 8, and (2) the Siricoidea (including Syntectidae, Xiphydriidae, Siricidae, and Orussidae) have the occipital foramen separated from the maxacava by a genapont, fig. 19 .

These two superfamilies are closely related. This is shown by the similarity in the wing venation of the Cephidae and the Syntectidae and Xiphydriidae, the loss or reduction in each of one of the apical tibial spurs of the prothoracic legs and the similar ventral tilting of the tentorium. The Cephidae, however, represent an offshoot of the Siricid stem before the others had developed the genapont. The two lines resulting from this branching have become modified in entirely different characters. The 
Cephoidea followed the line leading to a petiolate abdomen and a head capsule with a more open maxacava, whereas the Siricoidea followed the line leading to extreme consolidation of the thorax and abdomen, resulting in the loss of all flexibility between the two, and the development of a stronger head with a more enclosed maxacava.

The selection of the characters mentioned above as being indicative of relationships has been fraught with many difficulties. In the first place, so many instances have been discovered of true parallel evolution that it has been problematic to decide when similarities were significant of relationship or merely another case of parallel evolution. These instances will doubtless have been noticed in a perusal of the foregoing discussion of the morphology. There has frequently occurred, also, the combination of very primitive and very specialized characters in the same form, where it has been necessary to decide which ones were the more significant. In order to harmonize these observations it seems advisable to present a hypothetical reconstruction of the origin and development suggested for the different groups segregated in this treatise.

Members of the early sawfly stem had a simple head capsule, fig. 2, distinct sterno-pleural sutures, figs. 129, 134, slender and multi-segmented antennae, fig. 88, and tibiae with two unmodified apical spurs and at least one to four preapical spurs, fig. 110. This is simply an assemblage of the generalized characters found in existing forms of the group.

The Tenthredinoidea branched off before this collective pattern had changed greatly. After their separation from the main stem, these sawflies developed the strophandrous or turned male genitalia. Very likely the mesosternum resolved itself into its present trapezoidal shape at this time also. The group was exclusively a leaf-feeding one and probably evolved its large number of genera and species concurrently with the increasing diversity and evolution of the surrounding flora. It split up into a number of well-marked groups which correspond to the families recognized in this paper.

The earliest families to emerge from the group were the Pergidae, Argidae, Loboceridae, Perreyiidae, and the Pterygophoridae-Acorduleceridae complex. All these have retained the preapical spurs and the sterno-pleural sutures in at least their primitive genera. They have developed many differences of an apparently adaptive nature - the Pergidae have reduced, clavate antennae; the Argidae have antennae still further reduced, the flagellum composed of only a single, thick segment, fig. 97, which is furcate in some of the males, fig. 98; the Perreyiidae and Pterygophoridae have antennae modified in the opposite direction, with a multi-segmented flagellum, serrate in the female and pectinate in the male (similar to figs. 106 and 105, respectively). There is a series of characters of somewhat the same nature in the wings. Media and first 
medio-cubital cross-vein may be parallel or divergent, many of the crossveins may be present or absent, and the anal veins may assume various patterns. These characters appear in random combination throughout the Tenthredinoidea.

The behavior of the sterno-pleural sutures and the preapical spurs in some of these families is indicative of the condition we find in the more specialized Tenthredinoidea. For instance, in the Argidae the sternopleural sutures are present in some members, weak in others, and apparently absent in the remainder; and the preapical spurs of the tibiae are present in the genus Arge but not in Atomacera, Sterictiphora, Sericoccra, and others. Again, the Acorduleceridae and Pterygophoridae are apparently very closely related and evolved from a common parent, but in the former the sterno-pleural sutures are entirely absent and the preapical spurs present, whereas in the latter the preapical spurs are absent and the sterno-pleural sutures are distinctly present.

The more recently differentiated Tenthredinoidea have lost both sterno-pleural sutures and preapical spurs. They comprise three families, the Diprionidae, Cimbicidae, and Tenthredinidae. These have developed peculiar characteristics which set them off from each other distinctly. The Cimbicidae have conspicuous capitate antennae, fig. 100, and also have the abdominal terga angulate on the lateral margin, so that their ventral portions appear to be pleurites. The Diprionidae are characterized by the antennae, which have thirteen or more segments, serrate in the female, fig. 106, and pectinate in the male, fig. 105. The Tenthredinidae have setaceous, fig. 103, rarely clavate, fig. 101, antennae and a peculiar modification of the caudal margin of the mesoscutellum, fig. 124 (pt), known as the post-tergite.

Most of the Tenthredinidae have another interesting difference from the remainder of the Tenthredinoidea. Instead of both apical spurs of the front tibiae being simple and alike, one of them is furcate at the tip, fig. 114. It is interesting to note that this or some variation of it is the condition found throughout the Orthandria. Not all the Tenthredinidae possess this character. Athalia has both spurs unmodified, similar in this respect to the other Tenthredinoidea; in the small species of the leafmining Phyllotominae and a few Nematinae the apical incision in the modified spur is absent; but in all the other members of the family which I have seen this furcation is pronounced.

Except for lacking the sterno-pleural sutures and the preapical spurs, the Tenthredinidae are probably the most unmodified family in the entire superfamily. Its primitive genera have an almost hypothetical wing venation, antennae unmodified except by reduction in the number of segments, and a distinct prepectus. In addition, the family is represented at the present time by more genera and species than any other sawfly 
family. For this reason the family may be truly called the growing bud at the end of the Tenthredinoid branch.

The other main stem of the sawflies (the Orthandria) had meanwhile broken up into numerous groups. Before this fraction occurred, however, the anterior ends of the sterno-pleural sutures had met on the meson and the mesoepisterna had formed a presternal bridge in at least some measure. Apparently, also, one of the apical spurs of the front tibiae had become furcate as in the Tenthredinidae.

The Megalodontoidea were the first group to break off. This occurred before the head had changed from the primitive open type. This group early resolved itself into its component families, the Xyelidae, Pamphiliidae, and Megalodontidae, which have evolved along entirely different paths and clearly indicate their early separation by their fundamental differences, set forth on page 35 .

After the digression of the Megalodontoidea, the Orthandria split dichotomously into the Siricoidea and Cephoidea. Both groups are represented in our fauna only by wood-boring or stem-boring species or parasites of wood-boring insects.

The Siricoidea developed the genaponta, fig. 19, almost immediately after their differentiation as a group. They also lost the preapical tibial spurs. There has been a very marked tendency towards a consolidation of the body sclerites in all four families of this superfamily.

Syntectidae is the most primitive family of the Siricoidea. It has distinct sterno-pleural sutures, fig. 130, which are similar in position to those of the Xyelidae and suggest a close relationship of these two families. The mesoepisterna are curiously produced anteriorly and are probably an orthogenetic expression of this relationship. The pronotum, fig. 122, is like the rectangular type found in the Megalodontoidea and Cephoidea, and forms a convenient intermediate between these sawflies and the remainder of the Siricoidea. The Xiphydriidae, fig. 123, have the pronotum much more reduced on the meson, and have developed a secondary suture across the mesonotum between the wings. The Siricidae, fig. 127, have undergone a great consolidation of the sclerites of the thorax and of the metathorax with the abdomen. The praescutum is only faintly discernible, the transverse suture across the mesonotum is present as two lateral diagonal grooves, and the scutellar sutures have the same groovelike appearance. The mesoepisterna and mesosternum have completely fused, leaving only a very faint trace of the sterno-pleural suture; according to this trace and the position of the furca, figs. 137, 138, there is a very narrow presternal bridge. The entire thorax and base of the abdomen form a solid mass, with no flexibility remaining. The antennae, fig. 18 , have migrated ventrally on the head and come to lie adjacent to the 
pretentorinae; the clypeus is half turned under, and the labrum is almost entirely concealed under it.

The Orussidae, fig. 142, like the Siricidae, have a solid and inflexible thorax and abdomen. The praescutal sutures are present, but do not join on the meson, continuing longitudinally to the secondary suture across the scutum. This suture is as well marked as in the Xiphydriidae. The wing venation, fig. 177 , has been greatly reduced by atrophy, and is obviously a derivative of the Xiphydriid type of venation. The antennae, clypeus, and part of the frontal region have migrated on to the ventral aspect of the head, presumably a more advanced expression of the tendency shown in the Siricid head. In the Orussidae, also, the antennae are adjacent to the pretentorinae, both being situated on the ventral aspect of the head.

The three families Xiphydriidae, Siricidae, and Orussidae comprise an interesting complex. In all of them the paraglossae and alaglossa have become decidedly fused, either entirely or in part. They have the secondary transverse suture across the mesoscutum, which is also a conspicuous feature of many of the Apocrita. All three families, also, have the tentorium deflected antero-ventrally, and in the last two mentioned the antennae and other parts of the head have migrated ventrally.

The Orussidae have been placed as a separate suborder by Rohwer and Cushman (1917) and held as such since then by various authors. The parasitic habit of the larva of Orussus, the ventral position of the antennae and the closed condition of the end of the abdomen of the male were the chief characters upon which the family was raised to subordinal rank. Considering that both the Xiphydriidae and Siricidae have treeboring larvae, there is reason to suppose that an offshoot of their branch might produce a parasite whose host was a wood-borer, as is the host of Orussus (Dicerca, Buprestidae; see Burke, 1917). The reduction of the thoracic legs in the larvae of Orussus could easily be purely adaptative to a parasitic life. It seems no more fundamental than the loss of abdominal legs by the Cephidae and other Siricoidea, which have boring larvae. The ventral position of the antennae in Orussus is one of the strongest arguments proving its close relationship to the Siricid stem, rather than one for separating it widely from all the sawfly group. It is true that the Orussidae have some extremely distinctive characters, such as the unique type of male genitalia, fig. 169, the form of the praescutal sutures, the atrophy of the supratentorial arms, and the atrophy of many of the wing veins. But on the other hand they are of decided Siricoid stock and actually possess no more distinctive characters than the Siricidae. For this reason it seems a better expression of their relationship to consider them as belonging to the Siricoidea.

The other major group of the ancestral Siricoid stem developed into 
the Cephidae. In these, the wing venation, fig. 175, has remained to the present day almost exactly as we find it in the Syntectidae and Xiphydriidae. The hind wings, however, have lost the short row of bristles present at the base of the wing in the Xyelidae and the two latter families, figs. 171, 176. The preapical spurs on the tibiae are still retained; but the single apical spur on the front tibiae is different from any others in the group, figs. 114-119. There are several characters found in this family which apparently represent the beginnings of specializations found in the Apocrita or higher Hymenoptera: the metanotum is very closely united with the mesonotum, and the first abdominal tergite with the metanotum, whereas a marked constriction has developed between the first and second abdominal terga and a rudimentary articulation exists between them; the corpotentorium has a very small corpotendon and the supratenorial arms join the exoskeleton near the margin of the eye; the cenchri are absent; the mesopostnotal apodeme is long, as in fig. 152; and the wings show a decided tendency towards the atrophy of the first radial cross-vein.

The Braconidae (which are accepted as the most primitive family of the Apocrita) apparently arose from a Cephoid ancestor. The chief differences between the Braconids and the sawflies may be summarized as follows:

\section{Symphyta}

1. Abdomen not petiolate (except slightly in Cephidae).

2. Postgenae and maxillariae not shelved in around maxacava.

3. Corpotendon absent (except in Cephidae).

4. Mesopostnotal apodeme short (except in Cephidae, Siricidae).

5. Male genitalia with harpes distinct (except in Cephidae).

6. Cross-vein $1 r$ present (except in Orussidae and some Cephidae).

\section{Braconidae}

1. Abdomen petiolate, a distinct articulation between tergites 1 and 2 .

2. Postgenae and maxillariae angled in to form a shelf around maxacava.

3. Corpotendon distinct and large.

4. Mesopostnotal apodeme long, similar to Cephidae.

5. Male genitalia with harpes entirely fused with gonostipes.

6. Cross-vein $1 r$ absent.

This tabulation shows the close relationship of the Cephidae and Braconidae. It is not intended to use this as an argument for grouping the Cephidae with the Apocrita, for they are essentially sawflies in every sense of the word. The significant point is that many specializations of the lower Apocrita beyond the sawflies have at least some expression in the Cephidae. In other words, it establishes the hypothesis that the Cephidae represent the ancestral form of the primitive Apocrita.

The more specialized Apocrita have developed the transverse suture across the mesonotum and the longitudinal condition or entire atrophy of the parapsidal (praescutal) sutures, such as we find in the Orussidae and Siricidae, respectively. These conditions, however, are not found in 
the Braconidae, which have a mesonotum similar to that of the Cephidae. According to the hypotheses set forth in this reconstruction, the Orthandria constitute a veritable experimental ground from a biological sense. The most primitive members are external leaf feeders, the more specialized ones are stem and wood borers, and two separate branches have each produced a parasitic form, the Orussidae from the Siricoidea and the Braconidae from the Cephoidea. The former was accompanied by several changes in the adult insect, but none of these were more than would be expected from an aberrant offshoot. In the case of the Braconidae, however, the entire adult has undergone a radical reorganization which has been a marked change from the prevailing condition among the sawfly groups. This is exemplified in the head, especially the tentorium, and the articulate, petiolate abdomen. The product resulting from this reorganization has apparently been vigorous and well adapted to a predator-parasitoid rôle. Furthermore, this adaptability has been very flexible, as is evidenced by the numerous types of parasitic, predaceous, phytophagous, and omnivorous biologies which have evolved from it. Whereas their closest relatives, the Siricoidea and Cephoidea, are at the present time in the class of decadent groups, the Apocrita constitute a very abundant, virile stem successfully following a large number of avenues of existence.

It is interesting to note in this connection that of all the sawflies the superfamily Tenthredinoidea alone has the appearance of being an ascending and not a decadent group. Among these, the family Tenthredinidae stands out as the most virile stem of the entire superfamily. At the present day it contains approximately eighty per cent of all the species of the Symphyta.

No attempt has been made to place the family Blasticotomidae in the present phylogenetic arrangement. It has been impossible to obtain specimens for dissection of Blacticotoma filiceti (Klug), the sole representative of the family. Consequently the course of the sterno-pleural sutures (which are atrophied) and the orientation and composition of the male genitalia could not be determined. Without knowledge of these parts and others which must be dissected out, it is impossible to make any accurate placement of the family.

\section{Comparison with Other Classifications}

In the main features of arrangement, the present classification is similar to that of Konow (1905), which was the first really comprehensive one to be outlined. The categories are quite different from Konow's, but this is chiefly due to the subsequent elevation of lower groups to family ranking. 
Ashmead (1898) proposed a radically different classification using units based on such characters as wing venation and relative body proportions. It has been abandoned by all authors since that time, and has been found equally untenable by the present author.

The classification proposed by MacGillivray (1908) is subject to much the same criticism as Ashmead's. The entire group is considered as one superfamily, divided into nine families, and one of these, the Tenthredinidae, into twenty-four subfamilies. The basis for the entire classification is the wing venation. Figuring prominently among the characters are the presence or absence of the radial cross-vein, the condition of the anal cells, the parallel or divergent condition of $\mathrm{M}$ and $1 m-c u$, and cell $\mathrm{R} 1 \& 2$ being appendiculate or not. These characters are subject to variation between the two indicated extremes, and have been one of the richest grounds for parallel development. The use of this single set of characters has led to the following misconceptions: (1) grouping together unlike families due to parallel evolution of certain features of the wings (e.g., Megalodontidae and Siricidae); and (2) improper stratification of groups. This last is well exemplified by his treatment of the Tenthredinidae. The families Argidae, Cimbicidae, and Diprionidae are in reality units of about the same status as the family Tenthredinidae. The family Tenthredinidae includes the subfamilies Nematinae, Selandriinae, Blennocampinae, and others, which are comparable to subfamilies of the Diprionidae and Cimbicidae, not to the entire families themselves. Yet on the basis of only one set of characters, MacGillivray has listed these groups of different status (Diprionidae, Cimbicidae, Nematinae, Selandriinae) as units of the same category (subfamilies).

In the family Tenthredinidae as herein restricted, the wing venation has proved to be the best basis yet known upon which to make subfamily divisions. In these, many of MacGillivray's subfamilies have proved highly satisfactory, but others again reflect the use of too variable characters.

Rohwer (1911e and subsequent emendations) has followed Konow's classification very closely. He has added to that a large number of new characters and made use of superfamily and family categories to bring out more fully the phylogenetic significance of the groupings. The family units are at great variance with those employed by MacGillivray, but seem to be logical from the standpoint of utility and comparability. They are accepted in this paper with but one or two exceptions.

The chief differences between Rohwer's classification and the one embodied herein are as follows: (1) Rohwer considers the Orussidae to represent a separate suborder, the Idiogastra, whereas it is considered here to be a family allied to the Siricidae, Xiphydriidae, and Syntectidae; (2) the Cephidae are here considered as a separate superfamily, 
whereas they are grouped with the Megalodontoidea by Rohwer; (3) the unique genus Syntexis is placed in the Cephidae by Rohwer, but here is transferred to the superfamily Siricoidea and placed in a separate family, the Syntectidae.

Enslin (1912-18) used a system differing markedly from any of these, in that the Megalodontoidea and Tenthredinoidea of this paper are grouped by him into a single family. This seems to have been done chiefly on the basis of the tibial spurs. The Cephidae were considered a subfamily of the Siricidae. A more complete analysis of this arrangement will show it to be strikingly similar in one or two important respects to that proposed in this paper, except for a difference in the ranking of the different groups. For instance, the tribes and subfamilies used by Enslin are the subfamilies proposed by Rohwer and myself. Aside from this the close relationship of the Cephidae and Siricoidea is expressed, and also the fact that the Tenthredinoidea are more closely related to the Megalodontoidea than to any other group .

Boulonge (1924), in his study of the musculature of the male genitalia, arrives at these same two conclusions. He states, furthermore, that the Siricidae have the most primitive male genitalia of any sawfly, and from this infers that this family is the most primitive of the Symphyta. The highly specialized characters of the family indicate rather that it separated from its progenital stem almost as early as any group.

\section{Larval Characters}

The morphological data presented by Yuasa (1923) in his classification of larval sawflies and horntails neither substantiates nor refutes the main hypotheses just presented. In the first place, the larvae have relatively few differentiated areas or parts as compared with the adults. For instance, there are no definite sclerites on the thorax and no structures comparable to the male genitalia bearing a number of characters and parts. In the second place, what parts are evident do not present the wide range of difference the same part does in the adult. This is well shown in the maxillae and labia. In the larvae they differ only in number of segments of the appendages and only slightly in shape. In the adults these same parts assume a great variety of shapes.

The most significant larval characters seem to be the lack of segmented thoracic legs in the Siricoidea and Cephoidea. This, however, may be correlated more with the stem-boring habits of this group than with phylogeny. This same condition is approached by the leaf-mining genera of the distantly related Tenthredinidae. The Siricoidea and Cephoidea are further set off in having reduced or atrophied ocellarae and reduced mouthparts. 
On the whole, it would appear that characters affording distinct grouping of the sawfly group into large segregates either are not present or have not yet been located in the larvae. It may well be that their characters are adaptive to their habits and environment to such an extent as to obscure phylogenetic differences.

One valuable indication the larvae do give, the probable antiquity of some dichotomies in our genealogical tree. These points are of considerable interest in a few cases, which will be discussed in detail.

The Xyelidae and Megalodontidae are closely related, yet differ more in head structure of adult than any other two families of sawflies. The larvae show equal diversity. Those of the Xyelidae have larvapods on all segments of the abdomen and no subanal appendages; those of the Megalodontidae have no larvapods but have well developed subanal appendages. This difference adds much weight to the opinion that the dichotomy of these two families is very old.

Yuasa considers that a combination of the characters of these two families would give a hypothetical ancestral larva for the sawflies, with the following: abdomen with larvapods on all segments, subanal appendages, functional metaspriacles, and little indication of annulations on the segments.

The Tenthredinoidea are unique in having some abdominal segments, at least the first and ninth, sometimes also the seventh and eighth, without larvapods while the remainder possess them. This morphological differentiation on the abdomen is probably a significant character, in view of the distinctness of the group based on adults.

A study of the leaf-mining Tenthredinidae brings out clearly how rapidly larval changes accompany burrowing habits. The subfamily Phyllotominae consists of a genus of free leaf feeders, Caliroa, and a number of leaf-mining forms, such as Phyllotoma, Metallus, and Fenusa. These latter genera have the antennae reduced from five segments to four, three, two, or one; the thoracic legs sometimes with trochanters and tibiae fused with femur, in one instance (Phyllotoma) with the tarsal claws represented by only fleshy tubercles. This does not reach the state of reduction found in the Siricoidea but shows how soon such a state could be acquired in connection with the burrowing habit.

\section{Biology}

The biology of the sawflies adds some interesting points to their phylogenetic considerations. Alone they do not seem of great importance but taken in conjunction with what has just been discussed they present some corroborative evidence. A brief résumé will first be given of the more diagnostic points in their biology. I have definite information only on nearctic families. 
Tenthredinoidea.-Larvae external leaf-feeders with the following exceptions: three genera of the Tenthredinidae (Lycaotella, Eunra, and some Nematus) are gall makers; several species of Nematus form a leaf curl; all the Tenthredinid tribe Phyllotominae except Caliroa are leaf miners; one Tenthredinid genus Caulocampus is a petiole miner in maple leaves; another, Hoplocampa, mines in fruits of Rosaceae; and several Argidae are leaf miners in their early instars. The pupae of the Argidae, Cimbicidae, and Diprionidae are all enclosed in hard cocoons which can be formed on an open surface. The pupae of the Tenthredinidae are divisible into two groups: (1) the subfamilies Cladiinae and most $\mathrm{Ne}-$ matinae form cocoons similar to the preceding; (2) the pupae of the remainder of the family have either a weak cocoon or none and are dependent for protection on earthen cells or chambers in twigs, rotten wood, etc. The pupae are quiescent.

Megalodontoidea.- - Larvae either free leaf feeders, leaf curlers, or feed in the staminate cones of pine. Pupae formed in a cell in the ground. The few recorded observations known indicate that the pupae are active. Mr. J. M. Langston has written me as follows concerning the pupae of Megaxyela langstoni: "One interesting point was that the pupae came to the surface of the soil and there cast the pupal skins. They are able to walk before casting these skins." This active condition is similar to the condition found in the Megaloptera. It undoubtedly represents the most primitive pupal condition in the Hymenoptera.

Sirtcoidea (except Orussidae) and Cephoidea. - The larvae of these are exclusively stem borers, the Cephidae in smaller stems such as grasses and raspberries, the Siricoidea in trees. The pupa, which is inactive, is formed in a thin cocoon at the terminus of the mine.

Orussidae.-This family is parasitic on the larvae of Buprestidae (Coleoptera). The larvae are extremely reduced as far as appendages are concerned compared to other members of the family (Rohwer and Cushman, 1917).

In applying this information to the phylogeny, it is evident that the parasitic Orussidae arose from a wood-boring ancestor. Interesting is the fact that its host is a wood-boring beetle larva.

Since the more primitive Apocrita, or higher Hymenoptera, are predator-parasites and the Cephidae are stem borers, there is no biological reason why the former could not have arisen from the latter.

\section{Host Plants}

It was thought at one time that a list of plant families indicating the sawfly groups feeding on them would have a marked significance in determining the primitiveness of the sawflies. When the tabulation was 
started it was soon found that the exceptions obscured whatever significance there might be in it.

Two circumstances are worthy of note. The commonest hosts are all very primitive plants and include Polypodiaceae (ferns), Pinaceae (conifers), Graminales (grasses and sedges), Amentifera (willows, alders, hickories, oaks, etc.), and Rosaceae (almost every native genus). There are sawflies which feed on other hosts, but aside from these named few sawflies attack them. Thus only a few species of sawflies feed on such highly specialized families as the Ericaceae, Caprifoliaceae, and Compositae.

A few sawfly groups are very narrowly restricted in host range. The family Diprionidae feeds only on Pinaceae, most of the subfamily Selandriinae (Tenthredinidae) only on Polypodiaceae, and in other groups many genera are confined to a single plant genus. A few groups show a striking range of hosts within a single phylogenetic complex. For instance, in the Nematinae (Tenthredinidae), Pikonema feeds only on Picea (spruce), Pachynematus on grasses and sedges, and Pristiphora on a wide variety of plants including Betula, Ribes, Sorbus, and some conifers; yet these three sawfly genera are difficult to separate on external characters.

It is evident, therefore, that host relationships must remain purely corroboratory in making decisions on sawfly phylogeny.

In this regard there is an interesting bit of speculation. The sawfly group has been demonstrated to be an offshoot of an early Panorpoid branch (Ross, 1936a). It has been shown by several paleontologists that the diversification and splitting up of the Panorpoid complex progressed at a rapid gait during the Permian of the Palæozoic era, so it is possible to assume that the sawfly branch arose at this time also. Granting this, it is necessary to assume that ferns and conifers were their earliest hosts, since none of their other hosts were known to exist at that early period. On the basis of this hypothesis it would seem that the sawflies flourished concurrently with a rapidly evolving flora.

\section{Summary of Phylogeny}

Every source of evidence shows that the sawflies form two distinct groups, the Strophandria (Tenthredinoidea) and Orthandria (Megalodontoidea, Siricoidea, and Cephoidea).

The Strophandria are a unique, detached group of early origin and have evolved into a large number of phytophagous groups. No existing members can be classified as strictly archaic.

The Orthandria are of a different nature. The archaic family Xyelidae, with its primitive venation and active pupa, links the Hymenoptera to a Mecopteroid ancestor, while the Cephidae link the sawfly 
group to the parasitic and more specialized Hymenoptera. This substantiates still further the hypothesis of Ross (1936a) that the Hymenoptera are a close derivative of the Panorpoid complex as shown by the wing venation.

The abundance of fundamental differences in head capsule, tentorium, subdivisions of the mesonotum and mesosternum, and structure of larvae, found within the Orthandria eclipse the differences within the Apocrita or higher Hymenoptera. This indicates (1) that the groups contained in the Orthandria are of great geologic age, and (2) that the Orthandria represent the early experimental grounds of the Hymenoptera. 


\section{TAXONOMY}

The opinions previously expressed in regard to the morphology and phylogeny have been applied in this section to the arrangement and differentiation of the families, subfamilies, and genera represented by the fauna of nearctic America.

\section{Construction of Keys}

Many of the characters considered of importance in the phylogeny of the group have proved unsatisfactory in making keys for the recognition of the families. Some are confined to one sex, such as the male genitalia; others, such as the mouthparts, are impossible to see without relaxing the specimen; and still others, such as the structure of the head capsule, can be seen only after clearing and dissecting the specimen. In the key to families, therefore, only characters which are easily seen and interpreted have been used. A key is primarily for use in identification and not necessarily for bringing out phylogenetic relationships, and for this reason all the keys given below have been made with a view to practicability and accurate determination.

The keys in this paper are designated for separating only the groups known to occur in the nearctic region. They are purely artificial, the phylogenetic angles being discussed in the text. This is in the interest of simplicity and has aided greatly in making many keys easy to interpret.

\section{Identification of Sexes}

In many keys to the genera it is necessary to key out the two sexes separately. They can be differentiated thus: In the female, the apical sternites are cleft by a variously shaped, scabbard-like sheath, fig. 293. In the male, the apical sternites are not divided along the meson, fig. 424.

\section{ORDER HYMENOPTERA}

\section{Suborder Symphyta}

The suborder Symphyta includes those Hymenoptera in which there is neither a narrow constriction nor a ball and socket articulation between the first and second abdominal segments, figs. 139-143.

\section{Treatment of Superfamilies}

The characterization of the superfamilies is more a matter of phylogenetic interest than an essential to classification. It is easier to construct an artificial key to the families of the entire sawfly group than to burden 
the identifier with keys to the superfamilies. These are described on page 33 , and no further keys are given.

\section{KEY TO FAMILIES}

1. Antennae inserted on the ventral aspect of the head, fig. $24 . . .$. . Orussidae

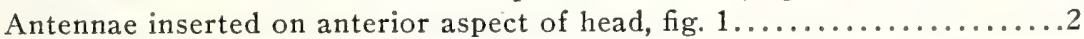

2. Antennae have 3 segments, figs. $97,98 \ldots \ldots \ldots \ldots \ldots \ldots \ldots \ldots$. . . . . . . . . . . . .

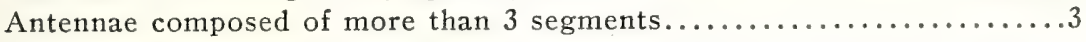

3. Third antennal segment very long, surmounted by a slender terminal filament composed of $9-25$ segments, figs. $86,87 \ldots \ldots \ldots \ldots$ Xyelidae Antennae without a slender terminal filament subordinate to an elongated

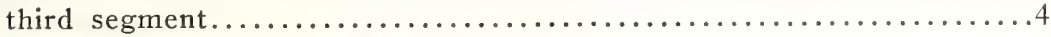

4. Antennae capitate, figs. $99,100 \ldots \ldots \ldots \ldots \ldots \ldots \ldots \ldots \ldots \ldots$ Cimbicidae

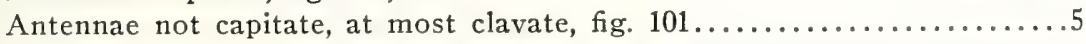

5. Antennae with six segments, fig. 95; scutellum with anterior margin sinuate,

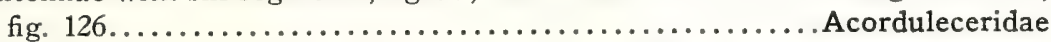
Antennae with more than 6 segments; scutellum with anterior margin

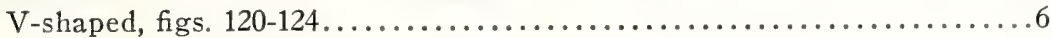

6. Front tibia with two apical spurs, figs. $113,114 \ldots \ldots \ldots \ldots \ldots \ldots \ldots \ldots \ldots$

Front tibia with one apical spur, figs. $116-119 \ldots \ldots \ldots \ldots \ldots \ldots \ldots \ldots . \ldots \ldots$

7. Mesoscutum with two diagonal furrows running from the lateral margin of the scutum to the anterior margin of the scutellum, fig. 127, y; prae-

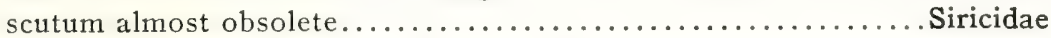

Mesoscutum without diagonal furrows; praescutum distinctly set off by

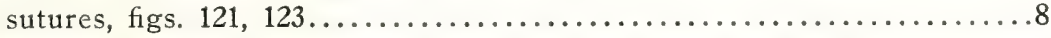

8. Pronotum reduced to a narrow collar on the meson, fig. 123.. Xiphydriidae Pronotum not greatly reduced on the meson, figs. $121,122 \ldots \ldots \ldots \ldots \ldots 9$

9. Apical spur of front tibia with inner margin pectinate, fig. 118.. Syntectidae Apical spur of front tibia with inner margin simple, fig. 119...... Cephidae

10. Antennae composed of $7-12$ segments, figs. $101-104 \ldots \ldots \ldots$. Tenthredinidae Antennae composed of 13 or more segments, figs. $88,105 \ldots \ldots \ldots \ldots \ldots 1$

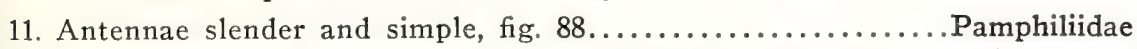
Antennae either serrate, figs. 106,107 , or pectinate, fig. $105 \ldots$... Diprionidae

\section{SUPERFAMILY TENTHREDINOIDEA}

\section{Family Argidae}

This family is at once recognized by its three-segmented antennae, which are furcate in the males of some genera, fig. 98.

Diagnostic characters.-Antennae three-segmented, fig. 97, furcate in the males of some genera, fig. 98. Posterior margin of mesoscutellum without a post-tergite, anterior margin V-shaped or slightly sinuate. Mesosterno-pleural sutures usually present, fig. 134, but sometimes atrophied. Preapical spurs present in one genus, Arge. Both apical spurs of front tibiae simple. 
At present it does not seem advisable to attempt to divide the Argidae into subfamilies. They obviously form a closely knit group. Furthermore, the family contains many tropical genera, a greater knowledge of which would undoubtedly alter any conceptions based on the nearctic fauna.

\section{KEY TO GENERA}

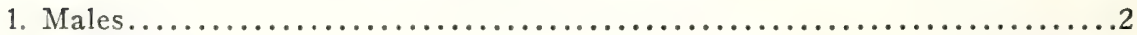

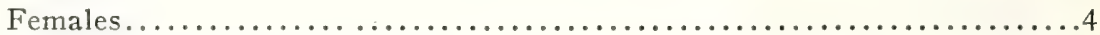

2. Third antennal segment furcate for its entire length, fig. $98 \ldots \ldots \ldots \ldots \ldots 6$

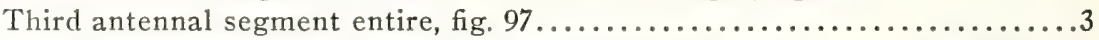

3. Hind wing with cell $\mathrm{R}_{1}$ closed at apex as in fig. $218 \ldots \ldots \ldots \ldots \ldots$................. Hind wing with cell $R_{1}$ open at apex as in fig. $214 \ldots \ldots \ldots$..... Atomacera (pt.)

4. Both front and hind wings with cell $R_{1}$ closed at apex, fig. 218...Arge (pt.) At least hind wing with cell $\mathrm{R}_{1}$ open at apex, fig. $214 \ldots \ldots \ldots \ldots \ldots \ldots . . . . . . .5$

5. Tarsal claws bent over at nearly a right angle, just below middle, fig. 215, and with the base forming a wide tooth................. Atomacera (pt.)

Tarsal claws not bent much, and only towards apex, the base narrow, not

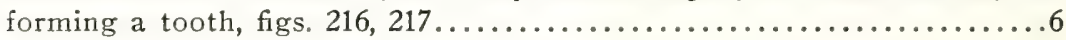

6. Head wide and shallow, without a raised crest between antennae,

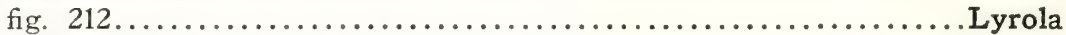

Head not so wide but deeper, with a raised crest between antennae, fig. 213

Sterictiphora

\section{Arge Schrank}

Cryptus Jurine, 1801, p. 163. Monobasic, genotype-Cryptus segmentarius Panzer. Name set aside by International Zoological Congress, 1935.

Arge Schrank, 1802, p. 209. Genotype by subsequent designation of Rohwer, 1911b. -Tenthredo enodis Linnaeus.

Hylotoma Latreille, 1802, p. 302. Monobasic, genotype.-Tenthredo rosae Linnaeus. Cryptus Panzer, 1805, Heft 88, pl. 17. Monobasic, genotype-Cryptus segmentarius Panzer.

Corynia Imhof et Labram, 1836, p. 23. Genotype by subsequent designation of Rohwer, 1911b.-Corynia rosarum Imhof et Labram.

Acanthoptenos Ashmead, 1898, p. 212. Genotype by original designation.-Acanthoptenos weithii Ashmead = Arge macleayi (Leach).

Characteristics.-Hind tibiae with a preapical spur on outer margin. Both wings with cell $\mathrm{R}_{1}$ closed at apex, fig. 218 . Antennae simple in both sexes, flagellum in female clavate, in male filiform. Tarsal claws simple, long and slender.

Contains a considerable number of nearctic species which are badly in need of revision.

\section{Atomacera Say}

Atomacera Say, 1836, p. 212. Monobasic, genotype-Atomacera debilis Say. Micrarge Ashmead, 1898, p. 213. Genotype by original designation.--Atomacera ruficollis Norton. New synonymy.

Characteristics.-Tibiae without preapical spurs. Wings with cell $R_{1}$ open at apex due to atrophy of apex of vein $R_{1}$. Antennae simple in 
both sexes, flagellum subclavate. Tarsal claws, fig. 215, bent over at a sharp angle before middle.

As far as known, restricted to the nearctic region, and contains only three or four species.

\section{Sterictiphora Billberg}

Characteristics.-Flagellum clavate in female, lyriform in male, fig. 98. Head with distinct, carinate crest between antennal sockets. Front wings with cell $R_{1}$ either open or closed at apex, hind wing with this cell open and vein $2 \mathrm{~A}$ various.

The members of this genus in the broad sense form a closely knit group, united by the lyriform male antennae, mesal crest on the head, and similar general appearance. There is no doubt, however, that the species known at present can be segregated into distinct phylogenetic units which it seems convenient to keep separate. These differences are to be seen chiefly in the genitalia, but most of the groups have some external characteristic correlated with them. At present these groups, here considered subgenera, have been worked out only for those species occurring north of Mexico. When others are known it will probably be necessary to subdivide some groups further.

\section{KEY TO SUBGENERA}

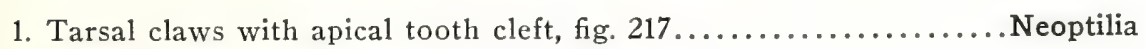

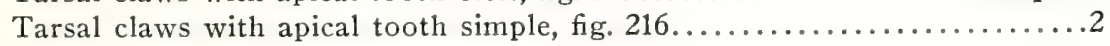

2. Front wings with cell $\mathrm{R}_{1}$ open at apex, fig. $214 \ldots \ldots \ldots \ldots \ldots \ldots \ldots \ldots \ldots$

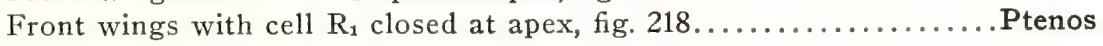

3. Hind wing with vein $2 \mathrm{~A}$ atrophied, resulting in the loss of the anal cell,

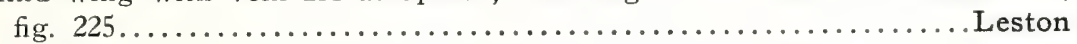

Hind wing with vein $2 \mathrm{~A}$ present, anal cell present, fig. $224 \ldots \ldots \ldots \ldots \ldots 4$

4. Hind wing with anal cell much longer than its apical petiole,

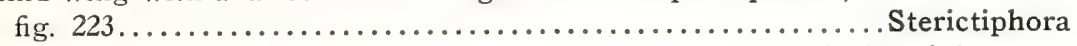

Hind wing with anal cell subequal to or shorter than its apical petiole,

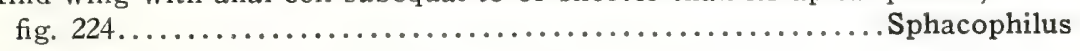

\section{Subgenus Ptenos Norton*}

Ptenos Norton, 1872, p. 77. Genotype by subsequent designation of Rohwer, 1911b. -Ptenos niger Norton.

Characteristics.-Front wings with cell $\mathrm{R}_{1}$ closed at apex, fig. 218, hind wings with vein $2 \mathrm{~A}$ atrophied, fig. 225. Tarsal claws simple, long and curved at apex, fig. 216. Hind basitarsus shorter than the three following combined.

This subgenus contains probably a dozen nearctic species, known to occur in either Mexico or the extreme southwestern United States.

*Preoccupied. Use Ptenellus Malaise, 1937, Entomologisk Tidskrift, p. 56. Genotype by original designation.-Ptenos nigripectus Norton. 


\section{Subgenus Neoptilia Ashmead}

Neoptilia Ashmead, 1898, p. 213. Genotype by original designation.-Neoptilia mexicana Ashmead.

Characteristics.-Differs from Ptenos chiefly in having the tarsal claws cleft at the apex, the two rays close together, fig. 217.

A single species, $N$. malvacearum Cockerell, has been described from North America.

\section{Subgenus Sterictiphora Billberg}

Sterictiphora Billberg, 1820, p. 99. Monobasic, genotype.-Hylotoma furcata Fabricius.

Schizocera Lepeletier, 1828, p. 572. Genotype by subsequent designation of Westwood, 1840.-Hylotoma furcata Villers.

Cyphona Dahlbom, 1835, p. 8. Genotype by subsequent designation of Rohwer, 1911b.-Hylotonta furcata Villers.

Characteristics.-Differs from Ptenos in venation, as follows: front wing with cell $R_{1}$ open at apex, hind wing with vein $2 \mathrm{~A}$ distinct, joining 1A near $c u-a$, so that cell $1 \mathrm{~A}$ has only a very short petiole, fig. 223.

Contains two nearctic species, sericea (Norton) and prunivora (Dyar).

\section{Subgenus Sphacophilus Provancher}

Sphacophilus Provancher, 1889, p. 427. Monobasic, genotype-Sphacophilus crazii Provancher.

Characteristics.-Differs from Sterictiphora s. st. chiefly in having cell $1 \mathrm{~A}$ of the hind wing short, with an apical petiole as long as the cell, fig. 224.

Contains an undetermined number of nearctic species, including many whose range extends into the neotropical region. The South American group, Brachyphatnus, Konow (1906, p. 250) is a close relative of this subgenus.

\section{Subgenus Leston new subgenus}

Characteristics.-As for Sterictiphora, having high, sharp median crest between antennae, flagellum clavate in female and lyriform in male, both wings with cell $\mathrm{R}_{1}$ open at apex, and tarsal claws slender, curved at apex. Differs in having $2 \mathrm{~A}$ atrophied in the hind wing so that cell $1 \mathrm{~A}$ is open posteriorly, fig. 225.

Genotype.-Schizocerus zabriskei Webster and Malley by present designation.

Contains only a single species, the genotype.

\section{Sterictiphora zabriskei (W. \& M.)}

Schizocerus zabriskei Webster and Malley, 1900, p. 51.

Schizocerus sericeiformis Rohwer, 1908, p. 112. New synonymy.

Schizocerus lineatus Rohwer, 1909, p. 12. New synonymy. 
Schizocerus collaris Rohwer, 1909, p. 13. New synonymy.

Schizocerus johnsoni MacGillivray, 1909b, p. 403. Neze synonymy.

\section{Lyrola new genus}

Characteristics.-Head wide and transverse, the area between the antennal sockets almost flat, not produced into a crest, fig. 212. Third antennal segment of female distinctly fusiform and shorter than width of head. Front wing with appendiculate cell absent as in fig. 214. Hind wing with $2 \mathrm{~A}$ joined to $1 \mathrm{~A}$ half the distance from base to $c u-a$. Tarsal claws slender, curved towards apex, fig. 216. Hind coxae of males contiguous at apex, of females slightly separated. Male subgenital plate convex and curved dorsad, so that its axis is oblique.

Genotype.-Schizocera brunniventris Cresson, original designation.

The neotropical genus Sericocera will key out with this one. Sericocera differs in having the hind coxae of the female separated by at least their width at apex and the subgenital plate of the male concave transversely, not curved dorsad, its axis therefore longitudinal.

The genotype is the only species known to belong in this new genus.

\section{Lyrola brunniventris (Cresson) new combination}

Schizocera brunniventris Cresson, 1880, p. 2, ô, $q$.

Schizocera tristis Cresson, 1880 , p. 52, ㅅ, ㅇ. New synonymy.

Schizocerus tristis var. fumipennis Dyar, 1893, p. 195, ô, q. Nezw synonymy.

This species occurs in southern California and Arizona, and has been reared from various legumes, including Lotus and Hosackia. The abdomen in both sexes varies from rufous through brown to black.

\section{Themos Norton}

Themos Norton, 1867, p. 58. Monobasic, genotype.-Themos hyaline Norton.

This genus originally included a single species represented by a unique specimen and has not since been studied. The characters used to differentiate it from other Argids are not satisfactory; furthermore, Norton expresses the belief that the locality label "Pennsylvania" of the type specimen is probably an error and perhaps should be Mexico or South America. For these reasons Themos is simply mentioned here.

\section{Family Acorduleceridae new family}

Diagnostic characters.-Antennae filiform, 6-segmented, fig. 95. Mesoscutellum without a post-tergite, its anterior margin sinuate, fig. 126; praescutal sutures with their posterior portion atrophied, so that postero-mesally the praescutum is confluent with scutum. Meso- 
sterno-pleural sutures absent. Middle and hind tibiae with preapical spurs, the apical spurs of the front tibiae simple.

This family contains only one genus, Acordulecera Say. It has previously been considered as a subfamily of the Pterygophoridae by Rohwer (1911e). The two differ as follows:

Acorduleceridae

Antennae.......6-segmented, filiform.

Tibiae ........... Preapical spurs present.

Mesosternum...... Sterno-pleural sutures absent.

Mesonotum .......Praescutal sutures atrophied posteriorly.

Anterior margin of scutellum sinuate.

Distribution........American.

\section{Pterygophoridae}

Multisegmented, serrate in $q$, pectinate in $\hat{\sigma}$ (as in figs. 106, 105 , respectively).

Preapical spurs absent.

Sterno-pleural sutures present.

Praescutal sutures complete.

Anterior margin of scutellum V-shaped.

Australian.

The male genitalia of the two families are practically identical, fig. 164, so that there seems little doubt of their close relationship. In view of the striking differences between them, however, it seems advisable to separate the two groups as distinct families.

\section{Acordulecera Say}

Acordulecera Say, 1836, p. 210. Monobasic, genotype-Acordulecera dorsalis Say.

The only genus in the family, therefore characterized as in the latter.

The genus is restricted to the nearctic and neotropical regions. Dr. O. Conde, of Riga, Latvia, has revised in manuscript the nearctic species, of which about 20 have been described.

\section{Family Diprionidae}

Diagnostic characters.-Antennae composed of 13 or more segments, serrate in the female, fig. 107, and pectinate, fig. 105, or bipectinate in the male. Mesosterno-pleural sutures atrophied, mesoscutellum with anterior margin V-shaped, posterior margin with an extremely narrow and cordlike post-tergite. Tibiae without preapical spurs; apical spurs of front tibiae simple.

This family has been divided into two subfamilies on the basis of the anastomosis or separation of veins $2 \mathrm{~A} \& 3 \mathrm{~A}$ and $1 \mathrm{~A}$ in the front wing, and the unipectinate or bipectinate male flagellum. On the basis of other characters, especially genitalia, the family seems too closely knit to necessitate such a grouping.

The best digest of the nearctic members of the group is given by Rohwer, 1918b. 
KEY TO GENERA

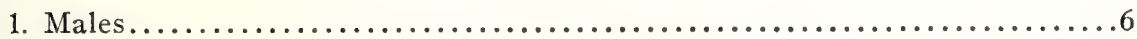

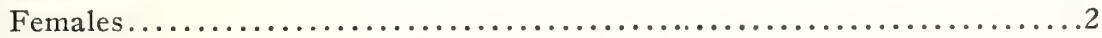

2. Supraclypeal area of head raised into a large tubercle below antennal

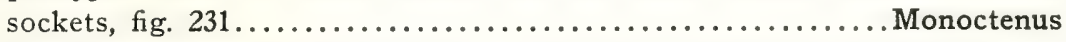

Supraclypeal area not tuberculate, in profile confluent with the clypeus,

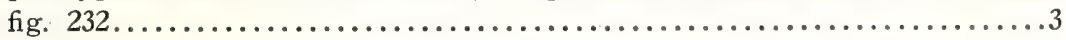

3. Head and thorax polished, practically impunctate, and metallic blue-black.

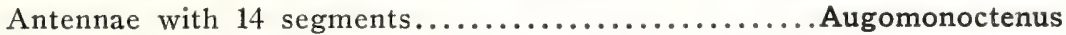

Head and mesoscutellum either not metallic or with dense conspicuous punctuation. Antennae with 16 or more segments.................4

4. Pulvillar pad of hind basitarsus almost as long as the basitarsus, fig. 229. Abdomen greenish-yellow or transversely banded with black or brown

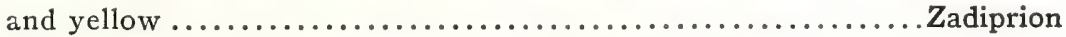

Pulvillar pad of hind basitarsus about one-half as long as the basitarsus, fig. 228. Abdomen brown, rufous or darker without transverse bands of

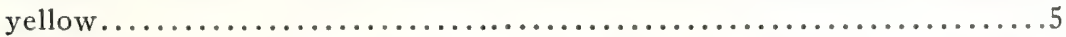

5. Mesoscutellum large, with its anterior margin forming a wide $V$, and entirely covered with large punctures, fig. $220 . \ldots \ldots \ldots \ldots \ldots$........ Diprion

Mesoscutellum smaller, with its anterior margin forming a narrower $V$, and only the apical or lateral portions bearing large punctures, fig.

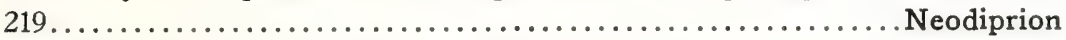

6. Flagellum with all segments unipectinate, fig. $233 . \ldots \ldots \ldots \ldots \ldots \ldots \ldots$

Flagellum with at least basal ten segments bipectinate, fig. $234 \ldots . . \ldots . .8$

7. Supraclypeal area of head tuberculate and raised above level of clypeus,

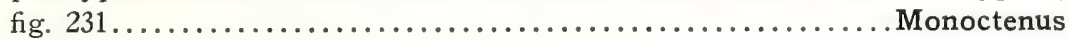

Supraclypeal area not tuberculate, confluent with profile of clypeus, fig. 232.

Augomonoctenus

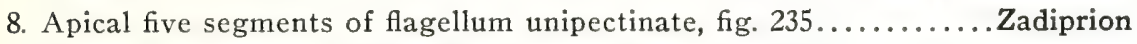

All but last segment of flagellum bipectinate, fig. $236 . . . . . . . . . . . .9$

9. Mesoscutellum large, with its anterior margin forming a wide $\mathrm{V}$, and entirely covered with dense, coarse punctuation, fig. 220............. Diprion

Mesoscutellum smaller, with its anterior margin forming a narrower $\mathrm{V}$, and with much sparser punctuation, fig. $219 . \ldots \ldots \ldots \ldots \ldots \ldots \ldots$.................

\section{Monoctenus Hartig}

Lophyrus subg. Monoctenus Hartig, 1837, p. 171. Monobasic, genotype--Tenthredo juniperi Linnaeus.

Characteristics.-Front wings with $\mathrm{Sc}_{2}$ present, $2 \mathrm{~A} \& 3 \mathrm{~A}$ fused for a variable distance with $1 \mathrm{~A}$. Head with supraclypeal area tuberculate, fig. 231. Antennae serrate in female, unipectinate in male, with 14-22 segments. Head and thorax not metallic.

Five nearctic species have been described.

\section{Augomonoctenus Rohwer}

Augomonoctenus Rohwer, 1918b, p. 81. Monobasic, genotype-Augomonoctemus libocedrii Rohwer. 
Characteristics.-Front wings with $\mathrm{Sc}_{2}$ absent, $2 \mathrm{~A} \& 3 \mathrm{~A}$ fused for a distance with $1 \mathrm{~A}$. Head with supraclypeal area confluent in profile with clypeus, area behind and above eyes considerably swollen and enlarged. Antennae of female serrate, 14-segmented, of male unipectinate. Head and thorax metallic blue-black with practically no punctuation.

Contains only one species, the genotype.

\section{Zadiprion Rohwer}

Neodiprion subg. Zadiprion Rohwer, 1918b, p. 83. Genotype by original designation. -Diprion grandis Rohwer.

Characteristics.-Front wings with at least base of $\mathrm{Sc}_{2}$ present, and $2 \mathrm{~A} \& 3 \mathrm{~A}$ separated from $1 \mathrm{~A}$ by a cross-vein. Head with supraclypeal area not tuberculate, area above and behind eyes wide and flattened. Antennae of female serrate, with 20-26 segments, male with 22-26 segments, the flagellum bipectinate except for the terminal five segments which are moniliform and undivided, fig. 235. Female with pulvillar pad of hind basitarsis subequal to length of basitarsus, fig. 229, male with pad only one-fourth length of basitarsus.

The genus contains four species.

\section{Neodiprion Rohwer}

Neodiprion Rohwer, 1918b, p. 83. Genotype by original designation,-Lophyrus lecontei Fitch.

Characteristics.-Differs from Zadiprion in the following points: male flagellum with all segments bipectinate except the apical one, fig. 236; female with pulvillar pad of hind basitarsus one-half or less length of basitarsus, fig. 228.

Contains a large number of nearctic species which have not been revised since 1869 .

\section{Diprion Schrank}

Pteroms Jurine, 1801, p. 163. Monobasic, genotype--Tenthredo pini Linnaeus. Name set aside by International Zoological Congress, 1935.

Diprion Schrank, 1802, p. 209. Genotype by subsequent designation of Rohwer, 1910d.-Tenthredo pini Linnaeus.

Lophyrus Latreille, 1802, p. 302. Monobasic, genotype--Tenthredo pini Linnaeus. Preoccupied.

Anachoreta Gistel, 1848, p. 9. New name for Lophyrus Latreille.

Cristiger Gistel, 1848, p. 144. Monobasic, genotype.-Tenthredo pini Linnaeus.

Characteristics.-Similar to Neodiprion, with the following principal exception: scutellum large, its lateral margins fairly long, anterior margin forming a wide $\mathrm{V}$, and densely covered with large punctures, fig. 220.

The genus is Eurasian in the native sense, but a few species have become established in recent years on conifers in North America. 


\section{Family Cimbicidae}

Diagnostic characters.-Antennae capitate, fig. 100. Lateral margins of the abdomen sharply angulate. Mesosterno-pleural sutures barely indicated by a slight ridge; mesoscutellum without a post-tergite and with the anterior margin V-shaped; tibiae without preapical spurs, and apical spurs of the front tibiae simple.

This family has been divided into two subfamilies on the basis of the anastomosis or separation of $2 \mathrm{~A} \& 3 \mathrm{~A}$ and $1 \mathrm{~A}$, but the division seems to serve no useful purpose, so it is not used here.

\section{KEY TO GENERA}

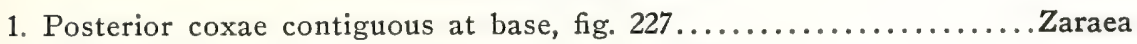

Posterior coxae well separated at base, fig. $226 \ldots \ldots \ldots \ldots \ldots \ldots \ldots \ldots . \ldots \ldots$

2. Posterior femora with a ventral tooth near apex, fig. $230 \ldots . .$. . Trichiosoma

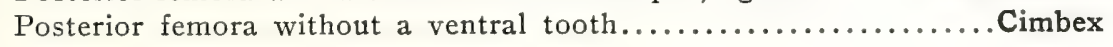

\section{Zaraea Leach}

Zaraea Leach, 1817, p. 113, no. 4. Monobasic, genotype-Tenthredo fasciata Linnaeus.

Abia Leach, 1817, p. 113, no. 5. Genotype by subsequent designation of Curtis, 1825. - Tenthredo sericeus Linnaeus.

Parabia Semenov, 1891, p. 174. Genotype by original designation.-Parabia jakowhervi Semenov.

Characteristics.-Posterior coxae contiguous at base, fig. 227, front wings with $2 \mathrm{~A} \& 3 \mathrm{~A}$ fused for a distance with $1 \mathrm{~A}$. Hind femora unarmed. Antennal club, fig. 99, not sharply set off from remainder of antennae.

Five species have been assigned to this genus in the nearctic region.

\section{Trichiosoma Leach}

Trichiosoma Leach, 1817, p. 108. Genotype by subsequent designation of Curtis, 1825.-Tenthredo lucorum Linnaeus.

Characteristics.-Body conspicuously hairy. Posterior coxae well separated at base. Posterior femora with a ventral tooth near apex, the tooth much larger in male than in female. Front wings with $1 \mathrm{~A}$ and $2 \mathrm{~A}$ \& 3A separated by a short cross-vein. Antennal club much more sharply set off from the remainder of the antenna. Mandibles almost perfectly symmetrical, much longer and sharper in the male than the female, figs. 221, 222.

The several described nearctic species are badly in need of intensive study to determine the species limits.

\section{Cimbex Olivier}

Crabro Geoffroy, 1762, p. 261. Genotype by subsequent designation of Bradley, 1919. - Crabro humeralis Fourcroy. Name set aside by International Zoological Congress, 1935. 
Clavellarins Olivier, 1789, p. 22. Genotype by subsequent designation of Latreille, 1810.-Tenthredo lutea L. Application has been made to the International Commission on Zoological Nomenclature to have this name set aside, as with Crabro.

Cimbex Olivier, 1790, p. 762. New name for Clavellarius Olivier.

Clavellaria Lamarck, 1801, p. 264. Emendation of Clavellarius Olivier.

Characteristics.-Differs from Trichiosoma as follows: Body not hairy. Hind femora unarmed beneath. Mandibles asymmetrical, dextral one polished, with a long, thin, apical tooth, sinistral one striate and roughened, apical tooth blunt and short.

The taxonomic status of the nearctic species of this genus is similar to the above.

\section{Family Tenthredinidae}

Diagnostic characters.-Antennae with 7-10 segments, varying in shape from setaceous and filiform, fig. 93, to clavate, figs. 101-103, the male of Cladius pectinicornis (Geof.) having the first three or four segments of the flagellum pectinate, fig. 104. Mesothorax with sterno-pleural sutures lacking, anterior margin of scutellum $\mathrm{V}$-shaped and the posterior margin usually with a distinct post-tergite, figs. 124-125. Tibiae without preapical spurs; apical spurs of front tibiae (except in some Nematinae) with the longer spur cleft at the apex, fig. 114 .

The division of this family into units has been one of the most controversial subjects in the study of sawflies. In the last thirty-five years different arrangements have been proposed by Ashmead (1898), Konow (1905), MacGillivray (1906), Rohwer (1911e), and Enslin (1912). The opinions brought out by these authors are startling in their great divergence. In attempting to arrive at the correct groupings of the genera contained in the family it soon became evident that there were no characters known at present which would separate the family by simple divisions into clean-cut subfamilies. For this reason it was necessary to adopt a different line of attack, which is embodied in the following procedure:

1. An exhaustive survey was made of all the genera, and their characters were tabulated.

2. The genera resembling each other more than any other genus were grouped into units. These were homogeneous by the very nature of their selection. This step sorted out about three-quarters of the genera.

3. The remaining genera were then studied in comparison with the groups formed in step 2. Many resembled one or another group so closely that they were placed in it. Others proved to be connecting forms between two groups which had perforce to be united into one. After this there remained less than half a dozen genera which had not been satisfactorily placed. 
4. By a comparison of these genera and generic units with each other and with other groups of sawflies, a hypothetical type or primitive ancestor was deduced. From this hypothetical ancestor all the conditions present in the Tenthredinoidea could be derived through comparatively simple changes.

5. After the deduction of the primitive ancestor, the generic units and the unplaced genera were arranged in a family tree in such a way that there was as far as possible a progression of all characters from the generalized or hypothetical to the specialized. This involved considerable "trial and error" manipulation.

\section{Principal Sets of Characters Used}

Cervical sclerites.-In the more primitive members of all the subfamilies the cervical sclerites are angulate and separated on the meson, fig. 155. In the Allantinae and Tenthredininae the more specialized genera have the mesal margins truncate and adjacent, figs. 157, 158, as is the case with the Dolerinae. In all three subfamilies this condition is probably for the purpose of strengthening the head articulation, and has been evolved independently in each group.

Mandibles.-A first glance at the mandibles of different members of the family gives the impression of random diversity (Plate III). The more different types are the four-toothed mandibles of the specialized Tenthredininae, figs. 42, 43, the scythe-like right mandibles of the specialized Allantinae, the curious bidentate type shown in fig. 47, and the flattened knife-like mandibles of the specialized Nematinae, fig. 59. Yet almost all of these different types may be traced back through the more primitive members of the subfamily to a simple bidentate type, figs. 46, 51,53 , and 57. The ancestor of the family undoubtedly possessed these simple mandibles, and each group branching away from it has ultimately developed its own characteristic modifications of these appendages. Various types of mandibles within the family are shown on Plate III arranged genealogically.

Anal veins.-An interesting case of reaching the same modification from the same basis by different methods is shown in the condition of the anal veins. The unmodified anal region of the front wing of the Tenthredinidae is the same as that in the sawfly ancestor, having the anal cross-vein present and $2 \mathrm{~A} \& 3 \mathrm{~A}$ forming a distinct angle where they join, fig. 203. In the Nematinae, figs. 202, 200, 198, 2A has gradually fused first with the anal cross-vein then basally along $1 \mathrm{~A}$, reducing the first anal cell to a small loop. Finally the distal portion of this loop has atrophied, leaving only the basal portion of $3 \mathrm{~A}$ present as a short stub. In the Blennocampinae the same fusion of $2 \mathrm{~A} \& 3 \mathrm{~A}$ with the anal cross- 
vein started, but the distal portion of the serial vein atrophied before it had anastomosed with $1 \mathrm{~A}$ to any great extent, figs. 206, 208. In the Phyllotominae the distal portion of $2 \mathrm{~A} \& 3 \mathrm{~A}$ has gradually atrophied without any fusion with the anal cross-vein or $1 \mathrm{~A}$, figs. 205, 207, 209. In all three cases the result has been the production of an isolated apical anal cell.

In some groups $\mathrm{M}$ is divergent from $1 m-c u$, fig. 182. In others, however, the two are parallel, fig. 181. In a few they may be either

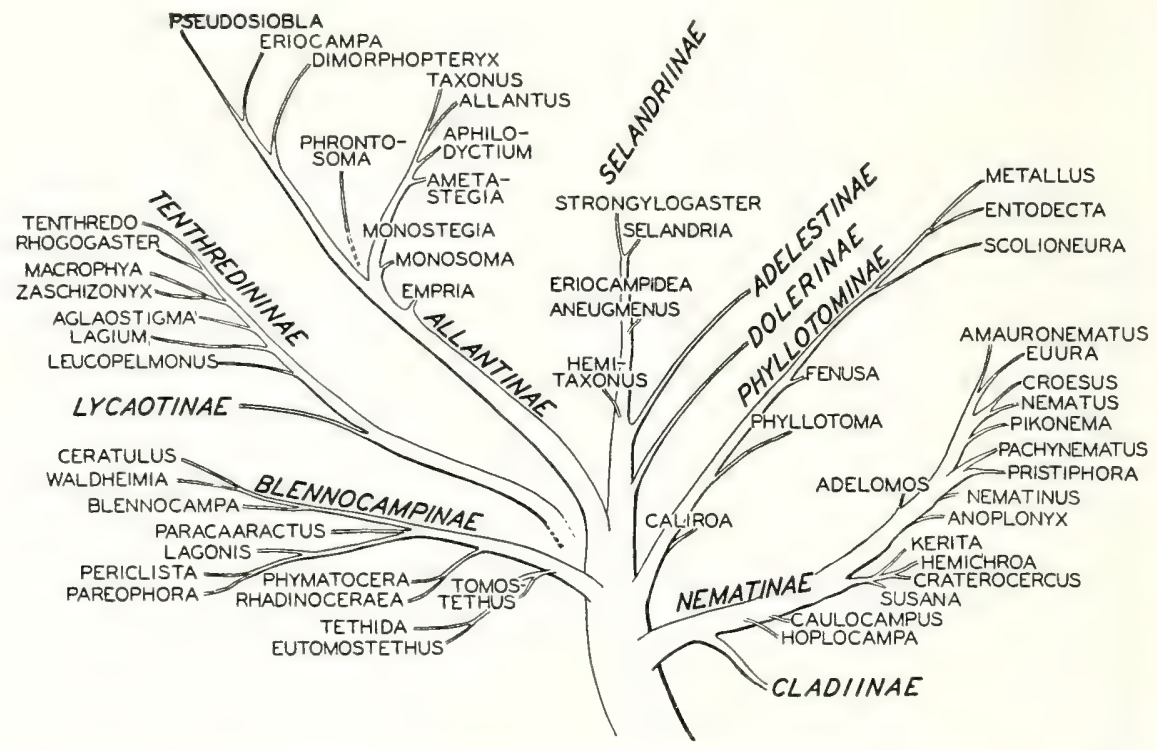

Chart 2.-Genealogical Arrangement of Subfamilies and Principal Genera of the Nearctic Tenthredinidae

parallel or divergent. It would seem, therefore, that in the primitive condition this juxtaposition was not fixed, and has become stabilized in some groups after their separation from the parent stem.

The condition of the prepectus and the anal veins have been considered major characters for the differentiation of the subfamilies of the Tenthredinidae by most authors. Yet it is apparent that in these characters the primitive members of almost all the subfamilies are at least somewhat similar, and furthermore, that in half the subfamilies at least two conditions of these characters are present.

\section{Phylogeny of the Family Subgroups}

Using the mandibles and wing venation as evidence, it is certain that (1) the family Tenthredinidae has subdivided into a large number 
of groups which have arisen from the parent stock in a radiating, palmate fashion, Chart $2 ;(2)$ in many cases the primitive genera of some branches are more difficult to separate from the primitive genus of another branch than from specialized genera of the same branch.

It seems apparent that the hypothetical ancestor of the family possessed (1) a prepectus; (2) bidentate mandibles; (3) simple antennae; (4) proximal anal cell contracted in middle and separated from the distal anal cell by the anal cross-vein, as in fig. 203 ; (5) media in front wing joining radius at point of separation of $R_{s}$, and probably fluctuating in respect to being parallel or not to $2 m-c u$.

This condition is found only in some specimens of the genus Hemitaxonus, but is approached by most genera in its subfamily, the Selandriinae. We may, then, safely consider the Selandriinae to be the most primitive subfamily of the Tenthredinidae.

From some such condition there has been a steady evolution along several diverse lines, leading ultimately to such specialized forms as the higher Nematinae, Tenthredininae, and Allantinae.

\section{KEY TO SUBFAMILIES}

1. Front wings with vein $2 \mathrm{~A} \& 3 \mathrm{~A}$ complete and not fused with $1 \mathrm{~A}$, figs. 183,

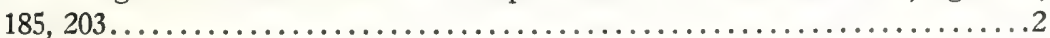

Front wings with vein $2 \mathrm{~A} \& 3 \mathrm{~A}$ either partially atrophied, figs. 205, 209, or

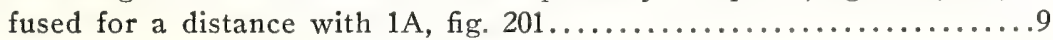

2. Front wings with anal cross-vein present, fig. $181 \ldots \ldots \ldots \ldots \ldots \ldots \ldots$

Front wings with anal cross-vein absent, fig. $183 \ldots \ldots \ldots$ Selandriinae, pt.

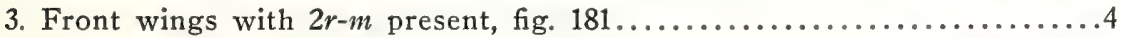
Front wings with $2 r-m$ absent, fig. $182 \ldots \ldots \ldots \ldots \ldots \ldots \ldots$ Dolerinae

4. Front wings with proximal anal cell markedly constricted near base, figs. 203,204 , vein $M$ at most joining $R$ very little proximad of fork of $R_{s}$,

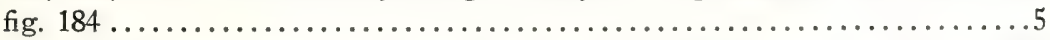

Front wings with proximal anal cell only feebly constricted, fig. 197, vein $M$ joining $R$ half its length proximad of fork of $R_{s}$, fig.

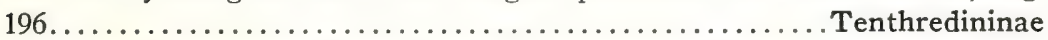

5. Mesopleurae rugose with large, crater-like punctures, fig. 329. Allantinae, pt. Mesopleurae at most with separate, inconspicuous punctures..........6 6

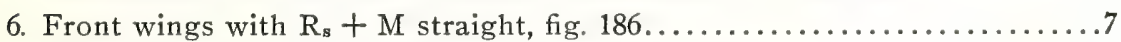

Front wings with $R_{s}+M$ markedly curved, fig. $184 \ldots \ldots \ldots \ldots \ldots \ldots \ldots$

7. Front wings with $\mathrm{M}$ parallel with $1 m-c u$, fig. $186 \ldots \ldots \ldots \ldots$ Allantinae, pt. Front wings with $\mathrm{M}$ and $1 m-c u$ divergent, fig. $185 \ldots \ldots$.... Phyllotominae, pt.

8. Front wings with proximal anal cell as long as distal anal cell, fig.

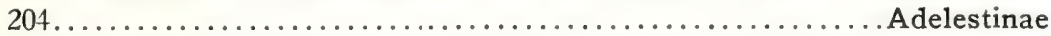

Front wings with proximal anal cell twice as long as distal anal cell, fig.

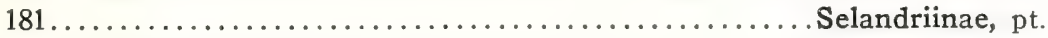

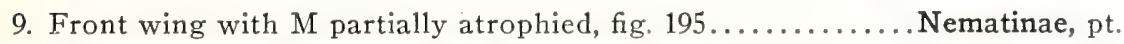
Front wing with $\mathrm{M}$ present for its entire length, fig. $193 . . . \ldots \ldots \ldots \ldots . . .10$

10. Front wings with $\mathrm{M}$ and $1 m-c u$ parallel or nearly so, figs. $192,194 \ldots \ldots \ldots 1$ Front wings with $\mathrm{M}$ and $1 m-c u$ markedly divergent, figs. $187,191 \ldots \ldots 13$ 
11. Front wings with $M$ joined to $R$ half-length of $M$ proximad of fork of

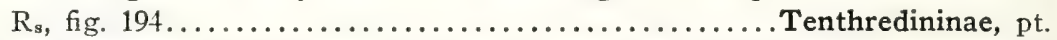

Front wings with $M$ joined to $R$ at or near fork of $R_{8}$, fig. $192 \ldots \ldots \ldots 12$

12. Front wings with proximal abscissa of $2 \mathrm{~A} \& 3 \mathrm{~A}$ distinct for its entire length, fused to $1 \mathrm{~A}$ for only a short distance, fig. 192......... Lycaotinae

Front wings with proximal abscissa of $2 \mathrm{~A} \& 3 \mathrm{~A}$ atrophied for a distance,

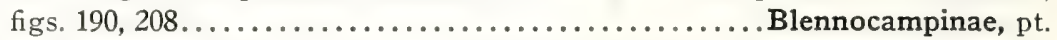

13. Front wings with $M$ joined to $R$ half-length of $M$ proximad of fork of $R_{s}$,

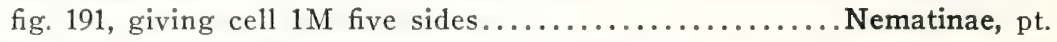

Front wings with $M$ joined to $R$ at or near fork of $R_{s}$, fig. 188, cell $1 M$

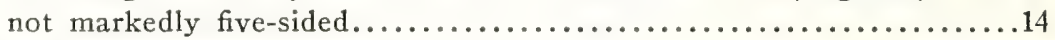

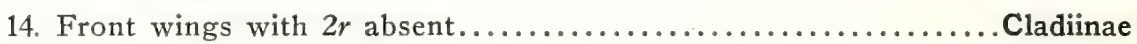

Front wings with $2 r$ present, but sometimes faint................. 15

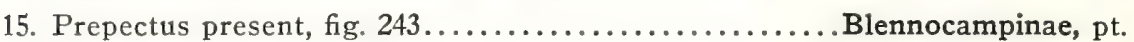

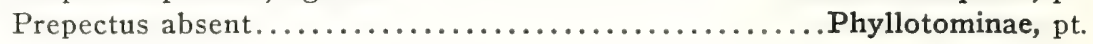

\section{Subfamily Selandritnae}

Prepectal suture present as a distinct suture or a furrow. Propleurae, fig. 155, with mesal margins pointed and not meeting. Front wings, fig. 181, with $\mathrm{M}$ either parallel with $1 m-c u$ or not, meeting $\mathrm{R}$ at or near fork of $R_{s} ; R_{s}+M$ with a decided bend; these conditions obscured in Selandria due to the enlargement of $\mathrm{R}$, fig. 183. Anal cross-vein present or absent; when present the proximal anal cell is considerably longer than the distal cell. Mesopost-tergite normal.

The members of this subfamily are quite uniform in fundamental structure. The chief differences occur in the proportions of the antennae, tarsal claws, shape of clypeus and male genitalia. The range of variation in genitalia within the genus Strongylogaster, however, is almost as great as the known extremes in the subfamily, so that their study concerns species more than genera.

In addition to having an abundant nearctic fauna, the Selandriinae have developed greatly in the neotropical regions. Several species taken in Arizona and New Mexico represent this neotropical assemblage in the United States.

\section{KEY TO GENERA}

1. Front wing with anal cross-vein present, fig. $181 \ldots \ldots \ldots \ldots \ldots \ldots \ldots \ldots . . \ldots \ldots$

Front wing with anal cross-vein absent, fig. $183 \ldots \ldots \ldots \ldots \ldots \ldots \ldots \ldots . . \ldots 4$

2. Prepectus a distinct sclerite, separated from episternum by a suture, fig.

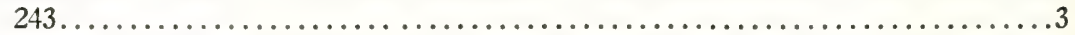

Prepectus a raised shoulder, separated from episternum by a furrow, fig.

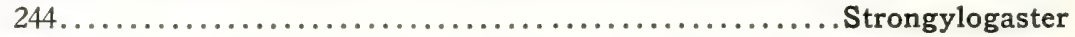

3. Antennae with sixth segment more than twice as long as wide, fig.

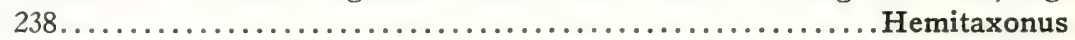

Antennae with sixth segment less than twice as long as wide, fig.

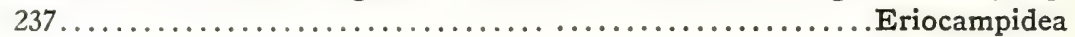


4. Mesepisternum with an inverted $\mathrm{V}$-shaped prepectal suture, forming a prepectus-like area on the postero-dorsal corner of the sclerite, in addition to the true prepectus on the anterior angle, fig. $242 \ldots \ldots \ldots \ldots$. . . . . .

Mesepisternum without this posterior "prepectus," only the anterior prepec-

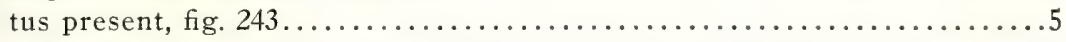

5. Antennae with last four segments reduced in size, together less than twice the length of third segment; flagellum at least somewhat fusiform; pedicel

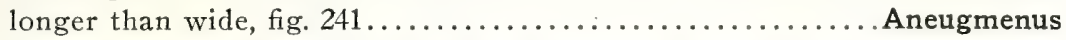

Antennae with total length of last four segments three or four times as long as third segment; flagellum almost filiform; pedicel no longer than wide,

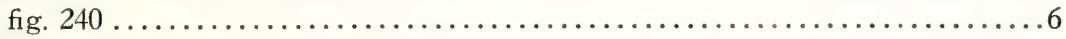

6. Prepectus and adjoining portion of episternum flat, on the same plane, and separated by a line-like suture, fig. $243 . . \ldots \ldots \ldots \ldots \ldots$..............

Prepectus shoulder-like, raised above level of episternum, and separated from it by a depressed suture or furrow, fig. 244 ......... Strongylogaster

\section{Hemitaxonus Ashmead}

Hemitaxonus Ashmead, 1898, p. 311. Genotype by original designation.-Taxomus dubitatus Norton.

Epitaxonus MacGillivray, 1908b, p. 365. Genotype by original designation.-Taxomus albidopictus Norton.

Characteristics.-Clypeus truncate or slightly emarginate; antennae long and slender, fig. 238; body long and slender. Some specimens with $\mathrm{M}$ and $1 m-c u$ of front wing distinctly diverging. Contains three or four species.

\section{Eriocampidea Ashmead}

Eriocampidea Ashmead, 1898, p. 256. Genotype by original designation.-Eriocampidea arizonensis Ashmead.

Cockerellonis MacGillivray, 1908b, p. 365. Genotype by original designation.Cockerellonis occidentalis MacGillivray = Eriocampidea arizonensis Ashmead. Characteristics.-Clypeus slightly emarginate; antennae short, fig. 237 ; body of medium robustness.

Represented by a single southwestern species, E. arizonensis.

\section{Aneugmenus Hartig}

Characteristics.-Anal cross-vein absent in front wing. Antennae with pedicel longer than wide, flagellum fusiform and proportioned as in fig. 241. Tarsal claws with an inner tooth which is parallel to outer and quite stout, fig. 245. Prepectal suture varying from a line to a deep furrow.

The larger species of this group (occurring in the tropics) have been considered as members of Stromboceros Konow, but they differ radically from that genus in antennae and tarsal claws and instead are related to the smaller northern species usually considered as decidedly not congeneric. 
KEY TO SUBGENERA

1. Legs entirely lemon yellow

Aneugmenus

Legs mostly black.

Stromboceridea

\section{Subgenus Aneugmemus Hartig}

Aneugmenus Hartig, 1837, p. 253. Monobasic, genotype--Tenthredo (Emphytus) coronata Klug.

Polyselandria MacGillivray, 1914a, p. 104. Genotype by original designation.-

Selandria floridana MacGillivray $=$ Aneugmenus flavipes var. flavitarsis Rohwer.

Contains three or four species set off by their short antennae, with the third segment slightly longer than half the length of the last four segments together.

\section{Subgenus Stromboceridea Rohwer new combination}

Stromboceros subgenus Stromboceridea Rohwer, 1911d, p. 392. Genotype by original designation.-Stromboceros (Stromboceridea) pilosulus Rohwer.

Contains many Mexican species, set off by the short terminal segments of the antenna, the last four being little longer than the third. A few species have been taken in the extreme southwestern United States.

\section{Selandria Leach}

Selandria Leach, 1817, p. 126. Genotype by subsequent designation of Brullé, 1846.Tenthredo serva Fabricius.

Coryna Lepeletier, 1828, p. 567. Genotype by subsequent designation of Rohwer, 1911b.-Selandria flavans Klug.

Paraselandria Ashmead, 1898, p. 255. Genotype by original designation--Selandria flavescens Thomson $=$ Selandria flavans Klug.

Selandridea Rohwer, 1911d, p. 388. Genotype by original designation.-Selandridea vanduzeei Rohwer.

Pseudoselandria MacGillivray, 1914a, p. 103. Monobasic, genotype.-Pseudoselandria oxalata MacGillivray = Selandria vanduzeei (Rohwer).

This is an aberrant genus in many respects. In the hind wing $1 r-m$ joins $\mathrm{R}$ basad of $\mathrm{R}_{\mathrm{s}}$ and $c u-a$ joins the anal veins at the union of $1 \mathrm{~A}$ and 2A \& 3A. In S. vanduzeei (Roh.), the front wing has costa and radius greatly swollen, fig. 183, and this occurs to some extent also in the other nearctic species, $S$. decorata Cress.

\section{Eustromboceros Rohwer new combination}

Stromboceros subgenus Eustromboceros Rohwer, 1911d, p. 394. Genotype by original designation.-Stromboceros (Eustromboceros) melanopterus Rohwer.

Characteristics.-Front wings without anal cross-vein. Antennae stout, filiform, the segments of the flagellum decreasing only slightly in length from base to apex; pedicel almost twice as broad as long, fig. 240. 
Tarsal claws long and slender, with a narrow minute inner tooth midway to base.

A few unidentified specimens from Arizona belong to this genus. They may represent species already described from Mexico.

\section{Strongylogaster Dahlbom}

Strongylogaster Dahlbom, 1835, p. 13. Genotype by subsequent designation of MacGillivray, 1908b.-Tenthredo cingulata Fabricius.

Thrina.x Konow, 1885a, p. 19. Genotype by subsequent designation of MacGillivray, 1908b.-Strongylogaster contigua Konow. New synonymy.

Prototaxomus Rohwer, 1910a, p. 49. Monobasic, genotype--Prototaxoms typicus Rohwer. New synonymy.

Pseudotaxonus A. Costa, 1894, p. 157. Monobasic, genotype-Tenthredo filicis Klug. New synonymy.

Polystichophagus Ashmead, 1898, p. 310. Genotype by original designation.-Tenthredo filicis Klug.

Of the five names listed above, Pseudotaxonus, Polystichophagus, and Prototaxonus are based on species which possess the anal cross-vein, the character upon which they have hitherto been separated from the other members of the genus. Thrinax and Strongylogaster lack this cross-vein. These latter two differ from each other in the tarsal claws, Thrinax having a claw without a tooth and Strongylogaster one with a very small tooth. In the absence of other differences this does not seem to be of much generic importance.

In a survey of the species of the nearctic fauna of Strongylogaster it is strongly evident that the genus can best be divided into groups on the basis of the male and female genitalia. One group, including lineata Christ, longulus Norton and distans Norton, has the sheath with large, lateral, wing-like expansions; another, including tacitus (Say), has a small sheath with small cup-like lateral expansions; and still another, including politus Prov., has a small sheath without lateral ornamentation. These groupings are substantiated by the punctuation of head and thorax and by various characters of the clypeus. The species hitherto placed in Pseudotaxomus (filicis and tibialis) agree in sheath, punctuation, and clypeus with the group including politus Prov., so closely that the latter group is evidently related more to Pseudotaxonus than to many other species of Strongylogaster s. st. It will be seen from this that the division previously made on the basis of the inter-anal cross-vein is an unnatural one. When a detailed study of the genus is made, Pseudotaxonus and Thrinax may serve to designate subgeneric units if these are necessary in the classification.

\section{Adelestinae new subfamily}

Prepectus absent. Mesonotum with post-tergite apparently not differentiated. Propleurae with mesal margins narrow and pointed, as in 
fig. 155. Front wings, fig. 184, with full complement of veins and crossveins ; $\mathrm{R}+\mathrm{M}$ with a distinct bend; $a$ transverse; cell $\mathrm{DA}$ almost as long as cell PA. Hind wings with $1 r-m$ joining $\mathrm{R}_{\mathrm{s}}$ near its separation from $\mathrm{R}$.

This subfamily is erected for a single species originally described by Norton (1867, p. 254) as Selandria nova. The species was relegated to the "lost" list. Recently, however, I was fortunate in obtaining for study a female so identified by Harrington, and undoubtedly Norton's species.

The bent vein $\mathrm{R}+\mathrm{M}$ places the species definitely in the Selandriine group. It differs from the Selandriinae in lacking a prepectus and in the long distal anal cell; from the Dolerinae in possessing cross-vein $2 r-m$, and in having the anal cross-vein transverse; and from both in lacking a post-tergite.

\section{Adelesta new genus}

Characteristics.-Body short and robust, shining, with practically no punctate areas. Head with antennae slightly serrate, fig. 239, of approximately the same thickness throughout. Clypeus very slightly emarginate. Labrum narrow and triangular. Mandibles not fully visible, but short, stocky, and at least bidentate. Malar space as wide as is middle of front tibiae. Legs with basitarsus subequal to following three together. Tarsal claws long and slender, without an inner tooth.

Genotype.-Selandria nova Norton (original designation).

\section{Subfamily Dolerinae}

Characteristics.-Prepectus absent. Mandibles quadridentate or tridentate, fig. 52. Cervical sclerites approximate and semitruncate on meson. Front wings with $2 r-m$ absent, both anal veins present, separated by an oblique anal cross-vein, and with cell PA constricted near middle, fig. 182. Hind wing with typical venation, possessing $3 r-m, m-c u$ and $2 \mathrm{~A}$.

Contains only a single genus, Dolerus.

\section{Dolerus Panzer}

This genus contains over 40 described nearctic species of which most are in Dolerus s. st. and only four in Loderus. These have been revised by Ross (1931 and 1935a).

\section{KEY TO SUBGENERA}

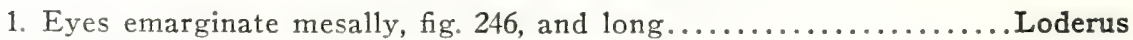

Eyes straight mesally, fig. 247, and short.

Dolerus

\section{Subgenus Dolerus Panzer}

Dolerus Jurine, May 30, 1801, p. 163. Genotype.-Tenthredo gonager Fabricius. Set aside by International Zoological Congress, 1935. 
Dolerus Panzer, September 3, 1801, Heft 82, p1. 11. Monobasic, genotype-Dolerus pedestris Panzer $=$ pratensis (Linnaeus).

Dosytheus Leach, 1817, p. 127. Genotype by subsequent designation of Brullé, 1846. - Tenthredo eglanteriae Fabricius $=$ Dolerus pratensis (Linnaeus).

Characteristics.-Head and thorax partially or completely rugose or coarsely punctate. Antennae setaceous or slightly fusiform. Tarsal claws with a tooth, either large or small.

\section{Subgenus Loderus Konow}

Loderus Konow, 1890, p. 240. Genotype by subsequent designation of Rohwer, 1911b.-Tenthredo pratorum Fallén.

Similar to Dolerus s. st., except as mentioned in the key. Some of the species lack an inner tooth on the tarsal claws.

\section{Subfamily Phyllotominae}

Characteristics.-Prepectus absent. Cervical sclerites pointed mesally, not approximate. Mandibles variable, either bidentate or tridentate. Front wings with $\mathrm{M}$ and $1 m-c u$ divergent; first abscissa of $\mathrm{R}_{\mathrm{s}}$ present or absent, $2 r-m$ always present; anal veins extremely variable. Venation of hind wings variable, $3 r-m$ always absent.

The genus Caliroa is the most generalized member of the group. It possesses bidentate mandibles, front wings with anal veins fully represented, and hind wings with cell $\mathrm{R}$ closed, and cross-vein $m-c u$ present. The larvae are external, slug-like, leaf feeders.

The remaining members are leaf miners in the larval stage. The mandible pattern changes to a tridentate condition, fig. 55, but other changes are almost entirely due to atrophy of veins. The ultimate reduction is shown in some species of Fenusa, in which only 1A is left in either pair of wings, the front wings lack the base of $R_{s}$, and the hind wings have cell $\mathrm{R}$ open and cross-veins $3 r-m$ and $m-c u$ both absent.

The few small genera comprising this group have been very poorly understood in North American literature, as can well be seen in the discussion of Entodecta, p. 71.

\section{KEY TO GENERA}

1. Front wings with vein 2A \& $3 \mathrm{~A}$ well marked for its entire length, figs. 203,

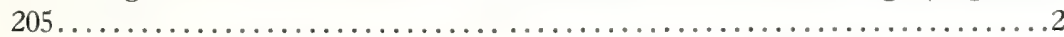

Front wings with $2 \mathrm{~A} \& 3 \mathrm{~A}$ with conspicuous portions of the basal abscissa

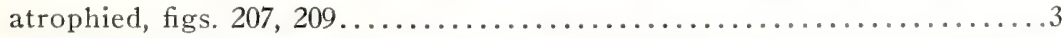

2. Head with anterior aspect markedly convex, fig. $251 \ldots . . . \ldots \ldots$. Caliroa Head with anterior aspect depressed between eyes and meson, fig.

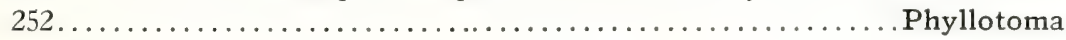

3. Hind wings with cell $R_{1}$ open at apex, fig. $259 \ldots \ldots \ldots \ldots \ldots \ldots \ldots \ldots$

Hind wings with cell $R_{1}$ closed at apex, fig. $258 \ldots \ldots \ldots \ldots \ldots \ldots . . . . . . . . .5$ 


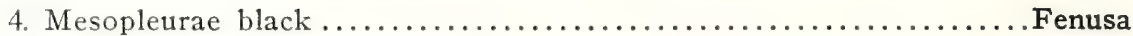
Mesopleurae yellow or rufous.......................... Profenusa

5. Antennae with third segment nearly as long as the fourth and fifth together, segments 4 to 9 diminishing only slightly, fig. $253 \ldots \ldots \ldots \ldots$...... Scolioneura

Antennae more nearly with all segments of flagellum gradually diminishing

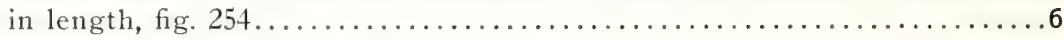

6. Front wing with $2 r$ curving sharply down to meet $\mathrm{R}_{\mathrm{s}}$ at almost a right

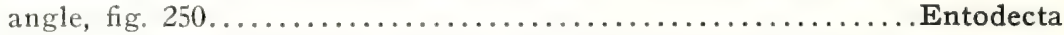

Front wing with $2 r$ curving only gradually and meeting $R_{s}$ obliquely, fig.

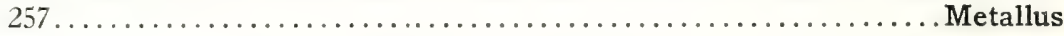

\section{Caliroa O. Costa}

Caliroa O. Costa, 1859, p. 59. Monobasic, genotype-Caliroa sebetia O. Costa = cinxia (Klug).

Eriocampoides Konow, 1890, p. 239. Genotype by subsequent designation of MacGillivray, 1909a.-Tenthredo limacina Retzius = Caliroa cerasi (Linnaeus).

Periclistoptera Ashmead, 1898, p. 255. Genotype by original designation.-Monostegia quercus-alba Norton.

Endelomyia Ashmead, 1898, p. 259. Genotype by original designation.-Monostegia rosae Harris $=$ Caliroa aethiops (Fabricius).

Characteristics.-Head robust, fig. 251, anterior aspect convex. Mandible bidentate. Antennae slender and slightly fusiform. Front wings, fig. 185, with first abscissa of $\mathrm{R}_{\mathrm{s}}$, and all anal veins present. Hind wings with cross-vein $m$-cu present and $2 \mathrm{~A}$ present.

Contains about a dozen species which have not been revised thoroughly.

\section{Phyllotoma Fallén}

Phyllotoma Fallén, 1829, p. 25. Genotype by subsequent designation of Rohwer, 1911b.-Phyllotoma vagans Fallén.

Heterarthrus Stephens, 1835, p. 94. Monobasic, genotype-Tenthredo (Emphytus) ochropoda Klug.

Decatria Stephens, 1835, p. 94. Monobasic, genotype-Tenthredo (Emphytus) ochropoda Klug.

Druida E. Newman, 1838, p. 484. Monobasic, genotype.-Druida parviceps E. Newman $=$ Phyllotoma nemorata Fallén.

Phlebatrophia MacGillivray, 1909a, p. 345. Monobasic, genotype--Phlebatrophia mathesoni MacGillivray = Phyllotoma nemorata Fallén.

Characteristics.-Head narrowed, with elongate concavities running along the inner margins of the eyes, appearing excavated from dorsal view, fig. 252. Antennae long, slender, and filiform, with 10-12 segments. Venation complete but with many parts faint. Hind wings with $m-c u$ absent.

Contains a single species in North America, P. nemorata Fallén, which is probably an introduced European species.

\section{Scolioneura Konow}

Scolioneura Konow, 1890, p. 249. Genotype by subsequent designation of MacGillivray, 1909c--Tenthredo (Allantus) betuleti Klug. 
Parabates MacGillivray, 1909c, p. 262. Genotype by original designation-Parabates histrionicus MacGillivray. New synonymy.

Melanobates MacGillivray, 1916, p. 158. Monobasic, genotype-Parabates leucostomus Rohwer. New synonymy.

Characteristics.-Head robust. Antennae as in fig. 253, with third segment subequal to fourth and fifth together. Venation variable; front wing with first abscissa of $R_{s}$ faint or absent and both anal cells open posteriorly; hind wing with cell $\mathrm{R}_{1}$ closed at apex, fig. 258 , and cell $1 \mathrm{~A}$ also closed.

Contains six described nearctic species which have not yet been revised.

\section{Entodecta Konow}

Entodecta Konow, 1886, p. 184. Genotype by subsequent designation of MacGillivray, $1909 \mathrm{c}$ - - Tenthredo (Allantus) pumila Klug.

Polybates MacGillivray, 1909c, p. 264. Monobasic, genotype--Polybates slossonae

MacGillivray. New synonymy.

Differs from Scolioneura chiefly in the antennae, which have all the segments of the flagellum gradually diminishing in length.

This genus contains only a single known nearctic species, whose synonymy is given below. The species alaskana Kincaid, placed in this genus by MacGillivray, belongs in Scolioneura.

The head sculpture and antennal proportions resemble Metallus in many respects and it may be necessary later to consider Entodecta as a synonym of that genus. This latter view is held by Benson, 1936.

\section{Entodecta capitalis (Norton) new combination}

Selandria capitalis Norton, 1867 , p. 247, 오.

Polybates slossonae MacGillivray, 1909c, p. 265, ㅇ. New synonymy.

Polybates secundus Rohwer, 1910c, p. 202, ․ . New synonymy.

Entodecta humilis Konow, 1908, p. 84, ㅇ. New synonymy.

This species varies somewhat in color and has a wide distribution, ranging from the Atlantic to the Pacific. The name capitalis was referred to Metallus by MacGillivray (1909c), but an examination of Norton's type proves it to be a light specimen of the species described by MacGillivray as Polybates slossonae.

\section{Metallus Forbes}

Metallus Forbes, 1885, p. 87. Monobasic, genotype--Metallus rubi Forbes.

Characteristics.--Front wing without basal loop of $2 \mathrm{~A} \& 3 \mathrm{~A}$; first abscissa of $R_{s}$ faint or absent. Hind wing with cell $R_{1}$ closed at apex, vein $2 \mathrm{~A}$ fully developed and joining $1 \mathrm{~A}$. Antennae with second segment small and annular, flagellum of male large and flattened, of female swollen.

Contains only one species, whose complete synonymy is presented here for the first time. 


\section{Metallus rubi Forbes}

Metallus rubi Forbes, 1885 , p. 87, ô.

Metallus rohweri MacGillivray, 1909c, p. 267, ㅇ. New synonymy.

Metallus bethunei MacGillivray, 1914c, p. 366, ô, 우.

The larva of this sawfly mines the leaves of blackberry. The color of the mesonotum of the adult varies from rufous through dark brown to black.

\section{Fenusa Leach}

Fenusa Leach, 1817, p. 126. Monobasic, genotype--Tenthredo (Emphytus) pumilus Klug (preoccupied, nec Tenthredo (Allantus) pumilus Klug) = Femusa pusilla (Lepeletier).

Kaliosysphinga Tischbein, 1846, p. 79. Monobasic, genotype-Kaliosysphinga dohrnii Tischbein.

Aphadnurus O. Costa, 1859, p. 40. Monobasic, genotype-Aphadnurus tantillus Costa $=$ Fenusa pusilla (Lepeletier).

Kaliofenusa Viereck in Smith, 1910, p. 591. Genotype by subsequent designation of Rohwer, 1911b.-Fenusa ulmi Sundevall.

Characteristics.-Antennae with 9 segments. Front wings with first abscissa of $R_{s}$ atrophied, base of $2 \mathrm{~A} \& 3 \mathrm{~A}$ either present as a semi-sclerotized loop, fig. 209, or absent. Hind wings with cell $\mathrm{R}_{1}$ open at apex, fig. 259; $2 \mathrm{~A}$ either entirely atrophied, present for its full length, or in various intermediate conditions. Head thick and rounded in front, as in Caliroa, fig. 251.

This genus contains quite a variety of forms. When more species are known by both sexes it may be advisable to subdivide it into subgenera. It has been briefly revised by Ross, 1937 .

\section{Profenusa MacGillivray}

Profenusa MacGillivray, 1914c, p. 364. Monobasic, genotype-Profenusa collaris MacGillivray $=$ Profenusa canadensis (Marlatt).

Differs from Fenusa chiefly in possessing the first abscissa of $R_{s}$, having longer and more slender wings and with vein $2 \mathrm{~A}$ of the hind wings fully developed.

\section{Profemusa canadensis (Marlatt) new combination}

Scolioneura canadensis Marlatt, 1895, p. 235, 오.

Profemesa collaris MacGillivray, 1914c, p. 364, ô, ‥ New synonymy.

This is the only known species in the genus. The larva mines the leaves of Crataegus.

\section{Subfamily Cladinae}

Characteristics.-Prepectus present, sometimes indistinct. Mandibles bidentate, the inner tooth small, fig. 56. Front wings with $\mathrm{M}$ joined to $\mathrm{R}$ a short distance before divergence of $\mathrm{R}_{\mathrm{s}} 2 \mathrm{r}$ absent, $2 \mathrm{~A} \& 3 \mathrm{~A}$ fused to 
$1 \mathrm{~A}$ so that the basal abscissa of the former is a short loop. Hind wings with full complement of veins and cross-veins. Tarsal claws cleft with a short inner tooth.

This group contains a few small genera of uniform habitus. The genera are best characterized by the saws of the female. Rohwer and Middleton (1922) revised the group but several species described a year previously by MacGillivray have never been incorporated into the keys.

The Cladiinae are remarkably similar in many characters to the Nematinae but appear to be a distinct, separate offshoot of the Nematine stem.

\section{KEY TO GENERA}

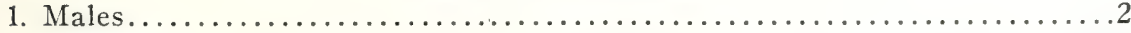

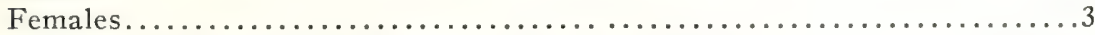

2. First three segments of flagellum pectinate, fig. 104...................... First three segments of flagellum not pectinate,

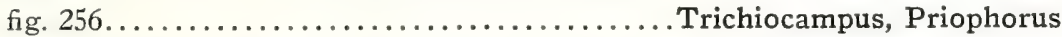

3. Third antennal segment strongly compressed bilaterally, short and emargi-

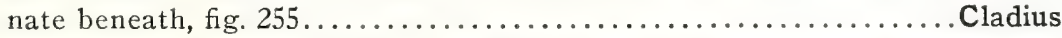

Third antennal segment round, long and scarcely emarginate beneath, fig.

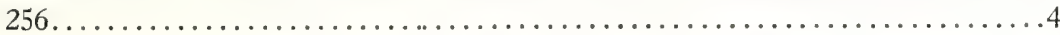

4. Ventral margin of saw nearly straight, armed with 12-14 serrations, fig.

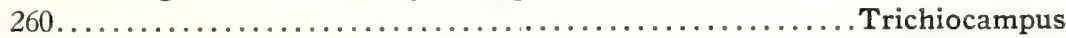

Ventral margin of saw concave, armed with 8 large teeth,

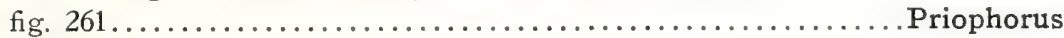

\section{Trichiocampus Hartig}

Cladius subg. Trichiocampus Hartig, 1837, p. 176. Genotype by subsequent designation of Rohwer, 1911b.-Nematus grandis Lepeletier = Trichiocampus viminalis (Fallén).

Characteristics.-Antennae long, slender, and setaceous, somewhat bilaterally compressed in male, the third segment in the male with a basal projection in some species. Front basitarsus shorter than the three following segments combined. Saw without lateral armature, but with twelve or more segments, fig. 260.

Six described species belong in this genus, but the synonymy has not yet been worked out.

\section{Priophorus Dahlbom}

Nematus subg. Priophorus Dahlbom, 1835, p. 4. Genotype by subsequent designation of Rohwer, 1911b.-Nematus (Priophorus) pilicornis Dahlbom $=$ Priophorus pallipes. (Lepeletier).

Stevenia Brullé, 1846, p. 667. No included species.

Characteristics.-Differs from Trichiocampus chiefly as follows: third segment of antennae of male never with basal projection, front basitarsus usually subequal to length of three following segments combined and saw with distinct lateral armature and only eight segments, fig. 261.

Contains about fifteen species which are badly in need of revision. 


\section{Cladius Rossi}

Cladius Rossi, 1807, p. 27. Genotype by subsequent designation of Latreille, 1810.Tenthredo difformis Panzer.

Characteristics.-Antennae of female shorter than in two preceding genera, the third segment short and concave ventrally; of male slender, with third, fourth, and fifth segments pectinate, fig. 104. Front basitarsus equal in length to three following segments combined. Saw similar to that of Priophorus, fig. 261.

Contains only one species in North America, C. isomerus Norton, which attacks cultivated roses and is probably a synonym of a European one,

\section{Subfamily Nematinae}

This subfamily has been divided into two or three subfamilies by various authors, but to do so destroys the picture of its composition. The various genera coming within its limits present an almost perfectly intergraded chain of conditions ranging from the most primitive genus, Hoplocampa, to a closely knit, specialized group of genera including Pristiphora, Nematus, and Euura.

In Hoplocampa the front wings, fig. 191, have $2 r$ present, the basal abscissa of $2 \mathrm{~A} \& 3 \mathrm{~A}$ present and showing the typical angulation, and $3 r-m$ received in cell $3 \mathrm{R}_{\mathrm{s}}$; the mandibles are triangular from a side view, fig. 270 ; and the penis valves of the genitalia are composed of only one leaf at the apex. Through differences shown in such genera as Hemichroa, Anoplonyx, and Platycampus, these gradually resolve themselves into the following: front wing, fig. 193, with $2 r$ absent, basal abscissa of $2 \mathrm{~A}$ \& $3 \mathrm{~A}$ absent, and $3 r-m$ received in cell $2 \mathrm{R}_{\mathrm{s}}$; mandibles with dorsal portion concave, appearing blade-like from a side view, fig. 272; and penis valves with apex composed of two leaves, a mesal membranous one and a lateral sclerotized one, fig. 314.

The only exception to this trend is the small group containing Psendodineura and Kerita, in which the mandibles are distinctly tridentate, fig. 318. There is slight indication of a beginning of the middle tooth in Susana and Hemichroa, fig. 317, so that this tridentate mandible apparently marks an early offshoot of the Nematinae.

The higher group of genera must have evolved some highly beneficial biological characteristics, because they are at present the most abundant boreal sawfly group in number of species and probably also in population. Most of them are not large or conspicuously colored, so that they are seldom collected abundantly by the general entomologist, but a close search usually reveals them in numbers. The most valuable paper in dealing with these forms is the revision of Marlatt, $1896 \mathrm{~b}$. 


\section{KEY TO GENERA}

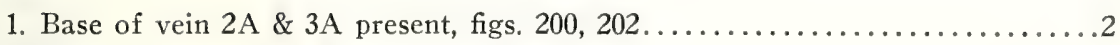

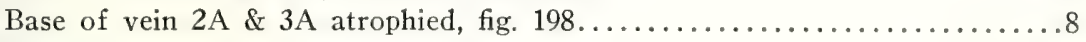

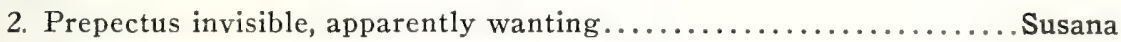

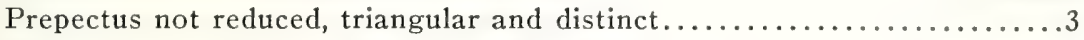

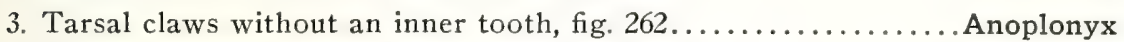

Tarsal claws with an inner tooth, either large or small...............

4. Antennae with second segment longer than wide, subequal in length to

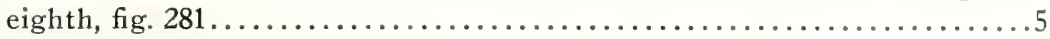

Antennae with second segment wider than long, at most half the length

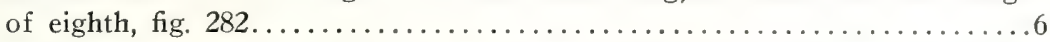

5. Tarsal claws bent over a sharp angle near middle, with a long inner tooth,

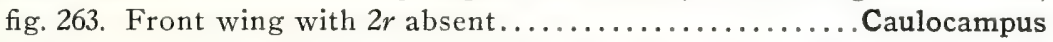

Tarsal claws only gently curved, with a short inner tooth, as in fig. 266.

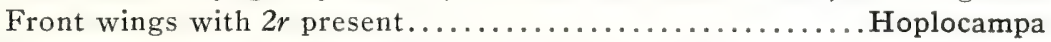

6. Malar space greater than length of first antennal segment, subequal to

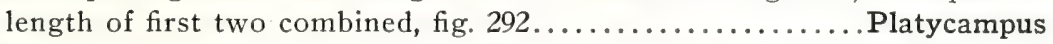

Malar space no greater than length of first antennal segment, fig. 291....7

7. Antennae stocky and approximately of same thickness throughout, fig. 282.

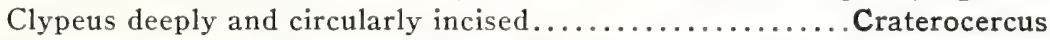

Antennae slender and tapering, fig. 283. Clypeus shallowly or angularly

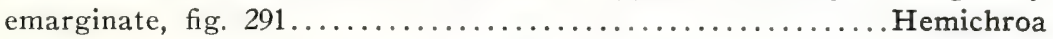

8. Hind wings with vein $2 \mathrm{~A} \& 3 \mathrm{~A}$ present, fig. $287 \ldots \ldots \ldots \ldots \ldots \ldots \ldots \ldots$

Hind wings with vein $2 \mathrm{~A} \& 3 \mathrm{~A}$ atrophied, fig. $288 \ldots \ldots \ldots \ldots \ldots \ldots . \ldots$

9. Ocelli forming a wide triangle, fig. 294................. Pseudodineura

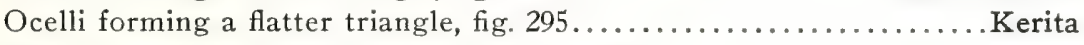

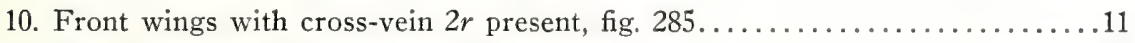

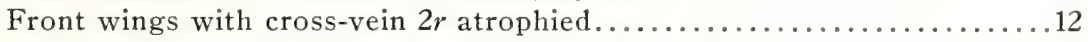

11. Tarsal claws cleft, with a large inner tooth, fig. $269 \ldots . . . . . .$. . Adelomos

Tarsal claws simple, without an inner tooth, fig. $262 \ldots . .$. Neopareophora

12. Hind basitarsus greatly expanded, fig. $277 \ldots \ldots \ldots \ldots \ldots \ldots \ldots$ Croesus

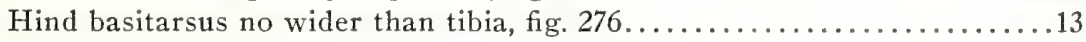

13. Front wings with cross-vein $2 r-m$ present, fig. $193 \ldots . . . \ldots \ldots \ldots \ldots \ldots . . . . . .14$

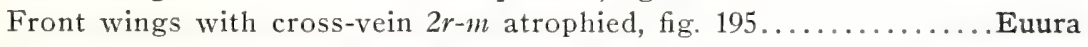

14. Tarsal claws without an inner tooth, fig. $262 \ldots \ldots \ldots \ldots \ldots$. Pristiphora

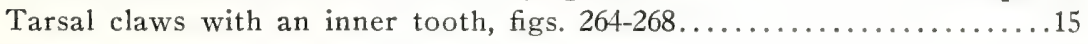

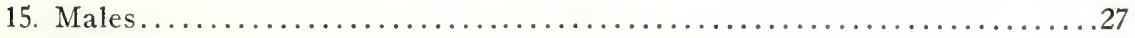

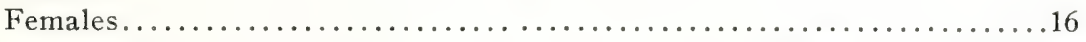

16. Ninth segment extremely large and wide, ventrally, fig. 293 ...... Nematinus Ninth segment much shorter or narrower ventrally than fig. 293 ........17

17. Tarsal claws with inner tooth either small, appearing as a subtooth of the outer one, fig. 264 , or quite a distance from it, fig. $265 \ldots \ldots \ldots \ldots . . . .18$

Tarsal claws with inner tooth at least approaching outer one in length and

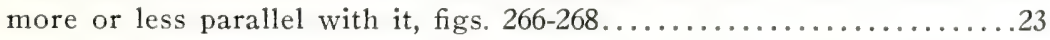

18. Sheath with lateral face polished, flat and with only microscopic setae....19 Sheath with lateral face either rough, mound-like or with most of its sur-

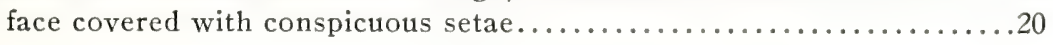


19. Sheath projecting considerably beyond apex of cerci, fig. 298....Pikonema Sheath projecting scarcely at all beyond cerci, fig. 304......... Pristiphora

20. Inner and outer teeth of tarsal claws forming a more or less semicircular

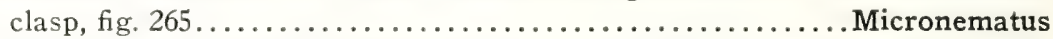

Inner tooth of tarsal claws merely a projection at base of outer tooth,

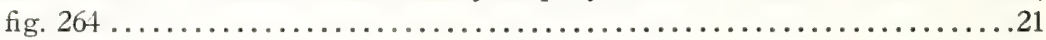

21. Sheath with a definite scopa, or shelf-like lateral process at apex as in

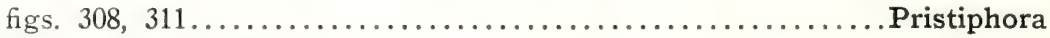

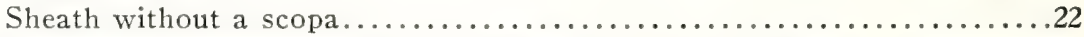

22. Clypeus almost truncate, not emarginate on meson, fig. 297 . . . . Pristiphora Clypeus definitely emarginate on meson, fig. 296............ Pachynematus

23. Left mandible seen in lateral view with base bulbous and apical portion

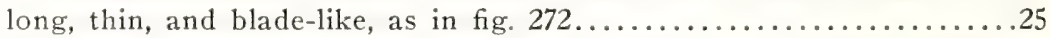

Left mandible either gradually tapering in width from base to apex, fig. 270 , or with the apical portion short and stubby, fig. $273 \ldots \ldots \ldots \ldots .24$

24. Antennae very long, slender, and markedly tapering, fig. 283.... Hemichroa Antennae shorter, stocky, and at most only slightly tapering, as in

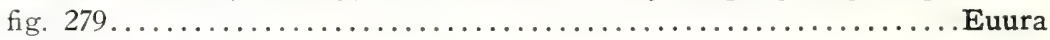

25. Head, figs. 299, 300, with median crest rounding off fairly evenly in lateral view, not hump-like and protuberant................. Amauronematus

Head, figs. 301, 302, with median crest protuberant and somewhat angled

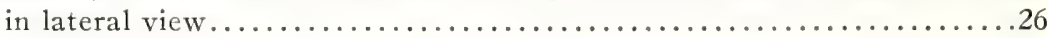

26. Sheath with a wide scopa as in fig. $308 \ldots \ldots \ldots \ldots \ldots \ldots . . . . . .$. Pristiphora Sheath without a scopa, at most with the apical margin slightly

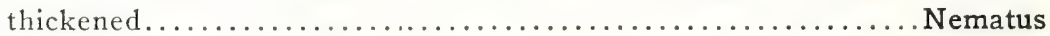

27. Clypeus emarginate on meson, forming two lateral lobes, fig. 296.......29

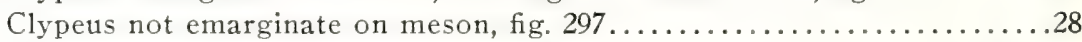

28. Penis valve with apical process of lateral flap on dorsal side, fig.

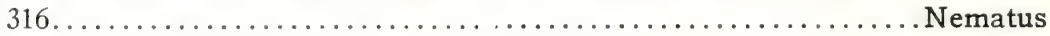

Penis valve with apical process of lateral flap not on dorsal side, figs.

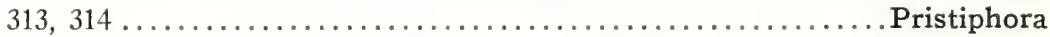

29. Apical sternite wide and emarginate at apex, fig. $306 \ldots \ldots \ldots \ldots \ldots \ldots . . . \ldots 30$

Apical sternite either much more narrowed towards apex or not at all

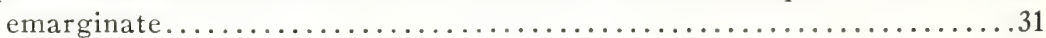

30. Left mandible tapering fairly regularly from base to apex without a necklike constriction between base and apical blade, fig. $271 \ldots . .$. Nematinus

Left mandible with base bulbous and with a definite narrowing between

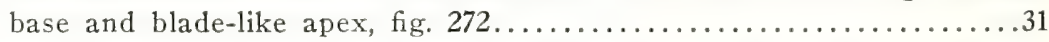

31. Tarsal claw with inner tooth very small and situated some distance from

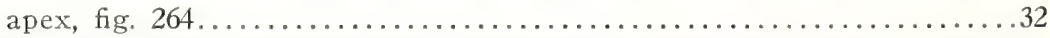

Tarsal claw with inner tooth either larger, fig. 265, or situated closer to

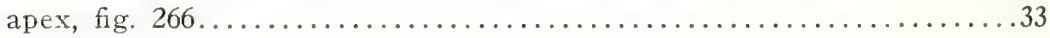

32. Eighth tergite with a procidentia, i.e., a median, raised process set off from the lateral areas by declivous sides, fig. $324 \ldots \ldots \ldots \ldots \ldots \ldots$. . . . . . . .

Eighth tergite produced or carinate but never with the median process set off from the lateral areas by declivous sides............ Pachynematus

33. Left mandible with the narrowed apical portion long, fig. $272 \ldots \ldots \ldots .34$

Left mandible with the narrowed apical portion short and stubby,

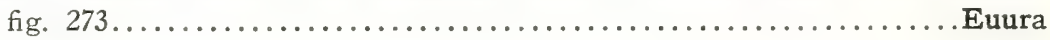


34. Tarsal claws with inner tooth situated some distance from apex and curved to form a semicircular clasp with outer tooth, fig. 265 ...... Micronematus

Tarsal claws with inner tooth situated closer to apex, not forming the

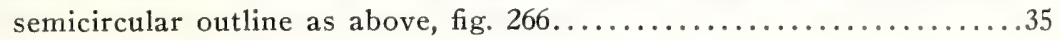

35. Head, figs. 299, 300, with median crest rounding off fairly evenly in lateral

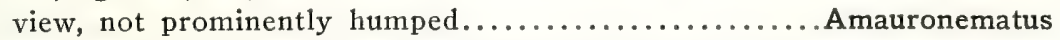

Head, figs. 301, 302, with median crest protuberant and somewhat angled

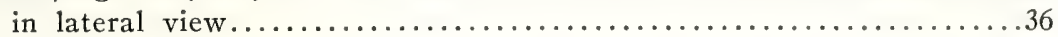

36. Eighth tergite with small, narrow, and inconspicuous procidentia, fig. 325, and apical sternite very short, bluntly-rounded at apex, fig. 305 Pristiphora

Either eighth tergite with a conspicuous, well-differentiated procidentia, as in fig. 324, and the apical sternite produced and more angulate

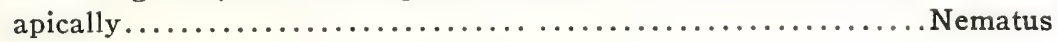

\section{Hoplocampa Hartig}

Hoplocampa Hartig, 1837, p. 276. Genotype by subsequent designation of Rohwer, 1911b.-Tenthredo (Allantus) brevis Klug.

MacGillivraya Ashmead, 1898, p. 257. Genotype by original designation.-MacGillivraya oregonensis Ashmead. Preoccupied.

Macgillivrayella Ashmead in Smith, 1899, p. 606. New name for Macgillivraya Ashmead.

Characteristics.-Small sawflies, usually shorter than $5 \mathrm{~mm}$. Front wings with $2 r$ and base of $2 \mathrm{~A} \& 3 \mathrm{~A}$ present. Antennae fairly short and robust, slightly tapering, the two basal segments together subequal to the third. Tarsal claws with small to medium-sized inner tooth. Malar space variable. Saw without marked transverse bands of setae. Penis valves simple, not divided into mesal and lateral flaps, but sometimes with filamentous lateral processes.

\section{Caulocampus Rohwer}

Caulocampus Rohwer, 1912b, p. 239. Genotype-Priophorus acericaulis MacGillivray.

Characteristics.-Similar to Hoplocampa in venation and general features. Differs in having the antennae shorter and stockier, and the inner tooth of the tarsal claws large and thick, fig. 263.

Contains only a single species, $C$. acericaulis (MacG.), which mines the petioles of maple leaves.

\section{Susana Rohwer and Middleton}

Susana Rohwer and Middleton, 1931, p. 93. Genotype by original designation.Susana cupressi Rohwer and Middleton.

Characteristics.-Front wings with $2 r$ absent or present, $2 m-c u$ joining cell $2 \mathrm{R}_{\mathrm{s}}$ or $1 \mathrm{R}_{\mathrm{s}}$, and base of $2 \mathrm{~A} \& 3 \mathrm{~A}$ present. Antennae slender, long and setaceous. Tarsal claws with a moderate inner tooth. Prepectus 
reduced to a very thin sclerite, usually invisible, along the antero-dorsal margin.

Contains two nearctic species.

\section{Craterocercus Rohwer}

Craterocercus Rohwer, 1911d, p. 385. Genotype by original designation.-Hemichroa phytophagica Dyar.

Characteristics.-Venation similar to Susana, usually with $2 r-m$ and $2 m-c u$ interstitial. Antennae long, slightly robust, and of the same thickness throughout, fig. 282. Clypeus narrow, arcuately emarginate, the lateral lobes pointed and finger-like. Malar space narrow. Saw with transverse rows of spines. Penis valve with lateral flap represented by a broad spine-like process.

This genus contains about eight species, which have been keyed out by Rohwer, 1918d. It is very closely allied to the European genus Mesoneura, differing chiefly in possessing the basal abscissa of vein $2 \mathrm{~A}$ $\& 3 \mathrm{~A}$ in the front wing.

\section{Hemichroa Stephens}

The two subgenera listed here may ultimately prove to be distinct genera. At the present, however, the male of one is unknown and no good diagnostic character of significance has been discovered for the female. On the other hand there is every evidence that the groups are closely related.

\section{KEY TO SUBGENERA}

1. Base of $2 \mathrm{~A} \& 3 \mathrm{~A}$ pigmented and forming a distinct loop, fig. 289 Hemichroa Base of 2A \& $3 \mathrm{~A}$ unpigmented and forming a smaller loop, fig. 290... Varna

\section{Subgenus Hemichroa Stephens}

Hemichroa Stephens, 1835, p. 55. Genotype by subsequent designation of Westwood, 1849.- Tenthredo alni Linnaeus.

Leptocerca Hartig, 1837, p. 228. Genotype by subsequent designation of Rohwer, 1911b.-Tenthredo alni Linnaeus.

Engages Gistel, 1848, p. 9. New name for Leptocerca Hartig.

Leptocercus Thomson, 1871, p. 76. Emendation of Leptocerca.

Characteristics. - Venation too variable to be described other than falling within the subfamily definition. Antennae long and setaceous, fig. 283. Clypeus, fig. 291, wide and angularly emarginate. Malar space short. Tarsal claws with a large inner tooth. Genitalia of both sexes similar to Craterocercus.

This subgenus contains only one nearctic species which is probably truly holarctic in distribution. Its full synonymy has not been given heretofore. 


\section{Hemichroa crocea (Fourcroy)}

Tenthredo crocea Fourcroy, 1785, p. 364.

Dineura americana Provancher, 1882, p. 292. New synonymy.

Hemichroa pallida Ashmead, 1890, p. 15. New synonymy.

Hemichroa dyari Rohwer, 1918d, p. 171. New synonymy.

Hemichroa washingtonia Rohwer and Middleton, 1931, p. 97.

The variant described by Provancher as Dineura americana has usually been considered a distinct species close to crocea. Three series of females from New York, Quebec, and England show both extremes and the bridging intermediates, so that the differentiation cannot be used.

\section{Subgenus Varna new subgenus}

Characteristics.-Both mandibles triangular from a lateral view, fig. 270. Front wings with base of vein $2 \mathrm{~A} \& 3 \mathrm{~A}$ either weak or absent, $2 m-c u$ received in cell $1 R_{s}$, and $r$ absent; tarsal claws deeply cleft, the inner tooth subequal and subparallel to the outer tooth; clypeus deeply and circularly emarginate; antennae very long, slender, and gradually tapering to apex. Based on female, since no males have yet been described.

Genotype by original designation.-Nematus militaris Cresson.

This genus may be separated by means of the accompanying key from those genera of the Nematinae in which the base of vein $2 \mathrm{~A} \& 3 \mathrm{~A}$ is present. Of those genera in which the base of vein $2 \mathrm{~A} \& 3 \mathrm{~A}$ is atrophied, Varna most closely resembles Nematus in general appearance, but can easily be separated from this latter genus on the basis of the left mandible being triangular, fig. 270, from the lateral aspect. In Nematus it is hollowed out dorsally and the lateral aspect is as shown in fig. 272. According to Yuasa's classification of the immature stages, the larva of Varna differs from that of Nematus in lacking suranal processes on the tenth abdominal tergum.

Varna includes three nearctic species, thoracicus (Harrington), militaris (Cresson), and amelanchieridis (Rohwer) which have formerly been placed in Nematus (Pteronidea).

\section{Pseudodineura Konow}

Dolerus subg. Pelmatopus Hartig, 1837, p. 244, preoccupied. Monobasic, genotypeDolerus (Pelmatopus) minutus Hartig.

Pseudodineura Konow, 1885c, p. 297. Genotype by subsequent designation of Rohwer, 1911b.-Tenthredo (Allantus) parvula Klug.

Characteristics.-Front wing with $2 r$ present and base of $2 \mathrm{~A} \& 3 \mathrm{~A}$ absent. Hind wing with $2 \mathrm{~A}$ atrophied, fig. 288. Prepectus typical. Antennae subfiliform, fig. 279. Malar space absent. Right mandible short and uniformly tapering from base to apex, fig. 319 , tridentate, the two 
inner teeth shorter than in fig. 318. Tarsal claws simple, without an inner tooth. Male abdomen without a procidentia.

The nearctic fauna in this genus is unexplored. To date only one North American species, parva (Norton), has been described.

\section{Kerita new genus}

Characteristics.-Venation typical of the Nematinae, the front wing, fig. 195, with $2 r$ present, $2 r-m$ absent, and the basal loop of $2 \mathrm{~A} \& 3 \mathrm{~A}$ absent; and with the free stem $M$ represented by a minute basal stub. Mandibles tridentate as in fig. 318, the outer tooth largest. Antennae slender and setaceous, fig. 284, the second segment wider than long, the remainder long and diminishing in length only gradually. Ocelli small, fig. 295, grouped together in a low triangle and separated from the eyes by a wide area. Malar space present, almost as long as the second antennal segment. Tarsal claws slender and simple, as in fig. 262.

Genotype.-Kerita fidala new species.

This genus represents, with Pseudodineura, the end of a small, specialized branch of the Nematinae. The progenitors of this group were probably forms allied to Hemichroa. The genus Kerita resembles only Pseudodineura, from which it differs in the smaller and more compact ocellar triangle, the distinct malar space, and the larger inner teeth on the mandibles. At present it is known only from the genotype.

\section{Kerita fidala new species}

Female.-Length $3.75 \mathrm{~mm}$. Color black with the following parts piceous: mandibles, trochanters, femora, tibiae, and base of basitarsus. Wings very slightly smoky, venation brown.

Head and body shining, clothed with sparse setae. Head with ocellar basin absent, represented by a narrow raised area extending from the ocelli to the supraclypeal area, with a slight concavity down the middle. At the anterior end of this raised area is a shallow, sunken, U-shaped area, the median fovea. Clypeus long and wide, its sides sloping and apical margin straight, the apex flat and the base slightly raised. Supraclypeal area hump-like, rising sharply from the clypeus. Thorax robust, scutellum practically flat, with a distinct post-tergite. Sheath slender and blade-like, practically identical with that of Pseudodineura, fig. 309. Saw with lance of 10 segments, humped in the middle and tapering to a point at apex; lancet, fig. 310, with 13 segments separated only by faint sutures, each lobe with 6-12 minute teeth, the last tooth produced basad to form a projection on the apical eight segments, the entire surface of the lobate area covered with sparse but conspicuous setae. 
Holotype, female.-Muncie (spelled "Munsey" on label), Illinois, April 25, 1914. In the collection of the Illinois State Natural History Survey.

\section{Neopareophora MacGillivray}

Neopareophora MacGillivray, 1908a, p. 289. Genotype by original designation.Neopareophora martini MacGillivray = litura (Klug).

Dineuridea Rohwer, 1912b, p. 240. Monobasic, genotype--Marlattia erythrothorax Rohwer.

Characteristics similar to above with the following distinctions: malar space distinct; antennae long and tapering, fig. 280; mandibles narrow, right one appearing thin and blade-like from lateral view, fig. 275; hind wings with $2 \mathrm{~A}$ present, fig. 287.

Female with sheath thick, margins shelf-like, with long cerci, figs. 308, 311 .

Contains two nearctic species which have been revised by Ross (1935b).

\section{Adelomos Ross}

Adelomos Ross, 1935b, p. 201. Genotype by original designation.-Adelomos cleone Ross.

Characteristics.-Front wing with $2 r$ present, base of $2 \mathrm{~A} \& 3 \mathrm{~A}$ absent. Hind wings with a radial cross-vein, fig. 286 , and with $2 \mathrm{~A}$ present. Prepectus present, triangular, well defined, and of moderate size. Antennae, fig. 278, almost filiform, the segments of the flagellum distinctly narrower at the base and wider at apex. Right mandible, fig. 274, broad at base with a fairly narrow blade. Tarsal claws cleft, the inner tooth stout and almost as long as the outer, fig. 269

Includes only the genotype. This form is unique among sawflies in possessing a radial cross-vein in the hind wing.

\section{Anoplonyx Marlatt}

Anoplonyx Marlatt, 1896a, p. 18. Genotype by subsequent designation of Rohwer, 1911b.-Nematus pectoralis Lepeletier.

Marlattia Ashmead, 1898, p. 287. Genotype by original designation.-Hoplocampa

laricis Marlatt. New synonymy.

Characteristics.-Front wings with $2 r$ present or absent, $2 m-c u$ joining cell $2 \mathrm{R}_{\mathrm{s}}$, basal loop of vein $2 \mathrm{~A} \& 3 \mathrm{~A}$ present. Antennae very slender and setaceous. Tarsal claws without an inner tooth, fig. 262. Saw curved at apex with curved rows of spines on each segment. Penis valves with a mesal membranous flap and a sclerotized, spike-like lateral one.

Anoplonyx and Marlattia have more recently been considered as subgenera of Platycampus and Hemichroa respectively. The two groups were separated on the basis of the presence or absence of the second 
radial cross-vein. In Platycampus sens. st. this cross-vein is always absent, but in Hemichroa sens. st. it may be present or absent. Furthermore, in a series of three specimens of Anoplonyx laricis (Marl.), one has $2 r$ absent, one has it weakly developed and the third has it well developed. It is, therefore, impossible to use this character as a basis for separating the genera. The species placed here, however, are allied by such distinctive attributes as simple tarsal claws and a type of saw peculiar within the group.

\section{Anoplonyx occidens new name}

Platycampus (Anoplonyx) laricis Rohwer and Middleton, 1931, p. 95. Preoccupied by $A$. laricis (Marlatt), 1896b, p. 257.

The merging of Marlattia and Anoplonyx brings into the same genus the two names laricis. Since the later species described by Rohwer and Middleton is a good species it is necessary to give it a new name.

\section{Platycampus Schiödte}

Nematus subg. Leptopus Hartig, 1837, p. 104, preoccupied. Monobasic, genotype.Nematus (Leptopus) hypogastricus Hartig = Platycampus luridiventris (Fallén). Platycampus Schiödte, 1839, p. 20. Genotype by subsequent designation of Rohwer, 1911b.-Nematus (Leptopus) hypogastricus Hartig = Platycampus luridiventris (Fall.)

Erasminus Gistel, 1848, p. IX. New name for Leptopus Hartig.

Camponiscus E. Newman, 1869, p. 215. Monobasic, genotype-Camponiscus healaei E. Newman = Platycampus luridiventris (Fallén).

Characteristics.-Front wings with base of $2 \mathrm{~A} \& 3 \mathrm{~A}$ present as a distinct loop, but $2 r$ absent. Mandible triangular from a side view. Antennae long and setaceous. Malar space very wide, greater than length of first antennal segment. Tarsal claws with a large inner tooth. Saw with indistinct lateral armature.

The species juniperi Rohwer, originally described in Platycampus, belongs in Susana. The removal of this species and Anoplonyx from Platycampus leaves a residue of four described nearctic species which form a compact genus. The specific status of the species is indefinite.

\section{Nematimus Rohwer}

Nematinus Rohwer, 1911b, p. 99. Genotype by original designation.-Tenthredo abdominalis Panzer.

Characteristics.-Front wings with both $2 r$ and base of $2 \mathrm{~A} \& 3 \mathrm{~A}$ atrophied. Mandibles representing an intermediate condition between the tapered and blade-like types, fig. 271. Antennae long and setaceous. Tarsal claws with a small inner tooth. Female with segment at base of sheath extremely large and broad at base, fig. 293. Male with no en- 
largement of apex of abdomen, eighth tergite produced into a broad, rounded lobe on meson, fig. 326, and with apical sternite emarginate, fig. 306.

Male.-Length $6 \mathrm{~mm}$. Color brownish yellow with the following parts piceous or black: two basal segments of antennae; a large, diamondshaped mark on ocellar region, reaching from eye to eye and antennae to back of head; posterior aspect of head; praescutum and scutum; mesopectus; and some indefinite blotches on the metanotum and first abdominal tergite. Wings stained with brown basad of stigma; beyond they are hyaline; venation brownish yellow.

General structure as given under genus. Penis valve, fig. 315, with mesal and lateral flaps not differentiated, but with apex divided into two small, membranous lobes and lateral face with a sclerotized spur. This is the spur which later tips the lateral flap in the more specialized genera.

Allotype, male.-Hampton, N. H., June 5, 1908, S. Albert Shaw. In the collection of the Illinois State Natural History Survey.

Several species, such as chloreus (Norton), have been incorrectly placed in this genus. When restricted according to the above diagnosis, it contains four or five very closely related if not identical species in the nearctic region.

\section{Specialized Nematinae}

The genera treated below form the "blossom" of the Nematine stem. Many are difficult to separate in a key but at the same time obviously form distinct phylogenetic groups. Large numbers of species are involved so that it was felt that as many phylogenetic units should be considered genera as possible. The plan followed has been simple-if key characters were found the groups were given generic rank, if not, subgeneric rank.

The entire assemblage has the following characters in common except where noted: front wings with $2 r$ and base of $2 \mathrm{~A} \& 3 \mathrm{~A}$ atrophied, fig. 193; right mandible with base bulbous and apex slender and bladelike, fig. 272; antennae setaceous, with the two basal segments short.

This entire group of genera is in chaotic condition taxonomically. The conventional specific differences of head sculpture and body color, etc., are entirely inadequate for the task. Detailed studies of genitalia and larval characters will be the very least that can be used in the future.

\section{Pristiphora Latreille}

Characteristics.-Clypeus usually truncate, fig. 297, in a few species decidedly emarginate. Tarsal claws varying from simple to possessing a medium sized tooth. Head with lateral walls of ocellar basin usually absent, at most merely indicated as ridges; the ocellar basin itself usually absent and represented by an area raised above the level of the surround- 
ing areas. Front wings with first abscissa of $\mathrm{R}_{\mathrm{s}}$ frequently atrophied. Genitalia of both sexes variable.

Judging by the male genitalia, this genus is the oldest of the specialized Nematinae. This is indicated first by the extreme differences evolved in the male genitalia and secondly that what might be considered as the generalized type of Pristiphora has a penis valve with the tooth of its lateral flap dorsal, whereas it is ventral in the others. There appear to be some distinct phylogenetic groups within the genus but a more detailed study of both nearctic and exotic species is necessary to bring out their worth as genera. Three of these are here classed as subgenera on the basis of genitalia.

\section{SYNOPSIS OF SUBGENERA}

1. Male with apex of eighth tergite with a fan-shaped mesal area which is either convex or somewhat carinate. Penis valves various, but not as in fig. 313. Female saw either with a "scopa" or pointed and subtriangular, its sides usually coarsely punctured. Tarsal claws various....Pristiphora

2. Male with apex of eighth tergite possessing a small, tapering procidentia, fig. 325. Penis valve with apical spur bent at right angles to valve, fig. 313 . Female sheath provided with a distinct scopa. Tarsal claws with a mod-

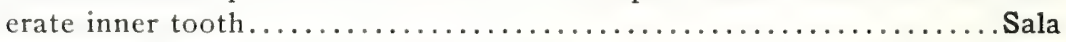

3. Male with apex of eighth sternite fan-shaped, but with a definite, narrow procidentia which is not produced beyond the apex of the segment. Female saw with a distinct scopa, differing from those of Pristiphora s. st. in having the disto-ventral margin incised so that the apex is pointed. Tarsal claws simple.............................. Gymnonychus

\section{Subgenus Pristiphora Latreille}

Pristiphora Latreille, 1810, p. 294. Genotype by original designation.-Pteronus testaceus Jurine.

Diphadnus Hartig, 1837, p. 225. Monobasic, genotype.-Nematus fuscicornis Hartig $=$ Pristiphora pallipes (Lepeletier).

Lygaeonematus Konow, 1890, p. 238. Genotype by subsequent designation of Rohwer, 1911b. -Nematus pini Retzius = Pristiphora abietinus Christ.

Neotomostethus MacGillivray, 1908a, p. 290. Genotype by original designation.Neotomostethus hyalinus MacGillivray. New synonymy.

This group contains some thirty or forty described North American species. The genus Neotomostethus was originally described in the Blennocampinae but its genotype is obviously a typical Pristiphora.

The gooseberry sawfly is referred to unanimously in North American economic literature as Diphadnus appendiculatus Hartig but it should be called Pristiphora pallipes (Lep.). This synonymy has been recognized by European authors for many years.

\section{Subgenus Gymnonychus Marlatt}

Gymnonychus Marlatt, 1896a, p. 122. Genotype by original designation.-Gymnonychus californicus Marlatt.

Contains only one known species, the genotype. 


\section{Subgenus Sala new subgenus}

Characteristics.-Clypeus emarginate. Antennae long and tapering. Dorsal portion of head without distinct ridges, ocellar basin represented by a raised area with sloping boundaries. Frontal crest raised and appearing somewhat angulate from side view, as in fig. 302. Depressions between eyes and antennal sockets neither very deep nor extending much above antennae. Tarsal claws with a long inner tooth subparallel with outer one, as in fig. 269. Female sheath with a scopa set off by a deep depression. Male with apical sternite round and short, fig. 305 ; eighth tergite with a narrow procidentia, fig. 325; and lateral flap of penis valve with a dorsal tooth bent over at right angles to the axis of the shaft, fig. 313 .

Genotype by original designation.-Nematus chloreus Norton.

The genotype has been described or placed in both Nematinus and Nematus (Pteronidea) but it does not belong in these genera. Its only ally is Pristiphora, in which it seems to form a quite distinct subgroup.

\section{Pristiphora chlorea (Norton) new combination}

Nematus chloreus Norton, 1867, p. 221, 우.

Nematus pallifrons Cresson, 1880 , p. 6, 今. New synonymy.

Pteronus quercus Marlatt, 1896a, p. 67, ㅇ. Neze synonymy.

This species feeds on oak, and is distributed from New York to Texas. I have examined the types of the three names involved. Another species described as Amauronematus vaculus MacGillivray from Oregon is either another synonym or a very closely allied species.

\section{Pachynematus Konow}

Pachynematus Konow, 1890, p. 238. Genotype by subsequent designation of Rohwer, 1911b.-Nematus capreae Panzer = Pachynematus trisignatus (Förster).

Characteristics.-Clypeus emarginate. Tarsal claws with a very small tooth situated some distance from apex of outer tooth, fig. 264. Frontal crest and lateral boundaries of ocellar basin sharp, although sometimes low. Female sheath never with scopa, tapering to a pointed apex. Male with apical sternite always at least somewhat produced; eighth tergite either with a carina-like procidentia or a long, convex produced one, penis valve with the tooth of the lateral flap ventral.

Contains 30 or 40 described species from North America. The association of the two sexes of many species is not known, and indicates the need for intensive study of the genus. The larvae of most of the species of this genus differ from those of all related genera in feeding on grasses and sedges and in having the posterior end of the body markedly tapering and pointed. 


\section{Micronematus Konow}

Micronematus Konow, 1890, p. 239. Genotype by subsequent designation of Rohwer, 1911b.-Nematus pullus Förster = Micronematus monogyniae (Hartig).

Very similar to Pachynematus, differing chiefly as follows: Size small, 4-5 mm. Inner tarsal claw tooth large, so that the two teeth form a Cshaped arc, fig. 265. Female sheath short, its ventral margin evenly rounded. Male with apical sternite tapering to a narrow, round tip; eighth tergite with a narrow, carinate procidentia which projects beyond the margin of the segment.

Contains one nearctic species, gregarius (Marlatt).

\section{Micronematus gregarius (Marlatt)}

Pachynematus gregarius Marlatt, 1896b, p. 256, 소, 우.

Pachynematus rarus MacGillivray, 1921a, p. 30, ㅇ. New synonymy.

Yuasa (1923) first pointed out the placement of this species in $\mathrm{Mi}$ cronematus on the basis of larval characters. The larvae feed gregariously on Salix.

\section{Pikonema new genus}

Similar in general structure to Pachynematus, differing as follows: Female sheath long, polished and projecting considerably beyond cerci, fig. 298. Male apical sternite, long, apex tapered to a semi-truncate point, fig. 307 ; eighth tergite with a procidentia projecting beyond segment, fig. 324 .

Genotype by original designation.-Nematus dimmockii Cresson.

A compact genus of five species feeding on spruce.

\section{Nematus Panzer}

Characteristics.-Clypeus emarginate. Tarsal claws with a large inner tooth subparallel with outer, figs, 267, 268. Head with ocellar basin distinct and usually with well defined lateral walls. Frontal crest appearing angulate from lateral view, fig. 301. Depressions between eyes and antennal sockets not so deep or long as in Amauronematus.

The genus has hitherto been considered as three or four separate ones. There seem to be no constant adult, larval, or biological differences, at least none that coincide with each other. For this reason these groups are considered here as subgenera, with no effort to give absolute diagnostic differences between them.

\section{SYNOPSIS OF SUBGENERA}

1. Large species, usually over $9 \mathrm{~mm}$. in length, with outer side of hind tibia and basitarsus markedly grooved, fig. 276. Antennae long and set-

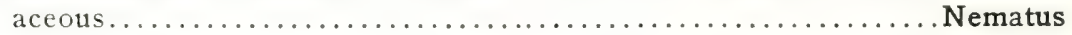

2. Medium to small species with outer side of hind tibiae usually convex or without such a distinct groove as in fig. 276. Antennae always long and setaceous in both sexes. Larvae not inhabiting leaf-curls or galls except

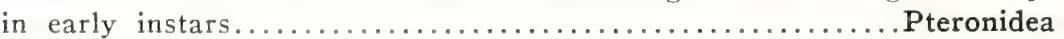


3. Small species, usually less than $5 \mathrm{~mm}$. in length, with hind tibiae only indistinctly grooved. Antennae almost always filiform in female, frequently markedly setaceous in male. Larvae inhabiting leaf-curls or galls for their

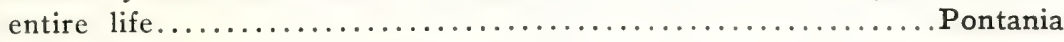

The entire genus contains about 200 described nearctic species. When a thorough study of the males is made it will probably be possible to define the subgenera in terms of male genitalia. All the groups are very imperfectly understood at present.

\section{Subgenus Nematus Panzer}

Nematus Panzer, 1801, Heft 82, pl. 10. Monobasic, genotype-Tenthredo (Nematus) lucida Panzer.

Hypolaepus Kirby, 1882, p. 324. Monobasic, genotype--Hypolaepus abbottii Kirby. New synonymy.

Holcocneme Konow, 1890, p. 238. Genotype by subsequent designation of Rohwer, 1911b.-Tenthredo crassa Fallén.

Contains only three or four nearctic species.

\section{Subgenus Pteronidea Rohwer}

Pteronidea Rohwer, 1911b, p. 98. Genotype by original designation.-Nematus ventralis Say.

This contains the larger proportion of the species in the genus. Later studies on genitalia will undoubtedly show that it is composed of several distinct phylogenetic groups.

\section{Subgenus Pontania O. Costa}

Pontania O. Costa, 1859, p. 20. Genotype by subsequent designation of Marlatt, 1896a.-Nematus gallicola Stephens.

Members of this subgenus have been confused with those of Eunra, since the venation of Eumra is variable and the two have been separated hitherto on this basis. Pontania contains some 40 or 50 described nearctic species.

\section{Genus Eunra E. Newman}

Euura E. Newman, January, 1837, p. 259. Genotype by subsequent designation of Rohwer, 1911b.-Eunra gallae Newman.

Nematus subg. Cryptocampus Hartig, March, 1837, p. 221. Genotype by subsequent designation of Rohwer, 1911b.-Nematus (Cryptocampus) medullaris Hartig.

Characteristics.-Essentially similar in general appearance to Nematus subg. Pontania. Head with ocellar basin sometimes indistinct, antennae usually filiform. Front wings usually with $2 m-c u$ absent. Differs from all related genera in having the blade of the left mandible shortened and stubby, fig. 273. Larvae of all species form leaf, petiole, or stem galls on willow.

Several species possessing this abbreviated mandible have in addition the cross-vein $2 r-m$, which has led to their description in Pteronidea and 
Pontania; these it is necessary to remove to Euura. Among these are the following known to me:

$\begin{array}{ll}\text { Pontania gracilis Marlatt } & \text { Pontania pisum Walsh } \\ \text { Pontania kincaidi Marlatt } & \text { Pontania pomum Walsh } \\ \text { Pontania pacifica Marlatt } & \text { Pteronus kincaidi Marlatt }\end{array}$

\section{Eunra hoppingi new name}

Pteronus kincaidi Marlatt, 1896a, p. 55; $\hat{o}$, ㅇ․ Preoccupied in Eunra by Pontania kincaidi Marlatt.

\section{Croesus Leach}

Croesus Leach, 1817, p. 129. Monobasic, genotype-Tenthredo septentrionalis Linnaeus.

Characteristics.-Apparently very closely related to Nematus differing from it and other Nematinae, however, in the expanded and foliaceous hind basitarsus and apex of hind tibiae, fig. 277.

Contains only three recorded species from North America. The larvae are extremely similar to those of Nematus and indicate a close relationship between them.

\section{Amauronematus Konow}

Amauronematus Konow, 1890, p. 237. Genotype by subsequent designation of Rohwer, 1911b.-Nematus fallax Lepeletier.

Pontopristia Malaise, 1921, p. 12. Genotype by present designation.-Pontopristia suavis var. fusca Malaise. New synonymy.

Characteristics.-Clypeus emarginate. Antennae slender and setaceous. Head with frontal crest appearing evenly convex from lateral view, fig. 299; ocellar basin usually without distinct antero-lateral corners; depressions between eyes and antennal sockets deeper, longer, and situated closer to eye than in Nematus. Tarsal claws with a large inner tooth subparallel with outer one.

This genus is a large one, containing forty or fifty species.

\section{Subfamily Allantinae}

Prepectus absent. Propleurae with mesal margins either pointed and not approximate, fig. 155, or truncate and meeting, fig. 158. Front wings, fig. 186, with $\mathrm{M}$ parallel with $1 m-c u$ and meeting radial stem near origin of $\mathrm{R}_{\mathrm{s}} ; a$ present. Mesopost-tergite triangular and well developed. Mandibles various.

\section{KEY TO GENERA}

1. Mesonotum and pectus entirely covered with thick coarse punctua-

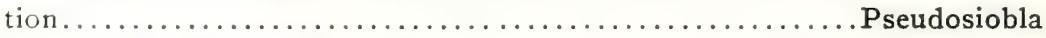

Mesonotum and pectus with large areas at most with small punctures

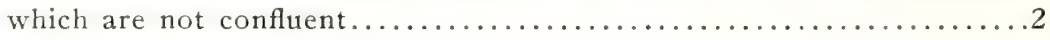


2. Mesopleurae entirely covered with close, crater-like punctures, fig. $329 \ldots 3$

Mesopleurae finely striate or with only small punctures................4

3. Praescutum with anterior portion of each half prominently raised, the posterior portion flat, fig. $331 \ldots \ldots \ldots \ldots \ldots \ldots \ldots \ldots \ldots \ldots$. Eriocampa

Praescutum with each half almost evenly convex over its entire length,

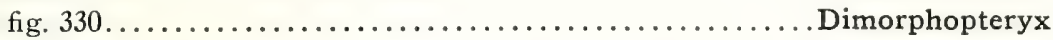

4. Abdomen with a pair of more or less oval, opalescent areas on the five or six basal tergites, giving it a unique, fenestrated appearance, fig.

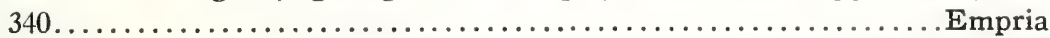

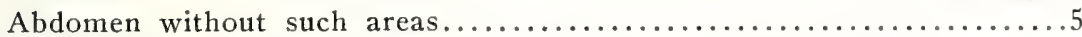

5. Malar space narrow, shorter than length of second antennal segment, fig. 334, and propleurae acute and not meeting on meson, fig.

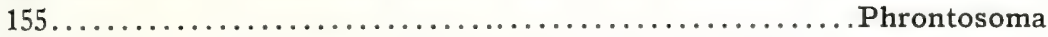

Either malar space longer than length of second antennal segment, or propleurae truncate and meeting on meson, fig. $158 \ldots \ldots \ldots \ldots \ldots \ldots 6$

6. Hind basitarsus at least one and one-third times as long as the remainder

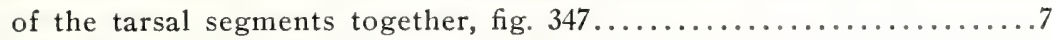

Hind basitarsus subequal to or shorter than remainder of tarsal segments

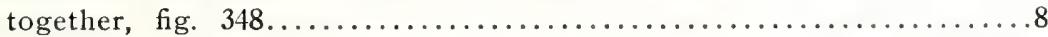

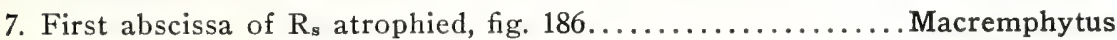

First abscissa of $R_{s}$ present, see fig. $170 \ldots \ldots \ldots \ldots \ldots \ldots$. . . . . . . . . . .

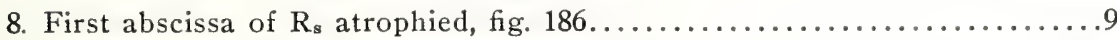

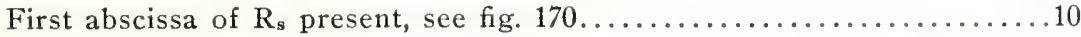

9. Anterior margin of clypeus circularly emarginate for one-half its mesal

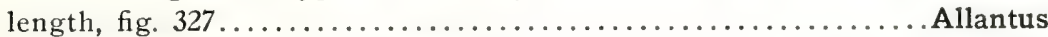

Anterior margin of clypeus emarginate for only a third or less of its length, and the incision forming a flatter arc, figs. 320, 322... Ametastegia in part.

10. Anal cross-vein nearly transversely placed across the anal cell, fig.

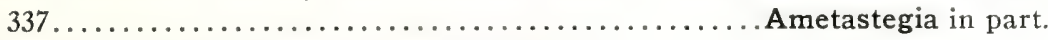

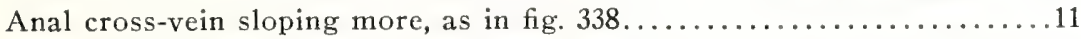

11. Clypeus, fig. 328, narrow, its anterior margin incised to form narrow

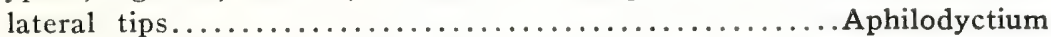

Clypeus, figs. 332, 333, wide, the incision either shallow or angled to form

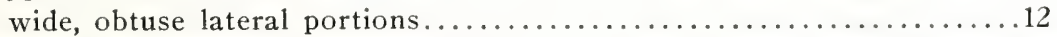

12. Hind tarsal segments almost cylindrical, fig. 345; together almost equal in

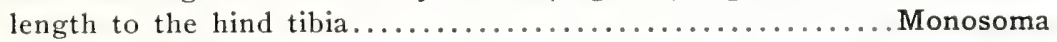

Hind tarsal segments considerably wider at apex and tapering to base, fig. 346; together only two-thirds the length of the hind tibia... Monostegia

The genus Empria probably represents the most generalized member of the subfamily. The other genera may be grouped around it into three tribes, as follows:

(1) Allantini. A regular series of genera lead from Empria, through Monostegia, Monosoma, Ametastegia, Aphilodyctium, and Allantus to the two most specialized genera of the group, Macremplytus and Taxonus. These latter two differ from Empria in having the propleurae truncate and approximate on the meson, fig. 158, the right mandible re- 
duced to a unidentate hook, fig. 49, and the praeputial processes incised to form narrow apical lobes, fig. 343.

(2) Phrontosomini, including only one nearctic genus, Phrontosoma, characterized by the very narrow malar space, and the very small, low praeputial processes in the male genitalia. In other respects the genus is quite generalized, and it is difficult to place it phylogenetically.

(3) Eriocampini, including Pseudosiobla, Eriocampa, and Dimorphopteryx. These three genera are grouped together chiefly on the rugose mesopleurae, but differ radically from each other in mandibular and antennal structure and genitalia. The praeputial lobes of the genitalia, fig. 341, resemble those of Empria, fig. 342, to some extent and probably indicate that these three genera are aberrant offshoots of an early stem.

\section{Empria Lepeletier}

This genus contains seven nearctic species revised by Ross, $1936 \mathrm{~b}$. They are separated on the basis of saws and male genitalia, and grouped into two subgenera.

KEY TO SUBGENERA

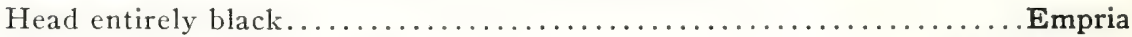

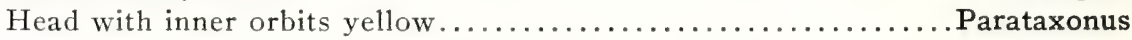

\section{Subgenus Empria Lepeletier}

Empria Lepeletier, 1828, p. 571. Genotype by subsequent designation of Brullé, 1846.-Dolerus (Empria) pallimacula Lepeletier.

Poecilostoma Dahlbom, 1835, p. 13. Genotype by subsequent designation of Rohwer, 1911b.-Tenthredo guttatum Fallén.

Prosecris Gistel, 1848, p. X. New name of Poecilostoma.

Poecilosoma Thomson, 1871, p. 227. Emended spelling of Poecilostoma.

Poecilostomidea Ashmead, 1898, p. 256. Genotype by original designation,-Emphytus maculatus Norton.

Tetratneura Ashmead, 1898, p. 256. Genotype by original designation.-Selandria ignotus Norton.

Empria subg. Triempria Enslin, 1914, p. 213. Genotype by original designation.-Empria tridens Konow.

Both mandibles bidentate, as in fig. 51. Propleurae with mesal angles pointed and not approximate, fig. 155. Clypeus with a median keel, variously incised, fig. 323. Antennae variable. Front wings with $a$ oblique, first abscissa of $R_{s}$ present or absent. Abdomen with at least the four or five basal segments bearing a pair of opalescent areas, fig. 340 .

\section{Subgenus Parataxomus MacGillivray}

Parataxonus MacGillivray, 1908b, p. 367. Genotype by original designation.Taxonus multicolor Norton.

Leucempria Enslin, 1913, p. 187. Genotype by original designation.-Tenthredo candidula Fallén. New synonymy. 
Differs from Empria s. st. in having the clypeus, fig. 321, with a wide, angular incision forming triangular lobes, and without a median keel; also in having a peripheral vein around the hind wing in the male, fig. 180.

\section{Monostegia O. Costa}

Monostegia O. Costa, 1859, p. 60. Genotype by subsequent designation of MacGillivray, 1908b.-Tenthredo abdominalis Fabricius.

Clypeus wide and only moderately emarginate, fig. 333. Hind tarsi only two-thirds the length of the hind tibiae, each segment wider at apex and tapering to base, fig. 346. Propleurae with mesal margins slightly truncate. Antennae with third segment almost as long as third and fourth together. Venation similar to Empria. Abdomen without opalescent areas.

This genus is closely related to Empria and is considered a subgenus of it by Enslin and others. It is represented in North America by only a single holarctic species, abdominalis (Fabr.), which has two synonyms hitherto unrecorded in North American literature.

\section{Monostegia abdominalis (Fabricius)}

Tenthredo abdominalis Fabricius, 1798, p. 216.

Monostegia martini MacGillivray, 1908b, p. 366, ㅇ․ New synonymy.

Monostegia nearctica Rohwer, 1912b, p. 209, 송, 우. New synonymy.

The only nearctic records for this species are along the Atlantic coast.

\section{Monosoma MacGillivray}

Monsoma MacGillivray, 1908b, p. 368. Genotype by original designation.-Taxonus inferentia Norton.

Monosoma Viereck in Smith, 1910, p. 583. Emended spelling of Monsoma.

Judging from MacGillivray's later papers and by his handwritten labels in his collection, the original spelling "Monsoma" was a lapsus calami and the emended spelling should stand.

Hind tarsi almost as long as hind tibiae, fig. 345, the segments almost cylindrical. Front wing with distal anal cell short, narrow, and sharply triangular, fig. 339. Clypeus wide and only moderately emarginate, fig. 332. Propleurae with mesal portion wide and almost truncate. Antennae with third segment subequal to length of fourth and fifth together.

\section{Ametastegia A. Costa}

The nearctic species of this and the following two genera have been revised by Ross (1937b). In common with other genera of the subfamily, they contained a great many synonymous names and misplacements.

\section{KEY TO SUBGENERA}

Front wings with first abscissa of $R_{s}$ present................ Ametastegia Front wings with first abscissa of $R_{s}$ absent.............. Protemphytus 


\section{Subgenus Ametastegia A. Costa}

Ametastegia A. Costa, 1882, p. 198. Monobasic, genotype--Ametastegia fulvipes

A. Costa $=$ Ametastegia glabrata (Fallén).

Aomodyctium Ashmead, 1898, p. 309. Monobasic, genotype-Strongylogaster abnormis Provancher $=$ Ametastegia glabrata (Fallén).

Unitaxonus MacGillivray, 1921b, p. 32. Genotype by original designation.-

Unitaxonus repentinus MacGillivray = Ametastegia equiseti (L.).

Clypeus only slightly or moderately emarginate, figs. 320,322 , the corners sharp. Mandibles, fig. 51, both bidentate. Antennae long. Front wings with $a$ almost perpendicular, distal anal cell shorter than proximal anal cell beyond constriction; first abscissa of $R_{s}$ present; hind wings with both $3 r-m$ and $m-c u$ always lacking. Head with walls of ocellar basin mound-like and not linear. Male genitalia with praeputial processes triangular, fig. 335, penis valve without "shelves" in dorsal portion.

\section{Subgenus Protemphytus Rohwer}

Protemphytus Rohwer, 1909, p. 92. Monobasic, genotype--Emphytus coloradensis Weldon.

Emphytina Rohwer, 1911d, p. 399. Genotype by original designation.-Emphytina pulchella Rohwer = Ametastegia recens (Say).

Simplemphytus MacGillivray, 1914c, p. 363. Monobasic, genotype--Simplemphytus pacificus MacGillivray = Ametastegia tener (Fallén).

Differs from Ametastegia in having the first abscissa of $\mathrm{R}_{\mathrm{s}}$ absent in front wings, and in having shelf-like folds in the dorsal portion of the penis valves.

Aphilodyctium Ashmead, 1898, p. 310. Genotype by original designation.Strongylogaster rubripes Cresson $=$ Aphilodyctium fidum (Cresson).

Polytaxonus MacGillivray, 1908b, p. 368. Genotype by original designation.-

Taxonus robustus Provancher $=$ Aphilodyctium fidum (Cresson).

Clypeus narrow and deeply emarginate, the two corners forming short, triangular processes, fig. 328. Mandibles bidentate. Mesal portion of propleurae narrowly truncate and approximate. Antennae slender, segments of flagellum gradually diminishing in length. Front wings with $a$ oblique, and $\mathrm{R}_{\mathrm{s}}$ entire, hind wings with $3 r-m$ and $m-c u$ absent. Male genitalia with apex of praeputial lobes forming more or less definite, narrowed projections, fig. 336.

Contains only one nearctic species, fidum (Cresson), whose synonymy has been discussed by Ross (1937b).

\section{Allantus Panzer}

Allantus Panzer, 1801, Heft 82, pl. 12. Monobasic, genotype--Tenthredo (Allantus) togatus Panzer.

Emphytus Klug, 1818, p. 273. Genotype by subsequent designation of Curtis, 1833.Tenthredo cinctus (Linnaeus). 
Clypeus deeply, circularly emarginate, often with a ridge around the edge, fig. 327. Right mandible bidentate, left one unidentate, fig. 50. Propleurae with mesal portion truncate. Antennae long and slender, slightly bilaterally compressed in male. Front wings with first abscissa of $\mathrm{R}_{\mathrm{s}}$ absent, $a$ oblique and cell DA subequal to cell PA beyond constriction. Hind wings $3 r-m$ and $m-c u$ absent. Abdomen black except for a transverse white band on the fifth tergite of the female. Hind basitarsus slightly shorter than remainder of tarsal segments together, fig. 348 .

The four nearctic species have been revised by Ross (1937b).

\section{Macremphytus MacGillivray}

Macremphytus MacGillivray, 1908b, p. 368. Genotype by original designation.Harpiphorus variamus Norton.

Differs from Allantus in having the antennae either moderately or strongly bilaterally compressed in both sexes, $m-c u$ usually present in the hind wing, and the hind basitarsus one and a third times as long as the segments beyond it together. Antennae usually bicolored.

There are nine described nearctic species, including some synonyms.

\section{Taxonus Hartig}

Taxomus Hartig, 1837, p. 297. Genotype by subsequent designation of Konow, 1896c.-Tenthredo (Allantus) nitida Klug = Taxomus agrorum (Fallén).

Ermilia O. Costa, 1859, p. 106. Monobasic, genotype.-Ermilia pulchella O. Costa $=$ Taxomus agrorum (Fallén).

Strongylogastroidea Ashmead, 1898, p. 308. Genotype by original designation.Strongylogaster apicalis Say.

Parasiobla Ashmead, 1898, p. 308. Genotype by original designation.-Strongylogaster rufocinctus Norton.

Hypotaxonus Ashmead, 1898, p. 311. Genotype by original designation.-Strongylogaster pallipes Say.

Clypeus deeply emarginate, the lateral angles produced into finger-like tips except in epicera. Left mandible with outer tooth cleft to give appearance of a tridentate condition, figs. 47,49 , right mandible unidentate. Antennae cylindrical. Front wings with $\mathrm{R}_{\mathrm{s}}$ entire, $a$ oblique. Hind wing with $3 r-m$ and $m-c u$ present or absent; in male with a peripheral vein, fig. 180, partially or entirely lost in one or two species. Hind basitarsus one and one-third times as long as the following segments together.

\section{Phrontosoma MacGillivray}

Phrontosoma MacGillivray, 1908b, p. 366. Genotype by original designation.Phrontosoma atrum MacGillivray.

Body short and robust. Clypeus, fig. 334, incised to form rounded lateral lobes. Propleurae with mesal angles narrow and sharp, fig. 155. Antennae, as in fig. 349 , short and stout, third segment as long as the two 
following together, the apical six almost subequal to each other. Front wings with $\mathrm{R}_{\mathrm{s}}$ entire, $a$ oblique. Hind wing with $3 r-m$ absent, $m-c u$ present.

Only a single species is known, belfragei (Cresson). The new synonymy connected with it is presented here.

\section{Phrontosoma belfragei (Cresson) new combination}

Selandria belfragei Cresson, 1880 , p. 15, ㅇ․

Caliroa nortonia MacGillivray, 1894, p. 324, ô. New synonymy.

Phrontosoma atrum MacGillivray, 1908b, p. 367, of. New synonymy.

Phrontosoma daeckei MacGillivray, 1908b, p. 367, ‥ New synonymy.

Phrontosoma collaris MacGillivray, 1908b, p. 367, ㅇ. Neze synonymy.

The body of the male is entirely black, of the female either black or with the mesonotum or mesopleurae and mesonotum rufous. The range of the species is extensive, records having been assembled for the following states: Alberta, Illinois, Iowa, Kansas, New York, Ontario, Pennsylvania, Quebec, and Texas.

\section{Eriocampa Hartig}

Eriocampa Hartig, 1837, p. 279. Genotype by subsequent designation of Rohwer, 1911b.-Tenthredo ovata Linnaeus.

Mesopleurae with large, adjacent, crater-like punctures. Mesonotum and sternum polished and almost impunctate. Praescutum with anterior half prominently raised, posterior portion flat. Mandibles both unidentate. Propleurae only slightly truncate on meson. Clypeus only slightly emarginate.

Contains two or three nearctic species.

\section{Dimorphopteryx Ashmead}

Dimorphoptery.x Ashmead, 1898, p. 308. Genotype by original designation.Strongylogaster pinguis Norton.

Differs from Eriocampa chiefly in having the praescutum evenly convex for its entire length, the mesonotum coarsely punctured, and the mandibles bidentate. The genus was revised by Rohwer (1915a).

\section{Pseudosiobla Ashmead}

Pseudosiobla Ashmead, 1898, p. 308. Genotype by original designation.-Macrophya excavata Norton.

Entire head and thorax with large, adjacent punctures. Propleurae with mesal portion thin and angular. Clypeus only very shallowly emarginate.

Contains three nearctic species. 


\section{Subfamily Blennocampinae}

Characteristics.-Front wing, fig. 190, with $M$ joining $R$ at point of separation of $\mathrm{R}_{\mathrm{s}}, 2 r$ present, $\mathrm{M}$ parallel with $1 m$-cu except in a few cases, $2 \mathrm{~A} \& 3 \mathrm{~A}$ with basal abscissa either very faint, fig. 206, or atrophied beyond bend, figs, 208, 210. Hind wings with venation variable. Prepectus present or absent. Mandibles bidentate. Cervical sclerites pointed and not appressed on meson.

Rohwer divides this group into two, using as the primary difference the presence or absence of the prepectus. It is plain, however, that the prepectal suture is highly unstable in the Blennocampinae. In Paracharactus rudis (Norton) it may be either entirely absent or well developed as a furrow. In such closely allied genera as Phymatocera and Rhadinoceraea it is present in one and not in the other.

Almost all the species in this subfamily are robust, short, and stocky. Approximately a hundred nearctic species have been described but such is the state of keys and literature that three-quarters of them are either synonyms or placed in the wrong genus. The separation of genera is difficult due to a lack of outstanding characters upon which to base phylogeny. It is hoped that future studies of both adults and larvae will bring to light more significant structures.

\section{KEY TO GENERA}

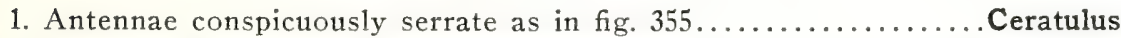
Antennae either not or only slightly serrate......................

2. Front wings with $\mathrm{M}$ and $1 m-c u$ markedly divergent, fig. $188 \ldots .$. Tomostethus Front wings with $\mathrm{M}$ and $1 m-c u$ not markedly divergent, fig. $190 \ldots \ldots \ldots \ldots$

3. Last four antennal segments much shorter than fifth and together only as long as third, fig. $351 \ldots \ldots \ldots \ldots \ldots \ldots \ldots \ldots \ldots \ldots \ldots \ldots \ldots \ldots \ldots \ldots \ldots \ldots$ Waldheimia

Last four antennal segments either subequal to fifth or together much

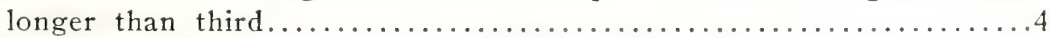

4. Front wing with stub of $2 \mathrm{~A} \& 3 \mathrm{~A}$ furcate at apex, fig. $359 \ldots \ldots \ldots \ldots . \ldots$ Front wing with stub of $2 \mathrm{~A} \& 3 \mathrm{~A}$ not furcate at apex, figs. $358,360 \ldots \ldots .7$

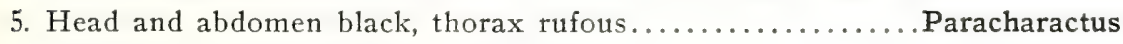

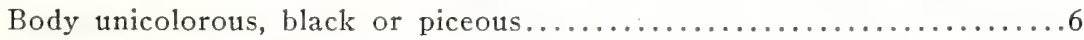

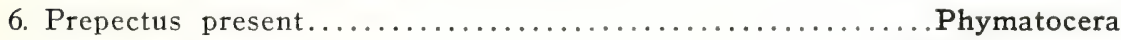

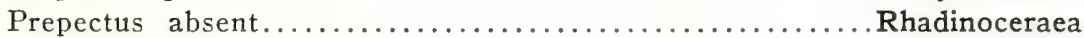

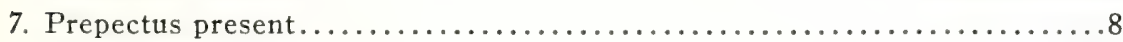

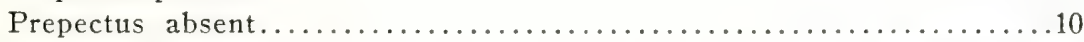

8. Third and fourth antennal segments subequal, fig. 354....... Paracharactus Third antennal segment at least one and one-half length of fourth, fig.

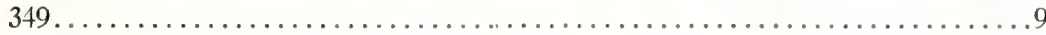

9. Prepectus flat and triangular, set off by a suture, fig. $361 \ldots \ldots \ldots$. . . Tethida Prepectus raised and shoulder-like, set off by a deep furrow, fig.

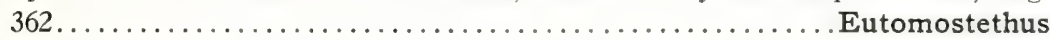

10. Front wing with stub of $2 \mathrm{~A} \& 3 \mathrm{~A}$ turned up at apex, fig. $358 \ldots \ldots \ldots \ldots . . . .16$ Front wing with stub of $2 \mathrm{~A} \& 3 \mathrm{~A}$ straight at apex, fig. $360 \ldots . . . . . . . .11$ 
11. Fourth and fifth antennal segments not noticeably longer or thicker than

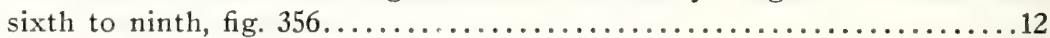

Fourth and fifth antennal segments noticeably longer and thicker than sixth to ninth, fig. $352 \ldots \ldots \ldots \ldots \ldots \ldots \ldots \ldots \ldots \ldots \ldots \ldots \ldots \ldots \ldots \ldots \ldots \ldots \ldots$ Wheimia

12. Third and fourth antennal segments of same length, fig. $354 \ldots \ldots \ldots \ldots \ldots 13$

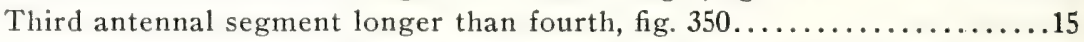

13. Antennae with seventh and eighth segments less than twice as long as

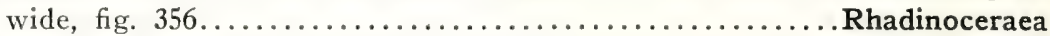

Antennae with seventh and eighth segments much longer than twice width, fig. 354 .

.14

14. Tarsal claws with a long but slender, inner tooth, fig. $357 \ldots$.... Claremontia

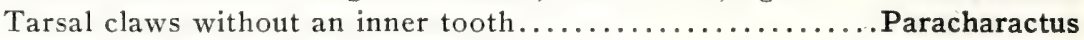

15. Malar space as narrow as width of tibial spur, fig. $367 \ldots \ldots$. . Blennocampa Malar space wider than width of tibial spur, figs. $365,366 \ldots \ldots \ldots \ldots \ldots 16$

16. Posterior orbits with a row of large punctures along posterior margin of

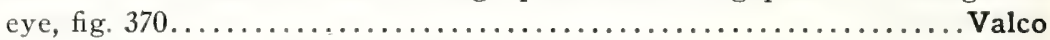

Posterior orbits smooth or only finely punctate along posterior margin of

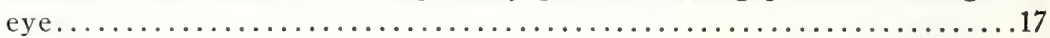

17. Antennae with third and fourth segments subequal in length, fig. $353 \ldots 18$

Antennae with third segment markedly longer than fourth, fig. $350 \ldots \ldots 19$

18. Eyes removed almost their own length from dorso-caudal margin of head,

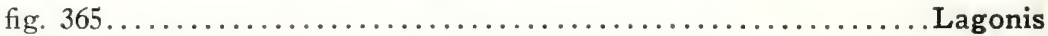

Eyes less than half their length from dorso-caudal margin of head, fig.

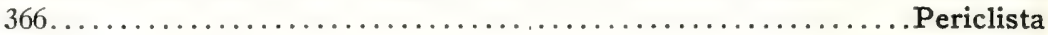

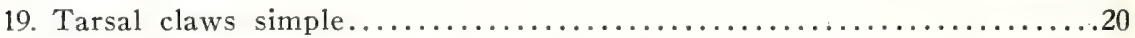

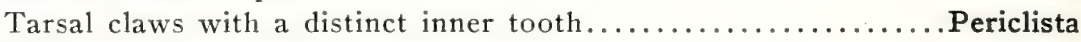

20. Eyes small, removed a considerable distance from dorso-caudal margin

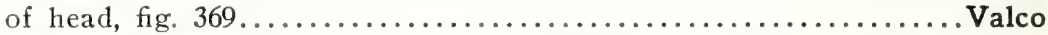

Eyes large, close to dorso-caudal margin of head, fig. 368......Pareophora

\section{Tomostethus Konow}

Tomostethus Konow, 1886, p. 184. Genotype by subsequent designation of Rohwer, 1911b.--Tenthredo nigrita Fabricius.

Characteristics.-Front wings with $\mathrm{M}$ markedly divergent from $1 m-c u$, and base of $2 \mathrm{~A} \& 3 \mathrm{~A}$ represented by a faint, sinuate line, fig. 206. Head with malar space practically obsolete, reduced to a thin line. Antennae stocky and filiform, with third segment as long as fourth and fifth together, four to nine gradually decreasing in length. Prepectus triangular, different in texture to episternum. Tarsal claws simple. Sheath short and expanded laterally at apex.

Contains only one described nearctic species, multicinctus Rohwer.

\section{Tethida new genus}

Characteristics.-Front wings with $\mathrm{M}$ parallel with $1 m-c u$, base of 2A \& 3A with apex practically indistinguishable. Malar space, antennae, and sheath as in Tomostethus. Prepectus, fig. 361, unusually 
large, shining, of same texture as episternum and set off by a line-like suture. Tarsal claws with a short, stocky inner tooth near base.

Genotype by original designation.-Tenthredo cordigera Beauvois.

\section{Tethida cordigera (Beauvois) new combination}

Tenthredo cordigera Beauvois, 1805, p. 97, ㅇ.

Tenthredo bardus Say, 1836, p. 218, ․ .

Selandria dubia Cresson, 1865, p. 244, ㅇ.

This is the only known species in the genus. The application of cordigera to this species was pointed out by Dalla Torre in 1895 but has not been followed by North American students.

\section{Eutomostethus Enslin}

Tomostethus subg. Eutomostethus Enslin, 1914, p. 286. Genotype by original designation.-Tenthredo luteiventris Klug.

Tomostethus subg. Atomostethus Enslin, 1914, p. 287. Genotype by original designation.-Tenthredo ephippium Panzer. New synonymy.

Characteristics.-Differs from Tethida as follows: front wings with $2 \mathrm{~A} \& 3 \mathrm{~A}$ represented only by a basal stub which may be curved up at the end, fig. 358; prepectus narrow, raised, and shoulder-like, fig. 362, set off by a deep furrow; tarsal claws simple; sheath narrow and blade-like.

Contains several species which appear to be truly holarctic.

\section{Paracharactus MacGillivray}

Paracharactus MacGillivray, 1908a, p. 292. Genotype by original designation.Paracharactus obscuratus MacGillivray.

Characteristics.-Front wings with $\mathrm{M}$ usually parallel with $1 m$-cu but sometimes slightly divergent from it; stub of $2 \mathrm{~A} \& 3 \mathrm{~A}$ straight at apex. Antennae narrow and slightly tapering, the segments of the flagellum decreasing almost imperceptibly in length. Malar space very narrow but distinct. Prepectal suture furrow-like, sometimes imperceptible. Tarsal claws simple or with a very small tooth. Sheath long, deep, thin and blade-like. Saw very simply serrate.

The few species in this genus have not yet been revised.

\section{Claremontia Rohwer}

Claremontia Rohwer, 1909, p. 397. Monobasic, genotype-Claremontia typica Rohwer.

Differs from the above as follows: prepectus always absent. Tarsal claws with a longer tooth, fig. 357, and with the outer tooth more curved. Saw with lobiform teeth, resembling many species of Blennocampa.

Contains only the genotype. 


\section{Blennocampa Hartig}

Blennocampa Hartig, 1837, p. 266. Genotype by subsequent designation of Rohwer, 1911b.- Tenthredo (Allantus) pusilla Klug.

Monophadnus Hartig, 1837, p. 271. Genotype by subsequent designation of Ashmead, 1898.-Tenthredo albipes Gmelin. New synonymy.

Monophadnoides Ashmead, 1898, p. 253. Genotype by original designation.-Monophadnus rubi Harris. New synonymy.

Characteristics.-Front wing with stub of $2 \mathrm{~A} \& 3 \mathrm{~A}$ straight, fig. 360 . Antennae with third segment longer than fourth, fourth to ninth practically subequal, as in fig. 350. Malar space narrow to subobsolete, never wider than width of tibial spur. Prepectus absent. Tarsal claws and sheath various.

The nearctic species of this genus have never been revised. Probably a dozen valid species occur in this region.

\section{Waldheimia Brullé}

Waldheimia Brullé, 1846, p. 665. Genotype by original designation.-Tenthredo braziliensis Lepeletier.

Erythraspides Ashmead, 1898, p. 128. Genotype by original designation.-Blennocampa pygmaea Say. New synonymy.

Characteristics.-Differs from Blennocampa chiefly in the antennae, figs. 351, 352. The last four segments are reduced in length, usually together no longer than third; the fourth and fifth are longer and wider than the apical ones; the third is the longest and is wider at the apex. The species carbonaria (Cresson) differs from the others in having somewhat less differentiation among the antennal segments, but it is without doubt a generalized member of this genus.

Several species occur in the nearctic region but the largest representation of the genus occurs in the neotropical region.

\section{Periclista Konow}

Periclista Konow, 1886, p. 184, no. 2. Genotype by subsequent designation of Rohwer, 1911b.-Tenthredo (Allantus) lineolata Klug.

Mogerus MacGillivray, 1895, p. 281. New name for Periclista.

Isodyctium Ashmead, 1898, p. 127. Genotype by original designation.-Isodyctium caryicolum Dyar.

Neocharactus MacGillivray, 1908a, p. 293. Monobasic, genotype-Neocharactus bakeri MacGillivray. New synonymy.

Aphanisus MacGillivray, 1908a, p. 295. Genotype by original designation.-Aphanisus lobatus MacGillivray. New synonymy.

Apericlista Enslin, 1914, p. 265. Genotype by original designation.-Tenthredo albipennis Zaddach. New synonymy.

Characteristics.-Front wings with stub of $2 \mathrm{~A} \& 3 \mathrm{~A}$ curved up at apex, fig. 358. Head with malar space wider than width of tibial spur, often as wide as length of second antennal segment; clypeus little de- 
flected from head; frontal crest rounded off and not jutting forward, fig. 366. Antennae slightly tapering, fourth to ninth segments gradually decreasing in length, third usually longer than fourth. Prepectus absent. Tarsal claws with a medium-sized inner tooth. Males of many species with a peripheral vein as in fig. 180 .

This is undoubtedly the largest Blennocampine genus in the nearctic region. The species whose biology is known feed on Quercus or Hicoria.

\section{Pareophora Konow}

Pareophora Konow, 1886, p. 184. Genotype by subsequent designation of Rohwer, 1911b.-Pareophora luridiventris Konow = nigripes $(\mathrm{Klug})$.

Differs from the above chiefly in having simple tarsal claws. The head of our only species has long eyes with their inner margins parallel, fig. 368 , and fairly short antennae.

\section{Pareophora minuta (MacGillivray) new combination}

Monophadnus minutus MacGillivray, 1908a, p. 291, + .

Pareophora guara MacGillivray, 1923a, p. 54, ๆ. New synonymy.

Pareophora guana MacGillivray, 1923b, p. 29, ․ New synonymy.

To date this is the only recorded nearctic species.

\section{Valco new genus}

Characteristics.-Front wings with stub of $2 \mathrm{~A} \& 3 \mathrm{~A}$ curved up at apex, fig. 358. Prepectus absent. Malar space slightly wider than width of tibial spur. Clypeus projecting at a distinct angle from head, frontal crest also projecting prominently, and with postocellar furrows very deep and short. Antennae short, with third segment longer than fourth, fig. 350. Tarsal claws simple or with a small inner tooth.

Genotype by original designation.-Selandria inrogata Cresson.

This genus and several others, such as Ardis, Pareophora, Eupareophora, and Monardis, each contain only a few species and may need grouping together at a later date. Until more material is studied, however, there seems little choice but to draw the generic limits closely.

\section{Lagonis new genus}

Characteristics.-Front wings with stub of $2 \mathrm{~A} \& 3 \mathrm{~A}$ curved up at apex, fig. 358. Head with wide malar space; eyes small, removed their own length from dorso-caudal margin, fig. 365. Antennae long and slender, third, fourth, and fifth segments subequal, sixth to ninth gradually decreasing in length, fig. 353. Prepectus absent. Scutellum and dorsal portion of mesepisternum with large, round punctures. Tarsal claws with a short inner tooth. 
Genotype by original designation.-Selandria nevadensis Cresson. Known only from the genotype.

Lagonis nevadensis (Cresson) new combination

Selandria nevadensis Cresson, 1880, p. 13, ㅇ․

Paracharactus leucostomus Rohwer, 1912b, p. 230, ㅇ. New synonymy.

The mesothorax of the female varies in color from almost totally rufous to totally black. The species is western in distribution.

\section{Phymatocera Dahlbom}

Phymatocera Dahlbom, 1835, p. 11. Monobasic, genotype--Tenthredo (Allantus) aterrima Klug.

Pectinia Brullé, 1846, p. 664. Genotype by original designation.-Tenthredo (Allantus) aterrima Klug.

Melanoselandria Ashmead, 1899, p. 606. Monobasic, genotype-Melanoselandria zabriskiei Ashmead. New synonymy.

Hypargyricus MacGillivray, 1908a, p. 290. Genotype by original designation.Hypargyricus infuscatus MacGillivray. New synonymy.

Characteristics.-Front wings with stub of $2 \mathrm{~A} \& 3 \mathrm{~A}$ furcate at apex, fig. 359. Malar space narrower than width of tibial spur. Antennae fairly filiform, usually with the fourth segment the longest, often with the apices of the segments considerably wider than the base. Prepectus present as a polished shoulder. Tarsal claws with a small inner tooth. Sheath blade-like, thin.

This genus contains five or six nearctic species which have never been revised. Most of them have the wings heavily and darkly infuscated.

\section{Rhadinoceraea Konow}

Rhadinoceraea Konow, 1886, p. 184. Genotype by subsequent designation of Rohwer, 1911b.-Tenthredo (Allantus) micans Klug.

Differs from the above chiefly in lacking the prepectus. The tarsal claws may lack an inner tooth.

The few nearctic species resemble those of Phymatocera in appearance and also are in need of revision.

\section{Ceratulus MacGillivray}

Ceratulus MacGillivray, 1908c, p. 454. Genotype by original designation-Ceratulus spectabilis MacGillivray.

Characteristics.-Front wing with stub of $2 \mathrm{~A} \& 3 \mathrm{~A}$ straight, fig. 360 . Antennae serrate, fig. 355, the lower, distal corner of the fourth to ninth segments markedly produced into a thumb-like process and the third segment triangular. Malar space about as long as width of tibial spur. Tarsal claws deeply cleft, the two rays subequal in size.

The genotype is the only species placed as yet in the genus, known only from Arizona. 


\section{Subfamily Lycaotinae}

Characteristics.-Prepectus absent. Cervical sclerites pointed and not approximate on meson. Front wings, fig. 192, with $2 r$ present, M parallel with $1 m-c u, 2 \mathrm{~A} \& 3 \mathrm{~A}$ fused for a short distance with $1 \mathrm{~A}$, and the basal abscissa of 2A \& 3A with only a poorly indicated sinuation, fig. 201. Hind wings with typical venation. Mandibles bidentate, fig. 46.

This is a small group which is undoubtedly the present day representative of the ancestor of the Tenthredininae. It contains two genera, separated basically by the radical differences in the female sex. Malaise (1933) has reunited these on the basis that genera are invalid if based only on characters confined to one sex or characters of an adaptive nature. This point of view seems to me untenable when one considers first the arbitrary nature of genera and secondly the difficulty encountered finding other diagnostic characters in many groups.

The characters of the members of this subfamily have been illustrated in detail by Ross (1932a).

\section{KEY TO GENERA}

1. Legs almost entirely black and wings entirely dark brown........ Lycaota Legs light reddish brown and wings almost hyaline............. Lycaotella

\section{Lycaota Konow}

Lycaota Konow, 1903, p. 147. Monobasic, genotype--Selandria sodalis Cresson.

Characteristics.-Hind tarsi shorter than middle tarsi but of same proportions, with a small tarsal claw with an exceedingly small tooth near middle, fig. 109. Tibial spurs of hind tarsi short, one-third length of tibia, fig. 109. Lancet of female saw with lobe-like teeth, fig. 363. Penis valve of male with circular head, fig. 371 .

Contains only one species, the genotype.

\section{Lycaotella Ross}

Lycaotella Ross, 1932a, p. 41. Genotype by original designation.-Selandria spissipes Cresson.

Characteristics.-Similar in general to above. Differs as follows: female with front and middle tibiae and tarsi as for Lycaota, fig. 109, but with hind tibiae, fig. 111, thicker, evenly tapered and with tarsal segments short and stout, fig. 111, the tibial spurs three-fourths length of basitarsus and tarsal claw large with a long, pointed basal tooth giving the claw a chelate appearance. Female saw with serrate ventral margin, fig. 364. Male penis valve with rectangular head, fig. 372 .

Contains only two species. 


\section{Subfamily Tenthredininae}

Characteristics.-Prepectus absent. Front wings, fig. 194, with M parallel with $l m-c u, M$ joining $\mathrm{R}$ considerably basad of separation of $\mathrm{R}_{\mathrm{s}}$, and the sinuation of $2 \mathrm{~A} \& 3 \mathrm{~A}$ almost smoothed out. Hind wings normal, sometimes with a peripheral vein in the male. Cervical sclerites, mandibles, and other characters various.

This subfamily represents one of the peaks of specialization in the Tenthredinidae. Within the subfamily can be traced a straight line development from the more primitive genera to the specialized. Apparently three characters have evolved hand in hand, the eyes, mandible, and cervical sclerites. Representative of the generalized condition is Leucopelmonus-mandibles bidentate, fig. 45, cervical sclerites pointed on meson, as in fig. 155, and eyes small, as in fig. 373. The specialized condition is found in Tenthredo-mandibles quadridentate, fig. 42, cervical sclerites truncate and appressed on meson as in fig. 158, and eyes usually large, fig. 375. Intermediates are furnished by Zaschizonyx and Rhogogaster.

The more primitive group is represented by several genera containing few species. They undoubtedly are remnants of evolutionary development, scattered widely over the holarctic region.

The recorded habits of the adults indicate that they are predaceous, which has probably paralleled the development of the specialized head.

\section{KEY TO GENERA}

1. Front wing with cell DA almost twice length of cell PA, fig. $380 \ldots \ldots \ldots 2$ Front wing with cell DA less than one and one-half length of cell PA,

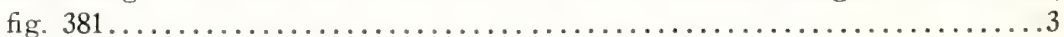

2. Inner margins of eyes straight and almost parallel, fig. $373 \ldots \ldots \ldots$...... Lagium Inner margins of eyes distinctly converging below, fig. $375 \ldots \ldots \ldots \ldots \ldots .5$

3. Sclerotized portion of basal plates forming a wide $\mathrm{V}$ on meson, nearly dividing the segment, fig. $379 \ldots \ldots \ldots \ldots \ldots \ldots \ldots \ldots \ldots \ldots \ldots \ldots$ Zaschisonyx

Sclerotized portion of basal plates either completely contiguous on meson

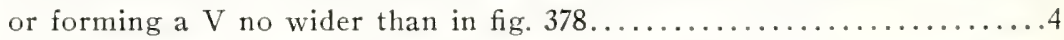

4. Tarsal claws with inner tooth much shorter than outer one and well separated from it, fig. 389 .

Leucopelmonus

Tarsal claws with inner tooth as long as the outer one and appressed to it,

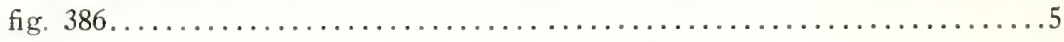

5. Eyes seen from anterior aspect short and widely separated at base as in figs.

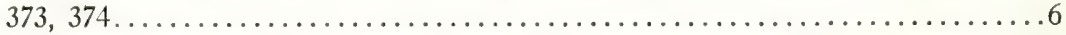

Eyes seen from anterior aspect larger and closer together at base as in

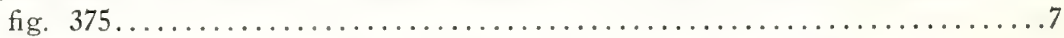

6. Clypeus with anterior margin straight or slightly sinuate, fig.

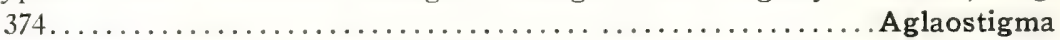

Clypeus with anterior margin definitely emarginate, forming two lateral

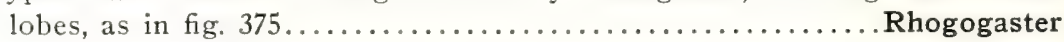

7. Mandibles with two subapical teeth, the upper one sharp and the lower one truncate, fig. 382

Rhogogaster 
Mandibles with more than two subapical teeth or not with the second one

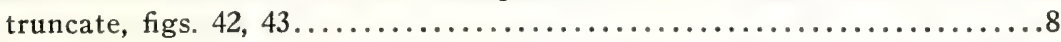

8. Middle coxae small, not overlapping the hind coxae, fig. 384..... Macrophya Middle coxae larger, overlapping base of hind coxae, fig. $383 . \ldots \ldots \ldots \ldots . . .9$

9. Hind femora distinctly swollen in outline, fig. $385 \ldots . . . \ldots \ldots$. Macrophya Hind femora slender, more nearly cylindrical, fig. $388 \ldots . . \ldots \ldots$. Tenthredo

\section{Leucopelmonus MacGillivray}

Leucopelmonus MacGillivray, 1916, p. 83. Monobasic, genotype-Leucopelmonus annulatus MacGillivray = confusus (Norton).

Characteristics.-Mandibles with only two teeth. Tarsal claws with inner tooth smaller than outer and separate from it, fig. 389. Clypeus deeply emarginate. Antennae long, slender, and setaceous. Eyes small and parallel, set far apart. Hind coxae not tremendously developed.

This genus is very closely related to the European Perineura, but differs in wing venation, mandibles, and genitalia.

Only a single species, the genotype, is known. Its synonymy has been given by MacGillivray (1919).

\section{Lagium Konow}

Lagium Konow, 1904, p. 246. Genotype by original designation.-Tenthredo atroviolaceum Norton.

Characteristics.-Mandibles with only two teeth. Tarsal claws with inner tooth same size as outer but not appressed to it. Clypeus shallowly but distinctly emarginate. Antennae long, slender, and setaceous. Eyes small and parallel, set far apart. Hind coxae large, appearing almost subequal in lateral area to mesoepisternum and sternum. The known species have the head, thorax, wings, and almost all the legs black.

There are five described species in the genus, but the status of some is open to question.

\section{Aglaostigma Kirby}

Aglaostigma Kirby, 1882, p. 325. Monobasic, genotype-Aglaostigma eburneiguttatum Kirby.

Laurentia A. Costa, 1890, p. 173. Monobasic, genotype-Laurentia craverii A. Costa $=$ Tenthredo gibbosa Fallén. New synonymy.

Bivena MacGillivray, 1894, p. 328. Genotype by original designation.-Bivena maria MacGillivray = Laurentia semilutea (Norton). New synonymy.

Homoeoneura Ashmead, 1898, p. 313. Genotype by original designation--Pachyprotasis delta Provancher $=$ Laurentia semilutea (Norton). New synonymy.

Neopus Viereck in Smith, 1910, p. 585. Genotype by original designation.Tenthredo 14-punctata Norton. Neze synonymy.

Macrophyopsis Enslin, 1913, p. 128. Genotype by original designation-Macrophya nebulosa Ed. André. New synonymy.

Astochus MacGillivray, 1914a, p. 107. Genotype by original designation.-Astochus fletcheri MacGillivray = Laurentia rubens (Cresson).

Kincaidia MacGillivray, 1914b, p. 137. Genotype by original designation.Tenthredopsis ruficorna MacGillivray. 
Parallomma Malaise, 1933, p. 53. Genotype by original designation-Rhogogaster lichtwardti Konow. New synonymy.

Neurosiobla Conde, 1935, p. 79. Genotype by original designation.-Neurosiobla malaisei Conde. New synonymy.

Characteristics.-Mandibles bidentate. Tarsal claws with inner tooth at least as stout and long as outer one, the two rays closely appressed, fig. 386. Antennae long and setaceous. Clypeus, fig. 374, with anterior margin straight or slightly sinuate. Eyes small, separated below by a distance greater than their height, their inner margins parallel or slightly converging below. Supraclypeal area raised and nodiform, pretentorinae large. Basal plates only partially fused on meson. Posterior coxae only moderately developed.

Seven species are represented in our fauna, involving considerable synonymy.

\section{Zaschizonyx Ashmead}

Zaschizony.x Ashmead, 1898, p. 257. Genotype by original designation.-Hoplocampa montana Cresson.

Opisthoneura Ashmead, 1898, p. 287. Genotype by original designation.-Opisthoneura crevecoeuri Ashmead = Zaschizonyx montana (Cresson).

Characteristics.-Mandibles with a third small tooth below apical pair, fig. 44. Tarsal claws as above. Labrum distinctly and angularly incised at apex. Clypeus deeply, circularly emarginate, the lateral angles sharp. Antennae short and filiform, the third segment considerably longer than the fourth. Head almost evenly convex, without deeply excavated furrows or high ridges. Eyes distant, distinctly converging below. Basal plates deeply excavated posteriorly on meson, fig. 379.

Contains only one species, the genotype.

\section{Rhogogaster Konow}

Rhogogaster Konow, 1884, p. 338. Genotype by subsequent designation of Rohwer, 1911b.-Tenthredo viridis Linnaeus.

Rhogogastera Konow, 1885b, p. 123. Emended name for Rhogogaster.

Characteristics.-Mandibles tridentate, the basal tooth on the right mandible small, on the left mandible large, fig. 382. Tarsal claws with appressed teeth. Antennae fairly long and setaceous. Labrum rounded, truncate, or slightly emarginate. Clypeus deeply emarginate. Supraclypeal area sloping up to form an angular crest between antennal sockets. Head shallow, eyes fairly distant and converging below, varying between the conditions shown in figs. 374, 375. Hind coxae not greatly developed. Basal plates various.

Contains four nearctic species, involving some synonymy.

\section{Tenthredo Linnaeus}

Tenthredo Linnaeus, 1758, p. 343. Genotype by subsequent designation of Latreille, 1810.-Tenthredo scrophulariae Linnaeus. 
Labidia Provancher, 1886, p. 21. Monobasic, genotype-Labidia columbiana Provancher $=$ opimus Cresson.

Tenthredella Rohwer, 1910d, p. 117. Genotype by original designation.-Tenthredo atra Linnaeus.

Zamacrophya Rohwer, 1912b, p. 221. Genotype by original designation.Zamacrophya nigrilabris Rohwer. New synonymy.

Characteristics.-Mandibles quadridentate, fig. 42, the apical tooth large, and simple, the next three more or less grouped together, the base sometimes projecting beneath this to form a tooth-like process. Eyes large and close together, fig. 375. Labrum usually slightly pointed, clypeus emarginate, antennae various. Head with deep furrows between eyes and antennae, and a crest between the antennal sockets. Tarsal claws with appressed teeth. Hind coxae only moderately developed.

This genus is one of the largest in the sawflies. Judging from present indications the genus has developed along many specialized lines in several parts of the world to form a large number of distinct phylogenetic units. Many of these units, however, are indicated only by male genitalia, and most can be separated only imperfectly by external characteristics. Many generic names have been applied to them but it seems best to reduce these to subgenera and thus remove unnecessary obstacles from the generic keys.

I believe that a satisfactory division of the genus into subgenera can be accomplished only after the world fauna is studied. Most of the nearctic species may be referred to one group with only few exceptions, so no effort is made here to subdivide the genus.

\section{Macrophya Dahlbom}

Macrophya Dahlbom, 1835, p. 11. Genotype by subsequent designation of Westwood, 1840.-Tenthredo rusticus auct., nec. Linnaeus= Macrophya montana Scopoli.

Pachyprotasis Hartig, 1837, p. 295. Genotype by subsequent designation of Westwood, 1840.-Tenthredo rapae Linnaeus.

Zalagium Rohwer, 1912b, p. 216. Genotype by original designation.-Zalagium clypeatum Rohwer. New synonymy.

Characteristics.-Mandibles quadridentate, forming more of a regularly decreasing series than in Tenthredo, fig. 43, the apical tooth largest. Eyes large and close together, fig. 375. Head without marked crest between or just above antennal sockets. Labrum usually truncate, clypeus variable. Tarsal claws with appressed teeth. Hind coxae large, appearing from lateral view nearly as large as mesosternum and episternum, and hind femora usually distinctly enlarged towards apex, fig. 385 .

This genus contains a large nearctic fauna which is at present badly in need of revision. 


\section{SUPERFAMILY MEGALODONTOIDEA}

\section{Family Xyelidae}

Diagnostic characters.-Antennae with the third segment elongate with a slender terminal filament composed of 9-25 segments, figs. 86, 87. Praescutum and scutellum distinct, scutum not divided transversely. Middle and hind tibiae with preapical spurs; front tibiae with two apical spurs, the longer one cleft at the apex, as in fig. 114. Front wings with vein $\mathrm{R}_{\mathrm{s}}$ divided, except in some species of $X$ yela.

Five genera are recognized in the nearctic fauna. They are markedly distinct from each other in many characters, including entirely different maxillae, clypei, wings, etc. This is another indication of the archaic nature of the family, for in no other group in the sawflies have the genera become so distinct morphologically.

The nearctic species have been discussed and keyed out by Ross (1932b) with the exception of the genus Xyela which was revised by Rohwer (1913).

\section{KEY TO GENERA}

1. Subcosta 2 either indistinguishable, fig. 392, or joining $\mathrm{R}$ before separation

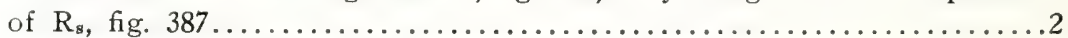

Subcosta 2 joining $R_{1}$ beyond separation of $R_{s}$, fig. $393 \ldots \ldots \ldots \ldots \ldots \ldots$

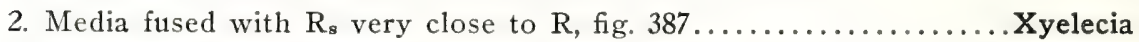

Media either not fused with $R_{\mathbf{B}}$, fig. 172 , or fused with it a considerable dis-

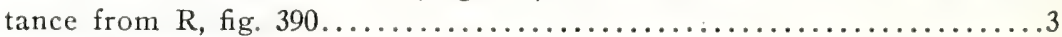

3. Antennae with apical thread as long as, or longer than, third segment, as

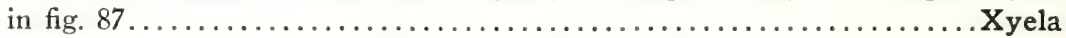

Antennae with apical thread shorter than third segment, fig. 86...Pleroneura

4. Clypeus produced into an irregular pointed apex, fig. 398........ Megaxyela Clypeus produced into a regular, bilobate apex, fig. $395 \ldots . . .$. . Macroxyela

\section{Xyela Dalman}

Pinicola Brebisson, 1818, p. 116, preoccupied. Genotype by subsequent designation of Rohwer, 1911b.-Pinicola julii Brebisson.

Xyela Dalman, 1819, p. 122. Genotype by subsequent designation of Curtis, 1824.Xyela pusilla Dalman.

Tritokreion Schilling, 1825, p. 43. No included species.

Mastigocerus Klug, M. S., in Lepeletier, 1823. Reference unknown, a synonym of Xyela by Lepeletier (Rohwer, 1911).

Neoxyela Curran, 1923, p. 20. Monobasic, genotype--Neoxyela alberta Curran. New synonymy.

Characteristics.-Antennal thread with nine segments, as long as, or longer than, third segment. Maxilla, fig. 61, with lacinia lobe-like; galea with an apical portion demarked by a crease, thus forming a distal "segment" ; palpus with third segment very long, terminal thread mostly membranous and indistinctly divided into several segments. Front wings, 
fig. 392, with subcosta either appressed to radial stem or distinct from it, with $\mathrm{Sc}_{2}$ joining $\mathrm{R}$ before separation of $\mathrm{R}_{\mathrm{s}}$; so-called $\mathrm{R}_{2}$ present or absent, cross-veins variable in number and position. Hind wings with cross-vein $2 r-m$ absent. Female sheath either straight or curving downward, fig. 402.

The species of the genus are in need of a thorough revision based on enough specimens to give an accurate determination of variation in the characters now used in their classification.

The genus Neoxyela was erected by Curran for a species in which vein " $R_{2}$ " was atrophied, fig. 390. A series of specimens has shown that this is a variable character of no particular significance.

\section{Pleroneura Konow}

Pleroneura Konow, 1897a, p. 56. Genotype by subsequent designation of Rohwer, 1911b.-Xyela dahli Hartig.

Pleuroneura Ashmead, 1898, p. 214. Misspelling of Pleroneura.

Manoxyela Ashmead, 1898, p. 214. Genotype by original designation.-Manoxyela californica Ashmead.

Characteristics.-Antennae with terminal filament much shorter than third segment. Mouthparts and venation similar to Xyela. The front wing, fig. 172, is unique among sawflies in having $R_{s}$ and $M$ entirely separate, with three cross-veins between them. Female sheath sabrelike, curving dorsad, fig. 403.

Seven nearctic species have been described in the genus but the status of most of them is not on a fundamental basis.

\section{Xyelecia Ross}

Xyelecia Ross, 1932b, p. 159. Monobasic, genotype--Xyelecia nearctica Ross.

Characteristics.-Antennae very long, fig. 87, antennal thread longer than third segment, composed of 24 or more segments. Maxillae as in fig. 62 ; lacinia knob-like; distagalia lobate and set with short, peg-like setae; palpus with third segment very long, terminal thread fused into a simple, elongate, submembranous segment, clothed with long setae. Front wings, fig. 387, with subcosta distinct and short, $\mathrm{Sc}_{2}$ joining $\mathrm{R}$ before separation of $\mathrm{R}_{\mathrm{s}}, \mathrm{M}$ joining $\mathrm{R}_{\mathrm{s}}$ close to radial stem. Hind wings with $2 r-m$ atrophied. Female sheath very short and broad, fig. 391.

Contains only one species, the genotype.

\section{Megaxyela Ashmead}

Megaxyela Ashmead, 1898, p. 214. Genotype by original designation.-Xyela major Cresson.

Odontophyes Konow, 1899a, p. 42. Monobasic, genotype--Pleroneura aviingrata Dyar.

Paraxyela MacGillivray, 1912, p. 294. Genotype by original designation.-Xyela tricolor Cresson. 
Characteristics.-Clypeus with a large, median, triangular tooth, fig. 398. Antennae with third segment three times as long as terminal filament, which has eight or nine segments. Maxillae as in fig. 65; lacinia spatulate; mesal lobe of galea short and broad; palpi with four segments, the last two subequal, the fourth sclerotized, with only weak setae, the apex membranous. Labial palpus with four segments. Front wings with subcosta distinct and long, $\mathrm{Sc}_{2}$ joining $\mathrm{R}$, beyond fork of $\mathrm{R}_{\mathrm{s}}$. Hind wings with $2 r-m$ present, fig. 176. Tarsal claws deeply cleft, the two rays subparallel.

Contains about five species.

\section{Macroxyela Kirby}

Macroxyela Kirby, 1882, p. 351. Genotype by original designation.-Xyela ferruginea Say.

Protoxyela MacGillivray, 1912, p. 294. Genotype by original designation.-Xyela aenea Norton.

Differs from the above as follows: clypeus, fig. 395, with two anterior lobes separated by a distinct emargination; labial palpi three segmented.

At present three species are placed in this genus, but the known differences between them are unsatisfactory and the species limits need further study.

\section{Family Pamphilinde}

Characteristics.-Antennae long, slender and multi-segmented, fig. 88. Head capsule, figs. 4, 5, with clypeus turned under and fused on venter with postgenae, labrum asymmetrical and carried on venter. Abdomen flattened, with sharp lateral margins. Remainder of body similar to Xyelidae. Wings with $\mathrm{R}_{2}$ always absent.

This family is a close relative of the European family Megalodontidae, but differs in possessing a presternal bridge, vein Sc in the front wing and in lacking processes on the antennae of the male.

The nearctic species form a very uniform group. Very few characters have been discovered upon which to divide the group into definite segregates. The key characters listed below represent almost all those which seem to be definite and constant. These include the relative size of the tarsal claws, presence or absence of certain preapical spines on the tibiae, presence or absence of vein $\mathrm{Sc}_{1}$ in the front wing and the shape of the seventh abdominal sternite in the female. Other characters, such as the post-genal ridge, relative length of the third antennal segment, and the junction of $M$ with $R$ or $R_{s}$ in the front wing, have been used to split off genera, but too many intermediate conditions arise for them to be employed for generic diagnosis. This arrangement of the genera is the same as that proposed by Rohwer in 1910b. 


\section{KEY TO GENERA}

1. Anterior tibiae with a preapical spur, fig. 399................. Acantholyda Anterior tibiae without a preapical spur...........................

2. Front wing with $\mathrm{Sc}_{1}$ entirely or partially atrophied, figs. 396, 400. Neurotoma

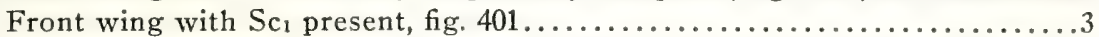

3. Tarsal claws with a small tooth some distance below apex, fig. 404. Cephalcia Tarsal claws with a large tooth near apex, which consequently appears

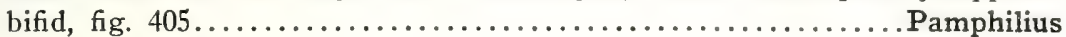

\section{Acantholyda A. Costa}

Acantholyda A. Costa, 1894, p. 232. Genotype by subsequent designation of Rohwer, 1910b.-Tenthredo erythrocephala Linnaeus.

Itycorsia Konow, $1897 \mathrm{~d}$, p. 13. Genotype by subsequent designation of Rohwer, 1910b.-Tenthredo hieroglyphica Christ.

Characteristics.-Anterior tibiae with a preapical spur, fig. 399. Front wing with $\mathrm{Sc}_{2}$ present. Tarsal claws with a small subapical tooth as in fig. 404. Female with seventh abdominal sternite divided on meson by a sub-triangular depression, fig. 409.

Contains a large number of nearctic species which have not been treated comprehensively. The group Itycorsia has been segregated on the basis of having a postgenal carina, but the character is not constant enough for accurate use.

\section{Cephalcia Panzer}

Cephalcia Panzer, 1805, Heft 86, pl. 9. Genotype by subsequent designation of Rohwer, 1911c.-Cephalcia arvensis Panzer $=$ Cephalcia signata (Fabricius).

Cephaleia Jurine, 1807, p. 68. Genotype by subsequent designation of Rohwer, 1911c.-Cephaleia arvensis Panzer $=$ Cephalcia signata (Fabricius).

Caenolyda Konow, 1897d, p. 15. Genotype by subsequent designation of Rohwer, 1910b.-Tenthredo reticulata Linnaeus.

Liolyda Ashmead, 1898, p. 209. Genotype by original designation.-Lyda frontalis Westwood.

Differs from Acantholyda in lacking the preapical spur on the front tibiae. Several nearctic species belong in the genus.

\section{Neurotoma Konow}

Neurotoma Konow, 1897d, p. 18. Genotype by subsequent designation of Rohwer, 1910b.-Tenthredo faviventris Linnaeus.

Gongylocorsia Konow, 1897d, p. 19. Monobasic, genotype-_Lyda mandibularis Zaddach.

Characteristics.-Anterior tibiae without preapical spur. Front wings with $\mathrm{Sc}_{1}$ partially or entirely atrophied, figs. 396, 400. Tarsal claws with a large inner tooth near apex. Female with seventh abdominal sternite incised on meson as in fig. 409.

Contains only two described nearctic species. 


\section{Pamphilius Latreille}

Pamphilius Latreille, 1802, p. 303. Monobasic, genotype-Centhredo sylvatica Linnaeus.

Lyda Fabricius, 1804, p. 43. Genotype by subsequent designation of Curtis, 1831.-

Tenthredo sylvatica Linnaeus.

Anoplolyda A. Costa, 1894, p. 233. Genotype by subsequent designation of Rohwer, 1910b.-Lyda alternans A. Costa.

Kelidoptera Konow, 1897d, p. 20. Monobasic, genotype-Lyda maculipennis Stein. Bactroceros Konow, 1897d, p. 21. Genotype by subsequent designation of Rohwer, 1910b.-Tenthredo vafer Linnaeus.

Characteristics.-Anterior tibiae without preapical spur. Front wings with $\mathrm{Sc}_{1}$ present. Tarsal claws with a large, inner tooth near apex, which appears cleft, fig. 405. Female with seventh abdominal sternite not incised but convex and slightly produced on meson, fig. 408.

A large number of species are contained in this genus. They have at various times been divided into smaller genera on the basis of $M$ in the front wing joining $R$ or $R_{s}$ and whether or not the third antennal segment was subequal to or almost twice as long as the fourth. A study of many species shows that both of these characters intergrade from one extreme to the other, hence they cannot be used for definite dividing points.

\section{SUPERFAMILY SIRICOIDEA}

\section{Family Syntectidae}

Diagnostic characters.-Antennae slender and setaceous, with about 16 segments, fig. 89. Tibiae without preapical spurs, front tibiae with only one apical spur which is pectinate on its inner margin, fig. 118. Mesonotum without a transverse suture, fig. 122.

This family contains only one described genus, Syntexis Rohwer, (1915c), with its sole species and genotype S. libocedrii Rohwer. It was placed by its describer in the family Cephidae, but differs from this family in having a genaponta instead of a maxaponta, in having cenchri and in lacking the distinct constriction between the first and second abdominal segments. Syntexis is most closely related to the Xiphydriidae, the two having similar antennae, wing venation, and type of head. Syntexis differs from the Xiphydriidae, however, in lacking the transverse suture of the mesoscutum, and in having a wide trench between the mesoand metanotum, fig. 122. On the basis of these characters Benson (1935b) erected a new family Syntexidae. According to the derivation of the name, however, the stem is Syntect-, and therefore the name should be Syntectidae.

The most distinctive characters of the genus are the incisions of the anterior margin of the mesoepisterna, fig. 130, and the curious formation 
of the alaglossa of the labium, figs. 78, 79. These two conditions are found nowhere else in the sawflies and form the chief basis for considering the genus a separate family.

\section{FAMily Xiphydritide}

Diagnostic characters. - Antennae slender and setaceous, having about 20 segments, fig. 90. Tibiae without preapical spurs, front tibiae with only one apical spur, which is cleft at the apex, fig. 117. Mesoscutum with a transverse suture, fig. 123 ; mesosnotum and metanotum approximate, with none of the mesopostnotum visible. Head above the eyes rounded and dome-shaped, fig. 22.

The nearctic species represent only the typical genus.

\section{Xiphydria Latreille}

Xiphydria Latreille, 1802, p. 304. Monobasic, genotype-Ichneumon camelus Linnaeus.

Hybonotus Klug, 1803, p. 8. Genotype by subsequent designation of Rohwer, 1911b. -Ichneumon camelus Linnaeus.

Xiphiura Fallén, 1813, p. 11. No species included.

Xiphidion Provancher, 1875, p. 374. Monobasic, genotype--Xiphidion canadense Provancher $=$ Xiphydria mellipes Harris.

Konowia Brauns, 1884, p. 220. Monobasic, genotype--Konowia megapolitana Brauns. New synonymy.

Pseudoxiphydria Enslin, 1911, p. 177. Genotype by original designation,-Pseudoxiphydria betulae Enslin. New synonymy.

This genus contains several nearctic species which have been treated by Rohwer (1918a). Except for the wings, all the species have such a similar morphological pattern that it accomplishes nothing to divide them into more than one group. The venation of the front wing is somewhat variable, especially the proximity at their base of veins $1 \mathrm{~A}$ and $2 \mathrm{~A} \&$ $3 \mathrm{~A}$ and the completeness of cross-vein $3 r-m$, which may be complete, reduced to a stub, or absent. These are the characters upon which were based the genera Konowia and Pseudoxiphydria.

\section{FAmily Siricidae}

Diagnostic characters.-Antennae filiform, with about 15 segments, fig. 91, frequently bilaterally compressed. Tibiae without preapical spurs, front tibiae with only one apical spur which is cleft at the apex, fig. 116. Mesonotum with the praescutum indistinct, its sutures represented only by faint traces; the scutum with two diagonal furrows running from the lateral margin to the anterior margin of the scutellum, fig. 127.

Bradley (1913) has revised and keyed out the North American species and genera of this family. 


\section{KEY TO GENERA}

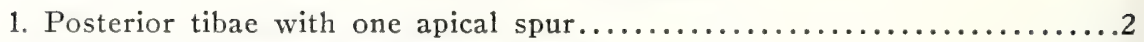

Posterior tibiae with two apical spurs.............................

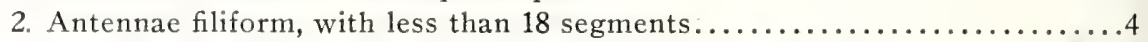

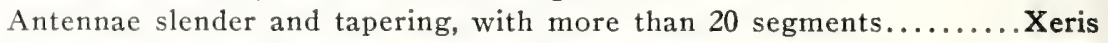

3. Head with a large white spot behind eye.................... Urocerus

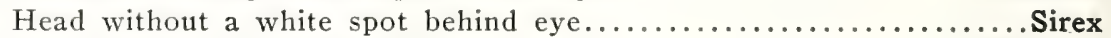

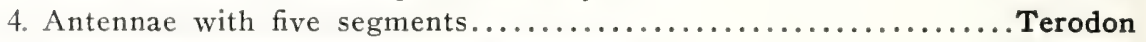

Antennae with sixteen or more segments................... Tremex

\section{Subfamily Siricinae}

Characterized chiefly by the labial palpi having three segments, fig. 84 ; presence of cerci; antennae with nineteen or more segments; and small cell $2 \mathrm{R}_{1}$.

\section{Sirex Linnaeus}

Sirex Linnaeus, 1761 , p. 396. Genotype by subsequent designation of Curtis, 1829.Sirex juvencus Linnaeus.

Paururus Konow, 1896a, p. 41. Genotype by subsequent designation of Rohwer, 1911b.-Sirex juvencus Linnaeus.

Characteristics.-Head immaculate. Cornus of female more or less triangular, not constricted at base and widened at apex. Posterior tibiae with two apical spurs.

Contains seven or eight species.

\section{Urocerus Geoffroy}

Urocerus Geoffroy, 1762, p. 264. Monobasic, genotype-Ichneumon gigas Linnaeus.

Differs from Sirex in having white marks behind the eyes, and in having a clavate cornus, which is constricted at the base.

There are four recognized species.

\section{Xeris A. Costa}

Xeris A. Costa, 1894, p. 295. Monobasic, genotype-Ichneumon spectrum Linnaeus.

Differs from Urocerus in having the hind tibiae with only one apical spur and the ovipositor as long as the body.

Contains three species.

\section{Subfamily Tremicinae}

Characterized as follows: labial palpi with two segments ; cerci absent ; antennae with 17 segments or less; front wings with a long cell $2 R_{1}$.

The genus Terodon is known only from Cuba and is included in the key for convenience. Our only nearctic genus is Tremex.

\section{Tremex Jurine}

Tremex Jurine, 1807 , p. 80 . Genotype by subsequent designation of Latreille, 1810.Sirex fuscicornis Fabr.

Xyloterus Hartig, 1837, p. 385, preoccupied. Monobasic, genotype-Sirex fuscicornis Fabricius. 
Xyloecermatium L. Heyden, 1868, p. 227. New name for Xyloterus.

Characteristics as for subfamily. Contains only one nearctic species, columba (Linnaeus).

\section{Family Orussidae}

Diagnostic characters.-Antennae with 10 segments, setaceous in the male, fusiform in the female, fig. 92, situated on the ventral aspect of the head, fig. 24. Tibiae without preapical spurs, front tibiae with two apical spurs, one very short, the other longer and cleft at the apex, fig. 115. Mesonotum with the praescutum more or less indistinct, the lateral sutures reaching the transverse suture of the scutum. Both wings with most of the venation represented only by pigmented bands, fig. 177 .

\section{KEY TO GENERA}

1. Face with two sharp, high carinae, fig. $410 \ldots \ldots \ldots \ldots \ldots \ldots$. Ophrynopus

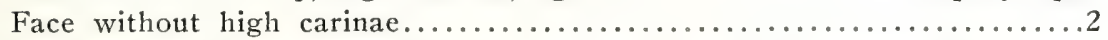

2. Front wing with $2 r$ joining stigma near apex, which is somewhat thickened,

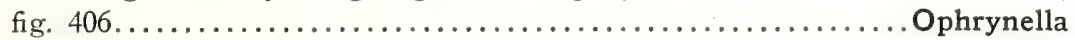

Front wing with $2 r$ joining stigma at middle, the apex of stigma gradually tapering to apex, fig. $407 \ldots \ldots \ldots \ldots \ldots \ldots \ldots \ldots \ldots$. O. . . . . . . . . . . .

\section{Orussus Latreille}

Orussus Latreille, 1796, p. 111. Genotype by subsequent designation of Latreille, 1810.-Orussus coronatus Fabricius $=O$. abietinus Scopoli.

Oryssus Fabricius, 1798, p. 218. Emended name for Orussus Latreille.

Characteristics.-Head with a crown of three pairs of distinct tubercles on dorsum, without carinae on face. Front wings with $M$ joining $\mathrm{R}_{\mathrm{s}}$ some distance from $\mathrm{R}$; stigma tapering at apex, $2 r$ joining it near middle, fig. 407. Hind femora more slender than in fig. 411.

Contains several nearctic species which have been treated by Rohwer (1912a).

\section{Ophrynella new genus}

Characteristics.-Head with a dorsal crown of five distinct pairs of tubercules forming a wide ring around anterior ocellus, as in fig. 23; front reticulate with close, sharp-walled pits but without carinae; postgenae with a distinct high crassa from mandible to dorsum of head. Maxillary palpi with five segments, the two basal ones short, the three apical ones long and slender. Front wings with stigma long, $2 r$ joining it near apex, the apex slightly enlarged, fig. 406 ; base of $R_{s}$ subequal to base of M. Hind femora swollen, fig. 411, the adjoining tibiae and tarsi short and stocky.

Genotype.-Oryssus nigricans Cameron (original designation and monobasic).

Benson (1936a) treats this species as a member of the genus Ophrynopus, but all described species of that genus have two high prominent 
carinae with an anterior joining one on the front. The species nigricans is undoubtedly closely allied to Ophrynopus on the basis of wing venation but seems to form a distinct unit from it.

The genotype is the only species yet placed in the genus. It has recently been captured in Texas.

\section{Ophrynopus Konow}

Ophrynopus Konow, 1897c, p. 605. Genotype by subsequent designation of Rohwer, 1911b.-Ophrynopus andrei Konow.

Stirocorsia Konow, 1897b, p. 372. Monobasic, genotype-Stirocorsia kohli Konow.

Differs from the above in having a series of high carinae on the front as in fig. 410.

To date only a single unidentified male of this genus has been recorded from the nearctic region, to wit, Arizona.

\section{SUPERFAMILY CEPHOIDEA}

\section{Family Cephidae}

(By Donald T. Ries, Ithaca, N. Y.)

Diagnostic characters.-Antennae with 20-30 segments, filiform, slightly fusiform, or clavate. Middle and hind tibiae frequently with preapical spurs; front tibiae with only one apical spur which is cleft at the apex, the inner tooth small and the outer tooth large, fig. 119. Cenchri absent, fig. 121. A distinct constriction between the first and second abdominal segments, fig. 143.

Detailed genitalic studies of the nearctic species together with a large number of the genotypes of many of the palearctic genera has shown that a large number of the genera must be grouped together in order to get a clear picture of the phylogeny of the Cephidae. This will result in some changes in the classification of the family as treated by Benson, 1935b. I have been unable to study sufficient species to make a complete classification of the world genera at the present moment but enough to make it possible to ascertain the limits of genera actually involved by nearctic species. For this reason only the generic names which involve nearctic species have been treated in this diagnosis.

In a revision of the nearctic Cephidae now nearing completion these phylogenetic groups will be taken up in greater detail.

\section{KEY TO GENERA}

1. Hind tibiae with preapical spurs, fig. $110 \ldots \ldots \ldots \ldots \ldots \ldots \ldots \ldots \ldots \ldots \ldots . . . \ldots \ldots$

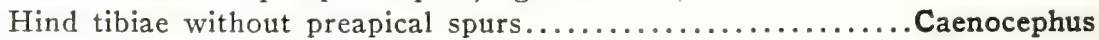
2. Tarsal claws with base wide and lobular below junction of teeth,

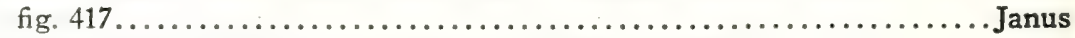
Tarsal claws with base tapering and slender, fig. $420 \ldots \ldots \ldots \ldots \ldots \ldots . . . . . .3$ 
3. Flagellum constricted at base for less than one-fourth its length and with marked shortening of the segments occurring beyond the third,

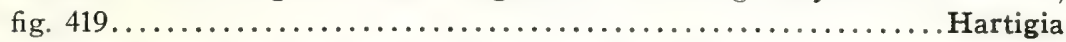

Flagellum constricted for half its length and with marked shortening of the segments not occurring until the fifth or sixth, figs. $416,418 \ldots \ldots$... Cephus

\section{Caenocephus Konow}

Caenocephus Konow, 1896b, p. 151. Monobasic, genotype-Caenocephus jakozvleffi Konow.

Characteristics.--Hind tibiae without preapical spurs. Antennae with third segment longer than fourth. Left mandible with two triangular subequal teeth of similar shape. Hind wings with $3 r-m$ absent. Tarsal claws with two stout, subequal apical teeth. Male sternites simple.

Contains only two described nearctic species from the Rocky Mountain region. These represent the two sexes of only one species.

\section{Cephus Latreille}

This genus embraces a large number of species which differ radically in the genitalia and ornamentation of the seventh to ninth abdominal sternites in the male. All other characters, however, group these species into a single phylogenetic unit, characterized by the shape of the tarsal claws and the antennae.

On the basis of the males it is possible to group the nearctic species into two subgenera as follows:

Eighth sternite at most with row of scale-like setae along apex, fig. 423 Cephus Seventh and eighth sternites with distinct cavities filled with long, needle-like

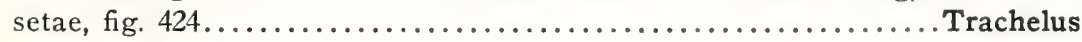

\section{Subgenus Cephus Latreille}

Astatus Jurine, 1801, p. 163. Monobasic, genotype--Sirex pygmaeus Linnaeus. Name set aside by International Zoological Congress, 1935.

Cephus Latreille, 1802, p. 303. Genotype by subsequent designation of Latreille, 1810.-Sirex pygmaeus Linnaeus.

Calameuta Konow, 1896b, p. 159. Genotype by subsequent designation of Rohwer,

1911b.-Cephus filiformis Eversmann. New synonymy.

Characteristics.-Hind tibiae with one or two preapical spurs. Hind wings with $3 r-m$ present. Tarsal claws various, figs. 421, 422. Antennae slightly clavate beyond tenth segment.

Contains three species in the nearctic region, including the western grain-stem sawfly, $C$. cinctus Norton, and the European wheat-stem sawfly, C. pygmaeus (Linnaeus).

\section{Subgenus Trachelus Fabricius}

Astatus Panzer, 1801, p. 83, preoccupied. Genotype by subsequent designation of Rohwer, 1911b.-Sirex trogylodyta Fabricius. 
Trachelus Jurine, 1807, p. 70. Monobasic, genotype.-Sirex tabidus Fabricius. Cepha Billberg, 1820, p. 98. Monobasic, genotype.-Sirex tabida Fabricius. Eumetabolus Shulz, 1906, p. 211. New name for Astatus Panzer.

Trachelastatus Morice and Durrant, 1915, p. 383. New name for Cepha Billberg.

Our fauna contains only the introduced black wheat-stem sawfly, C. tabidus (Fabricius).

\section{Janus Stephens}

Janus Stephens, 1835, p. 107. Genotype by subsequent designation of Westwood, 1840.-Janus connectens Stephens = Janus luteipes (Lepeletier).

Phylloecus Newman, 1838, p. 485. Monobasic, genotype-Phylloecus faunus Newman.

Ephippionotus O. Costa, 1860, p. 10. Monobasic, genotype.-Ephippionotus luteiventris O. Costa $=$ Janus compressus (Fabricius).

Characteristics.-Antennae with flagellum narrow at base (first three segments), remainder uniformly wider with the exception of a slight tapering towards apex, fig. 419. Left mandible bidentate, the upper tooth shouldered at base, fig. 415. Tarsal claws with extremely wide base which appears as a broad basal tooth; the two apical teeth long, stout, and curved at a distinct angle to the base, fig. 417. Male abdomen without ornamentation on the sternites. Some species (Janus abbreviatus and male of $J$. bimaculatus) exhibit an interesting condition of a partial atrophy of cross-vein $1 r$.

Contains four nearctic species, two of which have been reared from willow, poplar, and currant.

\section{Hartigia Schiödte}

Hartigia Schiödte, 1838, p. 332. Genotype by subsequent designation of Boie, 1855.Astatus satyrus Panzer = Hartigia nigra (Harris).

Cerobactrus O. Costa, 1859, p. 9. Monobasic, genotype--Macrocephus ulmariae Schlectendal = Hartigia linearis (Schrank).

Cephosoma Gradl, 1881, p. 294. Monobasic, genotype-Cephosoma syringae Gradl = Hartigia nigra (Harris).

Copiosoma Kirby, 1882, p. 364. Misspelling for Cephosoma Gradl.

Adirus Konow, 1899b, p. 74. Monobasic, genotype-Cephus trimaculatus Say.

Paradirus Dovnar-Zapolskij, 1931, p. 39. Monobasic, genotype--Paradirus algiricus Dovnar-Zapolskij.

Characteristics.-Antennae with flagellum narrow at base (first three segments), remainder fairly stout, slightly and evenly fusiform, fig. 419. Left mandible bidentate, the upper tooth with a wide base and a small nipple-like apex, fig. 414. Tarsal claws slender, with large inner tooth, both teeth curving considerably from axis of claw, fig. 420. Male abdominal sternites simple.

Contains three described species from the nearctic region of which H. cressonii (Kirby) mines in the stems of raspberries, blackberries, and roses, and $H$. trimaculatus (Say) bores in blackberries and roses. 


\section{BIBLIOGRAPHY}

AshmeAd, W. H.

1898. Classification of the horntails and sawflies, or the suborder Phytophaga. Canadian Entomologist, 30: 141-145, 177-183, 205-213, 225-232, 249-257, 281-287, 305-316. June-December.

1890. On the Hymenoptera of Colorado. Bulletin, Colorado Biological Association, 1: 1-47.

Beauvois, Palisot DE.

1805-1821. Insectes recueillis en Afrique et en Amérique. Paris, Levrault. 16 and 276 pp., 90 col. pls.

Benson, Robert B.

1935a. On the genera of the Orussidae. Occasional papers of the Rhodesian Museum, 4: 1-10, 10 figs. April 30.

1935b. On the genera of the Cephidae, and the erection of a new family Syntexidae (Hymenoptera, Symphyta). Annals and Magazine of Natural History, 16: 534-553, 20 figs. November.

1936. Two new European sawfly genera of the subfamily Fenusinae (Hymenoptera, Tenthredinidae). Annals and Magazine of Natural History, 18: 620-626, 9 figs. December.

Billberg, G. J.

1820. Enumeratio Insectorum in Museo Billberg. Gadel, Stockholm, 138 pp. BiRd, R. D.

1926. The external morphology of the adult of Hoplocampa halcyon Nort. (Hymen., Tenth.). Annals of the Entomological Society of America, 19: 268-279, 2 pls. September.

Bischоғғ, $\mathrm{H}$.

1926. Ueber die systematische Stellung der Orussidae. Internationaler Entomologen-Kongress, Zurich, 2: 134-144. July.

Bore, F.

1855. Beobachtungen und Bemerkungen. Stettinger Entomologische Zeitung, 16: $48-51$.

Boulonge, Henry.

1924. Recherches sur l'appareil copulateur des Hyménoptères et spécialement des Chalastogastres. Mémoires et Travaux des Facultés Catholiques de Lille, 28: 444 pp., 3 pls.

Bradley, J. Chester.

1913. The Siricidae of North America. Journal of Entomology and Zoology, 5: $1-35,5$ pls.

1919. The synonymy and types of certain genera of Hymenoptera, especially of those discussed by the Rev. F. D. Morice and Mr. Jno. Hartley Durrant in connection with the long-forgotten "Erlangen List" of Panzer and Jurine. Transactions of the Entomological Society of London, 2: 50-75. August 15.

Brauns, S.

1884. Eine neue Xiphydrinengattung. Wiener Entomologische Zeitung, 3: 220-222. August 20.

Brebisson, L. A. DE.

1818. Sur un nouveau genre d'Insecte de l'ordre des Hyménoptères. Nouveau Bulletin de la Société Philomathique pour 1818: 116-117.

Brulle, Auguste.

1846. Histoire naturelle des insectes. Hyménoptères. (Suites à Buffon.) Paris, Roret, Bd. 4. 689 pp. 
Burke, H. E.

Cameron, Peter.

1917. Oryssus is parasitic. Proceedings of the Entomological Society of Washington, 19: 87-89.

1882. Sessiliventria. Biologia Centrali-Americana, 1: 1-70, pls. 1-4.

Conde, O.

1935. Oryssoidea et Tenthredinoidea collecta in Ussuri et Sachalin ab N. Delle. Notulae Entomologicae, 14: 67-87, 6 figs. December 1.

\section{Costa, A}

1882. Rapporto preliminare e sommario sulla ricerche zoologiche fatte in Sardegna. Rendiconti dell' Accademia di Scienze fisiche e matematiche di Napoli, ser. 1, 21: 189-201.

1890. Miscellanea entomologica; Memoria terza. Rendiconti dell' Accademia di Scienze fisiche e matematiche di Napoli, ser. 2, 4: 171-174.

1894. Prospetto degli imenotteri italiani da servire di prodroma di imenotterologia italiana per Achille Costa. Naples.

Costa, O. G.

1859. Fauna del Regno di Napoli, C. Imenotteri. Dai Torchi del Tramate, Naples, incomplete volume.

Crampton, G. C.

1919. The genitalia and terminal abdominal structures of males, and the terminal abdominal structures of the larvae of "Chalastogastrous" Hymenoptera. Proceedings of the Entomological Society of Washington, 21: 129-155, 4 pls. June.

1923. A phylogenetic comparison of the maxillae throughout the orders of insects. Journal of the New York Entomological Society, 31: 77-107, 6 pls.

1926. A comparison of the neck and prothoracic sclerites through the orders of insects from the standpoint of phylogeny. Transactions of the American Entomological Society, 52: 199-248, 8 pls. October 5.

Cresson, E. T.

1865. Catalogue of Hymenoptera in the collection of the Entomological Society of Philadelphia, from Colorado Territory. Proceedings of the Entomological Society of Philadelphia, 4: 242-313.

1880. Descriptions of new North American Hymenoptera in the collection of the American Entomological Society. Transactions of the American Entomological Society, 8: 1-52.

Curran, C. H.

1923. A new genus and species of Xyelidae (Tenthredinoidea, Hymenoptera) from Western Canada. Canadian Entomologist, 55: 20. January.

Curtis, John.

1823-1840. British entomology; being illustrations and descriptions of the genera of insects found in Great Britain and Ireland. E. Ellis and Co., London, 3: species 257-343, each with plate and text, each plate bearing date of publication.

Daнlвom, A. G.

1835. Conspectus Tenthredinidum, Siricidum, Oryssinorum Scandinaviae, Hymenopterorum familiae. Gyldendal, Hafniae, 16 pp.

Dalla Torre, C. G.

1894. Catalogus Hymenopterorum; vol. I, Tenthredinidae incl. Uroceridae (Phyllophaga \& Xylophaga). Engelmann, Lipsiae, 459 pp. 
Dalman, J. W.

1819. Nagra nya Insekt-genera, beskrifna. Svensk Vetenskap Akademien Handlingar, 40: 117-127, $1 \mathrm{pl}$.

DovNAR-ZAPOLSKY, D. P.

1931. Cephiden-Studien. Annuaire du Musée Zoologique, Leningrad, 32: 37-49.

Dyar, Harrison G.

1893. Notes on two species of Tenthredinidae, from Yosemite, Cal. Canadian Entomologist, 25: 195-196. August.

ENSLIN, E.

1911. Pseudoxiphydria, ein neues Siriciden-Genus aus Deutschlands (Hym.).

Deutsche Entomologische Zeitschrift, Jahrgang 1911: 177-179. March 11.

1912-18. Die Tenthredinoidea Mitteleuropas. Deutsche Entomologische Zeitschrift, Beiheft, Jahrgang 1912-1917. 790 pp., 123 figs.

\section{FABRicius, J. C.}

1798. Supplementum Entomologiae Systematicae. Proft et Storch, Hafniae, $572 \mathrm{pp}$.

1804. Systema Piezatorum. Reichard, Brunsvigae, 440 pp.

FALLÉN, C. F.

1813. Specimen novam Hymenoptera disponendi methodum exhibens. Berling, Lund, 42 pp., 1 pl.

1829. Monographia Tenthredinidum Sueciae. Berling, Lund, 48 pp.

Forbes, S. A.

1885. Fourteenth Report of the State Entomologist on the Noxious and Beneficial Insects of the State of Illinois. 136 pp., 12 pls.

Fourcroy, A. F.

1785. Entomologia Parisiensis. Paris, 544 pp.

Geofrroy, E. L.

1762. Histoire abrégée des Insectes qui se trouvent aux environs de Paris. Durand, Paris, 2: 690 pp., 12 pls.

Gistel, J. N.

1848. Naturgeschichte des Thierreichs für höhere Schulen. Hoffmann, Stuttgart, 16 u. 216 u. 4 pp., 32 pls. (Insects pp. 110-155, pls. 12-17).

GRADL, VON H.

1881. Aus der Fauna des Egerlandes. Entomologische Nachrichten, 7: 294-309.

October.

Hartig, Theodor.

1837. Die familien der Blattwespen und Holzwespen. S. J. Joseephy, Berlin, 416 pp., 8 pls.

HEYDEN, L.

1868. Ueber das sither unbekannte Männchen von Xyloterus fuscicornis $\mathrm{F}$. Berliner Entomologische Zeitschrift, 12: 227-230.

Imнof, Ludwig, et Labram, J. D.

1836. Insecten der Schweiz. Verfasser, Basel, 1: 60 pp., 60 pls.

JURINE, LouIS.

1801. Nachricht von einem neuen entomologischen Werke, des Hrn. Prof.

Jurine in Geneva. Intelligenzblatt der Litteratur-Zeitung, Erlangen, 1: 161-164. May 30. Written by Panzer, accredited to Jurine; see Morice and Durrant, 1915. 
1807. Nouvelle méthode de classer les Hyménoptères et les Diptères. Paschoud, Geneva, 319 pp., 14 pls.

Kirby, W. F.

1882. List of Hymenoptera in the British Museum. Taylor and Francis, London, 450 pp., 16 pls.

Klug, J. C. F.

1803. Monographia Siricum Germaniae, atque generum illis adnumeratorum. Berolini, Schueppel, 12, 64 \& 7 pp., 8 pls.

1818. Die Blattwespen nach ihren Gattungen und Arten zusammengestellt. Konow, F. W. Magazin, Gesselschaft naturforschender freunde, Berlin, 8: 273-307.

1884. Bemurkungen über Blattwespen. Deutsche Entomologische Zeitschrift, 28: 305-354.

1885a. Ueber die Blattwespen-Gattungen Strongylogaster Dahlb. und Selandria Klg. Wiener Entomologische Zeitung, 4: 19-26. January 15.

1885b. Bemerkungen über einige Blattwespengattungen. Wiener Entomologische Zeitung, 4: 117-124. May 1.

1885c. Ueber Blattwespen. Wiener Entomologische Zeitung, 4: 295-301. December 10.

1886. Die europaischen Blennocampen. Wiener Entomologische Zeitung, 5: 183-188, 211-218, 243-246, 267-271. June-October.

1890. Tenthredinidae Europae. Deutsche Entomologische Zeitschrift, J. 1890. 225-255.

1896a. Verschiedenes aus der Hymenopteren-Gruppe der Tenthrediniden. Wiener Entomologische Zeitung, 15: 41-59. February 29.

1896b. Ueber Blattwespen. Wiener Entomologische Zeitung, 15: 150-179. May 15.

1896c. Neue und einige bisher verkannte Arten aus der familie der Tenthrediniden. Entomologische Nachrichten, 22: 308-319. October.

1897a. Ueber die Xyelini: Entomologische Nachrichten, 23: 55-58. February.

1897b. Zwei neue Siriciden und einige palaarktische Tenthrediniden. Entomologische Nachrichten, 23: 372-376. December.

1897c. Systematische und kritische Bearbeitung der Siriciden-Tribus Oryssini. Természetrajzi Füzetek, Kiadja a Magyar nemzeti Múzeum, Budapesth, 20: 602-610.

1897d. Systematische und kritische Bearbeitung der Blattwespen-Tribus Lydini. Annalen des K. K. Naturhistorischen Hofmuseums, 12: 1-32.

1899a. Ueber einige neue Chalastogastra. Wiener Entomologische Zeitung, 18: 41-46. March 31.

1899b. Einige neue Chalastogastra-Gattungen und Arten. Entomologische Nachrichten, 25: 73-80. March.

1903. Neue Tenthrediniden. Zeitschrift für Systematische Hymenopterologie und Dipterologie, 3: 145-153.

1904. Ueber einige exotische Tenthrediniden. Zeitschrift für Systematische Hymenopterologie und Dipterologie, 4: 241-248.

1905a. Hymenoptera, Fam. Lydidae. Genera Insectorum, 27: 27 pp., 1 pl. April 10.

1905b. Hymenoptera, Fam. Siricidae. Genera Insectorum, 28: 14 pp., 1 pl. April 15.

1905c. Hymenoptera, Fam. Tenthredinidae. Genera Insectorum, 29: 176 pp., 3 pls. August 14. 
1906. Neue mittle- und südamerikanische Argini. Zeitschrift für Systematische Hymenopterologie und Dipterologie, 6: 241-253.

1908. De Chalastogastris miscellanea. Zeitschrift für Systematische Hymenopterologie und Dipterologie, 7: 81-93.

LAMARCK, JEAN BAPTISTE.

1801. Système des animaux sans vertèbres ou Tableau général des classes des ordres et des genres de ces animaux. Deterville, Paris, $8 \& 432$ pp.

Latreille, P. A.

1796. Précis des caractères génériques des Insectes. Brive, Bordeaux, 210 pp.

1802. Histoire naturelle, générale et particulière des Crustaces et des Insectes, vol. 3, Familles naturelles et Genres. Dufart, Paris, 467 pp.

1810. Considerations générales sur l'ordre naturel des animaux. F. Schoell, Paris, 444 pp.

LEACH, W. E.

1817. The zoological miscellany: III. E. Nodder \& Son, London, 151 pp.

Lepeletier de Saint-Fargeau.

1823. Monographia Tenthredinetarum. Levrault, Paris, 17 \& 176 pp.

1828. Encyclopédie méthodique. Dictionnaire des Insectes. Pankouke, Paris,

Linnaeus, C. 10: 833 pp. Edited by A. G. Olivier.

1758. Systema Naturae, 1. Laur. Salvii, Stockholm, 826 pp.

1761. Fauna Suecica. Laur. Salvii, Stockholm, 624 pp., 2 pls.

MacGillivray, Alex. D.

1894. New species of Tenthredinidae, with tables of the species of Strongylogaster and Monoctenus. Canadian Entomologist, 24: 324-328. November.

1895. New. Tenthredinidae. Canadian Entomologist, 25: 281-286. October 5.

1906. A study of the wings of the Tenthredinoidea, a superfamily of Hymenoptera. Proceedings of the United States National Museum, 29: $569-654$, pls. $21-44$.

1908a. Blennocampinae-descriptions of new genera and species-synonymical notes. Canadian Entomologist, 40: 289-297. August.

1908b. Emphytinae-new genera and species and synonymical notes. Canadian Entomologist, 40: 365-372. October.

1908c. A new genus and species of Blennocampinae from Texas. Canadian Entomologist, 40: 454-455. December.

1909a. A new genus and some new species of Tenthredinidae. Canadian Entomologist, 41: 345-360. October.

1909b. Two new species of saw-flies. Canadian Entomologist, 41: 402-404. December.

1909c. A synopsis of the American species of Scolioneurinae. Annals of the Entomological Society of America, 2: 259-271. December.

1912. New genera and species of Xyelidae and Lydidae. Canadian Entomologist, 44: 294-299. October.

1914a. New genera and species of Tenthredinidae: a family of Hymenoptera. Canadian Entomologist, 46: 103-108. March.

1914b. New genera and species of Tenthredinidae: a family of Hymenoptera. Canadian Entomologist, 46: 137-140. April.

1914c. New genera and species of Tenthredinidae: a family of Hymenoptera. Canadian Entomologist, 46: 363-367. October. 
1916. Tenthredinoidea in "Hymenoptera of Connecticut." Connecticut Geological and Natural History Survey, 22: 25-175, 2 pls.

1919. Leucopelmonus confusus, Norton-Tenthredinidae. Canadian Entomologist, 51: 33-35. February.

1921a. New species of Nematinae-(Hymenoptera). Journal of the New York Entomological Society, 29: 27-35. March.

1921b. New species of Emphytinae and Selandriinae-Hymenoptera. Psyche, 28: 31-35. April.

1923a. New species of Tenthredinidae from the east and middle west. Bulletin of the Brooklyn Entomological Society, 18: 53-56. April.

1923b. A century of Tenthredinoidea. University of Illinois Bulletin, 20: 6-38. August 13.

Malaise, René.

1921. Beitrage zur Kenntnis schwedischer Blattwespen. Entomologisk Tidskrift, 41: 1-20.

1933. A new genus and synonymical notes on Tenthredinoidea. Entomologisk Tidskrift, 53: 50-59, 2 figs.

Malaise, René, and Benson, Robert B.

1934. The Linnaean types of sawflies (Hymenoptera Symphyta). Arkiv för Zoologi, 26a: 1-14. January 10.

Marlatt, C. L.

1895. The American species of Scolioneura Knw. Proceedings of the Entomological Society of Washington, 3: 234-236. June 22.

1896a. A revision of the Nematinae of North America. Bulletin of the United States Department of Agriculture, Division of Entomology, Technical series, 3: 135 pp., 1 pl., 10 figs.

1896b. Some new namatids. Canadian Entomologist, 28: 251-258. October 2. Middleton, William.

1915. Notes on some sawfly larvae belonging to the genus Dimorphopteryx. Proceedings of the United States National Museum, 48: 497-501, 1 pl., 4 figs. March 18.

Morice, F. D., and Durrant, J. H.

1915. The authorship and first publication of the "Jurinean" genera of Hymenoptera. Transactions of the Entomological Society of London for 1914: 339-437. February 27.

Newman, Edward.

1837. Notes on Tenthredinina. Entomological Magazine, 4: 258-263. January.

1838. Entomological Notes. Entomological Magazine, 5: 483-500, 3 figs. October.

1869. Camponiscus Healaei, a new British Hymenopteron of the family Tenthredinidae. Entomologist, 4: 215-216. February.

NORTON, EDWARD.

1867. Catalogue of the described Tenthredinidae and Uroceridae of North America. Transactions of the American Entomological Society of America, 1: 31-84, 193-280.

1872. Notes on North American Tenthredinidae with descriptions of new species. Transactions of the American Entomological Society, 4: $77-86$.

Olivier, A. G.

1789-1791. Encyclopédie méthodique. Dictionnaire des Insectes. Pankouke, Paris, 4: 373 \& 331 p., 1789; 5: 793 p., 1790; 6: 704 pp., 1791. 
Panzer, G. W. F.

1801-1805. Faunae Insectorum Germaniae initia oder Deutschlands Insecten. Heft 73-84 (up to 1801), Heft 85-96 (up to 1805), each with 24 plates and text. Nürnberg, Felssecker.

Perkins, R. C. L.

1920. The British species of Andrena and Nomada. Transactions of the

Provancher, L. Entomological Society of London, 7: 218-319. April 1.

1875. Les Urocerides de Quebec. Le Naturaliste Canadien, 7: 368-376. December.

1882. Faune Canadienne, Hyménoptères, additions et corrections. Le Naturaliste Canadien, 13: 289-311. October.

1886-1889. Additions et corrections au volume II de la faune entomologique du Canada traitant des Hyménoptères. Darveau, Quebec. Additions et corrections à la faune Hyménoptèrologique de la province de Quebec, 1886: 4-345. Supplement aux additions aux Hyménoptères de la province de Quebec, 1889: 346-475.

ROHWER, S. A.

1908. New western Tenthredinidae. Journal of the New York Entomological Society, 16: 103-114. June.

1909. Notes on Tenthredinoidea, with descriptions of new species. Canadian Entomologist, 41: 9-21, January; 88-92, March; 397-399, November.

1910a. Notes on Tenthredinoidea, with descriptions of new species. Canadian Entomologist, 42: 49-56. February.

1910b. Notes on Tenthredinoidea, with descriptions of new species. Canadian Entomologist, 42: 215-220. June.

1910c. On a collection of Tenthredinoidea from eastern Canada. Proceedings of the United States National Museum, 38: 197-209. June 6.

1910d. Japanese sawflies in the collection of the United States National Museum. Proceedings of the United States National Museum, 39: 99-120. October 25.

1911a. On some Hymenopterous insects from the island of Formosa. Proceedings of the United States National Museum, 39: 477-485. January 11.

1911b. The genotypes of the sawflies and woodwasps, or the superfamily Tenthredinoidea. United States Department of Agriculture, technical series, 20: 69-109. March 4.

1911c. Additions and corrections to "The genotypes of the sawflies and woodwasps, or the superfamily Tenthredinoidea" (Hym.). Entomological News, 22: 218-219. May.

1911d. New sawflies in the collection of the United States National Museum. Proceedings of the United States National Museum, 41: 377-411, 14 figs. October 14.

1911e. A classification of the suborder Chalastogastra of the Hymenoptera. Proceedings of the Entomological Society of Washington, 13: 215-224.

1912a. Studies in the woodwasp superfamily Oryssoidea, with descriptions of new species. Proceedings of the United States National Museum, 43: 141-158, 2 pls., 6 figs. September 27.

1912b. Notes on sawflies, with descriptions of new species. Proceedings of the United States National Museum, 43: 205-251, 6 figs. September 30. 
1913. A synopsis and descriptions of the nearctic species of sawflies of the genus Xyela, with descriptions of other new species of sawflies. Proceedings of the United States National Museum, 45: 265-281, 1 fig. May 22.

1915a. Synopsis of the species of sawflies belonging to the genus Dimorphopteryx. Proceedings of the United States National Museum, 48: 445-448. February 11.

1915b. Descriptions of new species of Hymenoptera. Proceedings of the United States National Museum, 49: 205-249. July 16.

1915c. A remarkable new genus of Cephidae. Proceedings of the Entomological Society of Washington, 17: 114-117, 1 pl. September 18.

1917a. A report on a collection of Hymenoptera (mostly from California) made by W. M. Giffard. Proceedings of the United States National Museum, 53: 233-249. May 28.

1917b. Descriptions of thirty-one new species of Hymenoptera. Proceedings of the United States National Museum, 53: 151-176, 1 fig. June 5.

1918a. Notes on and descriptions of the nearctic woodwasps of the genus Xiphydria Latreille (Hym.). Entomological News, 29: 105-111. March.

1918b. New sawflies of the subfamily Diprioninae (Hym.). Proceedings of the Entomological Society of Washington, 20: 79-90. September 27.

1918c. The North American species of the sawfly genus Laurentia (Hym.). Proceedings of the Entomological Society of Washington, 20: 157-159. October.

1918d. Notes on, and descriptions of, sawflies belonging to the Tenthredinid tribe Hemichroini (Hym.). Proceedings of the Entomological Society of Washington, 20: 161-182. November.

1920. Descriptions of twenty-five new species of North American Hymenoptera. Proceedings of the United States National Museum, 57: 209-231. June 16 .

1921a. Notes on sawflies, with descriptions of new genera and species. Proceedings of the United States National Museum, 59: 83-109.

1921b. Notes and descriptions of neotropical sawflies of the subfamily Perreyinae. Proceedings of the United States National Museum, 59: 161-167. July 5.

Rohwer, S. A., and Cushman, R. A.

1917. Idiogastra, a new suborder of Hymenoptera, with notes on the immature stages of Oryssus. Proceedings of the Entomological Society of Washington, 19: 89-98, 2 pls.

Rohwer, S. A., and Middleton, William.

1922. North American sawflies of the subfamily Cladiinae with notes on habits and descriptions of larvae. Proceedings of the United States National Museum, 60: 1-46, 73 figs. January 26.

1931. Descriptions of five nearctic sawflies of the tribe Hemichroini. Proceedings of the Entomological Society of Washington, 34: 93-98, 1 fig. June.

Ross, Herbert H.

1929. Two new forms of the genus Zaschizonyx Ashmead (Tenthredinidae, Hymenoptera). Canadian Entomologist, 61: 272-273. September.

1930. The genera Selandria and Coryna in America north of Mexico. (Tenthredinidae, Hymenoptera). Canadian Entomologist, 62: 184189, 8 figs. August. 
1931. Sawflies of the sub-family Dolerinae of America north of Mexico. Illinois Biological Monographs, 12: 7-116, 6 pls. March 11.

1932a. The subfamily Lycaotinae in North America (Hymenoptera, Tenthredinidae). Canadian Entomologist, 64: 41-45, 1 pl. February.

1932b. The Hymenopterous family Xyelidae in North America. Annals of the Entomological Society of America, 25: 153-169, 2 pls. March.

1935a. Four new species of Dolerus (Hymenoptera, Tenthredinidae). Proceedings of the Entomological Society of Washington, 37: 88-93, 1 pl. April.

1935b. The nearctic sawflies of the Dineura complex (Hymenoptera, Tenthredinidae). Canadian Entomologist, 67: 201-205, 1 pl. September.

1936a. The ancestry and wing venation of the Hymenoptera. Annals of the Entomological Society of America, 29: 99-111, 2 pls. March.

1936b. The sawfly genus Empria in North America (Hymenoptera, Tenthredinidae). Pan-Pacific Entomologist, 12: 172-178, 1 pl. December.

1937a. The nearctic sawflies of the genus Fenusa (Hymenoptera, Tenthredinidae). Transactions of the Illinois State Academy of Sciences, 29: 263-266, 1 pl. January.

1937b. The nearctic sawflies of the genera Ametastegia, Aphilodyctium, and Allantus. Arbeiten über morphologische und taxonomische Entomologie, 4: 84-92, 25 figs. May 10.

Rossi, Peter.

1807. Fauna Etrusca, sistens Insecta, quae in provinciis Florentina et Pisana praesertim collegit. Masi, Liburni, edition 2, volume 2.

Salman, Kenneth A.

1929. The external morphology of Pepsis elegans Lepeletier (Hymenoptera,

Psammocharidae). Transactions of the American Entomological Society, 55: 119-154, 4 pls. May 7.

Say, Thomas.

1836. Descriptions of new species of North American Hymenoptera and observations on some already described. Boston Journal of Natural History, 1: 210-305.

Schilling, P. S.

1825. Tritokreion nov. gen. Hymenopterorum. Arbeiten und veränderungen, schlesische gesellschaft für vaterländische Kultur, 2: 43.

SchiöDte, J. C.

1838. Beretning om Resultaterne af en i Sommeren 1838 foretagen entomologisk Undersögelse af det sydlige Sjaelland, en Deel af Laaland, og Bornholm. Kroyer's Naturhistorisk Tidsskrift, 2: 309-395.

1839. Ichneumonidum ad faunam Daniae pertinentium genera et species novae.

Magazin de zoologie, Guerin, 9: no. 6-10, 27 pp., 5 col. pl.

Schlectendal, von D. H. R.

1878. Eine neue deutsche Siricidae Macrocephus ulmariae. Entomologische Nachrichten, 4: 153 .

Schrank, F. von P.

1802. Fauna Boica. Nürnberg (Ingolstadt, Landshut) 2: pt. 2, 412 pp.

Schulz, W. A.

1906. Spolia Hymenopterologica. Junfermann, Paderborn, 356 pp., 1 pl.

Semenov, A.

1891. Abia jakowlewi, sp. n. Descripsit. Horae Societatis Entomologicae Rossicae, 25: 172-174. 
Sмiтн, Јонм B.

1899. Insects of New Jersey. MacCrellish \& Quigley, Trenton, 755 pp., 392 figs.

1910. Annual Report for 1909 of the New Jersey State Museum including a Report of the Insects of New Jersey. MacCrellish \& Quigley, 888

Smulyan, M. T. pp., 340 figs.

1923. New England sawflies of the genus Tenthredella Rohwer. Proceedings of the Boston Society of Natural History, 36: 383-465, 2 pls. January.

SNODGRAss, R. E.

1911. The thorax of the Hymenoptera. Proceedings of the United States National Museum, 39: 37-91, 16 pls.

1931. Morphology of the insect abdomen. Part I. General structure of the abdomen and its appendages. Smithsonian Miscellaneous Collection, 85, no. 6: 128 pp., 46 figs. November 6.

Stephens, J. F.

1835. Illustrations of British Entomology; Mandibulata. Volume VII. Baldwin and Craddock, London, 310 pp., 4 pls.

Taylor, Elizabeth B.

1931. The morphology of the Tenthredinid head. Proceedings of the Royal Physical Society, Edinburgh, 22: 41-70, 10 pls.

Thomson, C. G.

1870. Opuscula Entomologica, Fasciculus secundus. Ohlsson, Lund, pp. 83-304.

1871. Hymenoptera Scandinaviae, vol. I, Phytophaga. Ohlsson, Lund, 342 pp. Tischbein, P.

1846. Verzeichniss der in den Fürstenthumern Lübeck und Birkenfeld von mir bisher aufgefundenen Blattwespen. Stettinger Entomologische Zeitung, 7: 75-80, 113-115.

VAN DINE, D. L.

1906. Notes on a comparative anatomical study of the mouthparts of sawflies. Proceedings of the Hawaiian Entomological Society, 1: 19-22, 2 pls. April.

Webster, F. M., and Malley, C. W.

1900. The purslane sawfly-Schizocerus zabriskiei Ashmead, M. S. Canadian

Entomologist, 32: 51-54, 3 figs.

Westwood, J. O.

1840. An Introduction to the Modern Classification of Insects: Vol. II. LongYuASA, Hachiro. man, Orme, Brown, Green, and Longmans, London, 158 pp., 133 figs.

1923. A classification of the larvae of the Tenthredinoidea. Illinois Biological Monographs, 7: 172 pp., 14 pls. February 9. 


\section{PLATES}

Unless otherwise noted, all figures represent parts of adult insects. 


\section{PLATE I}

FIG. 1,-Head of Tenthredo basilaris Say, anterior aspect.

FIG. 2.-Head of Tenthredo basilaris, posterior aspect.

FIG. 3.-Tentorium of Macroxyela ferruginea (Say), lateral aspect.

FIG. 4.-Head of Acantholyda luteomaculata (Cress.), anterior aspect.

FIG. 5.-Head of Acantholyda luteomaculata, posterior aspect.

FIG. 6-Tentorium of Tenthredo basilaris, lateral aspect.

FIG. 7.-Head of Cephus cinctus Nort., anterior aspect.

FIG. 8.-Head of Cephus cinctus, posterior aspect.

FIG. 9.-Tentorium of Cimbex americana Leach, lateral aspect.

Fig. 10.-Head of Aleiodes terminalis (Cress.), anterior aspect.

FIG. 11.-Head of Aleiodes terminalis, posterior aspect.

FIG. 12.-Tentorium of Janus integer (Nort.), lateral aspect.

FIG. 13.-Labrum of Lycaotella spissipes (Cress.).

FIG. 14.-Labrum of Acantholyda luteomaculata.

FIG. 15.-Labrum of Orussus terminalis Newm.

FIG. 16.-Labrum of Tremex columba (L.).

FIG. 17.-Tentorium of Aleiodes terminalis, lateral aspect.

$$
\begin{gathered}
c l \text { clypeus } \\
c p \text { corpotentorium } \\
c p t \text { corpotendon } \\
c r \text { crassa } \\
e \text { compound eye } \\
e p \text { epicranial stem } \\
f \text { frontal region } \\
f c l \text { fronto-clypeal } \\
\text { suture } \\
g \text { gena }
\end{gathered}
$$

\author{
Abbreviations \\ $l$ labrum \\ $m$ mandible \\ mp maxaponta \\ mt metatentorium \\ mtr metatentorina \\ $m x$ maxillaria \\ $o$ ocelli \\ oc occipital region \\ ocul ocularium \\ od odontoidea
}

\author{
$p g$ postgena \\ pr pretentorium \\ pta pretentorina \\ ptc postcoila \\ st supratentorium \\ sta supratentorina \\ $t t$ course of tentorial \\ thickenings
}




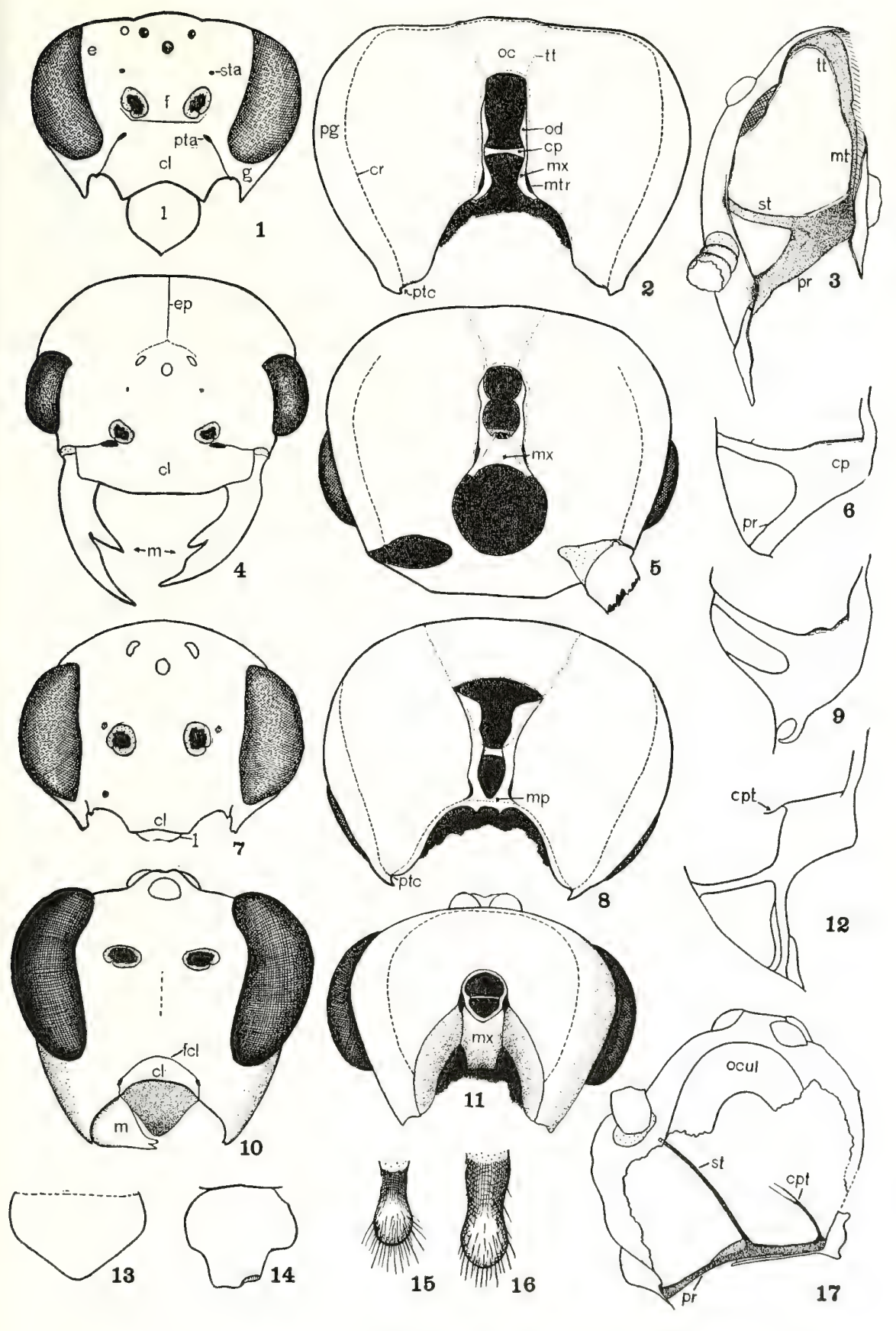

PLATE I 


\section{PLATE II}

FIG. 18.- Head of Tremex columba, anterior aspect.

FIG. 19.-Head of Tremex columba, posterior aspect.

FIG. 20.-Head of Syntexis libocedrii Rohwer, left half anterior aspect, right half posterior aspect.

FIG. 21,-Head of Syntexis libocedrii, lateral aspect.

FIG. 22.-Head of Xiphydria maculata Say, lateral aspect.

FIG. 23.-Head of Orussus terminalis, left half anterior aspect, right half posterior aspect.

FIG. 24.-Head of Orussus terminalis, ventral aspect.

FIG. 25.-Head of Xiphydria maculata, lateral portion cut away to show tentorium.

FIG. 26.-Tentorium of Orussus terminalis, lateral aspect.

FIG. 27.-Tentorium of Orussus terminalis, dorsal aspect.

FIG. 28.-Tentorium of Aleiodes terminalis, dorsal aspect.

FIG. 29.-Tentorium of Macroxyela ferruginea, dorsal aspect.

FIG. 30.-Tentorium of Tremex columba, lateral aspect.

FIG. 31.-Tentorium of Tremex columba, dorsal aspect.

FIG. 32.-Left mandible of Xiphydria maculata.

FIG. 33.-Left mandible of Syntexis libocedrii.

FIG. 34.-Mandibles of larva of Sterictiphora apios Ross, ventral aspect.

FIG. 35.-Mandibles of Macroxyela ferruginea, dorsal aspect.

FIG. 36.-Mandibles of Janus integer, dorsal aspect.

FIG. 37.-Right mandible of Orussus terminalis, lateral and dorsal aspects, respectively.

FIG. 38.-Mandibles of Sterictiphora apios, dorsal aspect.

$\begin{aligned} c l & \text { clypeus } \\ c p & \text { corpotentorium } \\ c p t & \text { corpotendon } \\ d a & \text { distadentes } \\ f & \text { frontal region } \\ g & \text { gena } \\ g p & \text { genaponta }\end{aligned}$

cl clypeus

$c p$ corpotentorium

$c p t$ corpotendon

da distadentes

$f$ frontal region

gp genaponta
Abbreviations

$\begin{aligned} & \text { Abbreviations } \\ g r & \text { antennal groove } \\ l & \text { labrum } \\ m & \text { mandibles } \\ m o & \text { mola } \\ m x & \text { maxillaria } \\ o d & \text { odontoidea } \\ p g & \text { postgenae }\end{aligned}$

pr pretentorium pta pretentorina

$p x$ proxadentes

st supratentorium

sta supratentorina

$t t$ course of tentorial thickenings 

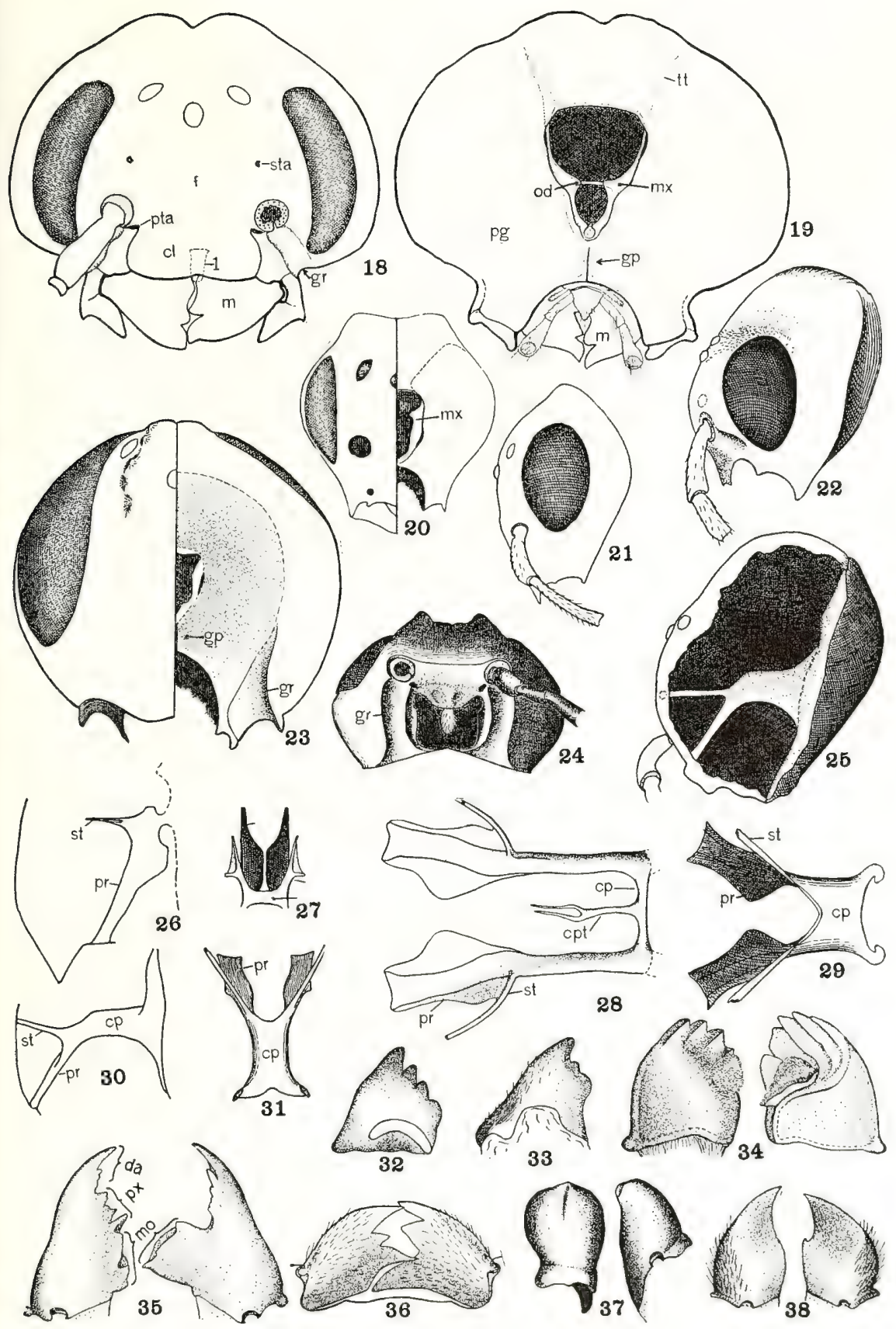

PLATE II 


\section{PLATE III}

\section{MANDIBLES, ANTERIOR ASPECT}

FIG. 39.-Right mandible of Phymatocera fumipennis (Nort.).

FIG. 40.-Right mandible of Tethida cordigera (Beauv.).

FIG. 41.-Right mandible of Tomostethus multicinctus Rohwer.

FIg. 42.-Right mandible of Tenthredo mellicoxa Prov.

Fig. 43.-Right mandible of Macrophya rapae (L.).

FIG. 44.-Right mandible of Zaschizony.x montana (Cress.).

FIG. 45.-Right mandible of Aglaostigma rubens (Cress.).

FIG. 46.-Right mandible of Lycaotella spissipes.

FIG. 47.-Left mandible of Taxonus pallidicornis (Nort.).

FIG. 48.-Right mandible of Eriocampa rotunda (Nort.).

FIG. 49.-Mandibles of Taxomus epicera Say.

FIG. 50.-Mandibles of Allantus cinctus (L.).

FIG. 51.-Right mandible of Strongylogaster distans Nort.

FIG. 52.-Right mandible of Dolerus acidus MacG.

FIG. 53.-Right mandible of Caliroa cerasi (L.).

FIG. 54.-Right mandible of Phyllotoma nemorata (Fall.).

FIG. 55.-Right mandible of Fenusa dohrnii (Tischb.).

FIG. 56.-Right mandible of Cladius isomerus Nort.

FIG. 57.-Right mandible of Hoplocampa sp.

FIG. 58.-Left mandible of Hemichroa militaris (Cress.).

FIG. 59.-Mandibles of Nematus mendicus Walsh.

FIG. 60--Left mandible of Euura salicis-nodus Walsh. 


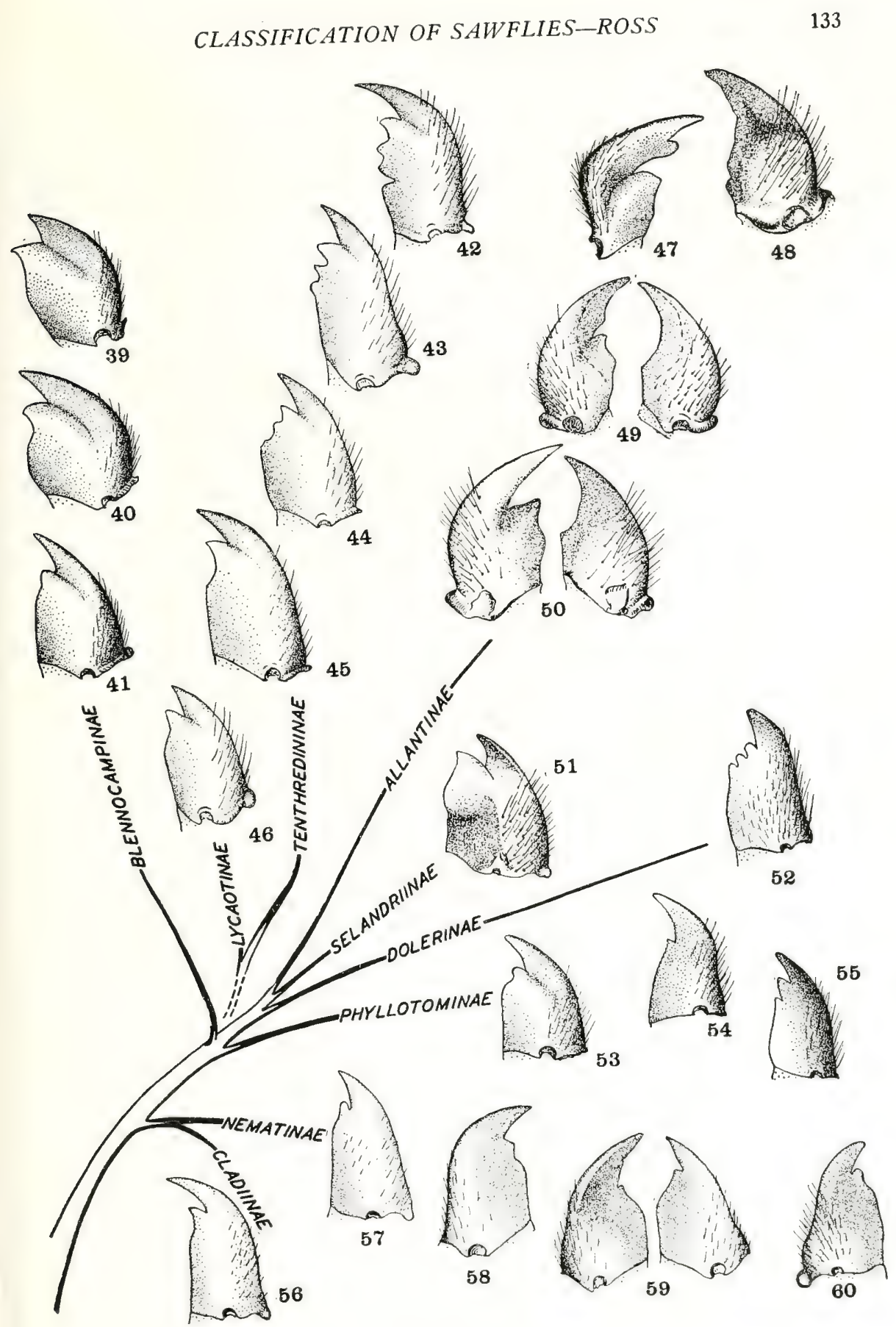

PLATE III 


\section{PLATE IV}

MAXillae, POSTERIoR ASPECT

FIG. 61--Galea and lacinia of Pleroneura aldrichi Ross.

FIG. 62.-Galea and lacinia of Xyelecia nearctica Ross.

FIG. 63.-Arge pectoralis (Leach).

FIG. 64.-Trichiosoma triangulum Kirby.

FIG. 65.-Macroxyela ferruginea.

FIG. 66.-Cephus cinctus.

FIG. 67.-Aleiodes terminalis.

FIG. 68.-Orussus terminalis.

FIG. 69.-Xiphydria maculata.

FIG. 70.-Syntexis libocedrii.

cd cardo

ecg ectogalea

eg endogalea
Abbreviations

$\begin{array}{cc}e u s \text { eustipes } & p \text { palpus } \\ g l \text { galea } & p s \text { parastipes } \\ l c \text { lacinia } & \end{array}$



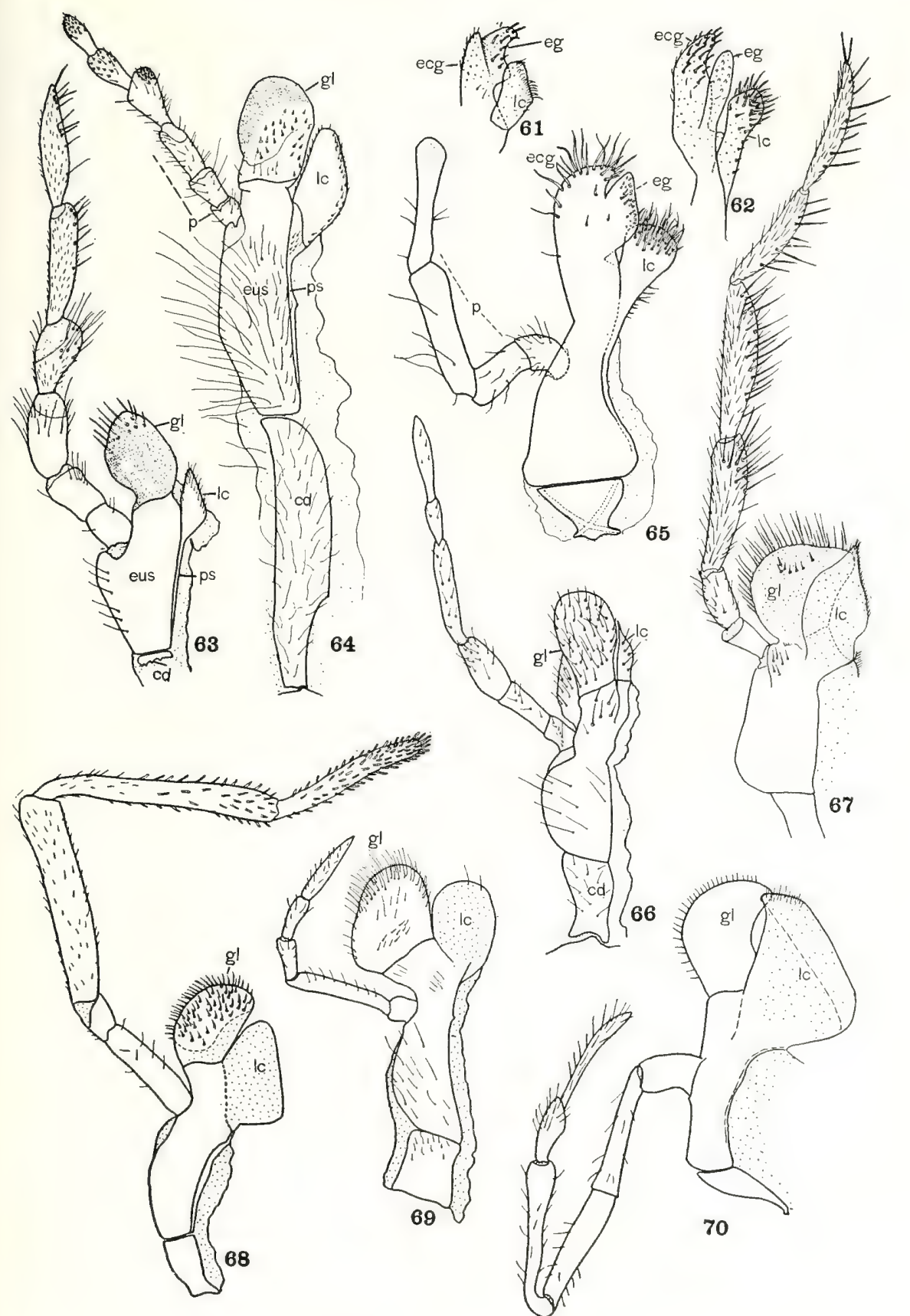

PLATE IV 


\section{PLATE V}

FIG. 71.-Labium of Trichiosoma triangulum, posterior aspect.

FIG. 72.-Labium of Arge pectoralis, lateral aspect.

FIG. 73.-Submentum and stipulae of Arge pectoralis.

FIG. 74.-Labium of Aleiodes terminalis, posterior aspect.

FIG. 75.-Labium of Aleiodes terminalis, lateral aspect.

FIG. 76.- Totaglossa of Incalia hirticornis Cam., posterior aspect.

FIG. 77.-Labium of Macroxyela ferruginea, posterior aspect.

FIG. 78.-Labium of Syntexis libocedrii, posterior aspect.

FIG. 79.-Labium of Syntexis libocedrii, lateral aspect.

Fig. 80.-Labium of Orussus terminalis, posterior aspect.

FIG. 81-Labium of Janus integer, posterior aspect.

FIG. 82.-Labium of Xiphydria maculata, posterior aspect.

FIG. 83.-Paraglossae and alaglossa of Xiphydria maculata.

Fig. 84--Maxillae and labium of Urocerus flavicornis Fab., dorsal aspect.

FIG. 85.-Labium of Urocerus flavicornis, lateral aspect.

$\begin{aligned} \text { alg } & \text { alaglossa } \\ c d & \text { cardo } \\ d g l & \text { duplaglossa } \\ g l & \text { galea } \\ h y & \text { hypopharynx }\end{aligned}$

\author{
Abbreviations \\ max.p maxillary palpus \\ $p$ labial palpus \\ pgl paraglossa \\ sm submentum
}

\author{
st stipites \\ sti stipulae \\ $t g l$ totaglossa \\ $x$ sclerotized area
}



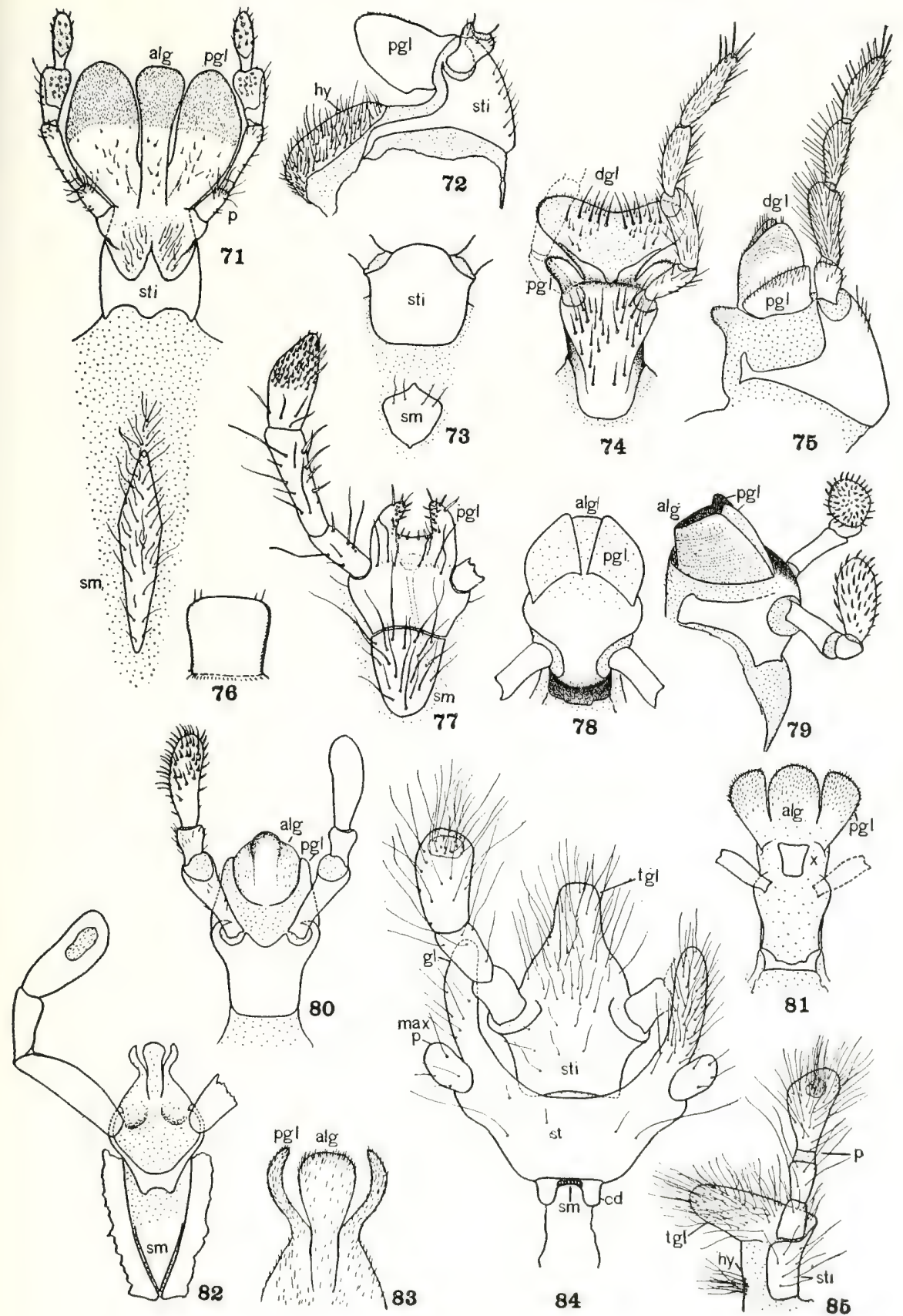

PLATE V 


\section{PLATE VI}

FIG. 86.-Antenna of female Pleroneura aldrichi.

FIG. 87.-Antenna of female Xyelecia nearctica.

FIG. 88.-Antenna of female Acantholyda luteomaculata.

FIG. 89.-Antenna of female Syntexis libocedrii.

FIG. 90.-Antenna of female Xiphydria maculata.

FIG. 91.-Antenna of female Tremex columba.

FIG. 92.-Antenna of female Orussus terminalis.

FIG. 93.-Antenna of female Hemitaxomus dubitatus (Nort.).

FIG. 94.-Antenna of male Megalodonta sp.

FIG. 95.-Antenna of female Acordulecera sp.

FIG. 96.-Antenna of female Blasticotoma filiceti (Klug).

FIG. 97.-Antenna of female Sterictiphora zabriskiei (W. \& M.).

FIG. 98.-Antenna of male Sterictiphora cellularis (Say).

FIG. 99.-Antenna of female Zaraea americana (Cress.).

FIG. 100.-Antenna of female Trichiosoma triangulum.

FIG. 101--Antenna of female Tenthredo subnigriceps Rohwer.

FIG. 102.-Antenna of female Tenthredo originalis Norton.

FIG. 103.-Antenna of female Macrophya montana (Scopoli).

FIG. 104.-Antenna of male Cladius isomerus.

FIG. 105.-Antenna of male Monoctenus sp.

FIG. 106.-Antenna of female Neodiprion affinis Rohwer.

FIG. 107.-Antenna of female Augomonoctenus libocedrii Rohwer.

FIG. 108.-Front leg of female Orussus terminalis.

FIG. 109,-Hind tarsi of female Lycaota sodalis (Cress.).

FIG. 110.-Hind leg of Janus integer.

FIG. 111.-Hind tarsi of female Lycaotella spissipes.

FIG. 112,-Hind tibiae and tarsi of Xiphydria maculata.

FIG. 113.-Apex of front tibia, tibial spurs and basitarsus of Neodiprion affinis.

FIG. 114.-Apical spurs of front tibia of Lycaota sodalis.

FIG. 115.-Apical spurs of front tibia of Orussus terminalis.

FIG. 116.-Apical spur of front tibia of Tremex columba.

Frg. 117.-Apical spur of front tibia of Xiphydria maculata.

FIG. 118.-Apical spur of front tibia of Syntexis libocedrii.

FIG. 119.-Apical spur of front tibia of Janus integer.

\section{Abbreviations}

asp apical spurs
$c x$ coxa
$f m$ femur
$p s p$ preapical spurs
ta tarsi
$t b$ tibia

tc tarsal claws

tr trochanters 

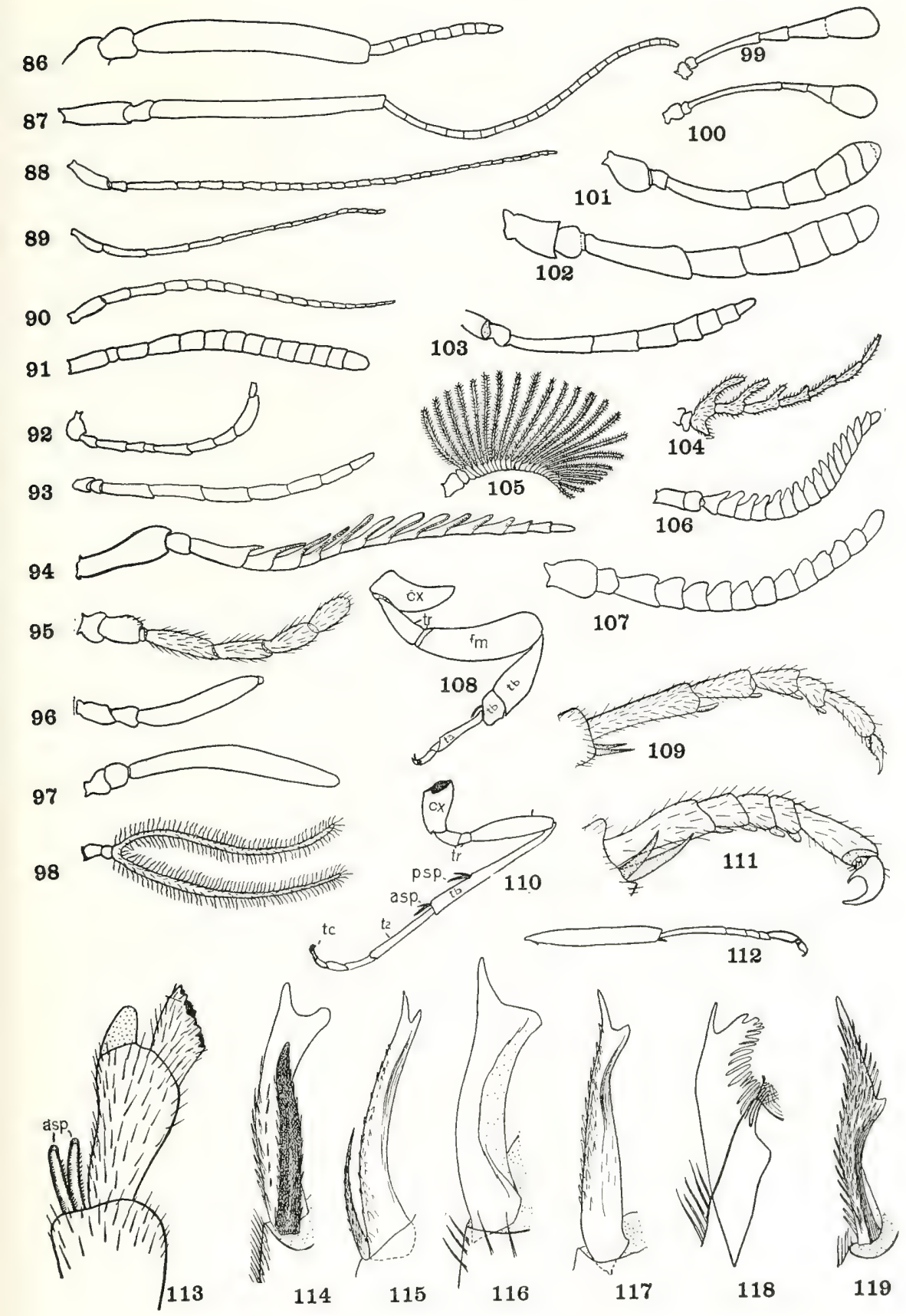

PLATE VI 


\section{PLATE VII}

FIG. 120.-Thorax of Macroxyela ferruginea, dorsal aspect.

FIG. 121.-Thorax of Janus integer, dorsal aspect.

FIG. 122.-Thorax of Syntexis libocedrii, dorsal aspect.

FIG. 123.-Thorax of Xiphydria maculata, dorsal aspect.

FIG. 124.-Pro- and mesonotum of Profenusa canadensis (Marl.).

FIG. 125.-Post-tergite of Dolerus similis (Norton).

Fig. 126.-Pro- and mesonotum of Acordulecera sp.

FIG. 127.-Pro- and mesonotum of Tremex columba.

FIG. 128.-Thorax of Orussus terminalis, dorsal aspect.

FIG. 129.-Thorax of Macroxyela ferruginea, ventral aspect.

FIG. 130.-Thorax of Syntexis libocedrii, ventral aspect.

FIG. 131.-Thorax of Janus integer, ventral aspect.

FIG. 132.-Thorax of Xiphydria maculata, ventral aspect.

FIG. 133.-Thorax of Orussus terminalis, ventral aspect.

FIG. 134.-Mesothorax of Arge pectoralis, ventral aspect.

FIG. 135.-Mesothorax of Hemitaxomus dubitatus, ventral aspect.

FIG. 136.-Portion of mesothorax of Allantus cinctus, ventral aspect.

FIG. 137.-Anterior portion of mesosternum of Tremex columba, ental aspect.

FIG. 138.-Mesothorax of Tremex columba, ventral aspect.

\author{
$a x$ axillary sclerites \\ bs basisternum \\ cn cenchri \\ $c v$ cervical sclerites \\ eps episternum \\ is parascutellum \\ ms mesosternum \\ $p n$ pronotum
}

\section{Abbreviations}

$\begin{aligned} p p & \text { prepectus } \\ p r s & \text { praescutum } \\ p s b & \text { presternal bridge } \\ p t & \text { post-tergite } \\ p t n & \text { postnotum } \\ s c l & \text { scutellum } \\ s c u t & \text { scutum } \\ s s & \text { spinisternum }\end{aligned}$

$y$ lobes of mesoscutum

1, 2 first and second segments of abdomen

$I, I I, I I I$ first, second, and third segments of thorax 

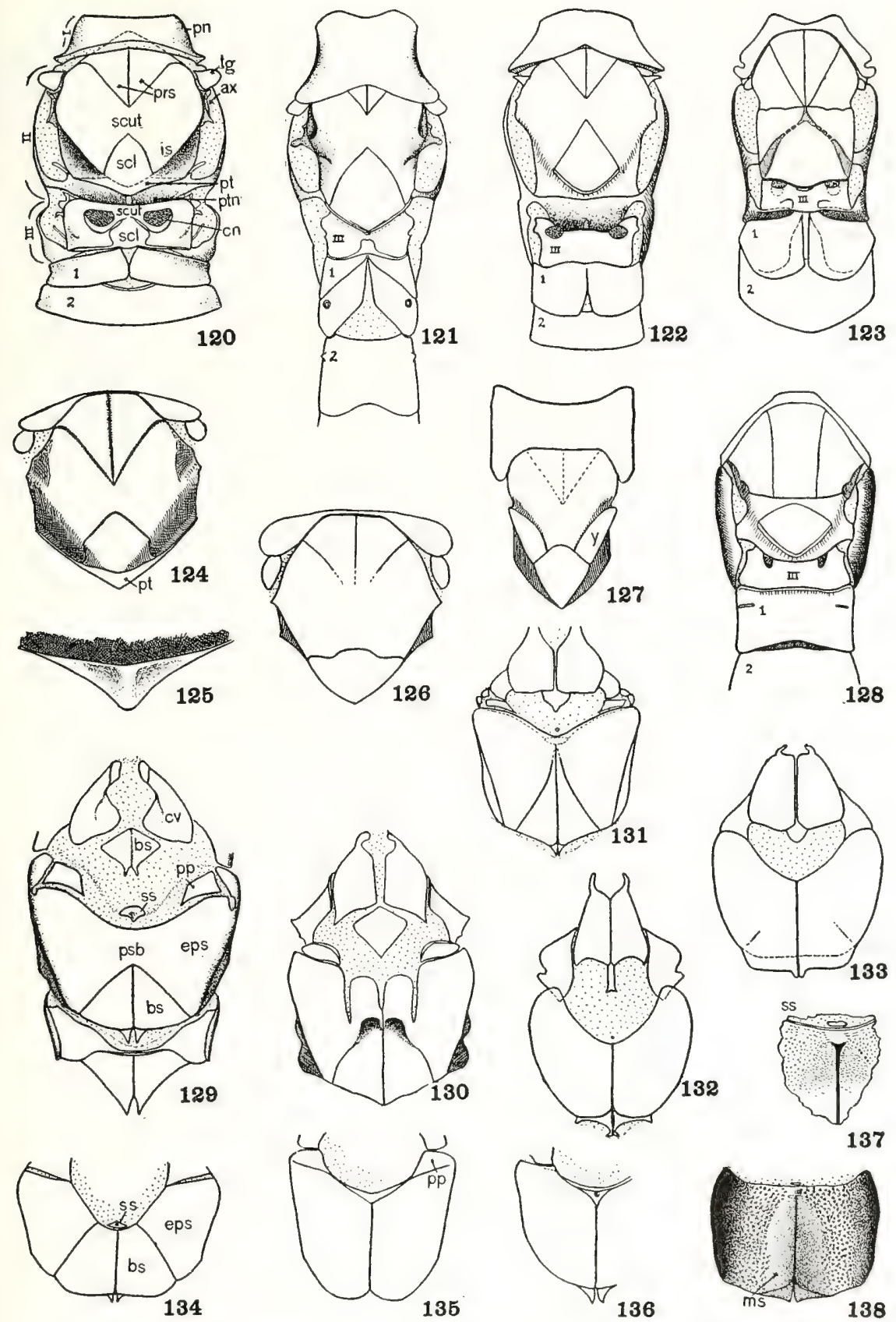

137

PLATE VII 


\section{PLATE VIII}

Fig. 139.-Thorax of Arge pectoralis, lateral aspect.

FIG. 140.-Thorax of Syntexis libocedrii, lateral aspect.

FIG. 141.-Thorax of Xiphydria maculata, lateral aspect.

FIG. 142.-Thorax of Orussus terminalis, lateral aspect.

FIG. 143.-Thorax of Janus integer, lateral aspect.

Fig. 144.-Thorax of Eremotylus sp., lateral aspect.

Fig. 145-Cervicum and propleurae of Panorpa sigmoides Carpenter, lateral aspect.

FIg. 146-Cervicum and propleurae of Arge pectoralis, lateral aspect.

FIG. 147.-Cervicum and propleurae of Xiphydria maculata, lateral aspect.

FIG. 148.-Cervicum and propleurae of Macroxyela ferruginea, lateral aspect.

FIG. 149.-Postnotum of Macroxyela ferruginea.

FIG. 150.-Postnotum of Orussus terminalis.

FIG. 151.-Postnotum of Tremex columba.

FIG. 152,--Postnotum of Janus integer.

FIG. 153.-Profurcella and mesofurcella of Acantholyda sp.

FIG. 154.-Cervicum and probasisternum of Macrophya formosa Klug.

FIG. 155.-Cervicum and probasisternum of Strongylogaster distans.

FIG. 156.-Cervicum and probasisternum of Hemitaxomus dubitatus.

FIG. 157.-Cervicum and probasisternum of Eriocampa rotunda.

FIG. 158.-Cervicum and probasisternum of Allantus cinctus.

FIG. 159.-Cervicum and probasisternum of Zaraea americana.

\author{
aem anepimeron \\ cem katepimeron \\ $c v$ cervical sclerites \\ eps episternum \\ $f c$ furca of mesobasi- \\ sternum
}

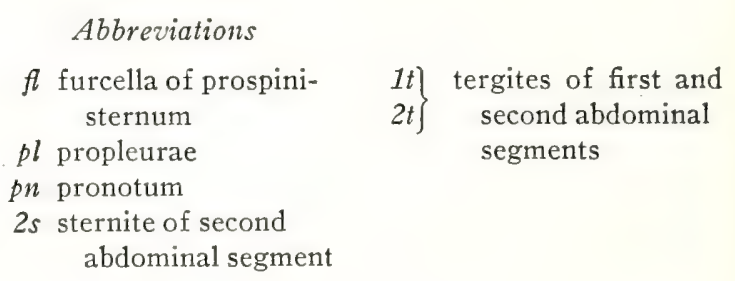



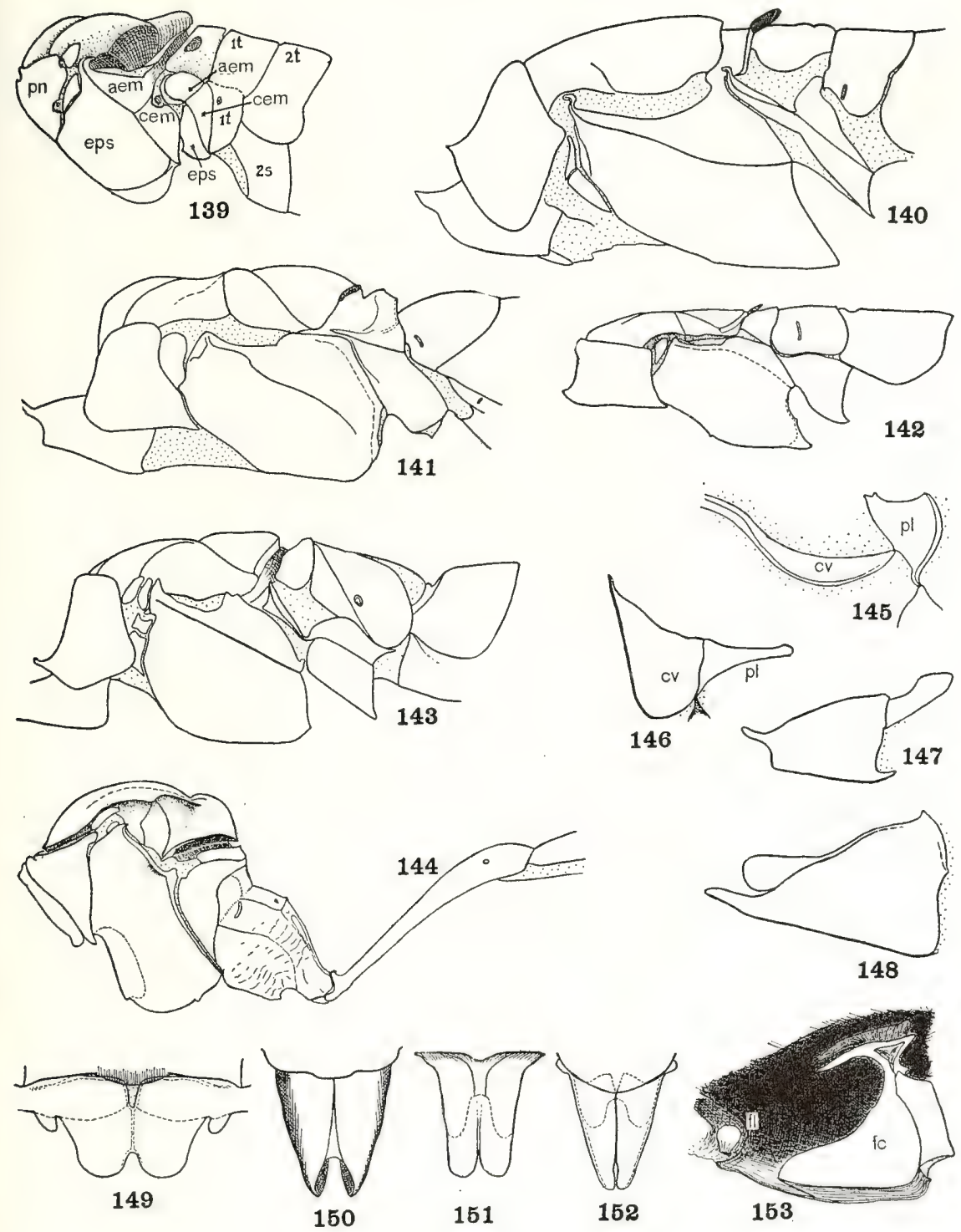

(2)

154

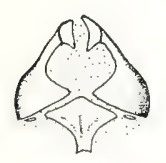

155

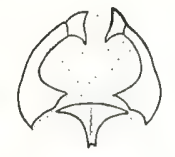

156

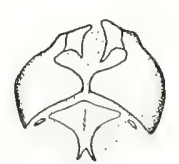

157
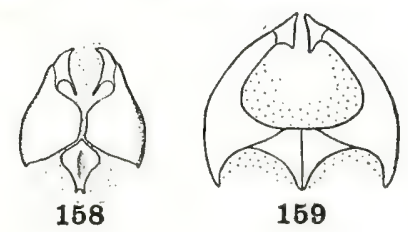

PLATE VIII 


\section{PLATE IX}

MALE Genitalia, figs. 160 and 162-169, with dorsal aspect on left half and ventral aspect on right

FIG. 160.-Arge pectoralis.

FIG. 161.-Sagittae and volsellae of Xiphydria maculata.

FIG. 162.-Xiphydria maculata.

FIG. 163.-Trichiosoma triangulum.

FIG. 164.-Acordulecera sp.

FIG. 165.-Janus integer.

FIG. 166.-Urocerus flavicornis.

FIG. 167.-Macroxyela ferruginea.

FIG. 168.-Aleiodes terminalis.

FIG. 169.-Orussus terminalis.

Abbreviations
ca gonocardo
gg parapenis
$g m$ gonamaculae
go gonostipes
$h$ harpes
ol volsellae

py penis valvae

sa sagittae 


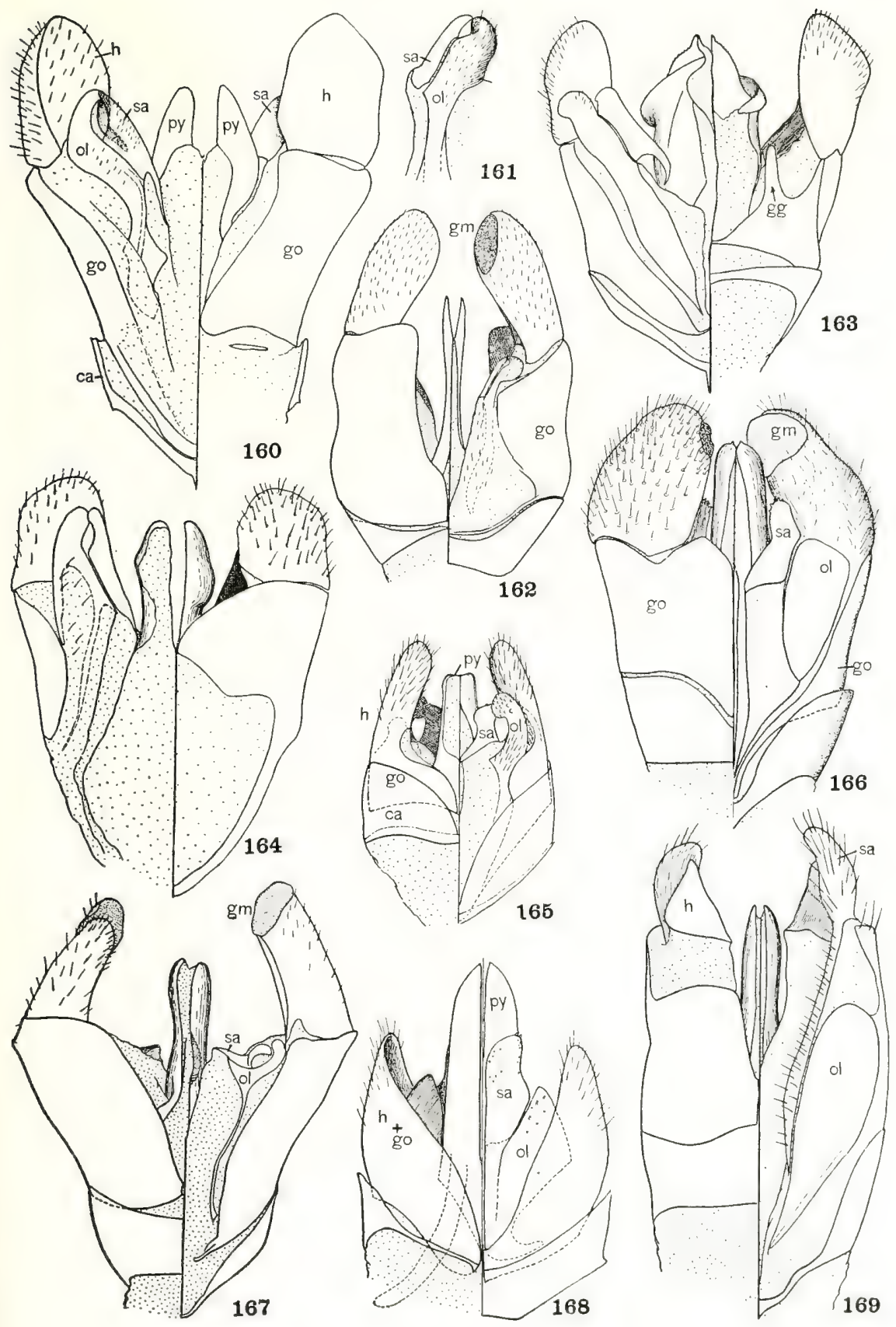

PLATE IX 


\section{PLATE X}

FIG. 170.-Hypothetical front wing of the Hymenoptera.

FIG. 171.-Wings of Syntexis libocedrii.

FIG. 172,-Front wing of Pleroneura sp.

FIG. 173.-Anal veins in front wing of Tremex columba.

FIG. 174.-Anal veins in front wing of Caliroa cerasi (L.).

FIG. 175,-Wings of Jamis integer.

FIG. 176.-Hind wing of Macroxyela ferruginea.

FIG. 177.-Wings of Orussus sp.

Fig. 178.-Hind wing of Arge sp.

FIG. 179.-Front wing of Tremex columba.

FIG. 180.-Hind wing of Taxomes epicera (Say), showing peripheral vein.

\section{Abbreviations}
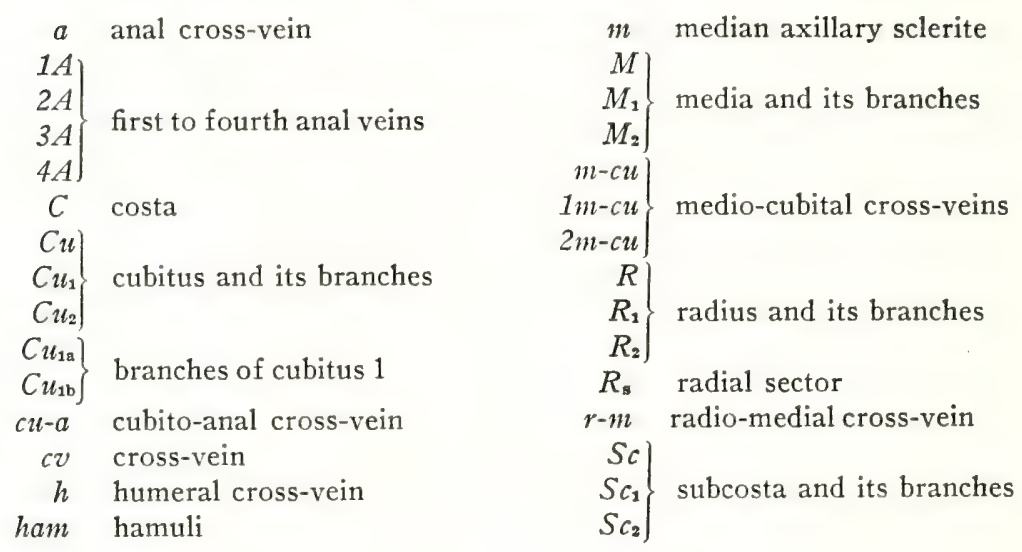


\section{PLATE XI}

Front Wings

FIG. 181--Hemitaxonus dubitatus.

FIG. 182.-Dolerus unicolor (Beauv.).

FIG. 183.-Selandria vanduzeei (Roh.).

FIG. 184.-Adelesta nova (Norton).

FIG. 185.-Caliroa cerasi.

FIG. 186.-Allantus cinctus.

FIG. 187.-Phyllotoma nemorata (Fall.).

FIG. 188.-Tomostethus multicinctus Rohwer.

FIG. 189.-Fenusa pumilla (Lep.).

FIG. 190.-Tethida cordigera.

FIG. 191,-Hoplocampa sp.

FIG. 192.-Lycaota sodalis.

FIG. 193.-Nematus ventralis Say.

FIG. 194.-Zaschizonyx montana.

FIG. 195.-Kerita fidala Ross.

FIG. 196.-Tenthredo rufopectus Norton.

Abbreviations same as for Plate $X$ 


\section{PLATE XII}

FIG. 197.-Anal veins of front wing of Tenthredo mellicoxa.

FIG. 198.-Anal veins of front wing of Nematus ribesii (Scop.).

FIG. 199.-Anal veins of front wing of Macrophya formosa.

FIG. 200.-Anal veins of front wing of Hemichroa crocea.

FIG. 201.-Anal veins of front wing of Zaschizonyz montana.

FIG. 202-Anal veins of front wing of Hoplocampa sp.

FIG. 203.-Anal veins of front wing of Caliroa aethiops (Fabr.).

FIG. 204.-Anal veins of front wing of Adelesta nova.

FIG. 205.-Anal veins of front wing of Phyllotoma nemorata.

FIG. 206.-Anal veins of front wing of Tomostethus multicinctus.

FIG. 207.-Anal veins of front wing of Metallus rubi Forbes.

FIG. 208. - Anal veins of front wing of Tethida cordigera.

FIG. 209.-Anal veins of front wing of Fenusa pusilla.

FIG. 210.-Anal veins of front wing of Blennocampa rubi (Harris).

FIG. 211.-Front wing of Caliroa aethiops showing the nomenclature of the cells.

FIG. 212.-Head of Lyrola brunniventris (Cress.), dorsal view.

FIG. 213.-Head of Sterictiphora apios Ross, dorsal view.

FIG. 214.-Portion of front wing of Sterictiphora apios.

FIG. 215.-Tarsal claw of Atomacera debilis Say.

FIG. 216.-Tarsal claw of Lyrola brunniventris.

FIG. 217.-Tarsal claw of Sterictiphora mexicana (Ashm.).

FIG. 218.-Portion of front wing of Sterictiphora niger (Nort.).

FIG. 219.-Scutellum of Neodiprion lecontei (Fitch.).

FIG. 220.-Scutellum of Diprion polytomum (Hartig).

FIG. 221.-Right mandible of female Trichiosoma triangulum.

FIG. 222.-Right mandible of male Trichiosoma triangulum.

FIG. 223.-Anal cells of hind wing of Sterictiphora cellularis.

FIG. 224.-Anal veins of the hind wing of Sterictiphora apios.

FIG. 225.-Anal veins of the hind wing of Sterictiphora zabriskiei.

FIG. 226.-Hind coxae of Trichiosoma triangulum.

FIG. 227.-Hind coxae of Zaraea americana.

FIG. 228.-Hind basitarsus and succeeding segment of Neodiprion lecontei (Fitch).

FIG. 229.--Hind basitarsus and succeeding segment of Zadiprion grandis (Rohwer).

FIG. 230.-Hind femur of Trichiosoma triangulum.

FIG. 231.-Head of Monoctemus fulvus (Nort.), lateral aspect.

FIG. 232.-Head of Neodiprion lecontei, lateral aspect.

\section{Abbreviations}

$a$ anal cross-vein

$1 A$ first anal vein

$2 A \mathcal{E} 3 A$ second and third anal veins

$C u_{1 \mathrm{a}}$ cell cubitus $1 \mathrm{a}$

$C u_{2 \mathrm{a}}$ cell cubitus $2 \mathrm{a}$

$D A$ distal anal cell

$1 M$ first medial cell

$2 M$ second medial cell

$3 M$ third medial cell
$M-C u$ medio-cubital cell

$P A$ proximal anal cell

$R$ radial cell

$1 R_{1}$ first cell radius 1

$2 R_{1}$ second cell radius 1

$3 R_{1}$ third cell radius 1

$1 R_{\mathrm{s}}$ first cell " $\mathrm{R}_{\mathrm{s}}$ "

$2 R_{\mathrm{g}}$ second cell " $\mathrm{R}_{\mathrm{s}}$ "

$3 R_{\mathrm{s}}$ third cell " $\mathrm{R}_{\mathrm{s}}$ " 

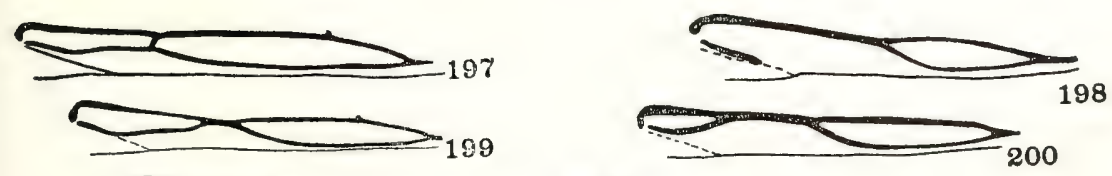

201
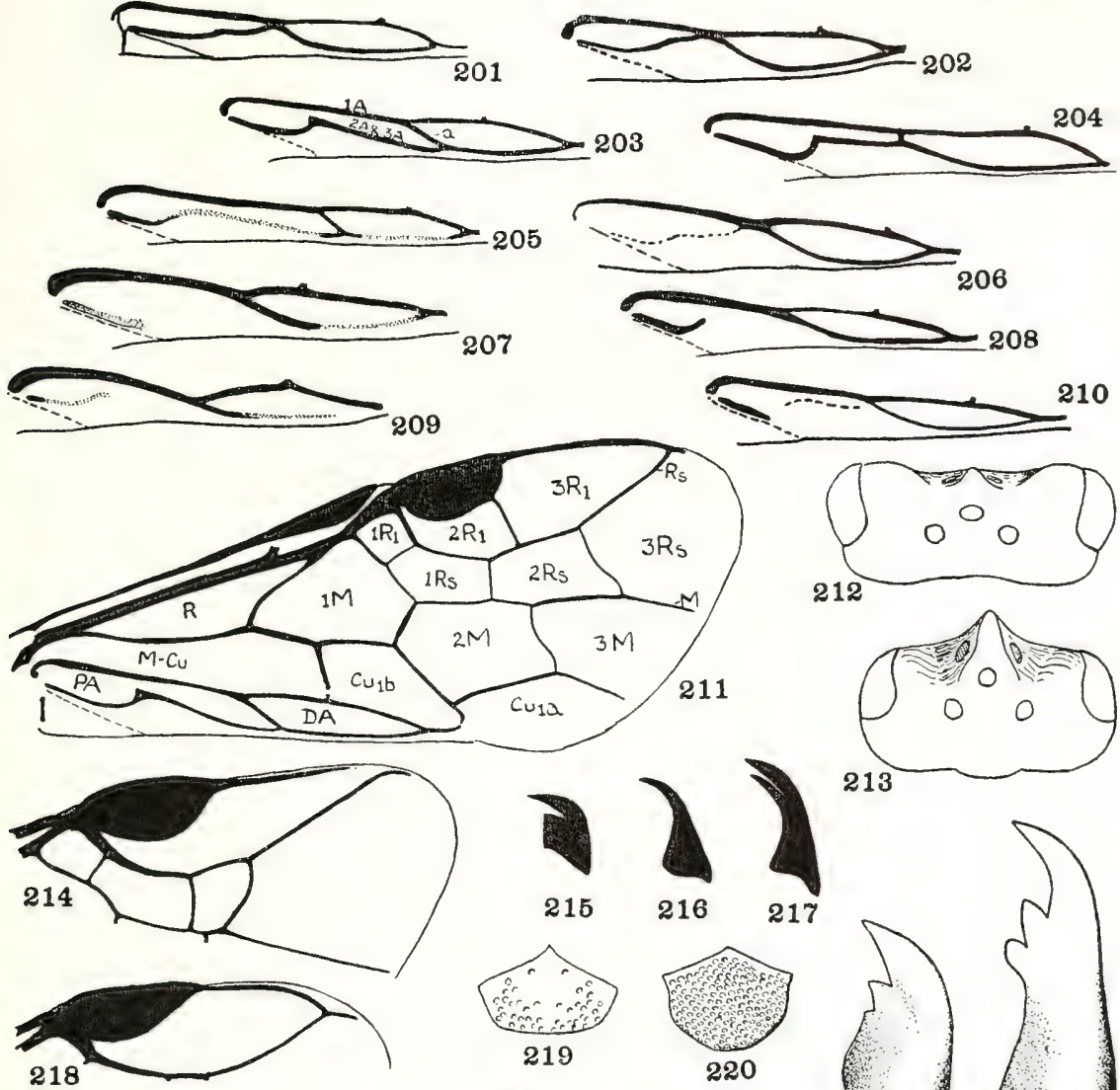

207
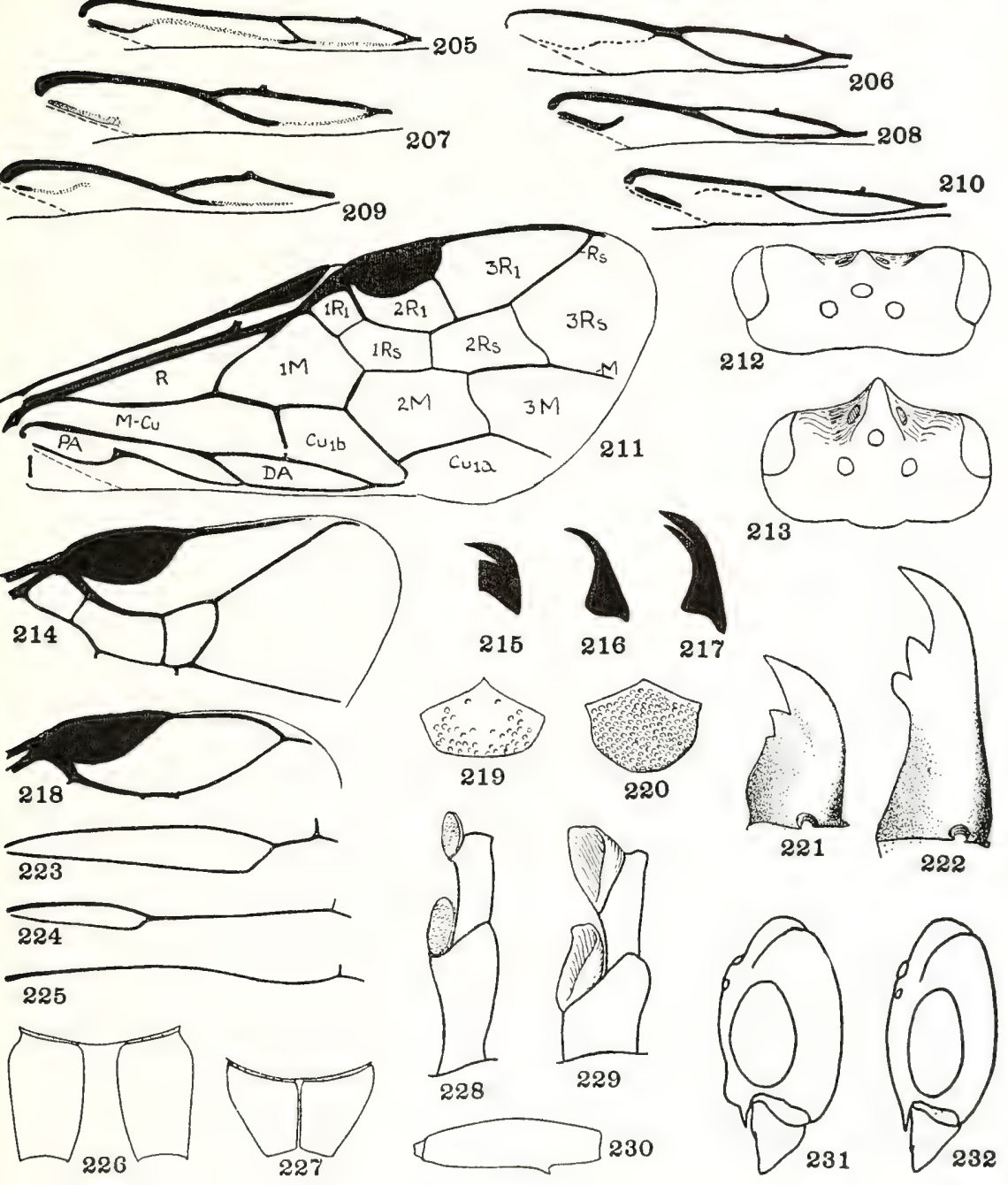

PLATE XII 


\section{PLATE XIII}

FIG. 233.-Cross-section of a unipectinate antennal segment.

FIG. 234.-Cross-section of a bipectinate segment.

FIG. 235.-Apical segments of antenna of Zadiprion grandis male.

FIG. 236.-Apical segments of antenna of Neodiprion lecontei male.

FIG, 237.-Apical segments of antenna of Eriocampidea arizonensis Ashm.

FIG. 238.-Apical segments of antenna of Hemitaxomus dubitatus.

FIg. 239.-Antenna of Adelesta nova.

FIG. 240.-Antenna of Eustromboceros sp.

FIG. 241.-Antenna of Aneugmenus flavipes (Nort.)

FIG. 242.-Mesopleurae of Selandria decorata (Cress.)

FIG. 243.-Prepectus of Eustromboceros sp.

FIG. 244.--Prepectal ridge of Strongylogaster distans (Nort.)

FIG. 245.-Tarsal claw of Aneugmenus flavipes.

FIG. 246.-Compound eye of Dolerus apricus (Nort.), anterior aspect.

FIG. 247.-Compound eye of Dolerus elderi (Kinc.), anterior aspect.

FIg. 248.-Tarsal claw of Adelesta nova.

FIG. 249.-Portion of hind wing of Adelesta nova.

FIG. 250.-Portion of front wing of Entodecta capitalis (Nort.)

FIG. 251.-Outline of head of Caliroa aethiops, dorsal aspect.

FIg. 252.-Outline of head of Phyllotoma nemorata, dorsal aspect.

Fig. 253.-Antenna of Scolioneura populi (Marl.).

FIG. 254.-Antenna of Entodecta capitalis.

FIG. 255.-Basal segments of antenna of Cladius pectinicornis.

FIg. 256.-Basal segments of antenna of Priophorus sp.

FIG. 257.-Portion of front wing of Metallus rubi.

FIG. 258.-Portion of hind wing of Entodecta capitalis.

Fig. 259.-Portion of hind wing of Fenusa alumna (MacG.)

FIg. 260.-Saw of Trichiocampus viminalis (Fall.)

FIG. 261.-Saw of Priophorus sp.

FIG. 262.-Tarsal claw of Anoplonyx canadensis (Harr.).

Fig. 263.-Tarsal claw of Caulocampus acericaulis (MacG.).

FIG. 264.-Tarsal claw of Pachynematus extensicornis (Nort.).

FIG. 265.-Tarsal claw of Micronematus gregarius (Dyar).

FIG. 266.-Tarsal claw of Pristiphora bivittata (Nort.).

FIG. 267.-Tarsal claw of Nematus ventralis.

FIG. 268.-Tarsal claw of Eunra sp.

FIG. 269.- Tarsal claw of Adelomos cleone Ross.

FIG. 270.-Left mandible of Hemichroa thoracica (Harr.), lateral aspect.

FIG. 271.-Left mandible of Nematinus unicolor (Nort.), lateral aspect.

FIG. 272.-Left mandible of Nematus ventralis, lateral aspect.

FIG. 273.-Left mandible of Euura hoppingi Ross, lateral aspect.

FIg. 274.-Left mandible of Adelomos cleone, lateral aspect.

FIG. 275.-Left mandible of Neopareophora litura (Klug), lateral aspect.

FIG. 276.-Hind tibia of Nematus abbottii (Kby.).

FIG. 277.-Hind tibia of Croesus latitarsus Nort. 
(b)

233234

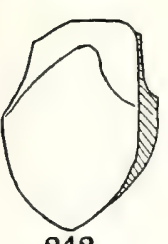

242

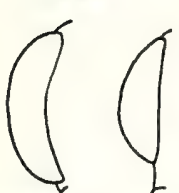

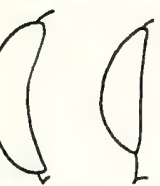

$246 \quad 247$
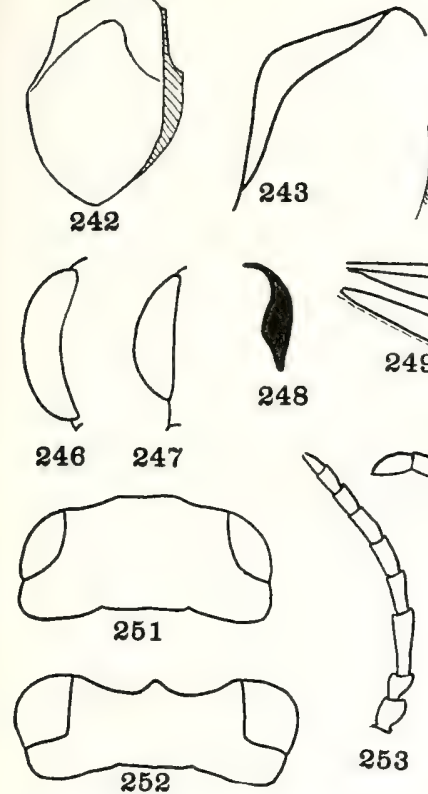

244
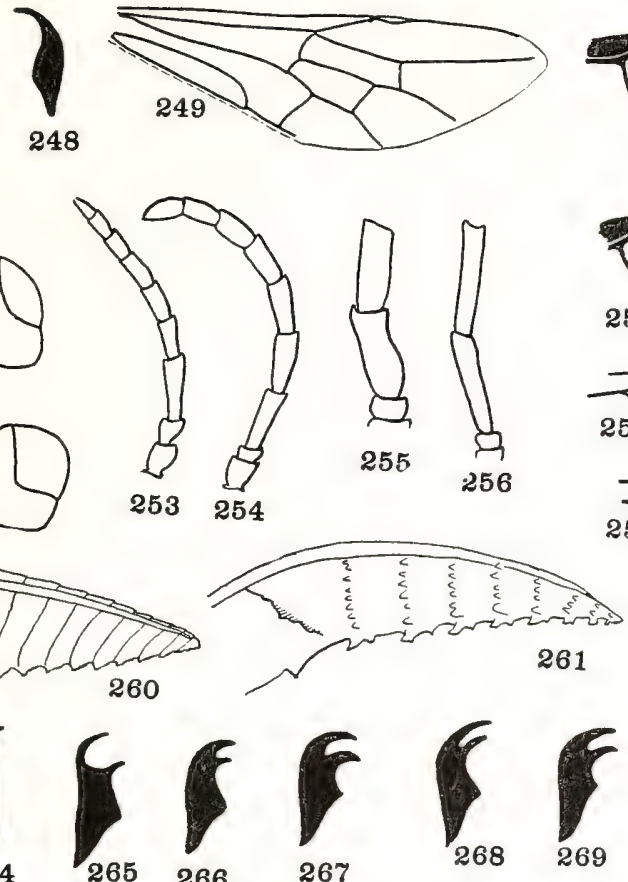

$262 \quad 263$
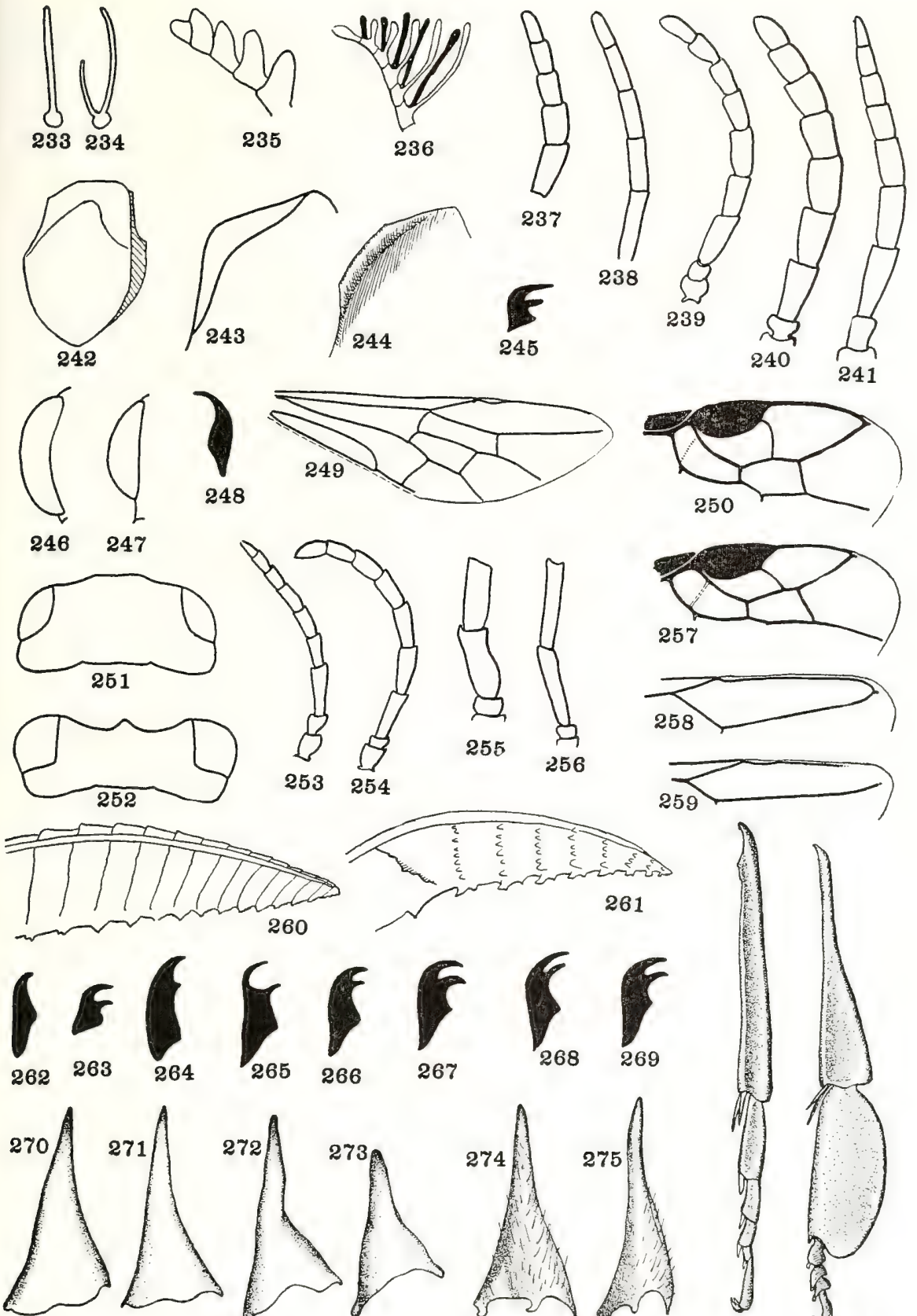

267
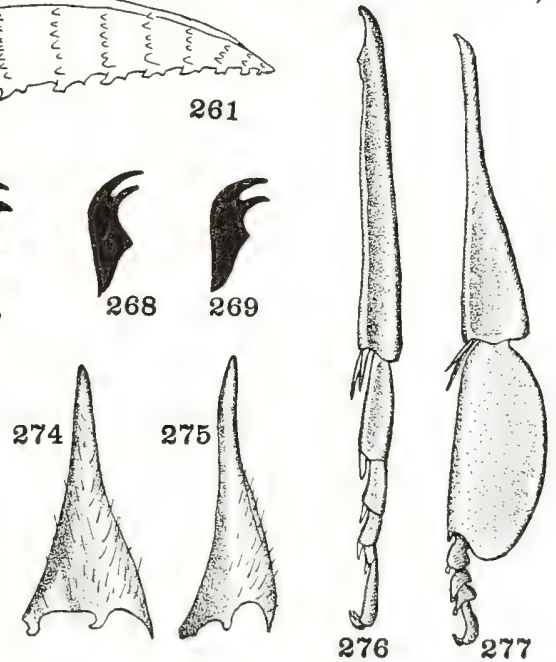

PLATE XIII 


\section{PLATE XIV}

FIG. 278.-Antenna of Adelomos cleone.

Fig. 279.-Antenna of Pseudodineura parvula (Nort.).

FIG. 280.-Antenna of Neopareophora litura.

FIG. 281.-Antenna of Hoplocampa sp.

FIG. 282.-Antenna of Craterocercus phytophagica (Dyar).

Fig. 283.-Antenna of Hemichroa crocea (Four.).

FIG. 284.-Antenna of Kerita fidala.

FIG. 285.-Portion of front wing of Adelomos cleone.

FIG. 286.-Portion of hind wing of Adelomos cleone.

FIG. 287.-Anal veins of hind wing of Neopareophora litura.

FIG. 288.--Anal veins of hind wing of Pseudodineura parrula.

FIG. 289.-Anal veins of front wing of Hemichroa crocea.

FIG. 290.-Anal veins of front wing of Hemichroa thoracica.

FIG. 291.-Head of Hemichroa crocea, anterior aspect.

FIG. 292.- - Head of Platycampus sp., anterior aspect.

FIG. 293.-Abdomen of female Nematinus unicolor, ventral aspect.

Fig. 294.-Head of Pseudodineura parvula, dorsal aspect.

FIG. 295.-Head of Kerita fidala, dorsal aspect.

FIG. 296.-Clypeus of Pachynematus extensicornis.

FIG. 297.-Clypeus of Pristiphora sp.

FIG. 298.-Sheath of Pikonema alaskensis (Roh.), lateral aspect.

FIG. 299.-Head of Amauronematus sp., lateral aspect.

Fig. 300.-Head of Amauronematus lineatus (Harr.), lateral aspect.

Fig. 301.-Head of Nematus sp., lateral aspect.

FIG. 302.-Head of Nematus ventralis, lateral aspect.

FIG. 303.-Sheath of Adelomos cleone, lateral aspect.

FIG. 304.-Sheath of Pristiphora erichsoni (Hartig), lateral aspect.

FIG. 305.-Subgenital plate of Pristiphora chlorea (Nort.).

FIG. 306.-Subgenital plate of Nematinus unicolor.

FIG. 307.-Subgenital plate of Pikonema alaskensis.

Fig. 308.-Sheath of Neopareophora litura, ventro-lateral aspect.

Fig. 309.-Sheath of Pseudodineura parula, lateral aspect.

FIG. 310.-Saw of Kerita fidala.

FIG. 311.-Sheath of Neopareophora litura, dorsal aspect.

FIG. 312.-Sheath of Pseudodineura parvula, dorsal aspect.

Abbreviations

$1 A$ first anal vein

$2 A \& 3 A$ second and third anal veins

$r, 2 r$ radial and second radial cross-veins, respectively 

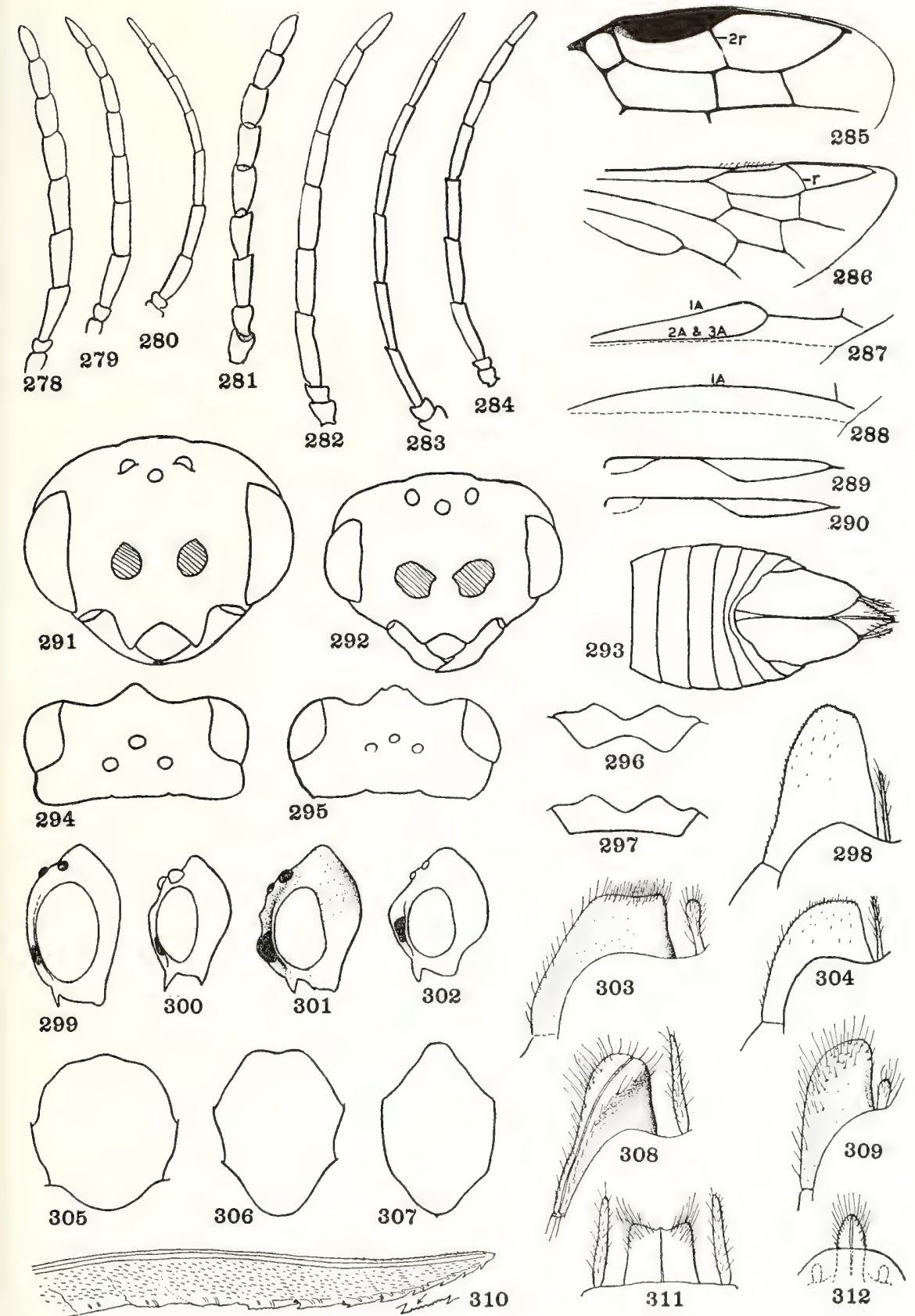

\section{PLATE XIV}




\section{PLATE XV}

FIG. 313.-Penis valve of Pristiphora chlorea.

FIG. 314.-Penis valve of Pristiphora erichsoni.

FIG. 315.-Penis valve of Nematinus unicolor.

FIG. 316.-Penis valve of Nematus ribesii.

FIG. 317.-Left mandible of Hemichroa thoracica.

FIG. 318.-Right mandible of Kerita fidala.

FIG. 319.-Left mandible of Pseudodineura parrula.

FIG. 320.-Clypeus of Ametastegia coloradensis (Weld.).

FIG. 321.-Clypeus of Empria multicolor (Nort.).

FIG. 322.-Clypeus of Ametastegia tener (Fall.).

FIG. 323.-Clypeus of Empria nordica Ross.

FIG. 324.--Procidentia of Pikonema alascensis.

FIG. 325.-Procidentia of Pristiphora chlorea.

FIG. 326.-Eighth tergite of Nematimus unicolor.

FIG. 327.-Clypeus of Allantus cinctus (L.).

FIG. 328.-Clypeus of Aphilodyctiutm fidum (Cress.).

FIG. 329.-Mesopleurae and sternum of Eriocampa rotunda (Nort.).

FIG. 330.-Praescutum of Dimorphopteryx abnormis Roh.

FIG. 331.-Praescutum of Eriocampa ovata (L.).

FIG. 332.-Clypeus of Monosoma inferentia (Nort.).

FIG. 333.-Clypeus of Monostegia abdominalis (Fabr.).

FIG. 334.-Head of Phrontosoma belfragei (Cress.), anterior aspect.

FIG. 335.-Praeputial plates of Ametastegia glabrata (Fall.).

FIG. 336.-Praeputial plates of Aphilidyctium fidum.

FIG. 337.-Anal veins of front wing of Ametastegia equiseti (L.).

FIG. 338.-Anal veins of front wing of Aphilodyctium fidum.

FIG. 339.-Anal veins of front wing of Monosoma inferentia.

FIG. 340.-Dorsum of abdomen of Empria obscurata (Cress.). showing white, paired areas.

FIG. 341.-Praeputial plates of Eriocampa rotunda.

FIG. 342.-Praeputial plates of Empria maculata (Nort.).

FIG. 343.-Praeputial plates of Taxonus unicinctus (Nort.).

FIg. 344.-Praeputial plates of Allantus mellipes (Nort.).

FIG. 345.-Hind tibia and tarsi of Monosoma inferentia.

FIG. 346.-Hind tibia and tarsi of Monostegia abdominalis.

FIG. 347.-Hind tarsi of Taxomus epicera.

FIG. 348.-Hind tarsi of Allantus cinctus. 

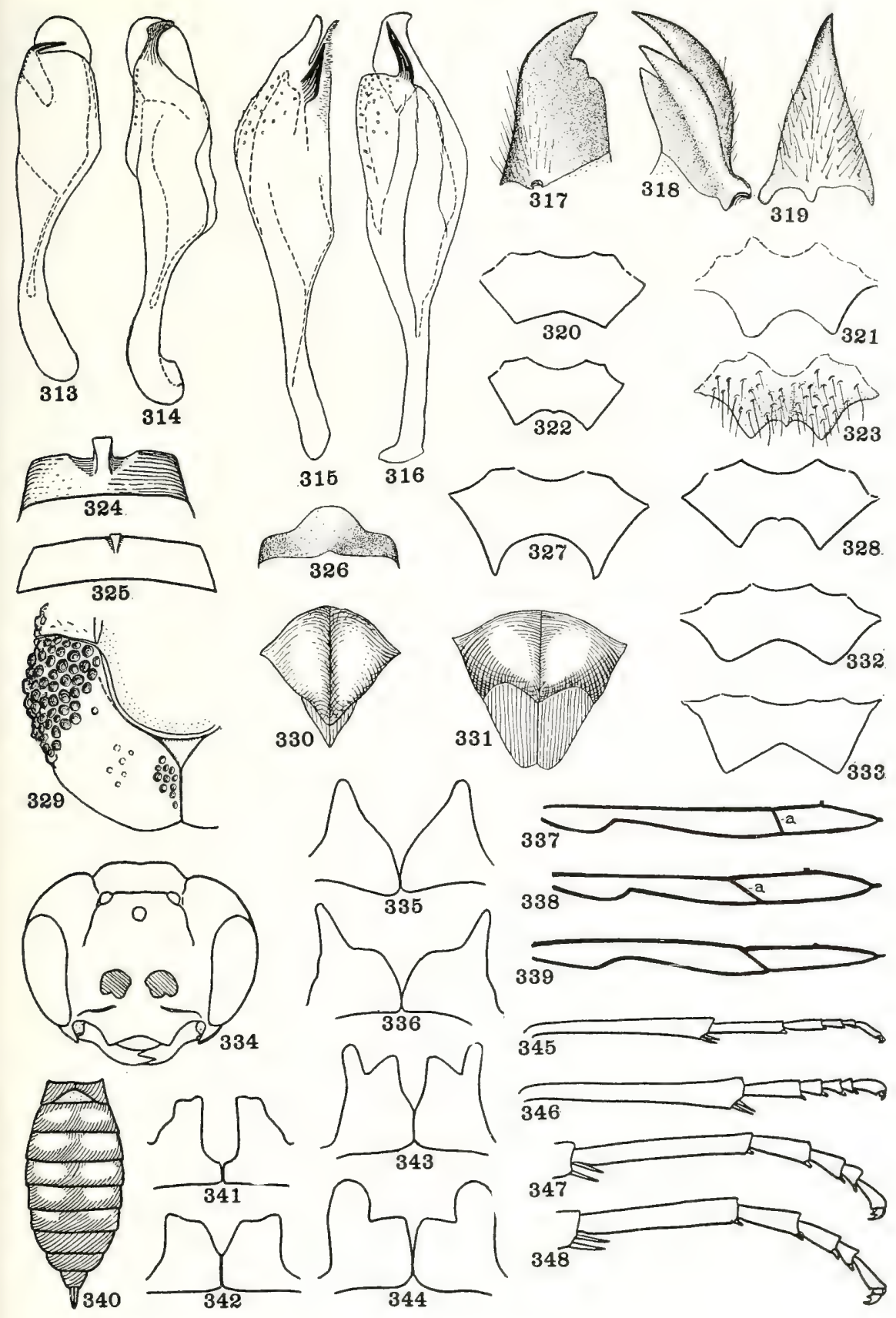

PLATE XV 


\section{PLATE XVI}

FIG. 349.-Antenna of Tethida cordigera.

Fig. 350.-Antenna of Valco irrogata (Cress.).

FIG. 351.-Antenna of Waldheimia pygmaea (Say).

LiIG. 352.-Antenna of Waldheimia carbonaria (Cress.).

FIG. 353.-Antenna of Lagonis nevadensis (Cress.).

FIG. 354.-Antenna of Paracharactus rudis (Nort.).

FIG. 355.-Antenna of Ceratulus spectabilis MacG.

FIG. 356.-Antenna of Rhadinoceraea aldrichi (MacG.).

FIG. 357.- Tarsal claw of Claremontia typica Rohwer.

FIG. 358.-Stub of vein $2 \mathrm{~A} \& 3 \mathrm{~A}$ of front wing of Lagonis nevadensis.

FIG. 359.-Stub of vein $2 \mathrm{~A} \& 3 \mathrm{~A}$ of front wing of Phymatocera fumipennis.

FIG. 360.-Stub of vein $2 \mathrm{~A} \& 3 \mathrm{~A}$ of front wing of Paracharactus niger (Harrington).

FIG. 361.-Prepectus of Tethida cordigera.

FIG. 362.-Prepectus of Eutomostethus ephippinm (Panzer).

FIG. 363.-Apex of lancet of Lycaota sodalis.

FIG. 364.-Apex of lancet of Lycaotella spissipes.

Fig. 365.-Head of Lagonis nevadensis, lateral aspect.

FIG. 366.-Head of Periclista californica Roh., lateral aspect.

FIG. 367.-Head of Blennocampa rubi, lateral aspect.

Fig. 368.- Head of Pareophora minuta (MacG.), lateral aspect.

FIG. 369.-Head of Valco sp., lateral aspect.

FIG. 370.--Head of Valco irrogata, lateral aspect.

FIG. 371.-Penis valve of Lycaota sodalis.

FIG. 372.-Penis valve of Lycaotella spissipes.

FIG. 373.-Head of Lagium atroviolaceum (Nort.), anterior aspect.

FIG. 374.--Head of Aglaostigma rubens (Cress.), anterior aspect.

FIG. 375.-Head of Macrophya sp., anterior aspect.

FIG. 376.-Head of Tenthredo subnigriceps, lateral aspect.

FIG. 377.-Head of Macrophya pluricincta, lateral aspect.

FIG. 378.-First and second abdominal tergites of Rhogogaster viridis (L.).

FIG. 379.--First and second abdominal tergites of Zaschizony.x montana.

FIG. 380.-Anal veins of front wing of Lagium atroviolaceum.

FIG. 381.-Anal veins of front wing of Rhogogaster sp.

FIG. 382.-Left mandible of Rhogogaster lateraria (Cress.).

FIG. 383.-Middle and hind coxae of Tenthredo pectoralis Norton.

FIG. 384.-Middle and hind coxae of Macrophya lineata Norton. 

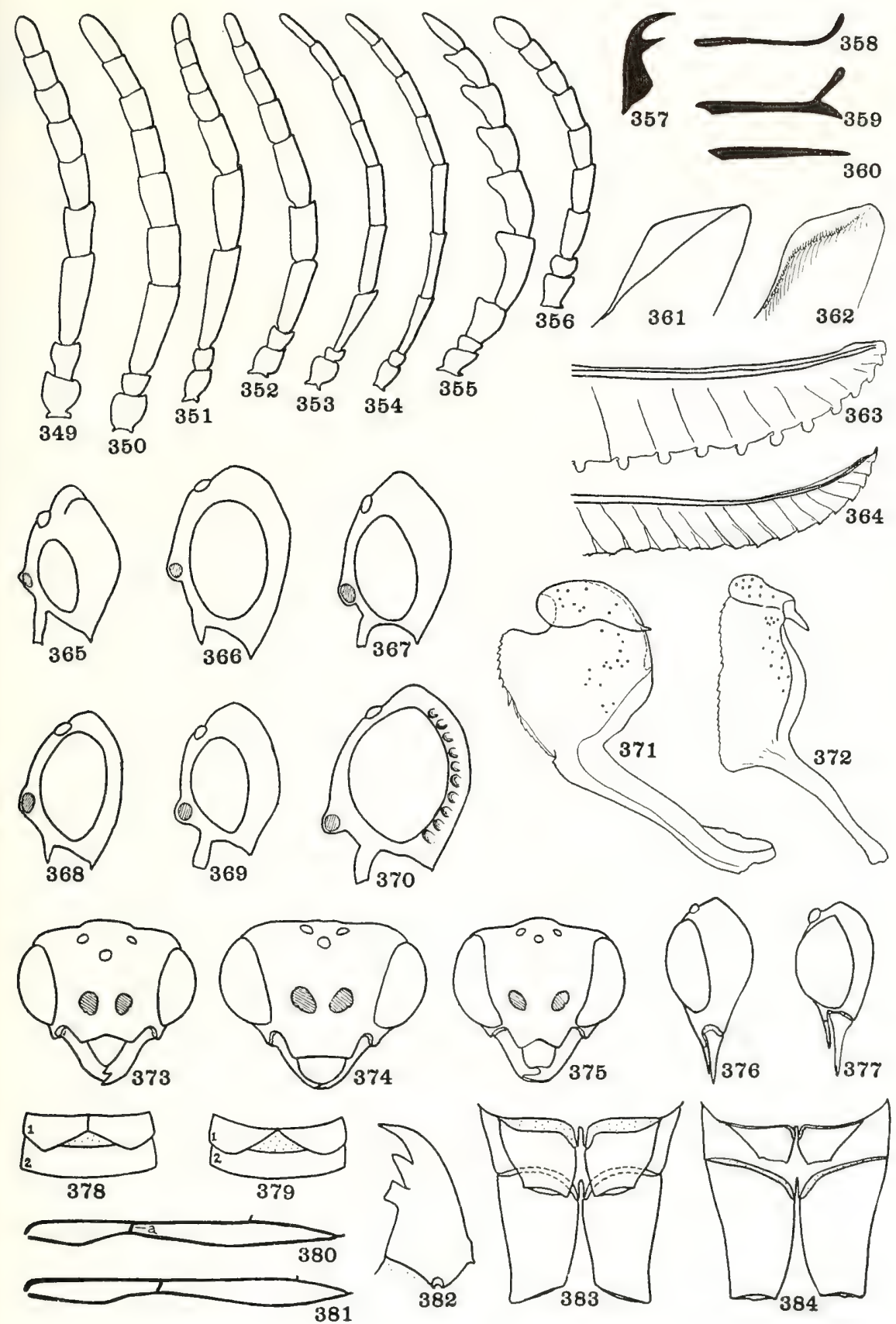

PLATE XVI 


\section{PLATE XVII}

FIG. 385.-Hind femur of Macrophya pluricincta.

FIG. 386.- Tarsal claw of Aglaostigma semilutea (Nort.).

FIG. 387.-Portion of front wing of Xyelecia nearctica.

FIG. 388.-Hind femur of Tenthredo dubius (Nort.).

FIG. 389.-Tarsal claw of Leucopelmonus confusus (Nort.).

FIG. 390.-Portion of front wing of Xyela alberta (Curr.).

FIG. 391.-Sheath of Xyelecia nearctica, lateral aspect.

FIG. 392.-Portion of front wing of Xyela sp.

FIG. 393.-Portion of front wing of Macroxyela ferruginea.

FIG. 394.-Sheath of Megaxyela aviingrata (Dyar), lateral aspect.

FIG. 395.-Clypeus of Macroxyela ferruginea.

FIG. 396.-Portion of front wing of Neurotoma fasciata (Nort.).

FIG. 397.-Sheath of Macroxyela ferruginea, lateral aspect.

FIG. 398.-Clypeus of Megaxyela aviingrata.

FIG. 399.-Front tibia of Acantholyda sp.

FIG. 400.-Portion of front wing of Neurotoma sp.

FIG. 401.-Portion of front wing of Acantholyda sp.

FIG. 402.-Sheath of Xyela sp., lateral aspect.

FIG. 403.-Sheath of Pleroneura aldrichi, lateral aspect.

FIG. 404.-Tarsal claw of Cephalcia frontalis (Newm.).

FIG. 405--Tarsal claw of Pamphilius sp.

FIG. 406.-Portion of front wing of Ophrynella nigricans (Cam.).

FIG. 407.-Portion of front wing of Orussus sp.

FIG. 408.-Seventh abdominal sternite of female Pamphilius sp.

FIG. 409.- - Seventh abdominal sternite of female Acantholyda sp.

FIG. 410.-Head of Ophrynopus sp., anterior aspect.

FIG. 411.-Hind femur and tibia of Ophrynella nigricans.

Fig. 412.-Left mandible of Cephus clavatus (Nort.), lateral aspect.

FIG. 413.-Left mandible of Cephus cinctus Nort., lateral aspect.

FIG. 414.-Left mandible of Hartigia bicincta (Nort.), lateral aspect.

FIG. 415.-Left mandible of Janus integer, lateral aspect.

FIG. 416.-Antenna of Cephus clavatus.

FIG. 417.-Tarsal claw of Janus integer.

FIG. 418.-Antenna of Cephus tabidus (L.).

FIG. 419.-Antenna of Hartigia cressonii (Kby.).

FIG. 420.-Tarsal claw of Hartigia cressonii.

FIG. 421.-Tarsal claw of Cephus clavatus.

FIG. 422,-Tarsal claw of Cephus pygmaeus (L.).

FIG. 423.-Apical male sternites of Cephus pygmaeus.

FIG. 424.-Apical male sternites of Cephus tabidus.

\section{Abbreviations}

$M$ media

$S c_{1}$ subcosta 1

$S c_{2}$ subcosta 2

$R_{\mathrm{s}}$ radial-sector
$R_{\mathrm{B} 1}$ first branch of radial sector

$R_{\mathbf{s} 2}$ second branch of radial sector

$2 r$ second radial cross-vein 

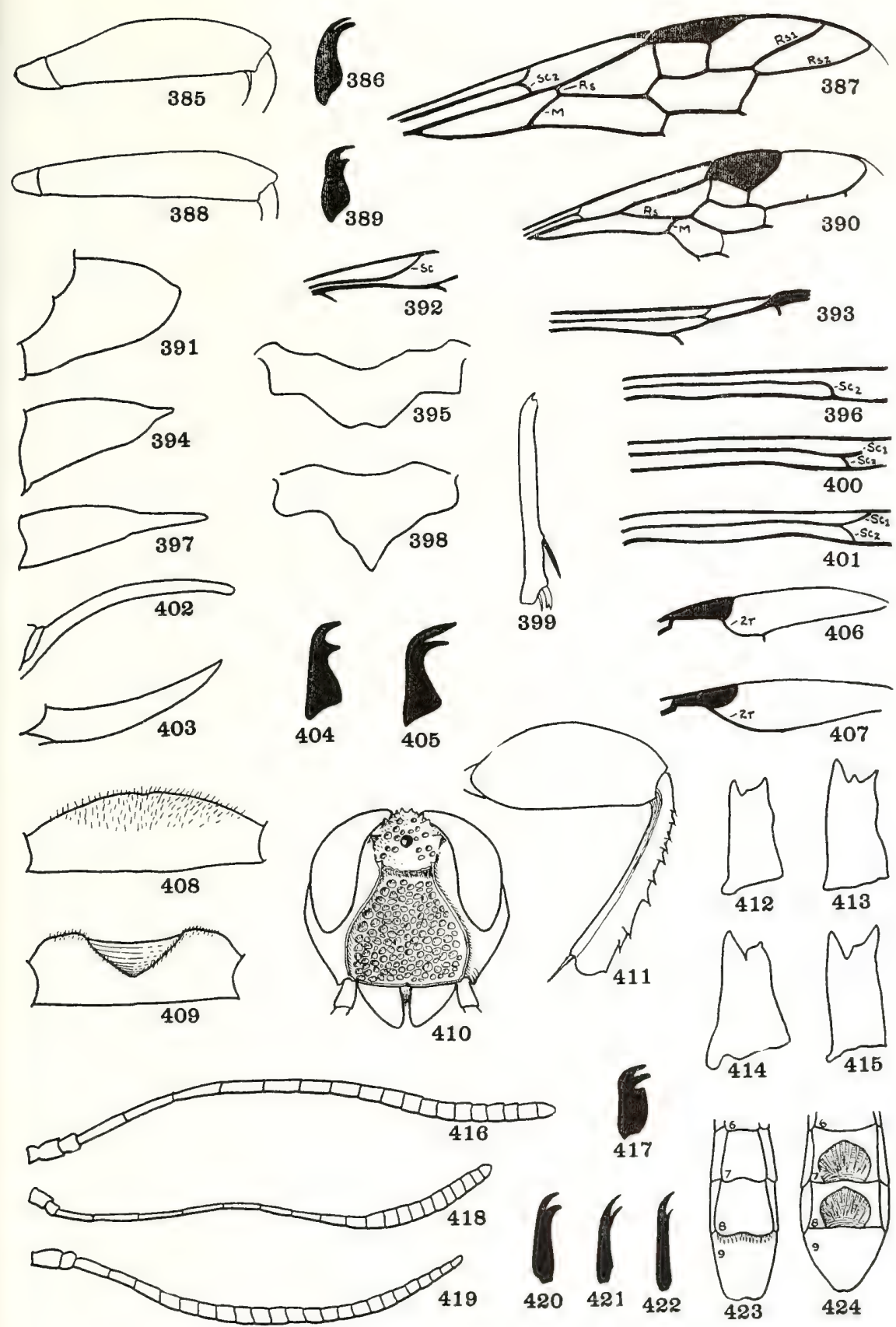

PLATE XVII 


\section{INDEX}

abbottii Kirby, Hypolaepus, 87

abbreviatus, Janus, 116

abdominalis (Fabricius), Monostegia, 91

abdominalis Fabricius, Tenthredo, 91

abdominalis Panzer, Tenthredo, 82

Abia Leach, 59

abietinus Christ, Pristiphora, 84

abietinus Scopoli, Orussus, 113

abnormis Provancher, Strongylogaster, 92

Acantholyda A. Costa, 109

Acanthoptenos, 52

weithii Ashmead, 52

acericaulis (MacG.), Caulocampus, 77

acericaulis MacGillivray, Priophorus, 77

Acordulecera Say, 55, 56

dorsalis Say, 56

Acorduleceridae, 34, 51, 55

Adelesta new genus, 68

Adelestinae, 63, 67

Adelomos Ross, 75, 81

cleone Ross, 81

Adirus Konow, 116

aenea Norton, Xyela, 108

aethiops (Fabricius), Caliroa, 70

Aglaostigma Kirby, 102, 103

eburneiguttatum Kirby, 103

agrorum (Fallén), Taxonus, 93

alaglossa, 18

alberta Curran, Neoxyela, 106

albidopictus Norton, Taxonus, 65

albipennis Zaddach, Tenthredo, 98

albipes Gmelin, Tenthredo, 98

Aleiodes, 32

algiricus Dovnar-Zapolskij, Paradirus, 116

Allantinae, 63, 88

Allantini, 89

Allantus Panzer, 89, 92

alni L., Tenthredo, 78

alternans A. Costa, Lyda, 110

Amauronematus Konow, 76, 77, 88

vaculus MacGillivray, 85

amelanchieridis (Rohwer), Varna, 79

americana Provancher, Dineura, 79

Ametastegia, 89, 91, 92

equiseti (L.), 92

fulvipes A. Costa, 92 glabrata (Fallén), 92

recens (Say), 92

tener (Fallén), 92

Anachoreta Gistel, 58

andrei Konow, Ophrynopus, 114

anepimeron, 27

Aneugmenus Hartig, 65, 66

flavipes var. flavitarsis Rohwer, 66

annulatus MacGillivray, Leucopelmonus, 103

Anoplolyda A. Costa, 110

Anoplonyx Marlatt, 75, 81

laricis (Marlatt), 82

occidens new name, 82

antacoila, 10

antennae, 10,20

antennal sclerites, 10

antennal socket, 10

Aomodyctium Ashmead, 92

Apericlista Enslin, 98

Aphadnurus O. Costa, 72

tantillus Costa, 72

Aphanisus MacGillivray, 98

lobatus MacGillivray, 98

Aphilodyctium Ashmead, 89, 92

fidum (Cresson), 92

apicalis Say, Strongylogaster, 93

Apocrita, 32, 42

appendiculatus Hartig, Diphadnus, 84

Ardis, 99

Arge Schrank, 52

macleayi (Leach), 52

Argidae, 34, 51

arizonensis Ashmead, Eriocampidea, 65

arvensis Panzer, Cephalcia, 109

Astatus Jurine, 115

Astatus Panzer, 115

satyrus Panzer, 116

Astochus MacGillivray, 103

fletcheri MacGillivray, 103

aterrima Klug, Tenthredo (Allantus), 100

atlas, 23

Atomacera Say, 52

debilis Say, 52

ruficollis Norton, 52

Atomostethus Enslin, 97

atra L., Tenthredo, 105 
atroviolaceum Norton, Tenthredo, 103 atrum MacGillivray, Phrontosoma, 93, 94

Augomonoctenus Rohwer, 57

libocedrii Rohwer, 57

aviingrata Dyar, Pleroneura, 107

Bactroceros Konow, 110

bakeri MacGillivray, Neocharactus, 98

bardus Say, Tenthredo, 97

basal plates, 29

basal ring, 30

basisternum, 23

belfragei (Cresson), Phrontosoma, 94

belfragei Cresson, Selandria, 94

bethunei MacGillivray, Metallus, 72

betulae Enslin, Pseudoxiphydria, 111

betuleti Klug, Tenthredo (Allantus), 70

bimaculatus, Janus, 116

biology, 46

Bivena MacGillivray, 103

maria MacGillivray, 103

Blennocampa Hartig, 96, 98

pygmaea Say, 98

Blennocampinae, 64, 95

Brachyphatnus Konow, 54

Braconid head, 14

Braconidae, 42

braziliensis Brullé, Tenthredo, 98

brevis Klug, Tenthredo (Allantus), 77

brunniventris (Cresson), Lyrola, 55

brunniventris Cresson, Schizocera, 55

brustiae, 16

Buprestidae, 41

Caenocephus Konow, 114, 115

jakowleffi Konow, 115

Caenolyda Konow, 109

Calameuta Konow, 115

californica Ashmead, Manoxyela, 107

californicus Marlatt, Gymnonychus, 84

Caliroa O. Costa, 69, 70

aethiops (Fabricius), 70

cerasi (L.), 70

cinxia (Klug), 70

nortonia MacGillivray, 94

sebetia O. Costa, 70

camelus L., Ichneumon, 111

Camponiscus E. Newman, 82

healaei E. Newman, 82

canadense Provancher, Xiphidion, 111

canadensis (Marlatt), Profenusa, 72 canadensis Marlatt, Scolioneura, 72

candidula Fallén, Tenthredo, 90

capitalis (Norton), Entodecta, 71

capitalis Norton, Selandria, 71

capreae Panzer, Nematus, 85

carbonaria (Cresson), Waldheimia, 98

cardo, 16, 30

caryicolum Dyar, Isodyctium, 98

Caulocampus Rohwer, 75, 77

acericaulis (MacG.), 77

cenchri, 26

Cepha Billberg, 116

Cephalcia Panzer, 109

arvensis Panzer, 109

signata (Fabricius), 109

Cephaleia Jurine, 109

Cephidae, 51, 114

Cephoidea, 33, 114

Cephosoma Gradl, 116 syringae Gradl, 116

Cephus Latreille, 115

filiformis Eversmann, 115

tabidus (Fabricius), 116

trimaculatus Say, 116

cerasi (L.), Caliroa, 70

Ceratulus MacGillivray, 95, 100

spectabilis MacGillivray, 100

Cerobactrus O. Costa, 116

cervical sclerites, 22

cervicum, 10

Cimbex Olivier, 59, 60

Cimbicidae, 34, 51, 59

cinctus L., Tenthredo, 92

cingulata Fabricius, Tenthredo, 67

cinxia (Klug), Caliroa, 70

chloreus Norton, Nematus, 85

chlorea (Norton), Pristiphora, 83, 85

Cladiinae, 64, 72

Cladius Rossi, 73, 74

isomerus Norton, 74

Claremontia Rohwer, 96, 97

typica Rohwer, 97

Clavellaria Lamarck, 60

Clavellarius Olivier, 60

cleone Ross, Adelomos, 81

closed head, 11

clypealiae, 10

clypeatum Rohwer, Zalagium, 105

clypeus, 10

Cockerellonis MacGillivray; 65

occidentalis MacGillivray, 65 
collaris MacGillivray, Phrontosoma, 94 collaris MacGillivray, Profenusa, 72 collaris Rohwer, Schizocerus, 55 coloradensis Weldon, Emphytus, 92 columba (L.), Tremex, 113 columbiana Provancher, Labidia, 105 compound eyes, 10 compressus (Fabricius), Janus, 116 confusus (Norton), Leucopelmonus, 103 connectens Stephens, Janus, 116 contigua Konow, Strongylogaster, 67 Copiosoma Kirby, 116 cordigera (Beauvois), Tethida, 97 cordigera Beauvois, Tenthredo, 97 coronata Klug, Tenthredo (Emphytus), 66

coronatus Fabricius, Orussus, 113 corpotentorium, 13

Coryna Lepeletier, 66

Corynia, 52

rosarum Imhof et Labram, 52 coxa, 27

Crabro Geoffroy, 59

humeralis Fourcroy, 59

crassa, 10

crassa Fallén, Tenthredo, 87

Craterocercus Rohwer, 75, 78

craverii A. Costa, Laurentia, 103

crawii Provancher, Sphacophilus, 54

cressonii (Kirby), Hartigia, 116

crevecoeuri Ashmead, Opisthoneura, 104

Cristiger Gistel, 58

crocea (Fourcroy), Hemichroa, 79

crocea Fourcroy, Tenthredo, 79

Croesus Leach, 75, 88

Cryptocampus Hartig, 87

Cryptus Jurine, 52

Cryptus Panzer, 52

segmentarius Panzer, 52

cupressi R. \& M., Susana, 77

Cyphona Dahlbom, 54

daekei MacGillivray, Phrontosoma, 94

dahli Hartig, Xyela, 107

debilis Say, Atomacera, 52

Decatria Stephens, 70

decorata Cress., Selandria, 66

delta Provancher, Pachyprotasis, 103

Dicerca, 41

difformis Panzer, Tenthredo, 74

dimmockii Cresson, Nematus, 86
Dimorphopteryx Ashmead, 89, 94

Dineura americana Provancher, 79

Dineuridea Rohwer, 81

Diphadnus Hartig, 84 appendiculatus Hartig, 84

Diprion Schrank, 57, 58 grandis Rohwer, 58

Diprionidae, 34, 51, 56

distadentes, 16

distans Norton, Strongylogaster, 67

dohrnii Tischbein, Kaliosysphinga, 72

Dolerinae, 63, 68

Dolerus Jurine, 68

Dolerus Panzer, 68

minutus Hartig, 79

pallimacula Lepeletier, 90

pedestris Panzer, 69

pratensis (L.), 69

dorsalis Say, Acordulecera, 56

Dosytheus Leach, 69

Druida E. Newman, 70 parviceps E. Newman, 70

dubia Cresson, Selandria, 97

dubitatus Norton, Taxonus, 65

duplaglossa, 20

dyari Rohwer, Hemichroa, 79

early sawfly stem, 38

eburneiguttatum Kirby, Aglaostigma, 103

ectogalea, 16

eglanteriae Fabricius, Tenthredo, 69

Emphytina Rohwer, 92

pulchella Rohwer, 92

Emphytus Klug, 92

coloradensis Weldon, 92

maculatus Norton, 90

Empria Lepeletier, 89, 90

tridens Konow, 90

Enages Gistel, 78

Endelomyia Ashmead, 70

endogalea, 16

enodis L., Tenthredo, 52

Entodecta Konow, 70, 71

capitalis (Norton), 71

humilis Konow, 71

epicera Say, Taxonus, 93

epicranial suture, 10

epimeral suture, 27

Epitaxonus MacGillivray, 65

Ephippionotus O. Costa, 116

ephippium Panzer, Tenthredo, 97 
equiseti (L.), Ametastegia, 92

Erasminus Gistel, 82

Eriocampa Hartig, 89, 94

Eriocampidea Ashmead, 64, 65

arizonensis Ashmead, 65

Eriocampini, 90

Eriocampoides Konow, 70

Ermilia O. Costa, 93

pulchella O. Costa, 93

Erythraspides Ashmead, 98

erythrocephala L., Tenthredo, 109

erythrothorax Rohwer, Marlattia, 81

Eumetabolus Shulz, 116

Eupareophora, 99

eustipes, 16

Eustromboceros Rohwer, 65, 66

Eutomostethus Enslin, 95, 97

Euura E. Newman, 75, 76, 87

gallae E. Newman, 87

hoppingi new name, 88

excavata Norton, Macrophya, 94

eye sclerite, 10

fallax Lepeletier, Nematus, 88

family groupings, 34

families, key to, 51

fasciata L., Tenthredo, 59

faunus Newman, Phylloecus, 116

female, 50

femur, 27

Fenusa Leach, 70, 72

pusilla (Lepeletier), 72

ulmi Sundevall, 72

ferruginea Say, Xyela, 108

fidala new species, Kerita, 80

fidum (Cresson), Aphilodyctium, 92

filicis Klug, Tenthredo, 67

filiformis Eversmann, Cephus, 115

first abdominal tergum, 29

flavans Klug, Selandria, 66

flavescens Thomson, Selandria, 66

flavipes var. flavitarsis Rohwer, Aneugmenus, 66

flaviventris L., Tenthredo, 109

fletcheri MacGillivray, Astochus, 103

floridana MacGillivray, Selandria, 66

14-punctata Norton, Tenthredo, 103

front, 10

frontalis Westwood, Lyda, 109

fulvipes A. Costa, Ametastegia, 92

furcata Fabricius, Hylotoma, 54 furcella, 23

fusca Malaise, Pontopristia suavis var., 88

fuscicornis Fabr., Sirex, 112

fuscicornis Hartig, Nematus, 84

galea, 16

gallae, E. Newman, Euura, 87

gallicola Stephens, Nematus, 87

genae, 10

genapontal head, 12

genital capsule, 30

gibbosa Fallén, Tenthredo, 103

gigas L., Ichneumon, 112

glabrata (Fallén), Ametastegia, 92

gonager Fabricius, Tenthredo, 68

Gongylocorsia Konow, 109

gonamaculae, 30

gonocardo, 30

gonostipes, 30

gracilis Marlatt, Pontania, 88

grandis Lepeletier, Nematus, 73

grandis Rohwer, Diprion, 58

gregarius (Marlatt), Micronematus, 86

gregarius Marlatt, Pachynematus, 86

guana MacGillivray, Pareophora, 99

guara MacGillivray, Pareophora, 99

guttatum Fallén, Tenthredo, 90

Gymnonychus Marlatt, 84

californicus Marlatt, 84

harpes, 30

Harpiphorus varianus Norton, 93

Hartigia Schiödte, 116

cressonii (Kirby), 116

linearis (Schrank), 116

nigra (Harris), 116

trimaculatus (Say), 116

head capsule, 9

head types, 11

closed, 11

genapontal, 11

maxapontal, 11

open, 11

healaei E. Newman, Camponiscus, 82

Hemichroa Stephens, 75, 76, 78

crocea (Fourcroy), 79

dyari Rohwer, 79

pallida Ashmead, 79

phytophagica Dyar, 78

washingtonia R. \& M., 79 
Hemitaxonus Ashmead, 64, 65

Heterarthrus Stephens, 70

hieroglyphica Christ, Tenthredo, 109

histrionicus MacGillivray, Parabates, 71

Holcocneme Konow, 87

Homoeoneura Ashmead, 103

Hoplocampa Hartig, 75, 77

laricis Marlatt, 81

montana Cresson, 104

hoppingi new name, Euura, 88

host plants, 47

humeralis Fourcroy, Crabro, 59

humilis Konow, Entodecta, 71

hyaline Norton, Themos, 55

hyalinus MacGillivray, Neotomostethus, 84

Hybonotus Klug, 111

Hylotoma Latreille, 52

macleayi Leach, 52

furcata Fabricius, 54

Hymenoptera, 50

Hypargyricus MacGillivray, 100

infuscatus MacGillivray, 100

hypogastricus Hartig, Nematus (Leptopus), 82

Hypolaepus Kirby, 87

abbottii Kirby, 87

Hypotaxonus Ashmead, 93

hypothesis of genealogy, 35

Ichneumon camelus L., 111

gigas L., 112

spectrum L., 112

ignotus Norton, Selandria, 90

inferentia Norton, Taxonus, 91

infuscatus MacGillivray, Hypargyricus, 100

irrogata Cresson, Selandria, 99

Isodyctium Ashmead, 98

caryicolum Dyar, 98

isomerus Norton, Cladius, 74

Itycorsia Konow, 109

jakowleffi Konow, Caenocephus, 115

jakowlewi Semenov, Parabia, 59

Janus Stephens, 114, 116

abbreviatus, 116

bimaculatus, 116

compressus (Fabricius), 116

connectens Stephens, 116

luteipes (Lepeletier), 116 johnsoni MacGillivray, Schizocerus, 55

julii Brebisson, Pinicola, 106

juniperi L., Tenthredo, 57

juniperi Rohwer, Platycampus, 82

juvencus L., Sirex, 112

Kaliofenusa Viereck, 72

Kaliosysphinga Tischbein, 72

dohrnii Tischbein, 72

katepimeron, 27

Kelidoptera Konow, 110

Kerita new genus, 75, 80

fidala new species, 80

Keys, 50

Kincaidia MacGillivray, 103

kincaidi Marlatt, Pontania, 88

Konowia Brauns, 111 megapolitana Brauns, 111

Labidia Provancher, 105 columbiana Provancher, 105 opimus Cresson, 105

labrum, 15

lacinia, 16

Lagium Konow, 102, 103

Lagonis new genus, 96, 99 nevadensis (Cresson), 100

laricis (Marlatt), Anoplonyx, 82

laricis Marlatt, Hoplocampa, 81

laricis R. \& M., Platycampus (Anoplonyx), 82

larval characters, 45

Laurentia A. Costa, 103

craverii A. Costa, 103

rubens (Cress.), 103

semilutea (Norton), 103

lecontei Fitch, Lophyrus, 58

legs, 27

Leptocerca Hartig, 78

Leptocercus Thomson, 78

Leptopus Hartig, 82

Leston new subgenus, 53, 54

Leucempria Enslin, 90

Leucopelmonus MacGillivray, 102, 103 annulatus MacGillivray, 103 confusus (Norton), 103

leucostomus Rohwer, Parabates, 71

leucostomus Rohwer, Paracharactus, 100

libocedrii Rohwer, Augomonoctenus, 57

lichtwardti Konow, Rhogogaster, 104

limacina Retzius, Tenthredo, 70 
linearis (Schrank), Hartigia, 116 lineata Christ, Strongylogaster, 67 lineatus Rohwer, Schizocerus, 54 lineolata Klug, Tenthredo (Allantus), 98

Liolyda Ashmead, 109

lobatus MacGillivray, Aphanisus, 98

Loboceridae, 34

Loderus Konow, 69

longulus Norton, Strongylogaster, 67

Lophyrus Latreille, 58

lecontei Fitch, 58

lucida Panzer, Tenthredo (Nematus), 87

lucorum L., Tenthredo, 59

luridiventris (Fallén), Platycampus, 82 luridiventris Konow, Pareophora, 99

lutea L., Tenthredo, 60

luteipes (Lepeletier), Janus, 116

luteiventris Klug, Tenthredo, 97

luteiventris O. Costa, Ephippionotus, 116

Lycaota Konow, 101

Lycaotella Ross, 101

Lycaotinae, 64, 101

Lyda Fabricius, 110

alternans A. Costa, 110

frontalis Westwood, 109

maculipennis Stein, 110

mandibularis Zaddach, 109

Lygaeonematus Konow, 84

Lyrola new genus, 52, 55

brunniventris (Cresson), 55

MacGillivraya Ashmead, 77

oregonensis Ashmead, 77

MacGillivrayella Ashmead, 77

macleayi (Leach), Arge, 52

Macremphytus MacGillivray, 89, 93

Macrocephus ulmariae Schlectendal, 116

Macrophya Dahlbom, 103, 105

excavata Norton, 94

montana Scopoli, 105

nebulosa Ed. André, 103

Macrophyopsis Enslin, 103

Macroxyela Kirby, 106, 108

maculatus Norton, Emphytus, 90

maculipennis Stein, Lyda, 110

major Cresson, Xyela, 107

malaisei Conde, Neurosiobla, 104

male, 50

male genitalia, 30

malvacearum Cockerell, Neoptilia, 54 mandible, 10, 15

mandibulariae, 10

mandibularis Zaddach, Lyda, 109

Manoxyela Ashmead, 107

californica Ashmead, 107

Manubria, 30

maria MacGillivray, Bivena, 103

Marlattia Ashmead, 81

erythrothorax Rohwer, 81

martini MacGillivray, Monostegia, 91

martini MacGillivray, Neopareophora, 81

Mastigocerus Klug, 106

mathesoni MacGillivray, Phlebatrophia, 70

maxacava, 11

maxapontal head, 11

maxillae, 16

maxillariae, 10

median sclerotized style, 30

medullaris Hartig, Nematus (Cryptocampus), 87

Megalodontidae, 108

Megalodontoidea, 33, 35, 106

megapolitana Brauns, Konowia, 111

Megaxyela Ashmead, 106, 107

Melanobates MacGillivray, 71

melanopterus Rohwer, Stromboceros (Eustromboceros), 66

Melanoselandria Ashmead, 100

zabriskei Ashmead, 100

mellipes Harris, Xiphydria, 111

mentum, 19

mesoepimeron, 27

mesoepisternum, 27

Mesoneura, 78

mesonotum, 25

mesopleurae, 26

mesosternum, 24

Metallus Forbes, 70, 71

bethunei MacGillivray, 72

rohweri MacGillivray, 72

rubi Forbes, 71, 72

metapleurae, 27

metanotum, 26

metatentorium, 13

methods, 7

mexicana Ashmead, Neoptilia, 54

micans Klug, Tenthredo (Allantus), 100

Micrarge Ashmead, 52 
Micronematus Konow, 76, 77, 86

gregarius (Marlatt), 86

monogyniae (Hartig), 86

militaris Cresson, Nematus, 79

minuta (MacGillivray), Pareophora, 99

minutus Hartig, Dolerus (Pelmatopus), 79

minutus MacGillivray, Monophadnus, 99

Mogerus MacGillivray, 98

mola, 16

Monardis, 99

Monoctenus Hartig, 57

monogyniae (Hartig), Micronematus, 86

Monophadnoides Ashmead, 98

Monophadnus Hartig, 98 minutus MacGillivray, 99 rubi Harris, 98

Monosoma MacGillivray, 89, 91

Monosoma Viereck, 91

Monostegia O. Costa, 89, 91 abdominalis (Fabricius), 91

martini MacGillivray, 91

nearctica Rohwer, 91

quercus-alba Norton, 70

rosae Harris, 70

Monsoma MacGillivray, 91

montana Cresson, Hoplocampa, 104

montana (Cresson), Zaschizonyx, 104

montana Scopoli, Macrophya, 105

multicinctus Rohwer, Tomostethus, 96

multicolor Norton, Taxonus, 90

nearctica Rohwer, Monostegia, 91

nearctica Ross, Xyelecia, 107

nebulosa Ed. André, Macrophya, 103

Nematinae, 63, 64, 74

Nematinus Rohwer, 75, 76, 82

Nematus Panzer, 76, 77, 86, 87

capreae Panzer, 85

chloreus Norton, 85

dimmockii Cresson, 86

fallax Lepeletier, 88

fuscicornis Hartig, 84

gallicola Stephens, 87

grandis Lepeletier, 73

hypogastricus Hartig, 82

medullaris Hartig, 87

militaris Cresson, 79

pallifrons Cresson, 85

pectoralis Lepeletier, 81

pilicornis Dahlbom, 73

pini Retzius, 84 pullus Förster, 86

ventralis Say, 87

nemorata Fallén, Phyllotoma, 70

Neocharactus MacGillivray, 98

bakeri MacGillivray, 98

Neodiprion Rohwer, 57, 58

Neopareophora MacGillivray, 75, 81 martini MacGillivray, 81

Neoptilia Ashmead, 53, 54 malvacearum Cockerell, 54 mexicana Ashmead, 54

Neopus Viereck, 103

Neotomostethus MacGillivray, 84 hyalinus MacGillivray, 84

Neoxyela Curran, 106, 107 alberta Curran, 106

Neurosiobla Conde, 104 malaisei Conde, 104

Neurotoma Konow, 109

nevadensis (Cresson), Lagonis, 100

nevadensis Cresson, Selandria, 100

niger Norton, Ptenos, 53

nigra (Harris), Hartigia, 116

nigricans Cameron, Oryssus, 113

nigrilabris Rohwer, Zamacrophya, 105

nigripes (Klug), Pareophora, 99

nigrita Fabricius, Tenthredo, 96

nitida Klug, Tenthredo (Allantus), 93

nortonia MacGillivray, Caliroa, 94

nova Norton, Selandria, 68

obscuratus MacGillivray, Paracharactus, 97

occidens new name, Anoplonyx, 82

occidentalis MacGillivray, Cockerellonis, 65

occipital region, 10

occipital suture, 10

occipitopostgenal suture, 10

ocelli, 10

ochropoda Klug, Tenthredo (Emphytus), 70

oculata, 10

odontoidea, 10

Odontophyes Konow, 107

open head, 11

Ophrynella new genus, 113

Ophrynopus Konow, 113, 114

andrei Konow, 114

opimus Cresson, Labidia, 105

Opisthoneura Ashmead, 104

crevecoeuri Ashmead, 104 
oregonensis Ashmead, MacGillivraya, 77

Orthandria, 30, 36, 37

Orussidae, 35, 51, 113

Orussus Latreille, 113

abietinus Scopoli, 113

coronatus Fabricius, 113

Oryssus Fabricius, 113

nigricans Cameron, 113

ovata L., Tenthredo, 94

oxalata MacGillivray, Pseudoselandria, 66

Pachynematus Konow, 76, 85

gregarius Marlatt, 86

rarus MacGillivray, 86

trisignatus (Förster), 85

Pachyprotasis Hartig, 105

delta Provancher, 103

pacificus MacGillivray, Simplemphytus, 92

pacifica Marlatt, Pontania, 88

pallida Ashmead, Hemichroa, 79

pallifrons Cresson, Nematus, 85

pallimacula Lepeletier, Dolerus (Em. pria), 90

pallipes (Lepeletier), Priophorus, 73

pallipes (Lepeletier), Pristiphora, 84

pallipes Say, Strongylogaster, 93

palpi, 16, 19

palpifer, 16

Pamphiliidae, 35, 51, 108

Pamphilius Latreille, 110

Parabates MacGillivray, 71

histronicus MacGillivray, 71

leucostomus Rohwer, 71

Parabia jakowlewi Semenov, 59

Paracharactus MacGillivray, 95, 96, 97

leucostomus Rohwer, 100

obscuratus MacGillivray, 97

paracoila, 10

Paradirus Dovnar-Zapolskij, 116

algiricus Dovnar-Zapolskij, 116

paraglossae, 19

Parallomma Malaise, 103

parapenes, 30

parascutellar areas, 25

Paraselandria Ashmead, 66

Parasiobla Ashmead, 93

parastipes, 16

Parataxonus MacGillivray, 90

Paraxyela MacGillivray, 107

Pareophora Konow, 96, 99

guana MacGillivray, 99 guara MacGillivray, 99

luridiventris Konow, 99

minuta (MacGillivray), 99

nigripes (Klug), 99

parva (Norton), Pseudodineura, 80

parviceps E. Newman, Druida, 70

parvula Klug, Tenthredo (Allantus), 79

Paururus Konow, 112

Pectinia Brullé, 100

pectoralis Lepeletier, Nematus, 81

pedestris Panzer, Dolerus, 69

Pelmatopus Hartig, 79

penis, 30

penis valves, 30

Pergidae, 34

Periclista Konow, 96, 98

Periclistoptera Ashmead, 70

Perineura, 103

Perreyiidae, 34

Phlebatrophia MacGillivray, 70

mathesoni MacGillivray, 70

phragma, 25

Phrontosoma MacGillivray, 89, 93

atrum MacGillivray, 93, 94

belfragei (Cresson), 94

collaris MacGillivray, 94

daekei MacGillivray, 94

Phrontosomini, 90

Phylogeny, 48, 62

Phylloecus Newman, 116

faunus Newman, 116

Phyllotoma Fallén, 69, 70

nemorata Fallén, 70

vagans Fallén, 70

Phyllotominae, 63, 64, 69

Phymatocera Dahlbom, 95, 100

phytophagica Dyar, Hemichroa, 78

Pikonema new genus, 76, 86

pilicornis Dahlbom, Nematus (Priophorus), 73

pilosulus Rohwer, Stromboceros (Stromboceridea), 66

pinguis Norton, Strongylogaster, 94

pini L., Tenthredo, 58

pini Retzius, Nematus, 84

Pinicola Brebisson, 106

julii Brebisson, 106

pisum Walsh, Pontania, 88

Platycampus Schiödte, 75, 82

juniperi Rohwer, 82

laricis R. \& M., 82

luridiventris (Fallén), 82 
Pleroneura Konow, 106, 107 aviingrata Dyar, 107

pleural suture, 27

Pleuroneura Ashmead, 107

Poecilosoma Thomson, 90

Poecilostoma Dahlbom, 90

Poecilostomidea Ashmead, 90

politus Prov., Strongylogaster, 67

Polybates MacGillivray, 71

secundus Rohwer, 71

slossonae MacGillivray, 71

Polyselandria MacGillivray, 66

Polystichophagus Ashmead, 67

Polytaxonus MacGillivray, 92

pomum Walsh, Pontania, 88

Pontania O. Costa, 87

gracilis Marlatt, 88

kincaidi Marlatt, 88

pacifica Marlatt, 88

pisum Walsh, 88

pomum Walsh, 88

Pontopristia Malaise, 88

suavis fusca Malaise, 88

postclypeus, 10

postcoila, 10

postnotum, 25

post-tergite, 25

praescutum, 25

pratensis (L.), Dolerus, 69

pratorum Fallén, Tenthredo, 69

preapical spurs, 27

preclypeus, 10

prepectus, 26

presternal bridge, 24

pretentoria, 13

Priophorus Dahibom, 73

acericaulis MacGillivray, 77

pallipes (Lepeletier), 73

Pristiphora Latreille, 75, 76, 77, 83, 84

abietinus Christ, 84

chlorea (Norton), 85

pallipes (Lepeletier), 84

probasisternum, 23

Profenusa MacGillivray, 70, 72

canadensis (Marlatt), 72

collaris MacGillivray, 72

pronotum, 25

propleurae, 22

propleurodeme, 23

propodeum, 29

Prosecris Gistel, 90

prosternum, 23 prostheca, 16

Protemphytus Rohwer, 91, 92

Prototaxonus Rohwer, 67 typicus Rohwer, 67

Protoxyela MacGillivray, 108

proxadentes, 16

Pseudodineura Konow, 75, 79 parva (Norton), 80

Pseudoselandria MacGillivray, 66 oxalata MacGillivray, 66

Pseudosiobla Ashmead, 88, 94

Pseudotaxonus A. Costa, 67

Pseudoxiphydria Enslin, 111 betulae Enslin, 111

Ptenos Norton, 53 niger Norton, 53

Pteronidea Rohwer, 85, 86, 87

Pteronus Jurine, 58 quercus Marlatt, 85 testaceus Jurine, 84

Pterygophoridae, 34, 56 pulchella O. Costa, Ermilia, 93 pulchella Rohwer, Emphytina, 92 pullus Förster, Nematus, 86 pumila Klug, Tenthredo (Allantus), 71, 72

pumilus Klug, Tenthredo (Emphytus), 72

pusilla Dalman, Xyela, 106

pusilla Klug, Tenthredo (Allantus), 98

pusilla (Lepeletier), Fenusa, 72

pygmaea Say, Blennocampa, 98

pygmaeus L., Sirex, 115

quercus Marlatt, Pteronus, 85

quercus-alba Norton, Monostegia, 70

rapae L., Tenthredo, 105

rarus MacGillivray, Pachynematus, 86

recens (Say), Ametastegia, 92

repentinus MacGillivray, Unitaxonus, 92

reticulata L., Tenthredo, 109

Rhadinoceraea Konow, 95, 96, 100

Rhogogaster Konow, 102, 104

lichtwardti Konow, 104

Rhogogastera Konow, 104

robustus Provancher, Taxonus, 92

rohweri MacGillivray, Metallus, 72

rosae Harris, Monostegia, 70

rosae L., Tenthredo, 52

rosarum Imhof et Labram, Corynia, 52

rubens (Cress.), Laurentia, 103 
rubi Forbes, Metallus, 71, 72

rubi Harris, Monophadnus, 98

rubripes Cresson, Strongylogaster, 92

ruficollis Norton, Atomacera, 52

ruficorna MacGillivray, Tenthredopsis, 103

rufocinctus Norton, Strongylogaster, 93

rusticus auct., Tenthredo, 105

sagittae, 30

Sala new subgenus, 84,85

satyrus Panzer, Astatus, 116

Schizocera Lepeletier, 54

brunniventris Cresson, 55

tristis Cresson, 55

Schizocerus collaris Rohwer, 55

johnsoni MacGillivray, 55

lineatus Rohwer, 54

sericeiformis Rohwer, 54

fumipennis Dyar, tristis var., 55

zabriskei Webster and Malley, 54

Scolioneura Konow, 70

canadensis Marlatt, 72

scrophulariae L., Tenthredo, 104

scutum, 25

scutellum, 25

sebetia O. Costa, Caliroa, 70

secundus Rohwer, Polybates, 71

segmentarius Panzer, Cryptus, 52

Selandria Leach, 65, 66

belfragei Cresson, 94

capitalis Norton, 71

decorata Cress., 66

dubia Cresson, 97

flavans Klug, 66

flavescens Thomson, 66

floridana MacGillivray, 66

ignotus Norton, 90

irrogata Cresson, 99

nevadensis Cresson, 100

nova Norton, 68

sodalis Cresson, 101

spissipes Cresson, 101

vanduzeei (Rohwer), 66

Selandridea Rohwer, 66

vanduzeei Rohwer, 66

Selandriinae, 63, 64

semilutea (Norton), Laurentia, 103

septentrionalis L., Tenthredo, 88

sericeiformis Rohwer, Schizocerus, 54

sericeus L., Tenthredo, 59

Sericocera, 55 serva Fabricius, Tenthredo, 66

sexes, identification of, 50

signata (Fabricius), Cephalcia, 109

Simplemphytus MacGillivray, 92

pacificus MacGillivray, 92

Sirex L., 112

fuscicornis Fabr., 112

juvencus L., 112

pygmaeus L., 115

tabida Fabricius, 116

trogylodyta Fabricius, 115

Siricidae, 35, 51, 111

Siricinae, 112

Siricoidea, 33, 35, 110

slossonae MacGillivray, Polybates, 71

sodalis Cresson, Selandria, 101

specialized Nematinae, 83

spectabilis MacGillivray, Ceratulus, 100

spectrum L., Ichneumon, 112

Sphacophilus Provancher, 53, 54

crawii Provancher, 54

spinisternum, 23

spissipes Cresson, Selandria, 101

Sterictiphora Billberg, 52, 53, 54

zabriskei (W. \& M.), 54

sterno-pleural sutures, 24

Stevenia Brullé, 73

stipes, 16, 30

stipulae, 19

Stirocorsia Konow, 114

Stromboceridea Rohwer, 66

Stromboceros Konow, 65 melanopterus Rohwer, 66

pilosulus Rohwer, 66

Stromboceridea Rohwer, 66

Strongylogaster Dahlbom, 64, 65, 67

abnormis Provancher, 92

apicalis Say, 93

contigua Konow, 67

distans Norton, 67

lineata Christ, 67

longulus Norton, 67

pallipes Say, 93

pinguis Norton, 94

politus Prov., 67

rubripes Cresson, 92

rufocinctus Norton, 93

tacitus (Say), 67

tibialis Cress., 67

Strongylogastroidea Ashmead, 93

Strophandria, 30, 36

suavis fusca Malaise, Pontopristia, 88 
submentum, 19

Superfamilies of sawflies, 33 supratentoria, 13

Susana R. \& M., 75, 77, 82 cupressi R. \& M., 77

sylvatica L., Tenthredo, 110

Symphyta, 42, 50

Syntectidae, 35, 51, 110

Syntexidae, 110

Syntexis, 110

syringae Gradl, Cephosoma, 116

tabida Fabricius, Sirex, 116

tabidus (Fabricius), Cephus, 116

tabidus Fabricius, Sirex, 116

tacitus (Say), Strongylogaster, 67

tantillus Costa, Aphadnurus, 72

tarsal claws, 27

tarsus, 27

Taxonus Hartig, 89, 93

agrorum (Fallén), 93

albidopictus Norton, 65

epicera Say, 93

dubitatus Norton, 65

inferentia Norton, 91

multicolor Norton, 90

robustus Provancher, 92

tener (Fallén), Ametastegia, 92

Tenthredella Rohwer, 105

Tenthredinidae, 34, 51, 60

Tenthredininae, 63, 64, 102

Tenthredinoidea, 33, 34, 51

Tenthredo L., 103, 104

abdominalis Fabricius, 91

abdominalis Panzer, 82

albipennis Zaddach, 98

albipes Gmelin, 98

alni L., 78

aterrima Klug, 100

atra L., 105

atroviolaceum Norton, 103

bardus Say, 97

betuleti Klug, 70

braziliensis Brullé, 98

brevis Klug, 77

candidula Fallén, 90

cinctus L., 92

cingulata Fabricius, 67

cordigera Beauvois, 97

coronata Klug, 66

crassa Fallén, 87 crocea Fourcroy, 79

difformis Panzer, 74

eglanteriae Fabricius, 69

enodis L., 52

ephippium Panzer, 97

erythrocephala L., 109

fasciata L., 59

filicis Klug, 67

flaviventris L., 109

14-punctata Norton, 103

gibbosa Fallén, 103

gonager Fabricius, 68

guttatum Fallén, 90

hieroglyphica Christ, 109

juniperi L., 57

limacina Retzius, 70

lineolata Klug, 98

lucida Panzer, 87

lucorum L., 59

lutea L., 60

luteiventris Klug, 97

micans Klug, 100

nigrita Fabricius, 96

nitida Klug, 93

ochropoda Klug, 70

ovata L., 94

parvula Klug, 79

pini L., 58

pratorum Fallén, 69

pumila Klug, 71, 72

pumilus Klug, 72

pusilla Klug, 98

rapae $L ., 105$

reticulata L., 109

rosae L., 52

rusticus auct., 105

scrophulariae L., 104

septentrionalis L., 88

sericeus L., 59

serva Fabricius, 66

sylvatica L., 110

togatus Panzer, 92

vafer L., 110

viridis L., 104

Tenthredopsis ruficorna MacGillivray, 103

tentorium, 13

Terodon, 112

testaceus Jurine, Pteronus, 84

Tethida new genus, 95, 96

cordigera (Beauvois), 97 
Tetratneura Ashmead, 90

Themos Norton, 55

hyaline Norton, 55

thoracicus (Harrington), Varna, 79

Thrinax Konow, 67

tibia, 27

tibialis Cress., Strongylogaster, 67

togatus Panzer, Tenthredo (Allantus), 92

Tomostethus Konow, 95, 96 multicinctus Rohwer, 96

totaglossa, 19

Trachelastatus Morice and Durrant, 116

Trachelus Fabricius, 115

Trachelus Jurine, 116

Tremex Jurine, 112

columba (L.), 113

Tremicinae, 112

Trichiocampus Hartig, 73 viminalis (Fallén), 73

Trichiosoma Leach, 59

tricolor Cresson, Xyela, 107

tridens Konow, Empria, 90

Triempria Enslin, 90

trimaculatus Say, Cephus, 116

trimaculatus (Say) Hartigia, 116

trisignatus (Förster), Pachynematus, 85

tristis Cresson, Schizocera, 55

tristis var. fumipennis Dyar, Schizocerus, 55

Tritokreion Schilling, 106

trochanter, 27

trogylodyta Fabricius, Sirex, 115

trophacava, 11

typica Rohwer, Claremontia, 97

typicus Rohwer, Prototaxonus, 67

ulmariae Schlectendal, Macrocephus, 116 ulmi Sundevall, Fenusa, 72

Unitaxonus MacGillivray, 92 repentinus MacGillivray, 92

Urocerus Geoffroy, 112

vaculus MacGillivray, Amauronematus, 85

vafer L., Tenthredo, 110

vagans Fallén, Phyllotoma, 70

Valco new genus, 96, 99 varianus Norton, Harpiphorus, 93

vanduzeei (Rohwer), Selandria, 66

Varna new subgenus, 78, 79

amelanchieridis (Rohwer), 79

thoracicus (Harrington), 79

ventralis Say, Nematus, 87

vertex, 10

viminalis (Fallén), Trichiocampus, 73

viridis L., Tenthredo, 104

volsellae, 30

Waldheimia Brullé, 95, 96, 98

carbonaria (Cresson), 98

washingtonia R. \& M., Hemichroa, 79

weithii Ashmead, Acanthoptenos, 52

wings, 28

Xeris A. Costa, 112

Xiphidion Provancher, 111

canadense Provancher, 111

Xiphiura Fallén, 111

Xiphydria Latreille, 111

mellipes Harris, 111

Xiphydriidae, 35, 51, 111

Xyela Dalman, 106 aenea Norton, 108 dahli Hartig, 107 ferruginea Say, 108 major Cresson, 107 pusilla Dalman, 106 tricolor Cresson, 107

Xyelecia Ross, 106, 107 nearctica Ross, 107

Xyelidae, 35, 51, 106

Xyloecermatium L. Heyden, 113

Xyloterus Hartig, 112, 113

zabriskei Ashmead, Melanoselandria, 100

zabriskei Webster and Malley, Schizocerus, 54

Zadiprion Rohwer, 57, 58

Zalagium Rohwer, 105 clypeatum Rohwer, 105

Zamacrophya Rohwer, 105 nigrilabris Rohwer, 105

Zaraea Leach, 59

Zaschizonyx Ashmead, 102, 104

montana (Cresson), 104 







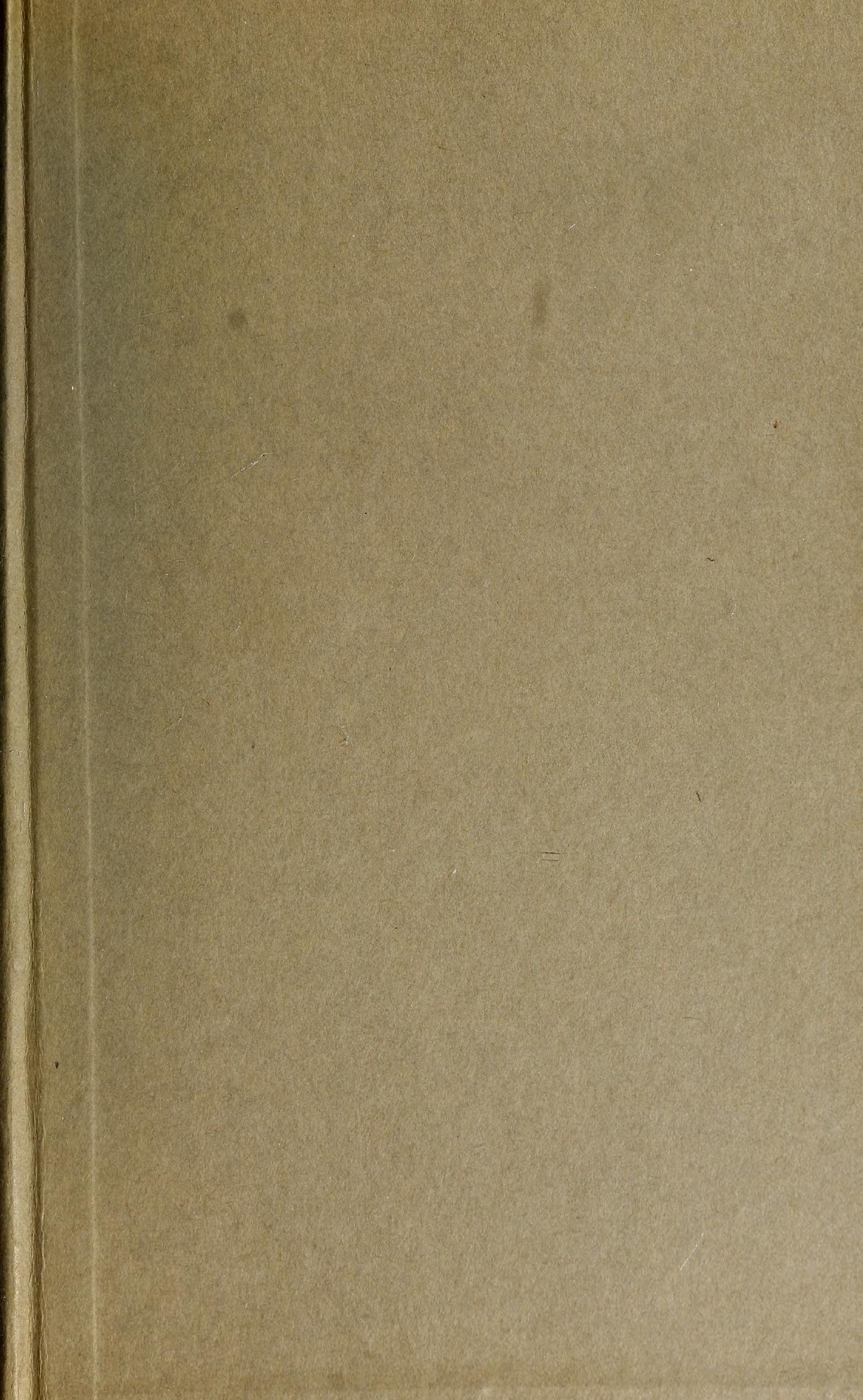


